\title{
Testing Grounds and Launching Pads: Situating the Artist-Run Space Today
}

\section{Emma Bugden}

\author{
A thesis submitted to \\ Victoria University of Wellington \\ in fulfilment of the requirements for the degree of \\ Doctor of Philosophy in \\ Museum and Heritage Studies
}

Victoria University of Wellington

2020 



\begin{abstract}
My research is concerned with the formation of artists as creative subjects in an increasingly neoliberalised art world. This study examines to what extent does the artist-run space offer alternatives to current neoliberal orthodoxy in the art world. There has been little research to understand the lived experiences of emerging visual artists within neoliberalism. The thesis is located in museum studies but stretches beyond this field in an interdisciplinary approach to explore the complexity of what it means to both make art and self-organise.
\end{abstract}

The thesis presents multiple case-study research into three New Zealand artist-run spaces; RM, Enjoy Contemporary Art Space and Meanwhile. Qualitative research brings the experiences of artist-run space participants to the fore through interviews, examining how they understand and articulate their involvement, negotiate tensions over power, and position themselves in an art world that seeks to enfold them in its own narratives. I analyse and discuss the findings through a series of connecting theoretical frameworks - assemblage theory, creative labour and governmentalitywhich together map the distinct practices that shape, and reshape, the artist-run space.

My research contributes to literature on creative workers within neoliberalism, providing new knowledge about tactics and strategies deployed by emerging visual artists to carve space for their activities on their own terms. The thesis argues that while artist-run spaces are embedded in the mainstream through both networks of strategic reciprocity and funding imperatives, the nuances which define an individual artist-run space are both broader and messier than their increasingly formal structure suggests. The identity formation of the artists and creative workers whose hard work and passion keep artist-run spaces going is similarly compromised, confounding simplistic readings. I propose that the notion of 'alternative' is too binary an understanding to describe artist-run spaces within a time of neoliberalism, instead, this thesis seeks to complicate and problematise the term. 


\section{Acknowledgements}

I undertook this study because of my belief in the importance of artist-run spaces. My research has affirmed for me their relevance and meaning. The thesis was made possible by the contributions of participants from the artist-run community, along with the broader art world. I am grateful for their openness about sometimes challenging times.

Thank you to my supervisors, Dr Conal McCarthy, Programme Director, Museum and Heritage Studies, Stout Research Centre for New Zealand Studies, Victoria University and Dr Deborah Jones, Programme Director, School of Management, Victoria University. Their encouragement and criticality pushed me to extend my thinking - the dissertation you are reading is not what I imagined I was capable of at the beginning. I am also grateful for the help and support of school manager Annie Mercer.

Life as a long-distance student is a lonely echo chamber and I'm grateful to all those who shared writing and thinking time. To colleagues in Museum and Heritage Studies, thank you for the feedback. Thank you to Anna-Marie White and the writing weekends: so much good food, so much writing. Thank you to the Confluence Study Group for showing me I wasn't the only adult student in Whanganui. Thank you to sporadic study buddies Dylan Rainforth and Wen Xiong - two laptops are a heartening thing. My writing retreat companion Sarah Farrar taught me about whiteboards and sticking with it, thank you for your constant gentle encouragement. My remote study support system with Ane Tonga was also greatly appreciated.

Juggling a $\mathrm{PhD}$ with mothering is a tangle of expectations and guilt and I'm grateful to all those who took care of my daughter so I had more time to work. Special thanks to Steph Ward, Iva Leonard, Wen Xiong, Brett Thompson, Kay Benseman, Lauren Lysaght, Andrew Smith and Hoddi Hoddinott, my own personal mama squad. Most of all, thank you to Frank Stark, for reading every word, many times, for removing an over-abundance of dangling demonstrative pronouns, indulging late night conundrums about governmentality and always encouraging me. 


\section{Contents}

List of Figures...........................................................

Abbreviations.......................................................... viii

Glossary...............................................................

Case Study Details......................................................

Prologue..............................................................iii

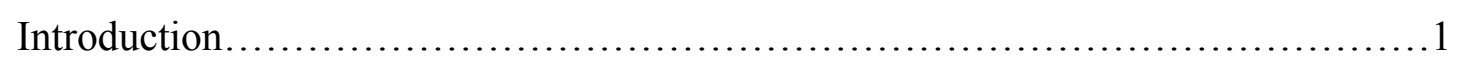

1.1 Research Topic................................................2

1.2 Research Aims and Questions......................................5

1.3 Definitions of Key Concepts........................................6

1.4 Space as an Expanded Notion........................................ 7

1.5 Literature Review...................................................

1.5.1 Introduction.......................................... 8

1.5.2 Telling Their Own Stories: Artist-Run Literature...............9

1.5.3 Locating Myself Within Museum Studies.....................10

1.5.4 Nodes Within Networks: Using Assemblage Theory...........13

1.5.5 Cultural Precarity: The Artist as a Creative Subject...........17

1.5.6 Reshaping the Artist-Run Organisation: Governmentality.....23

1.5.7 Speculations and Tactics for Resistance...................27

1.5.8 Conclusion............................................

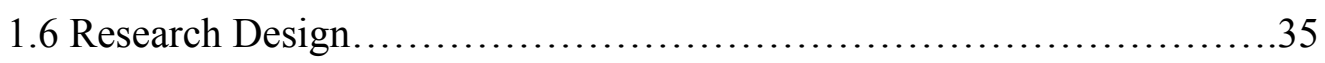

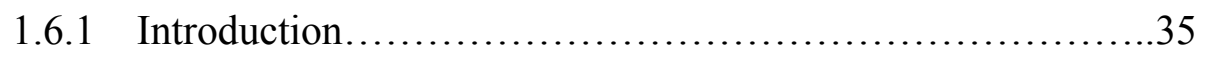

1.6.2 Theoretical Frameworks.................................37

1.6.3 The Insider Outsider: Ethnography and Auto-Ethnography...39

1.6.4 Case Study Selection...................................41

1.6.5 Methodology........................................42

1.6.6 Ethics..............................................43

1.6.7 Research Positions.......................................45

1.6.8 Research Methods and Findings..........................47

1.6.9 Boundary Spanners..................................50

1.6.10 Semi-Structured Interviews............................50 
1.6.11 Document Analysis.....................................52

1.6.12 Participant Observation...............................53

1.6.13 Data Analysis...........................................54

1.7 Significance of Thesis........................................55

1.8 Chapter Outlines.............................................57

Chapter One—Background: 'Finding a Space, Painting its Walls'..................59

2.1 Introduction..................................................... 59

2.2 A Brief History of Artist-Run Spaces..............................66

2.3 Changes to the Wider Art Sector..................................67

2.4 Neoliberalism and the Art World: The Rise of Creative Industries.........71

2.5 Case Study Snapshots..........................................79

2.5.1 RM................................................. 79

2.5.2 Enjoy Contemporary Art Space..........................84

2.5.3 Meanwhile............................................90

2.6 Conclusion........................................................ 95

Chapter Two-Trust and Exchange: The Artist-Run Space Assemblage.............97

3.1 Introduction.................................................. 97

3.2 Space Matters: How Physicality Shapes the Organisation...............99

3.3 Finding the Gap: The Artist-Run Exhibition.........................107

3.4 A Wider Network..................................................119

3.5 Conclusion..................................................... 137

Chapter Three - 'So Much Labour For Free': The Artist-Run Space Participant....139

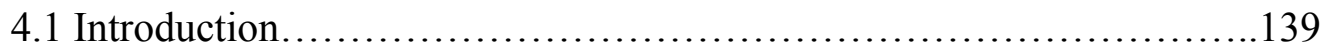

4.2 The Artist-Run's Precariat.............................................142

4.3 Insiders Club: Who is Included in the Artist-Run Space?.......................150

4.4 The Artist-Run Workplace...................................... 158

4.5 Career Paths ........................................................ 160

4.6 Conclusion.................................................. 164

Chapter Four-Governing Ourselves: The Artist-Run Space Organisation..........169

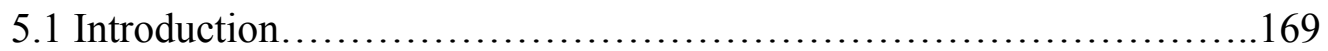

5.2 Come Together: A Collective of Artists............................172

5.3 Impacts of Funding ........................................... 183

5.4 Stories and Legacies: Organisational Ownership....................187

5.5 Conclusion........................................................ 194 
Chapter Five-Relative Autonomy: The Artist-Run Space within a Neoliberal Discourse

6.1 Introduction.

6.2 Offering an Alternative: The Artist-Run Space and Neoliberal

Orthodoxy.

6.3 Governmentality and Neoliberalism: The All-Consuming Policy

Narrative?.... 206

6.4 Independence and Interdependence: The Internal and External Forces that Shape the Artist-Run Space.

6.5 Finding Agency in Compromise: How the Identities of Participants are

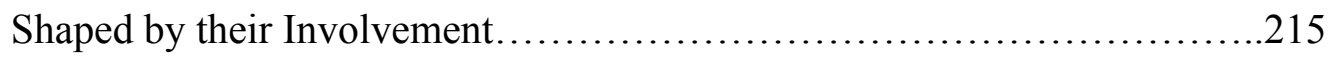

6.6 Working Together: Possibilities and Speculations....................219

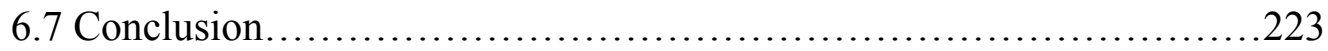

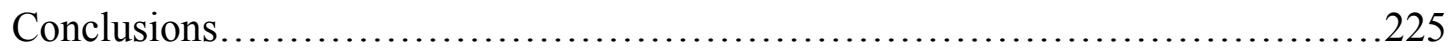

7.1 Reviewing the Research Process..................................225

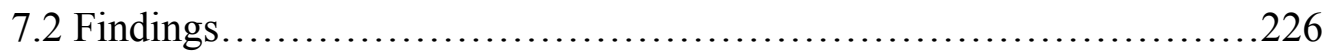

7.3 Answering the Research Questions.................................230

7.4 Research Limitations...........................................232

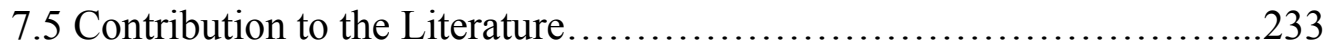

7.6 Professional Implications of my Research..........................235

7.7 Conclusion..................................................... 237

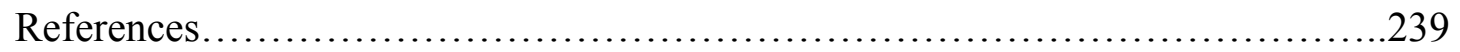

8.1 Interviews................................................... 270

8.2 Archives.....................................................271

Appendix One-Sample Case Study Information Sheet..........................2272

Appendix Two-Sample Boundary Spanner Participant Information Sheet.........275

Appendix Three-Sample Case Study Research Agreement.......................277

Appendix Four -Sample Participant Consent Form..........................................279

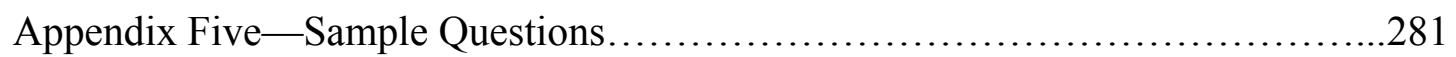

Appendix Six - Coding Categories......................................283 


\section{List of Figures}

Case Studies Data Table. 47

Additional Interviews with Boundary Spanners Data Table .49

An Almost Complete List of ARIs in Aotearoa, Hana Pera Aoake and Callum Devlin, 2017. .66

Vaughan Gunson (detail from inaugural exhibition), June 1997, rm3. Photo: $R M$ archives.

Andrea Wilson, Tim Checkley and Clint Watkins, Rm212, 2000. Photo: Joyoti

Wylie .83

Enjoy Under Construction, 174 Cuba Street 2000. Photo: Enjoy archives. .85

Ciaran Begley Speaking at Enjoy's Inaugural Opening, 2000. Photo: Rachel

Smithies. .86

Rachel Smithies at Enjoy's Inaugural Opening, 2000. Photo: Rachel Smithies. . .87

Callum Devlin, Jesse Bowling and Jordana Bragg, 2016. Photo: Meanwhile archives

Building Studio Spaces, Meanwhile, 35 Victoria Street, November 2016. Photo:

Meanwhile archives. .92

Walking Forwards Backwards, Annie Mackenzie, Enjoy, 2016. Photographer Shaun

Mathews. Photo: Enjoy archives.

Annie Mackenzie and Dave Marshall (detail from The Tomorrow People), Adam Art

Gallery 2017. Photographer Shaun Mathews. Photo: Adam Art Gallery. 117

RM Imagined as an Assemblage, 2018.

Opening of Timber Trophy: Kirstin Carlin and Carina Brand, RM, 2011. Photo: Sait Akkiman and Arts Diary. 124

Call to Join the $R M$ Collective, $R M$ Instagram Post, 18.09.2017. 125

Meanwhile Imagined as an Assemblage, 2018.

Enjoy Imagined as an Assemblage, 2018. 130

Art World Industry Model, diagram by Judy Darragh, 2017. Courtesy of Judy

Darragh. 145

How Do Artists Survive, diagram by Judy Darragh, 2017. Courtesy of Judy

Darragh. 148 
Enjoy Boosted Campaign, 2019. Photo: Enjoy archives.......................... 176

RM Instagram Post, 30.04.2018. Photo: $R M$ archives................................186

$R M$ Newsletter, 2009. Artists and Gallery Files, Fine Arts Library Special Collections, Auckland University Library.

Opening of No One is Sovereign in Love, Meanwhile, 2017. Photo: Meanwhile archives.

Opening of It's a Pond, Not a Moat, Meanwhile, 2017. Photo: Meanwhile archives 


\section{Abbreviations}

AGM-Annual General Meeting

ARI-Artist-Run Initiatives

ARS - Artist-Run Spaces

AUT_Auckland University of Technology

BFA-Bachelor of Fine Arts

BOAG_-Blue Oyster Art Gallery

CBD-Central Business District

CNZ - Creative New Zealand

DIY - Do It Yourself

GFC - The 2007-2008 Global Financial Crisis

KPI-Key Performance Indicator

$\mathrm{MCH}-\mathrm{Manatū} \mathrm{Taonga} \mathrm{Ministry} \mathrm{of} \mathrm{Culture} \mathrm{and} \mathrm{Heritage}$

NEA-National Endowment for the Arts

NGO-Non-Governmental Organisation

PACE_-Pathways to Arts and Cultural Employment

PBRF-Performance-Based Research Fund

QEII-Queen Elizabeth II Arts Council

SIAP — South Island Art Projects

WINZ - Work and Income New Zealand 


\section{Glossary}

\section{Aotearoa}

The Māori name for New Zealand, used by some as the country's primary name.

\section{Cultural Precariat}

A sociological term to describe artists and creative workers who operate in a state of precarity under post-Fordist economics (Virno 2004; Gill and Pratt 2008). The cultural precariat is generally a freelancer who juggles multiple contracts without stability or permanence, but who does so because of the belief in their chosen creative pursuit (Gill 2010; McRobbie 2002, 2016; Ross 2000). The term precariat is a portmanteau of 'precarious' and 'proletariat'.

\section{Creative Industries}

A term combining two older expressions: the creative arts and the cultural industries (Hartley, 2004). 'Creative industries' was first coined in 1948 (Adorno and Horkheimer 1997) but achieved prominence after its deployment as a key policy term in the 1990s by the UK New Labour Government (1997-2010).

\section{Fordist / Post-Fordist}

Fordism was first coined by Italian philosopher, Antonio Gramscri after the businessman Henry Ford. Fordism is used within social and organisational theory to describe the twentieth-century model of economic expansion through mass production, utilising mechanised assemblage. Post-Fordism (Virno 2004; Gill and Pratt 2008) signals the shift from the industrial to the information society, from largescale production to micro-specialisation which is more flexible.

\section{Kaupapa}

A Māori term describing a set of principles, values, foundations or plan. Kaupapa is used to describe both underlying systems and a specific agenda or subject. 


\section{Koha}

A Māori term for a gift, donation or contribution that acknowledges relationships and demonstrates respect. Traditionally, koha was the contribution of food for communal gatherings.

\section{Māori}

The indigenous people of Aotearoa New Zealand.

\section{Neoliberalism}

Neoliberalism is a term describing a late twentieth-century global move embracing free market, laissez-faire economies. Neoliberalism supports structural adjustments to the economy including fiscal restraint, deregulation, privatisation of state assets and market liberalisation (Williamson 1990). While it is an economic definition, it has increasingly been used to describe broader cultural rationalities (Ventura 2012). The term itself is one taken up predominantly by its opponents, in fact its proponents, Rajesh Venugopal argues, dare "not speak its name" $(2015,15)$.

\section{Pasifika}

A specifically New Zealand term to describe migrants from South Pacific nations, and their descendents who live in New Zealand.

\section{Pākehā}

A Māori term describing non-indigenous New Zealanders of European descent, increasingly taken up by Pākehā themselves as a personal identification that is locally specific. 


\section{Case Study Details}

For ease of reading I have simplified the titles of my case studies as follows.

'RM,' is referred to as $R M$. Previous incarnations of $R M$ include $r m 3, r m 4, r m 101, r m$ 104 and $\mathrm{rm}$, however, except where interview subjects directly refer to a particular name, I have used $R M$ as an overall title.

'MEANWHILE' is referred to as Meanwhile.

'Enjoy Contemporary Art Space' is referred to as Enjoy. Its original name was 'Enjoy'. and at the time of my research it was known as 'Enjoy Public Art Gallery'.

Where the multi-member aspect of an artist-run space is an important consideration, I have used a plural verb rather than the collective singular.

\section{Pronouns}

Three of my interview participants, Sean Burn, Jordana Bragg and Hana Pera Aoake, identify as non-binary and therefore have requested the personal pronoun 'they' be used to distinguish them. 
Emma Bugden 


\section{Prologue}

It was 1997, my final year studying sculpture, and I wanted something to happen.

"Don't show your work for the first ten years" our teachers warned, "hone your skills and eventually the art world will notice". Such advice seemed implausible: who was going to notice me in Dunedin, far from the hotbeds of the art world?

So, with two friends who had already graduated, I started a gallery. ${ }^{1}$ Our aims were simple: somewhere to show our work and that of our friends. We had a lead on a shabby room above the Dunedin Prostitutes Collective and Needle Exchange. We called it The Honeymoon Suite, a reflection of our attitude-insouciant, humorous and hopeful. Now we could get involved in the art world as participants, rather than on the sideline.

Before opening the space, we submitted a funding proposal to Creative New Zealand. The application read as though the gallery had been running for some time, exaggerating (indeed manufacturing) our achievements. By the time anyone read it, we postulated, we would in fact be doing all we had claimed.

We got the grant, a fairly modest sum of two thousand dollars, and with it the endorsement of the art establishment. Today, the process astounds me. Could a fledgling, largely imaginary, art space garner such institutional backing today? With an increasingly networked art ecology and constant emphasis on 'a track record of experience and success' it seems unlikely.

This story has stayed with me as I have moved from emerging artist to arts professional, from artist-run participant to public gallery curator. My connection to the artist-run has waned over the years, as public galleries became my focus, but my background has remained integral to my sense of self.

1 The Honeymoon Suite (1997-1998) was run by Jonathan Nicol, Warren Olds and myself, with additional support in the early stages by Kate Ross. 
As arguably the first New Zealand curator to have emerged from the artist-run scene, I was a trailblazer for such a trajectory, just ahead of Melanie Oliver, Charlotte Huddleston, Stephen Cleland and others. My movement from collective membership to institutional seniority was unusual locally (although not internationally) but it is now a standard arc for emerging curators. That transition of curators out of the artistrun movement, I believe, can foster artist-centred practice within institutions and change important aspects of gallery practice.

I'm also aware that co-option of radical practice by the mainstream contains the potential for dilution, erasure even. As I watch artist-run spaces reconfigure not just as launch pads for artists, but also as viable career pathways for curators, I wonder how it affects their own evolution. The individual route I had taken is now actively affirmed by training institutions and public galleries. Have artist-run spaces joined the establishment?

What does it mean for young artists and arts professionals to be involved in an artistrun space, 20 years after such spaces began to be established in New Zealand? Were their motivations the same as mine? Was running a space still the 'alternative' I had believed it to be? These questions have occupied me over many years, as I worked my way up and across the art world. They are the ground upon which this research takes shape. 


\section{Introduction}

This thesis takes as its topic artist-run spaces. Artist-run spaces are simultaneously sites for creative and intellectual research, workplaces and training grounds, and launching pads for professional development.

My research argues that artist-run spaces provide a crucial mechanism to enable participants to enter the art world, develop professional identities and position themselves within the sector. Because artist-run spaces attract emerging artists and art workers as they seek to establish their careers, examining them provides a fruitful research environment for understanding the conditions by which the art world enables and affirms new generations of participants, as well as the power relations artists and art workers negotiate in order to become established.

This introductory chapter sets the scene for the research to come. It introduces key questions alongside broader contextual information including a review of relevant literature and theoretical frameworks as well as defining research design and methodologies adopted. The research is humanities-based in the discipline of museum studies, developed from a subjective position and using methods that are interpretive.

To carry out research that is meaningful and specific, my research has actively engaged with three New Zealand case studies, RM, Enjoy and Meanwhile, and they are introduced here along with broader discussions of how and why they were chosen. Additionally, an overview of each chapter is provided, which outlines my argument across three distinct research topics, and then, in subsequent discussion and conclusion chapters, moves across the themes to ask, to what extent does the artistrun space offer alternatives to current neoliberal orthodoxy in the art world?

While the Introduction provides entry to the development of linear and sustained research, point by point, it also seeks to open up the pre-understandings with which I first approached the topic. In particular, it begins to describe the notion of 'alternative', a word which offered a useful starting point with its idea of an 'other'. As I developed my research my thinking changed and 'alternative' proved too binary 
a concept. Instead, I argue that, while the term is not invalid, my research complicates and problematises the idea of an alternative.

The Introduction therefore frames me, as writer and as participant in the art world, just as it frames my research. I began the study as a curator with a fervent belief in artist-run spaces as a model for activating both artistic practice and a sense of community, and as someone who personally benefited from the professional development offered by the artist-run space system, yet was uncomfortable with its growing role as incubator. While the thesis narrates the passionate, strategic, sometimes messy navigation of artist-run spaces by artists and arts workers today, it also charts my development as a researcher questioning my place in a neoliberalised art world that prioritises individualism and professional development over collectivism and marginality.

\section{Research Topic}

It is helpful to define an artist-run space within the context of my research. Artist-run spaces are galleries initiated and managed by artists. They are mostly located in urban environments and organised by recent graduates of art schools. ${ }^{2}$ Often, they have been developed by informal groups of friends and sometimes by more structured collectives.

The artist-run gallery takes many different forms (Coffield 2015; Jackson 2013; Robertson 2006, 2004) but most are characterised by an emphasis on selfmanagement and the desire to provide the physical and conceptual space for experimentation. ${ }^{3}$ While they were, at first, largely a Canadian and American phenomenon, artist-run spaces now exist around the world and operate across global networks. However, warns Australian artist-run space participant Brett Jones, “we

2 Contemporary artists work in a variety of media and practices. However, a useful summation of artists as an occupational group describes them as "on average younger than the general workforce, are better educated, tend to be more concentrated in a few metropolitan areas, show higher rates of self-employment, higher rates of unemployment and of several forms of constrained underemployment (non-voluntary part-time work, intermittent work, fewer hours of work) and are more often multiple job holders" (Menger 1999, 545). The recent Creative New Zealand survey of creative professionals in New Zealand (Colmar Brunton 2019) reflects this quote.

3 See Anderson 2008; Apple 1981; Bryn-Wilson 2011; Detterer and Nannucci 2012; Jackson 2013; Murphy 2016; Nemiroff 1985; Pryde-Jarman 2013; Robertson 2006; Sharon 1979. 
must not collapse artist-run spaces into some global homogenous phenomenon that speaks for all artists" (Jones 2002, 129).

Artist-run spaces are also known as alternative spaces, ${ }^{4}$ a usage which is significant in that it claims a position outside the mainstream.

It is a unique journey for a group of people to take, usually on a volunteer basis, to firstly create the physical space, to create the purpose and infrastructure, to earn confidence and a reputation from artists and the community, to commit lots of energy and to invigorate inspiration in yourself and others. (Eland 2002, 49)

This statement, by Steve Eland of Mass Gallery (Melbourne), is emblematic of the do-it-yourself narrative that runs through artist-run culture. In one of the first theses on artist-run culture, Canadian art historian Pamela Nemiroff states that, regardless of “the specific form artists' alternative structures take, all emphasise the need for selfdetermination and openness to experimentation" (Nemiroff 1985, 18), while Canadian curator Heather Anderson describes artist-run spaces as "an alternative to the system of art institutions and commercial galleries" (Anderson 2008, 17).

Although specific to their particular social and cultural landscapes, artist-run spaces demonstrate some common traits: sociability, independence and flexibility towards varied art practices. They first emerged in the United States and Canada in the late 1960s and 1970s, at a time of change, both in art making and within the cultural sector and can be understood as a reaction to these changes. In particular, artist-run spaces developed as a critical response to the perception of public art institutions as inflexible and remote from artists, and have been imagined both as an alternative to such institutions and as a challenge to them. This sense of difference, indeed

\footnotetext{
4 In New Zealand the term artist-run space is the norm, but a range of nomenclature is utilised around the world. Joanna Cooke suggests that the first written use of "artist-run space" was by sociologist Batia Sharon in her seminal 1979 article, Artist-Run Galleries: A Contemporary Institutional Change in the Visual Arts (Cooke 2006; Sharon,1979). 'Alternative space' is the standard term in the US, which places emphasis on the marginality of practice rather than its organisational collectivism. 'Alternative space' originated through its use by the National Endowment of the Arts (the US government funding agency) and has been credited to artist and critic Brian O'Doherty, in his role as Head of the Visual Arts at the NEA (Griffiths 2012; Wallis 2012). Clive Robertson states that 'artist-run centre', the standard descriptor in Canada, is a term that "becomes gradually accepted sometime between 1976 and 1978” (Robertson 2004, 15). In Australia, 'artist-run initiative' (ARI) is used, which again has been first credited to its application in funding literature, "as a means to categorise, and, in turn, monitor" art spaces (Griffiths 2012, 8). In my thesis, for ease of understanding, I will use the term artist-run space as an umbrella term, while allowing for individual terminology in quotes and citations.
} 
antagonism, was a marker of early artist-run culture and has become an established trope that new artist-run spaces must confront.

But are artist-run spaces truly alternative, and if so, alternative to what? The relationship between artist-run culture and the wider art ecology is complex and shifting, an elaborate dance which must acknowledge that "naming oneself alternative sets up both distance from, and bondage to, dominant institutions and ideas" (Ault 2010, n.pag.). As the mainstream art world has absorbed and adopted neoliberal orthodoxies, what role can and should grassroots and marginal organisations play?

This thesis argues that artist-run spaces no longer represent an alternative as clearly as they once did and that the shift from the margins to the centre of the art world has caused fissures within the artist-run community, as organisations and their participants reposition themselves accordingly. My research contends that, through neoliberalism, our understanding of the inside/outside paradigm has altered, and the artist-run space's historic attachment to notions of 'otherness' is threatened. The artistrun space, therefore, is increasingly convergent with other forms of art organising, such as the public art museum and the commercial sector. Changes, both top-down and bottom-up, have demonstrably occurred through the opening up of large and powerful institutions and through the challenge of artist-led activism.

The influence of curatorial new institutionalism, described in Chapter One, and the move of the artist-runs' participants into curatorial positions in public and commercial galleries, have made those institutions more responsive in their programming and what might be described as artist-led (or at least, they have absorbed these aspects into their customary behaviour). Programming of both public and commercial galleries has correspondingly shifted to become more inclusive of experimental practices. Simultaneously, many artist-run spaces have formalised their structure, adopting a hierarchy to establish separation between governance and operations.

Internationally, writers link the formalisation of artist-run spaces to funding criteria and suggest that changes to artist-run spaces are the result of cultural policy rather than an internal desire to formalise within the arts community (Robertson 2004; Ault 2010; Bronson, 2012, 1983; Detterer 2012; Griffiths 2012; Jackson 2013; PrydeJarman 2013; Wallace 1991). They argue that the demands of cultural policy 
emphasise the need for artist-run galleries to echo corporate models of organisation, with structural division between governance and management, as with many other NGOs. Gavin Murphy writes, "if funding is applied, a new level of bureaucracy and a standardisation of organisational structure is generally insisted upon" leading, "to the tendency to turn successful artist-run spaces towards established structures" (Murphy 2016, 11).

\section{Research Aims and Questions}

My research explores artist-run space culture at the present moment, through the particular experiences of three New Zealand case studies. My aim is not to determine the conceptual or aesthetic value of exhibition programmes, but rather to examine how and why artists come together to organise themselves.

Building on my experiences over 20 years in the art world, and engagement in purposeful conversations with artist-run space participants, this dissertation seeks to answer questions that concern me about the art world and my own role in it. My research examines whether artist-run spaces contribute a form of grassroots, disruptive leadership for the arts sector that challenges mainstream arts organisations. Or, my thesis asks, as artist-run spaces are increasingly embedded into the normative processes of the art sector, encouraged to be training grounds for emerging artists and curators which feed into mainstream institutions, have they become assimilated into the mainstream art discourse?

During my research, these concerns have been distilled down to the following questions. The project is led by my key research enquiry:

To what extent does the artist-run space offer alternatives to current neoliberal orthodoxy in the art world?

Secondary questions are:

What impact have funding, policy and wider art networks had in shaping the New Zealand artist-run space? 
How are the identities of participants shaped by their involvement in artist-run spaces?

My thesis builds on international research into post-alternative artist-run spaces, while being the first to focus on the New Zealand situation, drawing on literature across a wide range of disciplines. Using the theoretical lenses of assemblage theory, creative labour and governmentality I map the artist-run space physically and socially; seek to understand the identity formation of participants; and examine the role of external forces (funding, policy and wider art networks) in reshaping the artist-run space sector.

\section{Definitions of Key Concepts}

The thesis draws on key concepts from sociology as well as from museum studies and curatorial studies. My use of 'alternative' refers to practices that sit in opposition to a sectoral 'mainstream', in this instance the prevailing structures and systems of the art world. The word mainstream suggests institutional power, which is linked to hierarchies of markets and audiences.

The common United States term for artist-run spaces is 'alternative spaces' which denotes the movement's alignment to,

counter[ing] the status quo of mercantile circuits; to address needs of artists and audiences not addressed elsewhere; or to define themselves as antiestablishment, anti-institutional, experimental, artist-initiated, artist-run, artistcentred. (Ault 2002, 34)

In using the term 'art world' I draw on US sociologist Howard Becker's description of networked activities supported and framed by mutually understood conventions (Becker 1984). Specifically, I refer to the loose grouping of institutions (public galleries, commercial galleries, biennales, art schools, grassroots structures and auction houses) and individuals (artists, reviewers, curators, gallerists, patrons and collectors) who together constitute the structures that create, support, circulate and contextualise visual art.

With the term 'neoliberal orthodoxy' I refer to the normalisation of neoliberal thinking in New Zealand, beyond political or economic realms to a wider socialisation 
of concepts. In this I am considering neoliberalism in a holistic sense, stretching beyond an economic definition of a late twentieth-century global movement embracing free market, laissez-faire economies, to describe broader shifts in cultural rationalities (Ventura 2012).

In Chapter One I detail how government adoption of neoliberal economic policies has been argued to have led to increased precarity, coupled with a cultural shift in thinking about the self, emphasising individualism and freedom. My research is concerned with the formation of creative subjects through a neoliberal reworking of the cultural sector.

Research participants, and the literature, use the term 'white cube', to talk about a set of physical and, by implication, social expectations within the art world. The phrase 'white cube' emerged as a central tenant of modernism in art during the early twentieth century. It signifies a physical gallery space that, as far as practicable, is square or rectangular, featuring white walls, hidden light sources and homogenous flooring, which enables the artwork to perform without distraction against a neutral backdrop.

The notion of the white cube as neutral has been regularly critiqued since the 1960s by both artists and critics. In his influential series of essays first published in Art Forum in the 1970 s critic Brian O'Doherty argues that the white cube creates an environment where "the work is isolated from everything that would detract from its own evaluation of itself ... conventions are preserved by the repetition of a closed system of values" $(1986,14)$.

\section{Space as an Expanded Notion}

The word 'space' forms part of the artist-run nomenclature in New Zealand and spatiality as a broad theoretical terrain emerges as a core concept in the thesis. Research participants offer both pragmatic and metaphorical uses of the word 'space' to describe the physical gallery and the exhibitions it houses. Participants also use the term to evoke more abstract notions of 'making space' such as creating opportunities for diverse ideas and people. Interview subjects use 'space' to describe a variety of positions and approaches, from selecting a building for its aesthetic properties to 
selecting artist for the exhibition programme because they are under-represented in the mainstream art world.

To accommodate such multifaceted use of the word, the thesis shifts between different understandings of 'space', drawing on an expanded notion of the term. Here I draw on philosopher Henri Lefebvre's call for a repositioning of space, as not merely architectural and physical but as a social category, writing "space is not a thing but rather a set of relations between things" (Lefebvre, 1991, 83).

When Lefebvre describes "the active — operational or instrumental—role of space, as knowledge and action ... space serves, and hegemony makes use of it, in the establishment, on the basis of an underlying logic and with the help of knowledge and technical expertise, of a 'system"" he is seeking to span our different forms and understanding of physical and social space, asking "what does it mean to speak of producing space?" $(1974,23)$.

What does it mean for my research participants to produce space? While the issue of space is explicitly addressed in Chapter Two, tracing the artist-run space within an assemblage of physical and social zones, references to space reverberate in different ways through the research. For example, in Chapter Three, page 149, when Louisa Afoa speaks of the need to step down from $R M$ at a certain point in the future, to "make space for other people" (Afoa 2018) she evokes both physical room and a conceptual gap. Through my own expanded use of the term in this thesis I seek to capture the multifarious and slippery role it plays for my participants.

\section{Literature Review}

\section{Introduction}

This literature review lays the foundations for an enquiry into artist-run culture in New Zealand at this time, driven by my key research question: to what extent does the artist-run space offer alternatives to current neoliberal orthodoxy in the art world? The nature of my study is qualitative, foregrounding the experiences of participants themselves, making the way in which communities describe themselves pertinent to 
my research. Central to the Literature Review, therefore, is self-documentation by artist-run space participants as well as texts by academics, curators and art historians on artist-run culture. But my concerns extend beyond accounts of individual exhibitions, and my reading has stretched in various directions-from museum studies, art history and curatorial studies into sociology, organisational studies and cultural policy—-to acknowledge the interdisciplinary nature of my argument.

I have drawn on literature from these broad range of sources to support four distinct areas of focus: the artist-run space as a node within a larger network; the changing role of the artist as a creative subject; the artist-run space as an organisation shaped and redefined by cultural policy; and, finally, texts that cut across those issues to provide both theoretical speculations and concrete methods for resistance. Underpinning these areas are the three key theoretical frameworks I've used to understand my findings; assemblage theory, creative labour and governmentality, along with supporting theories of difference and discourse analysis.

I have braided these disciplines and frameworks to produce new research that sits within museum studies but acknowledges the diversity of knowledge that has informed my study. Through such a holistic approach I foreground, as Polish curator Kuba Zsreder writes, that "projects are not just means of production, neutral infrastructure ... every project is a material, temporal and localised embodiment of social apparatuses that regulate and support the making of these projects" (Zsreder 2015, 187).

\section{Telling Their Own Stories: Artist-Run Literature}

Academic writing on artist-run spaces began in 1979 when sociologist Batia Sharon undertook research into this new phenomenon in the San Francisco area (Sharon 1979), but most academic research has taken place in the last 15 years. From 2010 onwards, a number of books have also been published which take as their subject "the conditions, organisational models, and role of artist-led practice within contemporary art and society" (Murphy 2016, 5). 
My reading of international literature has been limited to what has been produced in English, which has led to a focus on United States, Canadian, United Kingdom and Australian texts. While the United States was a pioneer of artist-run culture, its funding model is substantially different from that of New Zealand, with greater emphasis on private philanthropy, while the United Kingdom, Canadian and Australian situations have significant similarities in cultural policy and funding systems. United States artist-run-space literature has been useful to understand artistrun-space development, but the United Kingdom, Canadian and Australian literature was most relevant for policy comparisons. Within the smaller field of New Zealand writing, I have had to confront my own voice, as a former participant in artist-run spaces, and as a writer and commentator.

The literature reveals the key role of gatekeepers in shaping well-known narratives of artist-run culture, and begins to outline the impact of generational shifts in thinking. In Chapter One I chart a broad picture of artist-run-space histories, in the United States and in New Zealand, but within the Literature Review I have focused on artistrun-space literature that directly supports my areas of focus.

\section{Locating Myself Within Museum Studies}

While my research is concerned with the field of contemporary art, I am not setting out to describe and evaluate individual artworks. Instead, my focus is "the complexity of the cooperative networks through which art happens" (Becker 1982, 1) and because of this, I situate my research within the field of museum studies, although there are strong connections to curatorial studies and art history.

In doing so I've taken the lead of Canadian historian Clive Robertson, in his argument that "artist-run culture cannot adequately be explained by art historical accounts of social formations of artists where the task remains focused upon enhancing the biographies of selected important artists or associated art movements" (Robertson 2004, 30). Similarly, while my research intersects with curatorial studies, my focus extends beyond "the experiential, scenographic and epistemic dimensions of exhibition-making" (Ribas 2016, 86), to consider the institution in a more holistic sense. Practice, in a broad sense, is my focus, from the physical manifestations of exhibition practice to less tangible practices of organisation and policy. 
It is the wider social movement of artist-run culture I am concerned with; the possibilities, and tensions, that arise when artists come together to develop their own organisational forms. I am in agreement with Canadian artist-run culture pioneer A. A. Bronson's description of artist-run space history as "not an image of continuous growth and development but the image of a pattern of cultural convulsions, personality cat-and-dog fights, occasional collaborations and multitudinous fragmented relationships" (Bronson 1983, 35).

Therefore the "boundary discipline" (Message 2009) of museum studies provides my study with a framework that takes into account "the wider mechanics of art's production and consumption" (Hebert, Szefer Karlsen and Blamey 2013, 3). I align myself with Australian museum studies scholar Kylie Message in her description of museums as encompassing "encounters, exchanges and the establishment and maintenance, as well as transgression, of boundaries" $(2009,127)$.

In its broadest sense, critical museum studies is concerned with describing and understanding museum culture, from exhibition presentation (Noordegraaf 2004), audience development (Heumann Gurian 2006) and collection preservation (Hein 2000; Pearce 1992, 1994), through to examining the organisational structures of the institutions themselves (Bouquet 2012; Janes 2013, 2009, 2007; Vergo 1989). This latter aspect is where my research is focused, understanding the museum "not as a static cultural monument but as fluid and responsive, dynamic, shaping, political, particular and complex" (Knell, MacLeod and Watson 2007, xx).

While an artist-run space is not a museum in the traditional sense, lacking the cultural authority that comes with the permanence of publicly-owned bricks and mortar, artistrun spaces provide a framing device for the circulation of art to audiences. Bronson calls them "museums by artists ... the living museum. That structure of perverse attributes has its own intrinsic self-definition, its own musculature, its own skeletal structure, its own cavities, resonances, mechanics of motion; it lopes, lingers, lumbers, lolls" (Bronson 1983, 36).

Within museum studies I locate my research in new modes of thinking that emphasise the connections between research and lived experience. Sharon Macdonald tracks 
three phases within museum studies; 'old museology', characterised by an emphasis on practical methods, 'new museology' (Vergo 1989) which sought to critique and theorise, particularly around questions of representation, and finally a third museology which understands that the complexity of museums calls for "a correspondingly rich and multi-faceted range of perspectives and approaches" that situates itself between theory and practice (Macdonald 2006, 2).

This current mode of museum studies, broader and richer in approach, is where I position my research, in agreement with New Zealand museum studies scholar Conal McCarthy's call for "new research methods that are practice-led and embedded" (McCarthy 2015, 206) enabling "scholar/practitioners to be more attentive to the complex organisational interplay of things, people and organisations with their constantly changing networks of social and material agency" (McCarthy 2016, 28). McCarthy cautions against studies that are "very detailed empirical investigations that zoom in on objects, particular exhibitions or individuals and lose sight of the wider institutional or social and historical standing” (McCarthy forthcoming 2020, 11).

The term 'new museology', now a defining element for museum studies, first came to prominence in the anthology The New Museology, which calls for a "radical reexamination of the role of museums" (Vergo 1989, 3). A significant challenge to the museum's singular voice was work undertaken by indigenous groups to contest the authority of Western ethnography and demand the management and control of their own cultural artefacts (Ames 1992, 1991, 1988; Bolton 2003; Butts 2007, 2003; McCarthy, 2009, 2006; Pearce 1994; Rosoff 2003). This led, in the 1990s and 2000s, to changes within many museums, opening up new partnerships and possibilities for co-management and co-curation with communities (Hooper-Greenhill 2000; Simon 2010).

My research situates itself in the crossflow between organisational dynamics and inter-organisational relations within a wider cultural field (Bourdieu 1993, 1990). Many writers have taken the internal workings of a museum as their focus, as a rich and complex site for investigating organisational change (Bagdadli and Paolino 2006; Christianson, Farkas, Sutcliffe and Weick 2009; Heumannn Gurian, 1995; Janes 2014, 1995; Macdonald 2002; Pacquette 2012; Suchy 2004). Reaching beyond individual experiences, other literature positions the museum as an actor negotiating 
within a larger network of systems and policies (McCall 2016; McCall and Gray 2014) "locating institutions and practices in relation to the contemporary desires and expectations of society, the individual and the ... discipline" (Knell, MacLeod and Watson 2007, xx).

I have found Anthony Shelton's description of critical museology particularly helpful because it emphasises the simultaneous difference and connectedness between theory and practice. To understand an institution, he suggests, we must compare management models "which represent the ideal distribution of power and authority within an institution, to their practical implementation" and thus "locate the contradictions and areas of tensions and contestations that play a fundamental role in institutional change and transformation" (Shelton 2013, 15). I use Shelton's understanding of critical museology to inform my approach, remaining mindful of his declaration that,

the purpose of critical museology is not, however, to reform institutions or to claim a privileged position for its own practice, but to sustain an ongoing critical and dialectical dialogue that engenders a constant self-reflexive attitude toward museum practices and their wider constituencies. (Shelton 2013, 18)

Following Shelton, I seek not to reform artist-run space culture but to engage in critical dialogue with its practices. Like Shelton's, my work aims to understand the artist-run space through tracking power relationships within and towards the artist-run space, bringing to the surface tensions and battles for ownership that shape the organisation.

\section{Nodes Within Networks: Using Assemblage Theory}

In Chapter Two I examine the artist-run space, not as a discrete entity, instead describing how spaces operate within a wider network, regularly interacting with colleagues and institutions. I argue that artist-run spaces cannot be considered as discrete entities, they are woven into a wider art world through formal and informal means, practically, strategically and symbolically. In addition, my research contends the social is deeply connected to the physical through the constituent make-up of the artist-run space, and to understand the relational and political dimensions of a space 
one must also consider the physical location as well as the artworks and exhibitions that populate it.

An increasing body of literature in museum studies draws on the sociological framework of assemblage theory, as a way of understanding organisations and situations holistically. Assemblage theory was first detailed by French philosophers Deleuze and Guatari in their book A Thousand Plateaus: Capitalism and Schizophrenia (1988) and further developed by DeLanda (2006) and many other writers since. Deleuze describes an assemblage as,

a multiplicity which is made up of many heterogeneous terms and which establishes liaisons, relations between them across ages, sexes and reignsdifferent natures. Thus, the assemblage's only unity is that of co-functioning: it is a symbiosis, a 'sympathy'. It is never filiations which are important but alliances, alloys; these are not successions, lines of descent, but contagions, epidemics, the wind ... (Deleuze and Parnet 1987, 69)

Assemblage theory makes no distinction between people, institutions or objects, all are considered component parts that come together to form complex, but fleeting and unstable assemblages (Bennett and Healy 2009; Cameron and McCarthy 2015). While assemblage theory is regularly used to understand a variety of different settings, organisational, political and social, some writers within museum studies claim it has particular relevance to cultural institutions because of its dual attention to mapping intangible networks that reach beyond organisational boundaries and its equal consideration of material elements (such as collections, objects, artworks or physical space) alongside social relations (Muller 2015). Cultural sociologist Tony Bennett has frequently utlised assemblage theory in writing on museological practice, examining "how museums and the social are stitched together in varying ways within different assemblages" (Bennett 2009, 100).

Anthony Shelton evokes assemblage theory in his call for critical museology to understand museums, not as the "latest manifestation of a long line of collectionbased institutions," but rather "as hubs within hypercomplex, though not necessarily cohesive, networked fields" $(2013,19)$. Similarly, cultural anthropologist Sharon Macdonald draws extensively on assemblage theory in recent work on museums and memorials to “designate some kind of 'entity' made up of constituent inter-related parts that then has effects... of its own" (Macdonald 2013, 6). Again, it is the broad 
focus that appeals to Macdonald, assemblage theory providing a mechanism to highlight the role objects (such as collection items) can play in shaping a cultural institution, taking "into account not only the human and the social but also the material or technical” (Macdonald 2011, 114).

Artist-run space culture, I argue, is enacted through a variety of social, visual and physical outcomes (exhibitions, performances, talks, openings, the spatial qualities of the space itself) and is fluid in its boundaries, as participants move from individual spaces to public and commercial galleries and back again. Assemblage theory enables me, in Chapter Two, to describe the shifting community that gathers around an artistrun space, not as a frame but as a distributed web, looking beyond the visible governance structure to understand more intangible connections and affects, and to acknowledge that art itself is an actor too. Although it might appear that assemblage theory levels out all information, leaving hierarchies unacknowledged, Australian feminist theorist Elizabeth Grosz adds a qualification. "It is not that the world is without strata, totally flattened; rather, the hierarchies are not the result of substances and their nature and value but of modes of organisation of disparate substances" $(1994,167)$.

How have writers directly analysed artist-run spaces through assemblage theory? Norwegian curator Anne Szefer Karlsen argues the self-organised art project constitutes itself as a network rather than an individual institution; a system that moves,

through [the] actions of individuals who build each other's networks, that in turn produce the structures that crystallise in institutions, that again shape human behaviour, constantly reignited and reinitiated by the actions of individuals mobilising, acting or simply believing. (2012, n.pag.)

The Institute for Applied Aesthetics, in their call-to-arms text The Artist-Run Space of the Future (Kennedy 2010), evokes the metaphor of a mushroom, sending out spores to endlessly replicate itself, as a metaphor to reveal the artist-run space as assemblage. The artist-run space, they argue, represents,

a formidable network, sometimes unseen and other times visible. A network, much like the rhizomatic structure of fungi, encompassing neither a beginning nor an end, but always a middle from which it grows and overspills ... a path through which many lines intersect and extend from. (Kennedy 2010, n.pag.) 
Irish curator Katherine Waugh continues the fungal metaphor in her essay Delicate yet Deadly, which suggests a movement away from constituting artist-run spaces as "organisation[s]" with all its attendant suggestions of "calcification and institutionalisation" and moving to "an emphasis on the activity of "organising' instead allowed more fluidity and resistance" (Waugh 2016, 146). Artist spaces of the future, she asserts "are mushrooms ... and the spores seek out crevices and cracks and just wait for their moment" $(2016,157)$.

Most writing about artist-run culture and assemblage theory takes the more abstract approach indicated above, which talks theoretically about the nature of the selforganised, without addressing specific case studies. A central premise of my study is to examine real-life situations through case study research, grounding the theoretical in the real and arguing for the particularity of rich detail. Therefore, I have sought out the limited literature that draws on assemblage theory to examine particular and specific art-world case studies.

I've taken the lead of Australian social anthropologist Philip Mar and Australian cultural geographer Kay Anderson in their tracking of $C 3 W e s t$, a collaborative project between Australian arts institutions, businesses, communities and artists. Mar and Anderson describe the complexity of this collaboration as a coming together of "a lumpy mix of more hierarchical formal organisations and more 'flexible' entities such as artists and mediators" (Mar and Anderson 2010, 38) and drawing on assemblage theory to provide "a more powerful way to understand the interfaces of organisation and aesthetic work ... with which to explore the complexities and contingencies of contemporary arts-based venues" (49).

My thesis shares with Mar and Anderson's research a desire to map real-life creative situations, which come "into momentary coordination from a co-assembly of (detachable) parts whose interactions, in turn, can bring into being new things and relations of varying intensities and durations" $(2010,49)$. The chance to apply assemblage theory across that 'lumpy mix' of larger, more structured organisations alongside the informality of artist-run spaces enables my research to map the flexible yet highly networked environment the artist-run space operates within. 


\section{Cultural Precarity: The Artist as a Creative Subject}

The artist is at the heart of the artist-run space project, as founder, participant, exhibiter and visitor. My research focuses on artists that establish and run artist-run spaces, in order to understand their specific experiences but also to provide insight into the wider challenges which participants of artist-run spaces face. In locating the artist in the artist-run space I draw on a broad range of literatures examining the role of the artist, and, more broadly, shifts in thinking about creativity and creative work.

In Chapter Three I argue that artist-run spaces are entangled in a bigger debate about creativity within neoliberalism, where, in a surprising policy turn towards the notion of creative industries over the last 20 years, artists find themselves shifting from marginality to centre-stage - "incorporated into the mainstream of the Government's political project" (Skilling 2008, 157). I am in agreement with the many writers in sociology who place an emphasis on a new kind of creative worker who is woven deep into the fabric of the creative narrative and, hitherto un- or under-valued, has risen to the fore under neoliberalism.

Beginning with stories told to me by participants about how, and why, they run their artist-run spaces, I have sought out literature in organisation studies that examines "how creative activities are pursued and viewed by practitioners themselves" (Taylor 2018, 330). United Kingdom social psychologist Stephanie Taylor argues that the recent research focus on creative industries and creative work does not "explain their attraction for the workers themselves" $(2011,356)$ and, like Taylor's, my work seeks to examine an "analysis of the meanings in creative workers' talk, the decisions and the ways in which workers are positioned, and position themselves" $(2012,44)$. Like the writing of Taylor and Littleton, my thesis highlights "the workers themselves and a curiosity about what it meant for them to be creative and make creative work" (Taylor and Littleton 2012, 2).

Neoliberalism is argued to have reshaped not just economic structures but to have impacted on broader shifts in cultural rationalities (Ventura 2012) using creativity as a means to an economic end (Potts and Cunningham, 2008). Australian sociologist Andrew Whelan identifies three elements to neoliberalism; a political economy that seeks to marketise existing social systems; a political rationality which sets out moral 
imperatives and a form of governmentality that "'makes people': subjects invoked by and appropriate to the managerial techniques and market logics by which they are governed" (Whelan 2015, 140).

Cultural precarity is a term that examines the reconfiguration of the artistic life under neoliberalism (Virno 2004; Gill and Pratt 2008). For most of the twentieth century in the West, the notion of precarity ran counter to normal labour conditions, as stability and longevity were emblematic of financial success (Lorey 2006). A modernist discourse on labour prioritised ways of working that seemed antithetical to the art world, with a focus on stability and permanence. Yet, in the adoption of neoliberal thinking, artists are positioned as ideal neoliberal subjects in their mobility, flexibility, precarity and passion for their work (Hardt and Negri 2004; Lorey 2006; McRobbie 2015, 2010a).

The broader labour shift towards mobility and instability under neoliberalism demonstrates, German political theorist Isabell Lorey argues, "the extent to which 'self-chosen' precarisation contributes to producing the conditions ... to become an active part of neoliberal political and economic relations" (Lorey 2006, 128). Artistic instability is not new but the difference today, United Kingdom cultural theorist Angela McRobbie claims, is that the romantic notion of the artist has been spliced into the entrepreneurial identity of neoliberalism (McRobbie 2015, 2010).

Angela McRobbie has theorised the term the 'pleasure-pain axis' to describe cultural work (McRobbie 2003), where belief in the project is coupled with, indeed fuelled by, an acceptance of difficult work conditions. "Work," wrote McRobbie in 2015, "becomes akin to a romantic relationship" (3). McRobbie's extensive writing on workers in the fields of fashion and music has focused on the 'industry' end of creative industries, but there are resonances with the experiences of my artist-run space subjects, who similarly grapple with the complexity of a deeply held belief in their career, coupled with an understanding of how much it demands of them. There is limited research into the experiences of visual artists within neoliberalism, and even less regarding art collectives, so within the thesis I shift between, and acknowledge, the connections and dissonances between broader creative industries and the specific terrain of the visual arts. 
Art making has long been linked to narratives of passion, and neoliberalism's emphasis on individualism and personal freedom has deep echoes within the art world's modernist tradition of the avant-garde. United States art historian Amelia Jones writes that by the late nineteenth century in France "the romantic artist figure came to represent an impossible apotheosis of the sovereign individual, divorced from commerce and bourgeois culture" (Jones 2012, n.pag.). However, a neoliberal reworking challenges the notion of the romantic artist individual removed from wider society, the "almost mystical belief that artists are endowed with special sensitivities and powers that set them apart from other people" (Goldbard 2002, 190). Instead, the new alignment merges artistic practice with broader notions of creativity in a "congruence between the image of a creative individual and the agentic entrepreneur" (Taylor, Littleton and Eteläpelto 2011, 2).

Artist-run space participants usually juggle the demands of a complex matrix of paid work, unpaid labour for the space and their own creative practices as artists. This thesis argues that increased financial pressure for artists balancing work with creativity means that the length of time individual artists can commit to an artist-run space is shrinking. I draw on United Kingdom cultural theorists Stephanie Taylor and Karen Littleton's (2008) concept of the 'double life', which outlines the scenario where a creative worker maintains an artistic practice alongside a waged job or jobs for financial support. Taylor and Littleton describe the double life as one which necessitates "the continual balancing and accommodation of competing demands, and therefore requires considerable energy and effort" $(2016,69)$. Artists undertake a double life through active choice, because they are demonstrating a commitment to artistic practice, deeply rooted in personal belief.

Who, exactly, is the new creative worker? Is the artist-run space participant representative of a broader field of creative workers? McRobbie's focus on the role that gender and age play in issues of cultural precarity, highlights the predominance of young, motivated women in creative labour markets $(2015,2010 \mathrm{~b}, 2007,2002)$. The question of who is most comfortable creating and visiting artist-run spaces and who might feel excluded from such communities is focused on in Chapter Three, and expanded on in Chapter Five, where I argue that the artist-run space affirms, but also complicates the normativity of the mainstream art world. While it does not form a 
major part of the research, I have drawn on the queer theory of difference (Allen 2004; Ashcroft 2014; Halberstam, 2012; McDonald 2015; Parker 2014) to understand the complex nature of identity. Difference theory, argues United States organisational communication scholar James McDonald, provides a useful framework to consider forms of identity that fall outside normativity because it conceptualises identity as multiple, fluid and unstable (McDonald 2015, 319). Rumens, de Souza and Brewis describe theories of difference as "a set of intellectual claims, practices and political actions which — broadly speaking - challenge normative knowledges and identities" (Rumens et al. 2019, 597). A study focused on difference, Halperin posits, can bring to the surface "whatever is at odds with the normal, the legitimate, the dominant" (Halperin 1995, 62).

I turned to writing on difference to support my argument that Meanwhile are forging new ground in New Zealand as an artist-run space that prioritises supporting difference above traditional notions of artistic risk. Writing about difference enables me to examine how Meanwhile strategically align themselves in support of many forms of otherness, claiming a deliberate and heartfelt position that differentiates them from the mainstream art world. Gender fluidity emerges as crucial for Meanwhile, with two of their core participants non-binary and a commitment to queer politics inflected in organisational rationalities. The organisational commitment to gender fluidity, I argue, demonstrates a generational shift away from rigid definitions of gender identity. Amelia Jones finds that "younger generations no longer tolerate or even register the invocation of simplistic binary structures to fix identity in terms of categories" (Jones 2012, n.pag.).

In my research I follow Jones' call “to redress binary hierarchies of identity while, still, necessarily, making note of them" amidst a growing sense "that identity must be understood as multiple, fluid, intersectional, performative, contingent”' (Jones 2012, n.pag.). Identity formation for all participants of artist-run spaces has emerged as a significant element in the research. My thesis argues that the identities of all artist-run space participants are bound up tightly with their work for the space, as well as their personal identification as artists. Running the space and running an individual art practice are both connected and separate; sometimes knitted tightly together and at other times struggling to reconcile competing demands. 
Artists are often acutely aware how their sense of creative selves mesh with broader cultural and social rationalities. Participants in the research were reflexive about the ways in which their artistic selves were both reinforced and contradicted by contemporary notions of labour. Such paradoxes were perceived as being part of the reality of living as an artist. While many writers detail the negative impacts of neoliberal work practices on the art sector, I align my research with literature that does not locate the (often young and female) arts worker solely as victim of circumstance, but allows her a personal sense of agency or resistance, acknowledging a situation in which positive and negative are entwined and inseparable, in "a complex discursive negotiation of the possibilities and constraints and conflicts around a creative identification" (Taylor and Littleton 2012, 4).

In their critical management analysis of a young art collective setting up a temporary art space in central London, Maria Ferreri and Valeria Grazano have undertaken some of the limited quantity of academic research into the reshaping of visual arts collectives through the expectations of cultural policy. They contend that while a passionate attachment to creative work is "often seen as an element in the subjection of cultural workers to the logic of precarity [it] can also be accompanied by a critical ability to discern and reflect upon conditions of unpaid/precarious commission". They conclude by advocating that researchers "attend to the details of how, through a commitment to the arts and a passion for ethical practice, individuals and collectives undergo a learning process as they negotiate, critique and challenge expectations" (Ferreri and Graziano 2014, 98). Tactics and strategies of resistance are discussed later in this review.

While closely reading literature focused on neoliberalism's impact on art and the creative industries, I have also examined broader literature on neoliberalism's impact on New Zealand. The current generation of young people, raised within a neoliberal environment of flexibility, competition and user-pays (Lawn and Prentice 2015, 7) and known variously as Digital Natives, Millennials and, within New Zealand, Roger's Children (Nairn, Higgins and Sligo 2012, has received increasing attention from theorists, who argue they are shaped by neoliberalist thought in a way very different to that which shaped earlier generations (Nairn, Higgins and Sligo 2012). They have never known New Zealand prior to the economic and labour reforms of the 
1980s and the subsequent turn to the market. However, rather than acting as the "passive recipients of neoliberal rationality", suggest Nairn and Higgins, they instead "have been involved in actively crafting their identities, making use of the resources that neoliberal and other discourses provide" (2007, 278-279).

In her influential 1998 study of young, female fashion workers, Angela McRobbie tells the story of how, instead of submitting to a neoliberal situation, the workers actively "modify government rationalities ... to suit their own needs, in this case making use of enterprise culture to allow them to pursue their careers" (McRobbie 1998, 18). In her more recent thesis, New Zealander Amanda Bill draws on and builds on McRobbie's work, arguing that it is not that a creative worker (Bill's term for New Zealand fashion students is "creative girl") is shaped by neoliberal ideologies, as McRobbie suggests, "but because she is made up by techniques and tactics of afterneoliberal governmentalities" (Bill 2008, 120).

Through this lens, Bill contends that young cultural workers, far from being unwilling yet compliant tools of neoliberalism, are, in fact, "in a mutually constitutive relationship with a creative economy" (Bill 2008, 120). Bill suggests that, "rather than deploying theory to 'cure' students of creativity, the goal is to distinguish creative subjectivity from creative subjection, and both from subjectification" (121). Bill's positioning of her subjects, not purely as victims of neoliberalism's co-option of creativity but as simultaneously knowing and productive agents, accords with my argument that a nuanced reading finds the artist-run space's relationship to neoliberalism to be both mutually beneficial and troublesome.

Little research has been undertaken at a close up, case-study level on the extent to which artist-run-space workers may have learnt to operate within neoliberal conditions, adapting to compromise and learning to work within it, or even against it from the inside, operating in what Amanda Bill terms "a mutually constitutive relationship" (Bill 2008, 120), where complicity is paramount. The literature focused on neoliberalism's impact on the creative industries in New Zealand is limited, ranging from music (Scott and Craig 2012), museum curatorship (Bieldt 2016) and film (Jones, Boon and Curnow 2009; Jones 2008). My research sits alongside and builds on their work, focusing on the particular and unique experiences of visual artists. 


\section{Reshaping the Artist-Run Organisation: Governmentality}

My thesis charts the tensions that can arise as an artist-run space takes the step from a founding group of friends to a more formalised set-up. I argue that New Zealand artist-run spaces have evolved into two distinct models of governance, each with different motivations and very different relationships to funding imperatives. United States sociologist Batia Sharon's analysis of San Francisco's burgeoning artist-runspace movement was simultaneously the first sustained analysis of artist-run culture and the first to signal concern at the new model's tendency to adopt corporate structures (Sharon 1979). Since then, "unease that the processes of professionalisation embraced in turn have reformed artist-run organisations, erasing certain function and ethical distinctions" (Robertson 2004, 5-6) has been a staple feature of artist-run literature (Atkins 2010; Bronson, 2012, 1983; Griffiths, 2012; Jackson 2013; McKee 2011; Pryde-Jarman 2013; Snider 2015; Trahan 2008; Wai and Ming 2002; Wallace 1991; Wong 2008).

Numerous writers have found a correlation between funding requirements and formalisation of practice, a development which, says Julie Ault, results in an "onset of bureaucracy and hierarchy" (Ault 2010, n. pag.). The impact of economic rationalist, neoliberal cultural policy in influencing Canadian artist-run culture towards growing formalisation is asserted by a number of writers (Barber 2008; Bronson 2012; Butler 2008; Labossiere 2008; Robertson 2006, 2004; Snider 2015). "For artist-run spaces in the United States and Canada, the transformation of informal organisational structures into formally regulated ones was speeded up by the necessity of fundraising" writes Italian critic Gabriel Detterer, in one of the first books to survey artist-run culture broadly $(2012,41)$.

In the Australian artist-run cultural landscape, in parallel in many ways with New Zealand's, criticism has been levelled at the Australia Council for "funding bodies which end up supporting institutional structures which mirror their own framework of professional responsibility" (Jackson 1995, 47). Similarly, Australian policy consultant Jo Caust suggests the "intervention of managerialist, government or political policies into the arts organisation's objectives and practices is problematic" (2003, 60). Once formalised, argues United Kingdom art historian Deborah Jackson, writing on the Scottish situation, artist-run spaces "occupy the contradictory position 
of being professionalised, fully-incorporated institutions, which, despite their small scale, physical size and budget, and their voluntary members, often significantly resemble the established institutions they were developed to provide an alternative to" (Jackson 2013, 57).

But if artist-run spaces are no longer antagonistic to the mainstream art world, then what? Cultural theorist Rebecca Gordon-Nesbitt asserts that "artists are increasingly obliged to play by the rules and a self-policing consensus has formed around the art world" (Gordon-Nesbitt 2009, 564). Katherine Waugh argues it is the art world itself which is complicit in willingly adopting corporate models of organisation, "ushering in a regime of micro-management wherein we effectively bolster a culture based on the institutionalism of the self" (Waugh 2016, 148).

Like a number of other recent writers on artist-run culture, Waugh turns to the theory of governmentality to provide "tools to help get beyond an impasse many artists ... encounter when trying to think and act in new ways within the labyrinth of power and institutional structures stultifying radical aspirations" (2016, 149). Brian Wallis finds, in his investigation of the role governmentality plays in the relationship between the United States' funding body NEA and alternative spaces, that the NEA exerts control through a variety of regulatory features which, "while less obvious than other forms of control, dramatically delimit alternative artistic practices" (Wallis 2002, 178).

Governmentality, a theoretical framework first developed by Foucault in 1977 and used increasingly within cultural analysis, is "not the question of regulating autonomous, free subjects, but instead, regulating the relations through which socalled autonomous and free subjects are first constituted" (Lorey 2006, 128). Governmentality does not strictly mean the Government but rather the broader notion of 'the conduct of conduct' (Foucault in Burchell, Gordon and Miller 1991; Lemke 2002; Rose 1999), or a continuum from political government through to selfregulation. It is the analysis of an order that is not forced upon people, but in which they are simultaneously an active part of self-regulation. Museum studies has increasingly drawn on governmentality theory since cultural sociologist Tony Bennett first deployed a Foucauldian reading to uncover the modernist museum as a site where official social behaviours and systems are performed and regulated in an environment designed to encourage self-surveillance (Bennett 1995). 
The notion of governmentality provides a way to understand the subtle drivers that come to bear on both artists and arts organisations, reshaping over time the cultural landscape they operate within, at a moment when, Kate Oakley and Sara Selwood have argued, "policy is increasingly stressing creativity" (Oakley and Selwood 2010, n.pag.). I utilise governmentality theory in this thesis to describe shifts within artistrun-space culture that appear self-directed, yet align with wider policy concerns of government (Burchell, Gordon and Miller 1991). My thesis argues that primary arts funder, Creative New Zealand, has shaped and formed artist-run culture through a variety of policy rationalities which emphasise formalisation and efficiency.

Clive Robertson deploys the theory of governmentality in research on artist-led organisations, to reveal "how the social and cultural interventions and ambitions of artist-run centres are re-designated by funding agency policy, and by artists themselves, to fit a narrower or more specific visual arts discourse" (Robertson 2004, 24-25). Looking closely at funding negotiations within the Canadian grassroots arts scene, Robertson charts the absorption of policy shifts by the arts community, often through incremental and unnoticed changes in discourse. He argues that there is a discursive flow in the relationship between art and cultural policy and calls for these connections to be registered more tangibly.

Individual artists and arts organisations who receive public funding and assist in, or accept, the processes of adjudication are policy subjects, who must bring into their own practices and organisational bodies considerations of where changing funding policy demands arrive and depart from their own goals and obligations. (Robertson 2004, 200)

Like Robertson's, my research examines closely the relationship of artist-run spaces to policy directives, seeking to understand the ways in which artist-run spaces have followed in the wake of Creative New Zealand as it has been reshaped along increasingly liberal lines. Cultural policy research underpins and informs my work, in conjunction with the theory of governmentality, enabling me to understand and articulate the relationships between artist-run space and funder and how funding imperatives might remake artist-run spaces in subtle but powerful ways. While focused on artist-run spaces, my research acknowledges a need for sector-wide policy engagement, in agreement with Sara Selwood and Stuart Davies' call for museums "to work harder to have a place in policy-making so that they have just a little more 
say in what happens to them" (Selwood and Davies 2015, 65).

Policy in its widest sense refers to "a historically specific set of institutionally embedded relations of government in which the forms of thought and conduct of extended populations are targeted for transformation" (Bennett 1992, 26). Cultural policy was first developed in Europe in the post-war period (Fesch 2014) and in this first period constituted a three-part mechanism to support "historical heritage, support of professional artists, and traditional cultural institutions" (Dubois 2014, 65). While cultural policy developed from the 1950s, cultural policy studies, academic research into the development and enactment of cultural policy, originated towards the end of the 1980s within a political science context (Frenander and Jönsson 2007) and has emerged as a diverse and inter-disciplinary practice.

While undertaking cultural policy research into the New Zealand situation, discussed in detail in the Creative Industries section of Chapter One and also drawn on in Chapter Four, I kept at the forefront of my thinking two questions suggested by cultural policy researchers Adrienne Scullion and Beatriz García; "how is culture shaping contemporary notions of governance; and how is culture administered and regulated?" $(2005,117)$. Scullion and Garcia argue that the hybrid nature of cultural policy research means it "inhabits the gaps and fissures of making, doing and interpreting, and requires research approaches that are (truly) inter-disciplinary" (125).

My research has included secondary data, with close readings of both recent publications by Creative New Zealand (policy documents and funding guides) and funding applications submitted to Creative New Zealand by my case studies. In reading these texts I wanted to discern connections and slippages from funding language to official representations by 'funding clients' to track how key terms might migrate. I read, and re-read the texts drawing on discourse analysis, to understand how language is used and replicated.

Discourse analysis is the broad study of language, both written and verbal. Foucault has written extensively on discourse analysis in The Archaeology of Knowledge (1982), explicitly focusing on the analysis of language to reveal power relations. He 
has identified a discourse as a way of "constituting knowledge, together with the social practices, forms of subjectivity and power relations which inhere in such knowledges and relations between them" (Weedon 1987, 108). Writing about the Australian contemporary art sector, Jo Caust describes how tracking changes in language can reveal structural change in the art sector.

Language is a powerful tool for reinvention of a world order where former valued ideals have disappeared and new ones given precedence. The arts sector is no exception; for instance, 'artists' have become 'clients', 'arts practices' have become 'programmes', and 'grants' have become 'incentive, investment or marketing schemes'. (Caust 2003, 56)

As in Canada, Creative New Zealand's arms-length funding model was adopted to provide distance between the arts and direct political control, and theoretically to ensure that government did not influence arts funding. However, the arms-length model can generate other, subtle forms of pressure on funding bodies, as Peter Skilling has written,

An agency Chair or Chief Executive who hopes for continued or increased funding will take some care to articulate their goals and objectives with the broader goals and values of the current administration. In this way, cultural policy may be centralised and politicised by stealth, and this process justified by the arms-length structure. (Skilling 2008, 163)

Skilling's argument that funding clients will reshape their activities in line with the "broader goals and values" of funders is one I develop further in Chapter Four, where I draw on governmentality and discourse analysis to argue Creative New Zealand's role in guiding and rewarding artist-run spaces to take up business efficiencies.

\section{Speculations and Tactics for Resistance}

In her book States of Insecurity, Isabell Lorey claims creative subjects are ambivalently caught between modes of self-determination and obedience. Yet she claims it is not an inescapable trap, as subject positions and social relationships still contain possibilities of exceeding and disrupting capitalist regulation (Lorey 2015, 103). In my reading I have sought out not just theoretical critique of the increasingly neoliberalised art world, but also literature that offers strategies for action, just as participants in my case studies argue the case for their own resistance through both institutional and personal tactics. 
Artist Anthony Davies writes that art institutions are now divided, some openly promoting "the liberating capacity of new revenue streams linked to consultancy, outsourcing, business incubation and enterprise activities" while others seek to find "more tactical models of engagement, looking to new constituencies and standards of practice to offset the crisis of legitimation which opens up as institutions are subjected to neoliberal agendas" (2007, n.pag.). Literature from both curatorial studies and cultural policy discusses how the current generation of artist-run-space participants are developing new methods of adaptation to an increasingly neoliberalised art world. These coalesce in two very different forms. The first calls for artists and artist-run spaces to engage directly with funders to reshape cultural policy, in alignment with United States cultural policy researchers Toby Miller and George Yudice's claim that "getting to know cultural policy and intervening in it is an important part of participating in culture" (Miller and Yudice 2002, 34). The second argues for strategies of withdrawal; actively rejecting funding norms and social expectations of efficiency and productivity.

My thesis charts various withdrawal techniques deployed by each of my case studies, particularly $R M$, but argues both strategies offer useful models and need not be positioned in binary opposition. Here I am in agreement with United Kingdom art historian Deborah Jackson when she suggests hybrid forms may be the only way for artist-run-space culture to survive, positing that "as the boundaries between the marginal and dominant cultures are blurring, a space between institutionalisation and independence, where negotiated, equitable structures can exist, becomes a distinct possibility" (Jackson 2013, 187). Similarly, art theorist Gene Ray posits "pure autonomy, we can agree, is a myth. For 'autonomy' we have to read 'relative autonomy" (Ray 2011, 175). Ray calls for strategic resistance through tactics to "recompose, reorganise and link struggles, through practical alliances and strategic fronts" (Ray 2011, 176).

Jackson's $\mathrm{PhD}$ research into institutional change at three artist-run spaces in Scotland emphasises policy engagement at a grassroots level as crucial, stating "it is of the utmost importance that artists' deliberations and their results should inform the making of cultural policy and not vice versa" $(2013,187)$. Jackson identifies a crisis because of "the lack of agency afforded to practitioners and facilitators of ARIs 
[artist-run initiatives]" and calls for "a framework whereby their voices are recognised by established institutions, legislators, policy-makers, developers, and each other" (25). She asks public sector arts funders to make a shift from requiring secure and measurable outcomes to understanding that artist-run spaces "promote risk-taking and invest in the speculative potential of artists" (185).

Clive Robertson's research into artist-run centres in Canada $(2006,2004)$ describes a cultural policy's logic of accountability, applying governmentality theory to understand struggles over caring for, and presenting, art at a grassroots level. He provides the most sustained and detailed research to date to focus on cultural policy implications for artist-run spaces, seeking to "define and 'make visible' policy as a site of practices and struggles to effect social direction and destiny" (Robertson 2004, 204).

Robertson argues artists themselves must be actively involved in policy development, in doing so, rejecting, he writes, "the idea that funding clients are merely readers of funding rule changes" instead viewing the artist-run movement "in terms of participatory citizenship formed through processes of re-defining particular sets of rights and responsibilities" (Robertson 2006, 8). His claims for artists to become active policy actors centre on reconfiguring the mechanisms for evaluating and processing grant applications, stating "the challenge is to insist on structures outside of funding juries where the implementation of funding programme changes can be negotiated" (8). Robertson's research charts previous generations of artist-run workers (1970s-1990s), primarily focused on strategies of direct activism by practitioners. My thesis, which is focused on contemporary artist-run-space participants' new relationships with both policy and practice, builds on and extends Robertson's work.

On what terms should artist-run spaces engage with policy change? And could that engagement include understanding and even combating their own neoliberal assumptions? While Robertson details specific policy engagement outcomes, there is limited literature to explain how this might have occurred, nor how to mitigate potential funding risks arising for artist-run spaces engaging in policy negotiation. Cultural theorist Jonathan Vickery, writing about the climate for artist-run spaces in the United Kingdom, warns that agency is difficult for small organisations to achieve 
in an environment of "state mediated authority, legitimacy and value" (Vickery 2014, 98).

Audit culture ensured that the organisational formations of public culture never exceeded its ability to monitor them, which meant that organisational innovation was only developed on the level of the service. It remains unusual to find an art organisation equipped with expertise sufficient for policy interventions in local urban-economic development. (Vickery 2014, 98)

More strident calls for policy intervention have come from curatorial studies. For example, Russian art historian and curator Ekaterina Degot believes that a turn against the state is imminent, or in fact, a move to replace the state through artist activism: "artists may look forward to a time when they might cut state or state-like organisations out of the loop entirely by assuming their functions and then giving this frame to others. Today, the state is becoming the horizon of artists' ambitions" (2015, 25).

A similarly polemical manifesto on self-organisation by artists Anthony Davies (United Kingdom), Stephan Dillemuth (Germany) and Jakob Jakobsen (Denmark) demands the complete separation from institutional engagement and subsequent dismantling of all existing institutional structures.

In our capacity as workers with a political commitment to self-organisation we feel that any further critical contribution to institutional programmes will further reinforce the relations that keep these obsolete structures in place. We are fully aware that 'our' critiques, alternatives and forms of organisation are not just factored into institutional structures but increasingly utilised to legitimise their existence ... we see no space for negotiation-we offer no contribution, no critique, no pathway to reform, no way in or out ... All we need is their cash in order to pay our way out of capitalism and take this opportunity to make clear our intention to supervise and mediate our own social capital, knowledge and networks. (Davies, Dillemuth and Jakobsen, 2005, 177)

While their text is largely intended to be provocative rather than prescriptive, it upholds the argument that self-organisation sits in opposition to a mainstream culture, "a tool for the little man with which to work in spite of, or in opposition to, the predominant system" (Drabble 2013, 19). Like Degot, Davies, Dillemuth and Jakobsen seek ultimately to dismantle the current institutional systems in favour of new, ethical, grassroots versions, which in turn distribute funding through more holistic forms of gatekeeping (although no proposal is made as to how this will be 
monitored). While the replacement of all institutional systems may be an extreme position, the manifesto largely operates as a warning.

While the writers above advocate change to funding structures themselves, many of the current generation of artist-run workers reject engagement with policy, calling instead for a further blurring of the boundaries between institution and alternative and between public and private. My thesis argues $R M$ 's refusal to map success in grant acquitals through career progression for individual artists demonstrates a strategic rejection of funding norms to prioritise experiences over development. In that sense, $R M$ can be understood as part of a broader international shift away from institutional compliance towards subtle resistance through modes of deliberate inefficiency and strategic obfuscation.

Distance is a tactic nominated by Norwegian curator Anne Szefer Karlsen, who argues for artist-run organisations to engage in a necessary separation from current paradigms through what she terms "aesthetical redirections". "This form of separatism," Szefer Karlsen contends, "should not be misunderstood as 'alternative' or oppositional to existing structures, but in addition to, and as holding real power and integrity" (2012, n.pag.). Specific instances provided to support this argument include separating the space's activities from commercial markets or the public funding system as well as adopting physical or ideological isolation (2012).

United States art theorist Marina Vishmidt posits the obscured anonymity of French artist gallery/collective Claire Fontaine, ambiguously neither an artist nor a gallery (Vishmidt 2013,43) as a means by which artist-led organisations could complicate art world hierarchies. Irish curator Katherine Waugh nominates tactics established by the artist-run space 55 Sydenham Road (Sydney), including substituting anonymity for artists' names and biographical details, to resist "the fostering of 'emerging' artists and artistic 'process' as a form of temporal rehearsal for success on an institutional level" (Waugh 2016, 154). Such a method speaks against the funding imperative to track individual development of emerging artists through the artist-run space system and into mainstream exhibition formats.

Productivity and efficiency are key goals for an institution honed to a business model. United Kingdom curator Barnaby Drabble's essay On De-Organisation (2013) calls 
instead for a shift towards a methodology of "the ad hoc, the last minute and the improvised" (23). De-organisation is offered by Drabble as a form of resistance against "the cult of professionalisation and the resulting equations of better organisation, quality and transparency [which] have had an increasingly stultifying effect on our museums" (25). By de-organisation Drabble is advocating for a slower pace of practice, with less emphasis on production and a rejection of "self-imposed micro-management that borders on the institutionalisation of the self" (26).

The definition of self-organisation used in the natural sciences is useful. In those fields the term describes the way in which particular natural systems have a tendency to develop, and take new and more complex forms, in a seemingly unplanned fashion, without the influence of an external or central authority. In such cases, changes to the nature of the whole system occur on account of numerous actions at a low level, with the smallest parts interacting locally without the need of an overall view of the whole. This is what scientists who analyse systems have come to call 'emergence'. (Drabble 2013, 25)

While Drabble offers only a theoretical framework for de-organisation, with no case studies or practical examples provided, a concrete form of institutional structural change by an institution is offered by Unlearning, a project by artist Annette Krauss with Utrecht-based art project space Casco (a small-scale gallery with paid staff, running since 2014). Similar to 'de-organising' in its rejection of conventional organisational strategies but more structured in its outcomes, Unlearning takes the form of a series of workshops and meetings, aimed at,

unlearning the norms and structures which are internalised in artist-run organisations, challenging ... and re-thinking the structural and hierarchical models often taken for granted as necessary evils; ideas of incessant productivity, promotion, the maintenance of achievement-based 'public profiles'. (Waugh 2016, 155)

This deconstruction of the institution is conceptually driven but enacted through a series of practical changes, or "unlearning tools" (Kraus and Casco, 2015) which range from a shared cleaning programme aimed at breaking down institutional hierarchies (as cleaning had ended up, by default, the responsibility of interns and exhibition workers rather than management), developing a process diagram that makes visible the reproductive labour inherent in each exhibition, and a documentation project that prioritises archiving existing projects over the production of new ones. 
These organisational changes were enacted to answer the following questions:

Why are we always so busy? Why do we feel the constant need to be productive? What does being productive mean to us? How does this particular feeling of responsibility affect our bodies and our minds? We realised that running a business, the business of an art institution, is irrevocably tied up with our personal feeling of 'busyness', the latter bringing stress and nervousness. Moreover, it became apparent that we continuously undervalue certain reproductive tasks, such as cleaning, cooking, hosting, and non-public administrative and organisational tasks. However, without this 'domestic' work, our institution would not exist. So we asked: How can we unlearn this form of valuing productivity and how can we value reproductive labour as an essential part of productivity and dismantle the rushed feeling of always being too busy? (Krauss and Casco 2015, n.pag.)

Irish curator Katherine Waugh advocates Unlearning as a model to generate transversal rationalities that operate at the heart of the organisation, not through the external outcomes of exhibitions and publications, but, less tangibly, within the social relations and structural underpinnings of the organisation itself. By 'unlearning' she suggests an art institution could take back some of the operational agency that funding imperatives might have restricted $(2016,155)$.

A second model seeks to negate the transparency demanded by a culture of public accountability. Maria Lind in her prescient text, The Future is Here, which imagines the art world in 2015 from the distant perspective of 2007, calls for strategies of negation, withdrawal and opacity (Lind 2010,76). Lind speculates that the only way forward is for artists and smaller institutions to turn "their backs upon the expectation to be constantly and immediately accessible through public institutions" (78) and engage in what she describes as a "certain strategic separation" (76).

The tactic of strategic separation is demonstrated in this research through the case study on $R M$ in their refusal to fulfil funder expectations by tracking the career development of individual artists from their involvement with $R M$. A strategic separation need not be an aggressive tactic, rather, in the case of $R M$, as I describe in Chapter Four, it can be a gentle redirection of focus, away from development narratives towards stories of encounters and creative dialogue. In this section of the Literature Review I have embraced texts within both cultural policy theory and curatorial studies that suggest strategies for artist-run spaces developing and practising a sense of agency within an increasingly regulated funding environment 
which calls for artist-run spaces to adopt business models in organisational management. While some of these methods are purely provocative, others, while remaining speculative, are grounded in real case studies - where my own research is located.

\section{Conclusion}

Throughout the literature review my key research question shaped my enquiry: to what extent does the artist-run space offer alternatives to current neoliberal orthodoxy in the art world? While the impact of neoliberal thinking on artist-run spaces has begun to be described in the literature, to date there has been "too little research on the role of contemporary art in the neoliberal city" (Vickery 2014, 92). In particular, there is still a significant absence of exploration of how new generations of artist-run practitioners conduct themselves within neoliberal conditions. The gap my research seeks to span is not only a New Zealand issue, but also constitutes a considerable lack of knowledge internationally on how artist-run space participants conduct themselves within a neoliberal orthodoxy, consciously and unconsciously.

Because of the shortage of research, my literature review moves back and forth between the limited number of texts focused primarily on the specific experiences of the artist-run space sector and, more broadly, the extensive writing on the turn to creativity and what it means to be a creative worker. Within the broader sphere of creative industries literature, my research situates itself alongside recent writing taking the view that creative subjects can be in "a mutually constitutive relationship" (Bill 2008, 120) with neoliberalism, rather than merely its passive recipients.

The interdisciplinary nature of this review has reflected the lateral and networked nature of artist-run culture itself, promiscuously expanding as, to quote United States artist-run-space researcher Christopher Kennedy, "the formation of ideas, of new policy and cultural structures [extends] beyond the threshold of the front door and into the surrounding neighbourhood like the roots of a tree" (Kennedy 2010, n.pag.). I have drawn together key concepts from this broad range of sources to support my thesis, which I situate in the field of critical museology, using Anthony Shelton's call to engage in direct dialogue with practice while remaining critically reflexive. 
Critical museology must, therefore, always maintain a sustained incredulity to itself as well as its field of application. It follows that critical museology could never be an operational tool or provide an alternative strategic mission for museums, though it needs to encourage institutions to adopt more experimental practices, champion openness and transparency, and support critical community engagement. (Shelton 2013, 18)

Throughout this thesis I hold at the front of my thinking Shelton's warning not to seek to provide operational tools for change. This imperative has allowed my research to engage deeply in the realities and tensions of the present moment without becoming embedded in a prescriptive outline of what artist-run spaces must do next. Instead, Shelton's guidance has led me to a position of contingent speculation regarding future possibilities for artist-run spaces. In my reading I have enjoyed the challenge provided by texts intended entirely as provocation. However, the literature I have found most useful examines real situations through the methodology of case study, while remaining speculative in the openness of its enquiry.

Within these narratives I have found, in the singularity and richness of detail, the most useful mechanism for understanding the dynamics of change as it is articulated through real life experience. Completing the Literature Review shaped my decision to undertake a longitudinal study of specific artist-run spaces over time, geared to understanding the past in relation to the concerns of the contemporary moment and seeking to evoke "the complexity and uniqueness of a particular project, policy, institution, programme or system in a 'real life' context”' (Simons 2012, 11).

\section{Research Design}

\section{Introduction}

My thesis offers new local data to analyse an under-researched area of the cultural sector — artist-run spaces - as well as original thinking that contributes to an Anglointernational literature, focused on the current generation rather than providing a historical revision. As the literature demonstrates, the topic of how creative work has been reconfigured under neoliberal conditions has received significant research attention, encompassing fashion, music and other creative industries, but little examination has been made of how visual artists are affected. As the first $\mathrm{PhD}$ 
research into artist-run spaces in this country, my thesis speaks to the particular experiences and conditions of the local, but its reach is wider, making a significant contribution to the international literature on artist-run spaces and neoliberalism.

In this thesis I employ three individual, yet convergent, theoretical frameworks: assemblage theory, creative labour and governmentality, led by my key research question to what extent does the artist-run space offer alternatives to current neoliberal orthodoxy in the art world? My analysis maps different elements in artistrun culture across three chapters, and then, in the discussion chapter, jumps across and between these frameworks, knitting elements together in a synthesis that brings to the fore ideas and findings that resonate.

My methodological starting point was qualitative research, which through its systematic enquiry of social phenomena best reflects the intrinsic sociability of the art world. This thesis research begins by listening, in order to "discover the meaning that people award to their social worlds and to understand the meaning of their social behaviour" (Boeije 2010, 12). And in the retelling of others' stories I have kept at the forefront a desire to evoke 'thick description', the phrase coined by Cliford Geertz (1973) to describe how rich narratives can capture "everyday experiences that remain hidden in the numerical anonymity of quantitative data" (Sallee and Flood 2012, 140).

I chose case-study research because I wanted to get in close, to understand commonalities across the artist-run spaces only through firstly acknowledging the particularity of each individual space - its location, history, aims and influences. Therefore, I undertook qualitative research into three case studies, two- $R M$ and Enjoy - with a multi-generational aspect to their histories. I chose three to enable data analysis both within each artist-run space and across the case studies (Yin 2003), and sought to remain conscious that data from three case studies which might suggest propositions cannot presume to speak for all artist-run culture (Simons 2012).

Case study research has enabled me to acknowledge and understand the intricacies, processes and changes of artist-run culture in close-up (Marshall and Rossman, 2010) within the real-world context of each organisation (Bromley 1986). In doing so I have mapped the dynamics of change within and across the artist-run spaces, understanding that "closely describing, documenting and interpreting events as they unfold in the 
'real life' setting ... can determine the factors that were critical in the implementation of a programme or policy and analyse patterns and links between them" (Simons 2012, 14).

My methodological focus shifts throughout the thesis, moving in and out of different modes of authority. At times I simply repeat, in their own voices, participants' accounts of their experiences: at other times I critically analyse their accounts. Additionally, sometimes I adopt a realist storytelling mode (van Maanan 1988) to draw on the words of participants to provide my own reading of a process, not as a scientific framework but as an interpretive and subjective case study.

The Literature Review has identified the limited nature of both critical and historical writing on artist-run culture. This scarcity is especially notable in contextual literature about the artist-run sector as a whole, its development as a sector and its relationship to the wider art world. To establish a broader context in which to situate my case studies I undertook additional interviews with a group of Boundary Spanners, understood as "intermediaries that link different kinds of people, knowledge and resources" (Larroa 2015, 12) who are "in and of their communities" (Miller 2008, 372). Within the context of my research, Boundary Spanners are individuals who act as a bridge between artist-run culture and the wider art world, either because of their institutional role as a gateway broker or because of personal cultural capital which means they act as connectors.

\section{Theoretical Frameworks}

My research examines artist-run space practices through three theoretical lenses: the assemblage, creative labour and governmentality. Theoretical frameworks are, states Schwandt, the "unified, systematic explanation of a diverse range of social phenomena" (1997, 54). I used theoretical frameworks in line with Anfara and Mertz's argument that frameworks can provide focus and meaning, enable connections to existing scholarship and aid in identifying strengths and weaknesses (2015). Anfara and Mertz suggest the use of multiple theoretical frameworks in a study encourages analytical skepticism, opening up the researcher "to alternative viewpoints and additional understandings ... that might contradict our expectations and promote change in our own understandings" $(2015,115)$. 
Each framework is addressed in detail through a chapter which applies a single theory to a specific area of artist-run space practice, enabling my research to focus on different elements in turn. Chapter Two maps the space of the artist-run, from physical to social, through the mechanism of Foucault's concept of the assemblage. Chapter Three uses the conceptual framework of creative labour and the cultural precariat to examine the work of running an artist-run space. Chapter Four uses the theory of governmentality to examine the artist-run space as an organisational form.

Using three theoretical perspectives as stand alone chapters rather than attempting to tell an integrated story, the thesis does not provide a detailed history of artist-run spaces in New Zealand; it does not even tell the full story about each of my case studies. Instead, each framework enables the research to focus on broader narratives which demonstrate the interconnectedness of institutional and personal relationships, and forms of power.

In the later part of the thesis, Chapter Four and Conclusions, I extend beyond the boundaries of the theoretical frameworks to bring together ideas which came to the fore through the proceeding three chapters. Moving across and between the frameworks in these final two chapters enables my thesis to develop those themes holistically, considering the artist-run space as a complex whole. Here I follow Georges' call for researchers using theoretical frameworks to "discover their own voices, along with the intellectual resources to construct theories that seek to emancipate, rather than control" (Georges 2005, 55).

The multiple framework structure is particularly useful for qualitative research because that focus on "alternative viewpoints and additional understandings" (Anfara $\&$ Mertz 2015, 115) acknowledges multiple truths or perspectives. While the three frameworks I have adopted (the assemblage, creative labour and governmentality) together build a coherent narrative about artist-run spaces and their relationship to wider networks, their intersection also facilitates contradictory voices. Those can reflect the multiplicity of individual participant experiences as well as the many competing demands on their organisations. 
The overlap of those particular frameworks makes explicit complex connections between personal belief, community activation and government policy. The relevance of this intersection could extend beyond the scope of my research to be usefully applied to other humanities research exploring power relationships between community organisations, their constituencies and the formal structures that fund them; such as community museums, performing arts cooperatives, activist groups or sport and hobby clubs.

\section{The Insider Outsider: Ethnography and Auto-Ethnography}

My research is ethnographic in approach, understanding ethnography as the study of the lived experience of a particular community through a process of "immersion and translation" (Cunliffe 2010, 227). Ethnography is appropriate because of its holistic, interconnected nature, focus on specific case studies with multiple data collection, and emphasis on the interpretation of social phenomena. Li Wei argues ethnography offers researchers a way of "describing and interpreting the shared and learned patterns of values, behaviours, beliefs, and language of specific culture-sharing groups" (Wei, 2019, 157).

Situated within the broader ethnographic approach, I utilise elements of autoethnographic reflection to acknowledge my role in the scene as a longstanding insider to the arts community. Auto-ethnography requires me to place myself critically in my research, engaging in a self-reflexive approach to "identify and interrogate the intersections between the self and social life" (Adams et al. 2017, 1). As I wrote, I sought to remain aware of those "intersections" between my personal history and the arts community. I stepped into these artist-run spaces reminding myself of the baggage I carry with me from other spaces; my own and those I have visited, written about and admired. This process was active and ongoing as, during the course of my $\mathrm{PhD}$ research, I contributed two essays to external artist-run publications on the topic of artist-run culture. ${ }^{5}$

While Robert Merton defines an insider researcher as someone possessing previous and intimate knowledge of the community they are examining (Merton 1972), I was 
drawn to research situated on a relational spectrum with "subtly varying shades of 'insiderism' and 'outsiderism'” (Hellawell 2006, 489). I see myself in Alison Griffith's description of the researcher as "always located somewhere", yet continuously moving back and forth between the "positional boundaries of insiderness and outsiderness" (Griffith 1998, 363).

I approached my research, therefore, as the insider/outsider, a shifting status that came into play from the beginning and one which I continued to observe and record as my perspective shifted. To emphasise this, some chapters provide a personal take on Van Maanen's impressionist tale as "evocative accounts of everyday organisational life ... in which the ethnographer is embedded ... reflecting on his or her role in the research process" (Cunliffe 2010, 226). I was drawn to the impressionist tale because of its ability to move between forms, encompassing elements of both realist and confessional writing (Van Maanen 2011, 7). Such tales enable me to describe how a visit to an artist-run space looks and feels, but also to chart how encounters with each artist-run space have subjectively shaped the research direction.

I started consciously as an insider, writing my research proposal from the perspective of working within my own community. I then embarked on interviews, and found that the interviews with founders of Enjoy and $R M$ were conducted in a spirit of peer-topeer communication, as with older Boundary Spanners (Jon Bywater remarked "it's your history as well”. (Bywater 2018)) In contrast, most of the current participants of $R M$ and Meanwhile had no knowledge of my career, other than information I provided as academic researcher.

Somewhat gallingly, I began to realise that the researcher they encountered, a middleaged woman juggling study with childcare and the challenges of provincial living, did not suggest an insider to them. And, although welcoming and often frank in their conversation, most did not seem to consider how I would work with the content, nor were they concerned about how my study might fit within a wider career. Only one interview subject enquired about personal outcomes beyond the thesis, asking if I planned to establish my own artist-run space with the knowledge I was acquiring.

The process was humbling, then propelling. After all, if participants in artist-run culture did not consider me an insider, what was I? I began to question my 
assumptions, and to understand my perspective was coloured by certain narrative expectations and pre-understandings (Dyson 2007). I returned to interviews and literature already understood, to read again with fresh eyes. As the insider/outsider researcher (Hellawell 2006), I captured these shifts in understanding to reflect how my own identity as researcher took form.

Therefore, a critical awareness of my own subjectivity is woven into the study, reflected not just in the choice of a qualitative, ethnographic research approach but through the auto-ethnography reflected in more personal anecdotes that open Chapters Two, Three and Five. In this way I seek to make explicit, as in the quote by Griffith above, that as researcher I'm "located somewhere", and that that location, in the form of my background and experiences, shapes the research.

\section{Case Study Selection}

In searching out three case studies I sought to ensure they were distinct in experiences, yet linked by enough of a common narrative to enable differences to appear more meaningful. To that end, the subjects have been selected to span different operational timeframes and organisational structures. However, it is crucial to my selection that each began as a non-hierarchical collective; a group of artists who were friends and peers coming together to establish a gallery. The 'space' of the artist-run space was important too, although I considered several collectives who engage in exhibition practices in public or temporary sites, I concluded that the physicality of an artist-run space was a strong element in the conversation I wanted to have.

Additionally, it was the act of artists' self-organising that concerned me, so I focused on participants in running the space rather than exhibitors or audience members.

Two of the spaces selected, $R M$ and Enjoy, have run for many years, allowing me to undertake inter-generational research. This is important as the impact of generational difference emerged as a key focus through my Literature Review. Yet, in spaces with a history spanning two decades, with over 40 former collective participants involved in $R M$ alone, the question of on whom, and at what time, to focus became imperative. I considered various possibilities, such as interviewing a random selection of participants from throughout a 20 -year history or interviewing not just participants but 
also exhibitors and audience members who intersected with the organisation during a particular year.

To enable a cohesive and comprehensive, yet manageable structure, I have focused on two groups within the collective: founders and the current generation of participants, that is, members of the founding group who began the space, and current participants at the time of interview. This enabled a longitudinal study that described commonality and difference over time, bringing to the fore how far an organisation might have moved from its starting position.

In order to present an alternative to a narrative of longevity, I selected one additional case study, a newer initiative I could capture in the early stages of identity formation. This took longer to select, because the initial spaces I considered were based in Auckland, and both-Rockies and Glove Box - closed before I had time to approach them. It was important to me that they were active during the initial phase of contact and I eventually chose Meanwhile, a Wellington-based space that opened in 2016.

\section{Methodology}

For a humanities-based thesis in the field of museum studies, my interpretive methodological approach has been established to provide background infrastructure rather than a foregrounded position. To generate "a confluence of evidence that breeds credibility" (Eisner 1991, 110) I chose to use three different methods of data collection: semi-structured interviews, document analysis and participant observation.

The starting point for contact with each space was different, according to my existing relationship. I approached staff of Enjoy informally, asking if the organisation might be interested, and I followed up with a formal email to the chairperson of the Enjoy Trust. I sent an initial email to the generic Meanwhile address, met with the members briefly and then sent an email with a formal invitation and research details. Similarly, I sent a first email to the generic $R M$ address, and subsequently corresponded with one member, Deborah Rundle.

My original intention was to begin my interview schedule with the broader context provided by Boundary Spanners and then work my way sequentially through each 
case study. However, this carefully thought-out linear structure proved difficult to achieve in reality, due to the complexities of geography and schedules, and I ended up interviewing as and when subjects were available, over a period of eight months.

I undertook extensive discussion with both research supervisors about whether to adopt the standard convention of pseudonyms for my interview subjects, as well as my case studies, and the resulting decision to offer this choice to my subjects is discussed in the following section.

\section{Ethics}

I received ethics approval for this research and followed Victoria University of Wellington's ethical guidelines throughout. Throughout my research I kept at the forefront Linda Tuhiwai Smith's admonition that "research is not an innocent or distant academic exercise but an activity that has something at stake and that occurs in a set of political and social conditions" (Tuhiwai Smith 2012, 5).

When Ioana Gordon-Smith reflected to me, "it's really hard to talk being inclusive of culture and race without thinking about the class position that institutions occupy and how that does or doesn't feel exclusionary or intimidating" I sought to apply that insight in connection to my own position as researcher. In interviews with participants I ensured they were as comfortable as possible, meeting them at venues suggested by them (which meant, in addition to the artist-run spaces, their homes, cafes and bars) at times that suited their busy schedules (such as evenings and weekends) and, in the spirit of reciprocity, bringing with me a small gift of food, drink or a book as koha. While none of my case studies identified specifically as a Māori organisation, several interview subjects were Māori or Pasifika and I kept aware of the possibility for unconscious bias as a Pākehā researcher. Additionally, three of my interview subjects identify as non-binary, using the personal pronoun "they" and the thesis reflects this preference.

I was mindful that my case-study interview subjects were, in some cases, critiquing their own workplace as well as relationships with key funders and that my subjects were predominantly young and at the beginning of their professional careers. I was therefore concerned to create a research environment that was sensitive to my subjects 
as well as one that encouraged frankness. As part of that duty of care participants were given the opportunity to be anonymous in the research, but all chose to be named. This is unusual within a research context, but reflected both their belief that the New Zealand art world is relatively small and intimate, making it difficult to conceal identities, but also that the participants were proud of their work and wanted to be acknowledged.

Formal Case Study Research Agreements (Appendix Three) were signed by representatives of each case study and interview subjects signed individual consent forms before the interview, of which a sample is attached here as Appendix Four. After each interview, subjects were sent the full transcripts of our interviews, and provided with the opportunity to change, delete or add information at that stage, taken up by approximately one third of interviewees. This enabled them to speak freely during the interview, knowing they would have the chance to revisit their words. The alterations spanned a number of concerns depending on the person: reflecting inaccuracies (for example, where I had misunderstood a name or they had provided the wrong date), deleting confidential and sensitive subject matter, and, with some participants, removing vernacular phrases such as 'like' and 'you know'. Out of the desire to be careful of my subjects, and after discussion with my supervisors, I removed a small number of additional quotes that I felt to be inflammatory or to potentially render the subject vulnerable.

I received different levels of access to information from the different case studies, with particular restrictions in regard to Enjoy. Ann Shelton, at that time the chairperson of the Enjoy Trust, initially requested sign-off on all interviews by Enjoy Trust members and staff, in addition to their own personal sign-offs. After discussion, she consented to the standard sign-off procedure with the additional measure that the chairperson would sight and provide feedback on the Enjoy case study section of the Introduction chapter at a final draft stage. Due to personnel changes over time, this measure was undertaken by incoming Co-Chairpersons, Melanie Oliver and Bridget Reweti.

The New Zealand art world is very small and because of this I have become accustomed to declaring and managing conflicts of interest throughout my 20 -year career in the arts. Although I do not currently have any professional or financial 
relationships with research participants, I am acutely aware of the rapidly changing networks of the New Zealand art world and of my various roles as a writer, curator, and occasional peer assessor for funding bodies, including Creative New Zealand. During the period I undertook $\mathrm{PhD}$ research I made myself unavailable to undertake peer assessment work for funding applications by artist-run spaces to Creative New Zealand, regardless of whether or not the organisation was a case study.

\section{Research Positions}

As the Prologue has indicated, I have a stake in the discussion. I am a Pākehā researcher from a working class background, who began my career in independent spaces. My sense of identity has been tied to a belief in the artist-run movement. As an active participant, I want my art world to be textured with multiple conversations, from institutional to grassroots. I want to see spaces (both physical and metaphorical) where new graduates and emerging artists can both disrupt the system and find pathways in.

I am interested in research, therefore, that takes a self-critical stance, acknowledging my position as researcher who is neither sociologist, nor art historian, although my research draws on literature from both disciplines. My role over 20 years as a curator and a writer provides me with particular boundaries as well as opportunities for access, and I wish to make explicit the complex threads of subjectivity and objectivity from which this thesis emerges, and in doing so acknowledge that "my personal experiences have informed the kinds of questions I asked, and was able to "see"" (Coffield 2015, 35). For example, Chapter Three details how my personal belief that artist-run spaces should facilitate and prioritise 'artistic risk' as a strategy and led me to question each participant on this, yet the notion of risk was emphasised by very few of my subjects, a finding which provided me with insight into generational shifts.

It is important to determine the basic structures in which my research was conducted in order to acknowledge what I may have missed. As the Research Design section outlined, I interviewed a range of participants alongside other informants on the wider art world. However, there are deliberate gaps within my interviews: for example, I have not interviewed anyone about their experience as an exhibiting artist, nor did I 
interview audience members (although various of my interviewees have been both and occasionally spoke from the audience's viewpoint). Volunteers outside the inner circle of the space were not interviewed, and participants were selected from two crucial time periods only: founders and current members. Additionally, changes to the personnel at my three artist-run spaces continued to occur, past my active research period, and, as much as I could, I attempted to ignore these, while acknowledging such developments in Conclusions. 


\section{Research Methods and Findings}

The following tables detail the range of interviews, archival research and field observation I deployed.

Case Studies Data Table

\begin{tabular}{|c|c|}
\hline Case Study & Data \\
\hline$R M$ & $\begin{array}{l}\text { Eight interviews: } \\
\text { Four face-to-face interviews with current } \\
\text { participants } \\
\text { One Skype interview with current } \\
\text { participant } \\
\text { Three face-to-face interviews with } \\
\text { founding members } \\
R M \text { artists archive } \\
R M \text { exhibitions archive } \\
R M \text { ephemera, Artists and Gallery Files, } \\
\text { Fine Arts Library Special Collections, } \\
\text { Auckland University Library } \\
\text { Internal documents supplied by } R M \text { : } \\
\text { including CNZ funding application } 2016, \\
\text { Artist Liason Guide, meeting minutes } \\
\text { Joyoti Wylie personal archives } \\
\text { Observation in the gallery during opening } \\
\text { hours } \\
\text { Attendance at one exhibition opening } \\
R M \text { instagram and facebook accounts } \\
R M \text { exhibition reviews }\end{array}$ \\
\hline
\end{tabular}




\begin{tabular}{|c|c|}
\hline Enjoy & $\begin{array}{l}\text { Seven interviews: } \\
\text { Three face-to-face interviews with current } \\
\text { Board members } \\
\text { Two face-to-face interviews with current } \\
\text { staff members } \\
\text { Two face-to-face interviews with } \\
\text { founding members } \\
\text { Enjoy exhibition archive } \\
\text { Ciaran Begley personal archive } \\
\text { Rachel Smithies personal archive } \\
\text { Internal documents supplied for sighting } \\
\text { only by Ann Shelton, Chairperson of } \\
\text { Enjoy Trust: CNZ funding application } \\
\text { date and Enjoy Trust AGM } 2018 \\
\text { Observation in the gallery during opening } \\
\text { hours and attendance at two exhibition } \\
\text { openings } \\
\text { Enjoy instagram and facebook accounts } \\
\text { Enjoy exhibition reviews } \\
\text { Enjoy publications }\end{array}$ \\
\hline Meanwhile & $\begin{array}{l}\text { Five Interviews: } \\
\text { Three face-to-face interviews with current } \\
\text { participants } \\
\text { Two face-to-face interviews with } \\
\text { founding members (who were also current } \\
\text { at time of interview) } \\
\text { A follow up email interview with one of } \\
\text { the founding members } \\
\text { Access to Meanwhile online archive, } \\
\text { including funding applications, strategic } \\
\text { documents, meeting minutes and } \\
\text { correspondence between members }\end{array}$ \\
\hline
\end{tabular}




\begin{tabular}{|l|l|}
\hline Meanwhile exhibition archive \\
Observation in the gallery during opening \\
hours \\
Attendance at one exhibition opening \\
Meanwhile instagram and facebook \\
accounts \\
Meanwhile exhibition reviews \\
Meanwhile publication
\end{tabular}

Additional Interviews with Boundary Spanners Data Table

\begin{tabular}{|l|l|}
\hline Name & Art world involvement \\
\hline Hana Pera Aoake & $\begin{array}{l}\text { Emerging artist and activist, member of } \\
\text { Fresh } n \text { Fruity }\end{array}$ \\
\hline Jon Bywater & $\begin{array}{l}\text { Academic, critic, former member of } \\
\text { CUCKOO artist collective }\end{array}$ \\
\hline Judy Darragh & $\begin{array}{l}\text { Senior artist, former member of artist-run } \\
\text { space Teststrip, former member of } \\
\text { CUCKOO artist collective }\end{array}$ \\
\hline Melanie Oliver & $\begin{array}{l}\text { Senior Curator at The Dowse Art Museum, } \\
\text { former employee of Enjoy, BOAG and } \\
\text { The Physics Room }\end{array}$ \\
\hline Ioana Gordon-Smith & $\begin{array}{l}\text { Public gallery curator, member of Whau } \\
\text { the People }\end{array}$ \\
\hline Erica van Zon & $\begin{array}{l}\text { Artist, former employee of Enjoy, } \\
\text { employee of Toi Poneke, community art } \\
\text { gallery }\end{array}$ \\
\hline
\end{tabular}




\section{Boundary Spanners}

Boundary Spanners were selected relatively informally because I felt they would add dimension to the research data that was otherwise lacking. Overall, I wanted participants who were experienced, both with artist-run spaces and the wider art world systems, and that were articulate and opinionated. I sought a generational sweep, so I selected Judy Darragh, in her sixties and Hana Pera Aoake, in her twenties and a cultural and gender mix. Two participants, Melanie Oliver and Ioana Gordon-Smith, held institutional positions in public art galleries, and one, Jon Bywater, an academic position in a tertiary institution. I wanted artists' voices to be prioritised, so I included three artists, Hana Pera Aoake, Judy Darragh and Erica van Zon.

\section{Semi-Structured Interviews}

I conducted 25 interviews in total, and these formed the core of my research, in accordance with my strong belief that "the interview is the main road to multiple realities" (Stake 1995, 64). As described above, I undertook interviews with current practitioners of my three case studies, RM, Enjoy and Meanwhile, as well as some of the original founding members of each space. Semi-structured interviews, mostly around an hour long, were sufficient time and informal enough to enable digressions by my interviewees, enabling me to understand "how case study participants construct reality and think about situations" (Yin 2012, 12). As indicated above, I let the subjects select where and when we met, meaning interviews were held both at artistrun spaces, but also at their homes, cafes and a bar. Interviews were one-on-one, except for the interview with Simon Gennard and Dilohana Lekamge, who elected to be interviewed together.

The interviews were approximately 60 minutes in length, to enable in-depth discussion, although interviews with very new participants (Jess Morgan, Simon Gennard and Dilohana Lekamge) were shorter and two interviews (Nick Spratt and Ciaran Begley) took considerably longer than an hour. I conducted a second interview with Ciaran Begley at his suggestion. While recording the interviews I did not take notes, to allow me to build intimacy and report with my subjects. However, immediately after each interview I took extensive notes, to capture nuances of 
emphasis and visual cues which might not be captured in interview transcripts or recalled long term (Wahyuni 2012).

I created three generic questionnaire templates, one for current members of a space (Appendix Five), and slightly different ones for founding members and Boundary Spanners. The templates were the starting point for the interviews however, I let each subject guide and shape the discussion, meaning the resulting transcripts differ widely.

Questions were divided into thematic groupings, such as: subject, space, broader networks, decision-making and the future, and selected for a variety of reasons. I began the interviews with questions to help me locate the participants, in terms of their personal histories both with, and prior to, involvement in the the artist-run spaces, but I hoped the questions would put the subjects at ease, making them comfortable with the process.

Specific questions were aimed at each of my theoretical frameworks; to track the broad activities and networks of the space as an assemblage ('Where do you see Enjoy fitting into the bigger art world? Are there any particular networks or friendships with other galleries that are important?'), to understand the participant as the subject of creative labour ('Do you consider it a job? How do you see it fitting into your long-term career?') and understand the impact of funding norms and other external pressures on the artist-run space ('Why do you think that CNZ fund Meanwhile? Do you think CNZ have certain expectations for Meanwhile?').

Questions were asked about the conceptual content of the artist-run spaces activities ('Is there a show that stands out for you as a defining one?') as well as the parameters of exhibition programming ('Is cultural diversity something you thought about when putting together a programme? How about gender?'). I asked each case-study participant to recommend documents they thought were important to their artist-run space, information I drew on when determining what I should focus on in document analysis. 


\section{Document Analysis}

Documents of varying types, Merriam states, "can help the researcher uncover meaning, develop understanding, and discover insights relevant to the research problem" $(1988,118)$. I have examined both unofficial documents (memos, notes, correspondence) and official records (strategic plans and funding proposals). In selecting and analysing documents I was eager to build up my general knowledge of the space and its history, but also to discern how the public presentation of the space (for example, website and publications) might differ from private presentations (to funders, their own personal archives) as well as the difference between written and spoken narratives.

In seeking out both the official and unofficial I was mindful of Simons' observation that "informal memos may carry as many clues about the culture of the organisation as formal documents outlining aims, objectives and vision" (Simons 2012, 64). I was interested in where official and unofficial accounts might concur and where they might differ, and what such a disjunct might suggest about tension between the funding imperatives and the way the organisation viewed itself. To this end I was also interested in tracking how key terms might have migrated from funding guides generated by funders into grant applications submitted by the artist-run spaces, and from there, into broader organisational missions and vision statements.

Case-study documents were sourced differently for each case study and I was allowed very different levels of access. In the case of Meanwhile, I was provided very quickly with access (including editing rights, which I did not take advantage of) to an online document and image archive stored on Dropbox, to which access was shared by all members of the Meanwhile collective. This contained meeting minutes, drafts and completed funding proposals, correspondence and strategic documents.

I spent time in RM's public artist and exhibition archive, along with an additional public archive held at the Fine Arts Library, Auckland University, that held copies of all $R M$ newsletters. Further, internal documents were provided to me by the $R M$ collective, after asking each of my current interview subjects to recommend documents they felt were important. 
In the case of Enjoy, I was notified by the chairperson not to discuss documents with any other staff or board members of the organisation, except herself, as she would understand best which documents were appropriate. The two documents I was provided access to, a funding application and minutes of an AGM, were given to me by the Chairperson under strict conditions. I was able to view them on a Dropbox archive, but not save them to my computer. Instead, I was able to apply to her for permission to use individual quotes in the thesis.

I also examined external publications including websites, social media, catalogues and journals. In addition, I examined policy documents released by both Creative New Zealand and Manatū Taonga, the Ministry for Culture and Heritage, as well as funding guides produced by Creative New Zealand. To provide broader context I also read related policy documents published by the Australia Council and British Council.

\section{Participant Observation}

When Becker used the phrase 'art world' to describe the loose network of artists, gallerists, collectors and other participants that form the contemporary art network, he detailed the "large groups of gallery goers, who attend openings, come to see shows, and generally diffuse interest in the gallery's artists by talking about them and recommending shows to others" (Becker 1982, 11). The exhibition opening is where central characters in an art world come together, to view art, to talk about art, to see and be seen. Kelm states, "art openings if investigated, observed, and described, can shed new light on the role of ritual in the contemporary visual arts and perhaps help us understand more thoroughly the contextual interactions of art and audience" (Kelm 1987, 3).

Participant observation formed a smaller element of my research, in part because of the logistics of visiting events, but mostly because I was wary of imbuing the selected events that I attended with too much significance. Participation observation has been largely used to provide flavour and context at the beginning of chapters, to contextualise and foreshadow more detailed discussion. 
I utilised semi-structured (O'Leary 2004) participant observation both at exhibition openings and during the day at the galleries. Direct observation of their activities and environments emphasised the centrality of visually-based knowledge (Bouquet 2012). I attended as a participant, endeavouring to ensure my research methods were unobtrusive, allowing me to observe without making other gallery visitors uncomfortable. I did not, therefore, write notes while at a venue, but immediately after a participant observation session I recorded descriptive field notes: noting the physical setting, including describing in detail the artworks exhibited; who, broadly, was in attendance (staff, volunteers, board members, exhibiting artists, public gallery curators, commercial gallerists, critics, artist peers, older artists, younger artists, patrons, family, members of the 'public') and any formal activities, such as speeches or performances. I also recorded reflective field notes: how I felt at the event and things I expected to see but didn't.

\section{Data Analysis}

Data analysis requires the dismantling and subsequent reassembling of data, "looking for patterns, searching for relationships between the distinguished parts, and finding explanations for what is observed" (Boeije 2010, 76). My original intention was to create a flat-file, searchable database using FileMaker Pro software to capture and store all relevant material in a searchable form as fragments. In practice I engaged in a number of more analogue systems, which suited my preference for techniques which were both visual and tactile. I analysed all interviews the same way, including the Boundary Spanners.

I was seeking to understand the material in light of the three overarching theoretical frameworks driving my research: assemblage theory, creative labour and governmentality, and the mechanisms I deployed sought to keep those concerns at the forefront. Firstly, I printed out copies of every document I had and physically cut them into sections that I laid out in thematic groupings. Secondly, I drew a series of large-scale mind-maps on paper to track multiple connections across the groups.

Finally, I came up with a set of headings ('community', 'time', 'power') and a series of more detailed sub-headings ('risk taking', 'foundational myths' and 'exhaustion'), and attached quotes to each of these headings (the full list of these sub-headings is 
included as Appendix Six). Some headings were developed prior to the interviews and contributed to the questions I asked, others emerged as a result of the interviews themselves. The system of mind-mapping I later adopted as the starting point for each new chapter, pulling me out of detailed writing and enabling me to consider the research holistically.

Through the isolation and then linking of these related fragments, I began to see beyond obvious hierarchies and chains of command to discern less visible networksclusters, temporary alliances and enmeshed relationships. Through mapping, the artist-run assemblage took shape, overlapping and intersecting with the wider ecology of the art world - artists, dealers, public galleries, critics, collectors and funders. In addition, this mechanism for sifting and sorting my information enabled me to track the emergence of repetition in accounts, or conversely, gaps or contradictions between official documentation (strategic, funding, public) and informal descriptions (interviews, emails, social media forums). Here I have sought to observe the invisible methods by which my case studies might engage in "governing, controlling, disciplining, and regulating one's self ... fashioning and [forming] one's self" (Lorey 2006, 128).

\section{Significance of Thesis}

In order to find out how institutions and agents interact, we must undertake an internal close examination of these processes, something that has rarely been done with reference to concrete situations. On a theoretical level, considerations of the relationship between individual and superstructure have been subject to intense scrutiny in connection with Foucault's concept of governmentality. However, these ideas have rarely been applied to art institutions, especially not as an analytical instrument to examine the actions of individuals within institutional structures. (Mader 2013, 41-42)

Because of their role as laboratories for debate and development, artist-run spaces offer a chance to study the art world at its most intense. Little research has been undertaken at a close-up, case-study level on the extent to which new generations of artists/workers may have learnt to operate within neoliberal conditions. The importance of generational differences between pioneers and current practitioners has not been explored in detail within the literature and my thesis brings new knowledge to this gap. 
My thesis constitutes the first sustained academic research to focus on New Zealand artist-run spaces within museum studies and the first New Zealand $\mathrm{PhD}$ to take artistrun spaces as a topic. But, although I take New Zealand case studies as my focus, the implications of my thesis stretch beyond a national context, adding to the limited data internationally examining how artist-run spaces have changed and adapted to an increasingly instrumentalised art sector. My research steps outside its immediate geographic context to provide a new contribution to existing literature on artist-run spaces from the United States, Canada, Europe and Australia. The particular focus of my thesis brings new knowledge to questions of agency, ownership and power within the art world, arguing that artist-run spaces, while modest in scale, have much to offer the broader sector, as crucial laboratories for development but also carving out space for difference.

As well, while my research focuses on a non-traditional form of museum practice, the value of my research has implications for the wider field of museum studies. Many of the specific concerns of my research - formalisation of infrastructure, the impact of policy on grassroots practice, the influence of neoliberal thinking on a new generation of practitioners - feed into broader questions about museum and art gallery history, theory and practice, against the current background of cultural and economic neoliberalism.

The outcomes of my research, therefore, also have implications for broader cultural policy work beyond specific artist-run space concerns. The impact of creative industries and neoliberal thinking on the arts sector is of particular interest to cultural policy researchers internationally, but focus has largely been on the macro (larger public institutions) or the micro (individual artists themselves) rather than on grassroots infrastructure. Additionally, in New Zealand, there has not, to date, been extensive research into creative industries within a post-Helen Clark environment, under the National Government (2008-2016) and this is a further gap my thesis explores.

I consider myself to be, in this research, a curator who is wishing to understand her art world in greater and more complex depth. My aim in this thesis is not purely to understand but to apply research to practice, developing strategies and approaches 
that are both theoretical and speculative, but which might also have practical application for the communities I am writing about.

\section{Chapter Outlines}

\section{Chapter One-Background: 'Finding a Space, Painting its Walls'}

Chapter One establishes the wider context for my case studies, from the international and national history of artist-run spaces through to broader social changes in the art world. In this chapter I introduce my three case studies, RM, Enjoy and Meanwhile, providing a brief overview of how each space began, as well as a more recent snapshot of the spaces at February 2018, the point where my active research stopped and writing began.

\section{Chapter Two-Trust and Exchange: The Artist-Run Space Assemblage}

The first of three chapters using a particular theoretical framework to explore the case studies, examining individual experiences and narratives through a single lens. Using Foucault's concept of the assemblage, Chapter Two maps artist-run spaces through the various elements that shape them, from the physicality of the gallery itself to exhibitions and relationships with a wider art community. The chapter understands the spaces via an expanded notion of what constitutes the institution, one that is both more fluid and unstable than a traditional history and more physical.

\section{Chapter Three-'So Much Labour For Free': The Artist-Run Space Participant}

Chapter Three explores the relationship between self and creativity. How, this chapter asks, are participants shaped by their involvement in the artist-run space? Using the conceptual framework of the cultural precariat, the chapter finds that artists are increasingly aware of their implication in neoliberal narratives around creativity, and asks, how do they negotiate this? Two different kinds of participants are identified in artist-runs: the professional and the artist, with very different motivations and expectations. 


\section{Chapter Four-Governing Ourselves: The Artist-Run Space Organisation}

Chapter Four examines the organisational form of the artist-run space. While each space is found to have its unique cultural identity alongside basic commonalities of purpose (exhibitions, public programmes, publications), two distinct organisational models emerge, which operate very differently from each other, one a collective approach and the other a hierarchy with division between governance and management. This chapter explores the impact of funding on the artist-run space through the process of governmentality, reshaping the artist-run form.

\section{Chapter Five-Relative Autonomy: The Artist-Run Space within a Neoliberal Discourse}

Chapter Five brings together and develops ideas raised in the previous three chapters in a broader discussion that explores independence and interdependence. Notions of relative autonomy are introduced, a fluid position which acknowledges both the impact of external forces but also the possibility for agency within this.

\section{Conclusions}

The final section restates the research questions and reviews my findings against them, analysing the research process followed. The limitations and boundaries of my research are acknowledged, and possibilities for additional research to build on this thesis are suggested. The significance of the arguments developed in chapters Two to Five are discussed, and the contribution to literature my research makes is outlined. While this thesis sits within academic literature, and therefore is speculative in nature, this section also asks, what are the professional implications of my research, and what impact could this research have on the sector? 


\section{Chapter One}

\section{Background: 'Finding a Space, Painting its Walls'}

\section{Introduction}

I remember when we were all sitting around on High Street. It was Daniel, me and Giovanni and Denise and Kirsty. ${ }^{6}$ At the time we observed that contemporary art had no traction. Or no one was acknowledging this new way or making art and thinking ... All of us were complaining, 'Where do we put our show?' We make it. There's nowhere to put it, no one's interested. (Judy Darragh 2018)

There are many moments at which a New Zealand history of artist-run spaces could begin, but for this writer a fitting place is with Teststrip, the collective of five artists who fired into action with a gallery space in 1992. Teststrip's influence on my generation of practitioners was inescapable. "The story of artist-run galleries begins with Teststrip" asserted Stella Brennan in 1998, although she qualified her claim by noting, "at least for my generation of emergent, post-pubescent, pre-mortgaged Auckland artists" (Brennan 1998, 43).

Teststrip was a role model for the establishment of the oldest of my case studies, $R M$, who saw in Teststrip an example to emulate, but also a representative of a community from which they felt excluded. Significantly, even in 2016, Meanwhile's Jordana Bragg was still defining themselves ${ }^{7}$ in relation to the impact of a space which closed its doors when they were toddlers.

I am heated over the idea of New Zealand artist-run spaces of the 80s and 90s. I want to be there, I want punk, I want DIY, I am nostalgic for my own naïve romanticisation of this generation. I was one in 1994, I need to feel that there is a fight in this. (Bowling, Bragg and Devlin 2016, n.pag.)

Yet that history is fleeting and frequently lost from generation to generation. "What artist-runs leave behind by way of a physical or digital record is tenuous" argued the editor of the only New Zealand survey of artist-run culture to date, Gabrielle Amodeo 
(2017, 67). Lessons learnt by one artist-run space can and sometimes must be learned again by a new space, or the same space, with new participants. To best understand my case studies, I begin with the wider ground on which they have developed, the models for practice to which they have responded, and the wider social and political movements that have shaped them, knowingly or unknowingly.

While my thesis is not concerned with artist-run history specifically, I'm mindful the record 'is tenuous'. Accordingly, this chapter provides an introduction to the artist-run space movement, both internationally and nationally, locating a wider context for my three case studies. The coming together of a climate for mobilisation and dissatisfaction with career opportunities for emerging artists resulted in a movement of artist-run spaces which quickly spread around the world. The chapter maps the early days of the movement, both internationally and in New Zealand, providing an overview of key moments that shaped the scene.

While forming a distinct community of their own, artist-run spaces are both a reaction and an intervention to a broader art scene as well as a wider political climate. Writing in 2005, curator and art historian Christina Barton argued Enjoy was both "an active agent and a not-so-innocent victim" in a system where the gallery might act as "a propellant of change" while being also "subject to its pressures" (Barton 2005, 59). While later chapters examine in detail these linked networks, this chapter is concerned with establishing the wider terrain — artistic and political— that scaffolds my case studies.

Starting with artist-run histories, this chapter then outlines two other major factors in artist-run culture since the 1990s: the curatorial movement of new institutionalism, adopted by mid-size and larger art institutions (in Europe but also New Zealand) and an international policy shift towards creative industries (Hesmondhalgh and Pratt 2005). While subsequent chapters examine specific threads within the artist-run, this chapter outlines the broader pressures and influences on artist-run culture, over time, and particularly within New Zealand culture. This specificity is set against a background of neoliberal thinking at a government and cultural policy level which has resulted in a new emphasis on accountability for all cultural institutions (Bieldt 2016; Blomkamp 2014). 


\section{A Brief History of Artist-Run Spaces}

SoHo was an incredible place back then; in a twenty-block radius, you had all of these visual artists and composers and choreographers and sculptors living in a kind of artists' ghetto. It became a hotbed where all kinds of new ideas were exchanged. (Chatham 2012, 49)

This quote evokes numerous narratives from around the world, which delineate artistrun culture as a coming together of a group at a specific, and special, time and place. They can be "testing grounds and springboards, intimate gatherings in apartments, pockets of activity that serve particular audiences at particular times ... sometimes they are meant to be temporary, and other times they can grow to become established institutions that a later generation of artists define themselves against" (Jackson 2913, 45-46).

There are many generalities in an artist-run space's narrative, just as there are particularities of shape and form that serve to develop and define them. Gabrielle Amodeo describes the commonalities in founder accounts.

There's a common thread of seeing gaps and deficencies in these parallel worlds, the physical gaps of their city's run down CBD; the vacuum left by other artistruns closing; the lack of opportunities if you weren't one of the few graduates to be immediately picked up by public or dealer galleries; or indeed, a backyard (with dying grass and a few trees) that needed reinvigorating. (Amodeo 2017, 64)

Although collectivism within art making has many longstanding traditions within art history, the contemporary shape of artist-run galleries first emerged in the alternative space movements of the 1960s and 1970s, notably in the United States and Canada (Apple 1981; Ault 2002; Bronson 2012; Detterer and Nannucci 2012; Robertson 2006; Rosati and Staniszewski 2012). Clive Robertson selected an Artnews report that "the spread of alternative spaces may well provide the stamp of identity for the seventies" (Robertson 2006, 2) as a marker of change.

It is often claimed that the impact of artist-run culture is under-represented in the official histories of art (Murphy 2016, 7). Gregory Sholette, United States artist and critic, argues that artist-run culture constitutes "an artistic shadow zone, or ... creative dark matter: that enormous mass of cultural activity that is only minimally visible within the mainstream art world, but whose gravitational force affects mainstream cultural institutions powerfully, if invisibly" (Sholette 2006). Referring specifically to 
the European art scene in the 1990s, United Kingdom curator Simon Sheikh suggests that "artist-run spaces and initiatives can be seen as the hidden history of the decadeor the shadow history to the success stories of Young British Artists or the Nordic miracle - as the production of discourse, context and subjects that makes these stories and these inscriptions possible" (Sheikh 2012, 370).

Yet, since the 1980s, artist-run initiatives have been cited by institutional curators and critics as significant. "When the history of art making in the latter half of the twentieth century is written, artist-run spaces will be accorded equal importance with other art movements of this period" attested cultural activist Roberto Bedoya in 1993 (5), while curator Charles Esche describes collective practices as "the key force in art making as artists have developed alternative strategies to negotiate a different basis for making institutions" (Gordon-Nesbitt 2003, n.pag.).

Artist-run spaces emerged as a response to perceived gaps both within the arts infrastructure and broader culture. Firstly, the political and social challenges of the late 1960s and 1970s, where a wider movement sought to encourage communal endeavours (Apple 1981; Bronson 2012; Frye Burnham 2011; Griffiths 2012; Lee 2013; Murphy 2016; Nemiroff 1985; Petryshyn 2005; Robertson 2006, 2004; Wallace 1991). Secondly, alongside these larger shifts in cultural activity, artist-run spaces emerged to challenge larger art institutions slow to recognise and accommodate new modes of practice, such as video, performance and installation. Artist-run spaces emerged as more responsive and nimble platforms for quickly changing practices (Apple 1981; Hassler 2013; Lee 2013; McCray 2002; Murphy 2016; Nemiroff 1985; Robertson 2006, 2004; Wallis 2002).

The third contributor was the artist-led movement of Institutional Critique through which artists began to explicitly challenge established gallery systems both in their work and through the establishment of their own spaces (Frye Burnham 2011; Jackson 2013; Lee 2013; Nemiroff 1985; Robertson 2006; Snider 2015). Art historian Nemiroff argues, "artist-run spaces have contributed to breaking the modernist myth of the neutrality of the 'frame'... for this reason, the artist-run space served as an implicit (and sometimes explicit) criticism of the museum, the ultimate 'frame' of the work of art within the discourse of modernism" (Nemiroff 1985, 6). Founder of $E$ Flux, Anton Vidokle, describes the development of artists utilising curatorial and 
administrative gestures in their work as "a response to the inadequacy of existing institutions, their hostility to artists, or their total absence" (Vidokle 2012, 225).

Historians of the artist-run often stress the homogeneity of artist-run culture, positing that "artist-run spaces are united by a common culture" that are "linked by a common goal" (Detterer 2012, 21), suggesting a shared global movement. Although artist-run networks can be found throughout the world, an emphasis on their cohesion does not allow for individual and regional heterogeneity.

Teststrip was not the first truly independent art gallery in New Zealand; a term claimed by various histories but convincingly established in the early 1980s with the opening of $100 \mathrm{~m}^{2}$ (Auckland 1979-1981) and the Women's Gallery (Wellington 19801984). These galleries were not-for-profit and offered artists space for emergent experimental and non-commercial practices such as performance, sound and installation.

But Teststrip was the first New Zealand enterprise to clearly distill into local form the particular collective model that had begun to define alternative art practices in the United States and Canada (Apple 1981; Ault 2002; Bronson 2012; Detterer and Nannucci 2012). The eight founding members of Teststrip, Kirsty Cameron, Judy Darragh, Gail Haffern, Giovanni Intra, Denise Kum, Lucy Macdonald, Daniel Malone and Merylyn Tweedie, were frustrated at the lack of opportunities for their own work in the art scene of Auckland, which Danny Butt argues, “wasn't so much a city as an oversized New Zealand town” (Butt 1998, 142).

The initial impetus was a familiar one, to show their own work. "One show each. A short-term project and then it escalated ... there was this need" (Darragh 2018). The first space was a warehouse in Vulcan Lane which Daniel Malone lived in - his bedroom partitioned off by a curtain — a "grungy space up a narrow flight of stairs" (McKenzie 1993 47). Eventually Teststrip would move to a larger space in Karangahape Road, an early arrival in what would eventually become a thriving contemporary art precinct of commercial and not-for-profit galleries, "we were the marker, I'd like to think" (Darragh 2018). 
Teststrip exploded onto the scene with enthusiasm, bravado and panache, more performative and playful than anything the local art world had seen to date, its members seizing the "opportunity to band together to make daring raids on the art world, under the pirate flag of loosely distributed networking and ambitious team orientation" (Butt 1998, 142). They showed their own work, they showed their friends', but overwhelmingly they exhibited "a range of other artists whose work is either unknown to public galleries or a bit too rugged to show without explanatory captions and general spit and polish" (McKenzie 1993, 34).

Although an artist-run space of similar scale and scope, High Street Project, opened almost simultaneously in Christchurch, Teststrip has claimed the mantle of first New Zealand artist-run space by being the most confident and ambitious and, perhaps most significantly, through core members going on to establish significant careers as artists and gallerists. Art critic Danny Butt (who would play a crucial role in enabling the establishment of $R M$ ) argued Teststrip were "the organisation which made artist-run spaces an integral part of the contemporary New Zealand art landscape" (Butt 1998, 142).

Auckland critic Jon Bywater describes the founders of High Street Project in Christchurch as having "an awareness of what Teststrip was doing in Auckland" and writes that the two spaces formed two ends of a spectrum, Teststrip very personality driven, while High Street Project "was a public gift to the arts community that ... stabilised as something reasonably democratic" (Bywater 2018). Yet, despite differing positions, they were connected by a sense of new developments, "the conditions that surrounded both those institutions in the early 90s are the key thing, what it meant to be self-organising, in that style then, was, to some extent, novel" (Bywater 2018).

Two art galleries that have provided continuing leadership in contemporary and experimental art, yet from inception have not been referred to as artist-run spaces, are Artspace and The Physics Room. Launched in 1987 in Federal Street, Auckland, Artspace began with a trust/staff model, with artist Mary-Louise Browne the inaugural director. Clear from the beginning that it was aiming at a more structured, professional practice, Artspace, argues former director Brian Butler (2005-2008) "has never been an artist-run space, but it has always been artist-centric" (Gifford 2008). 
Still running today, Artspace has attracted several international directors' and shows a programme of international and national significance.

Its smaller South Island counterpart The Physics Room opened in 1996, evolving from the siteless South Island Art Projects (1992-1996). Current director Jamie Hanton argues that the shift from SIAP to a gallery model was led by funding changes. "The QEII Arts Council, (now Creative New Zealand), said that it wanted to support infrastructure, rather than projects, so the response was to have a space that could administer funding to artists" (Feeny 2018). Writing at the time director Julian Bowron stated "we failed to persuade the Arts Board of Creative New Zealand that $S I A P$ is an efficient and effective organisation with an important role to play in sustaining a vigorous contemporary art practice in the South" (Bowron 1995, 3).

SIAP's regular newsletter was notable for forthright activism within the art world, in particular speaking out about cultural policy and the evolution of the QEII Arts Council into Creative New Zealand. In the first editorial, then-director Jude Rae wrote in 1992, "It can be argued that current QEII funding policies have taken money away from artists, that the drift is to a more 'institutionalised approach"” $(1995,1)$. Writing in a 1996 newsletter, just prior to closing, Jane Gregg argued forcibly that "the driving principles of institutions such as Creative New Zealand effectively dictate an art culture which eschews edgy critique in favour of feel-good fluff at worst, or selfreflexive play at best" $(1996,11)$. Its replacement, The Physics Room, runs a similar, but smaller model to Artspace, and has never been as publicly critical of Creative New Zealand as its predecessor. 


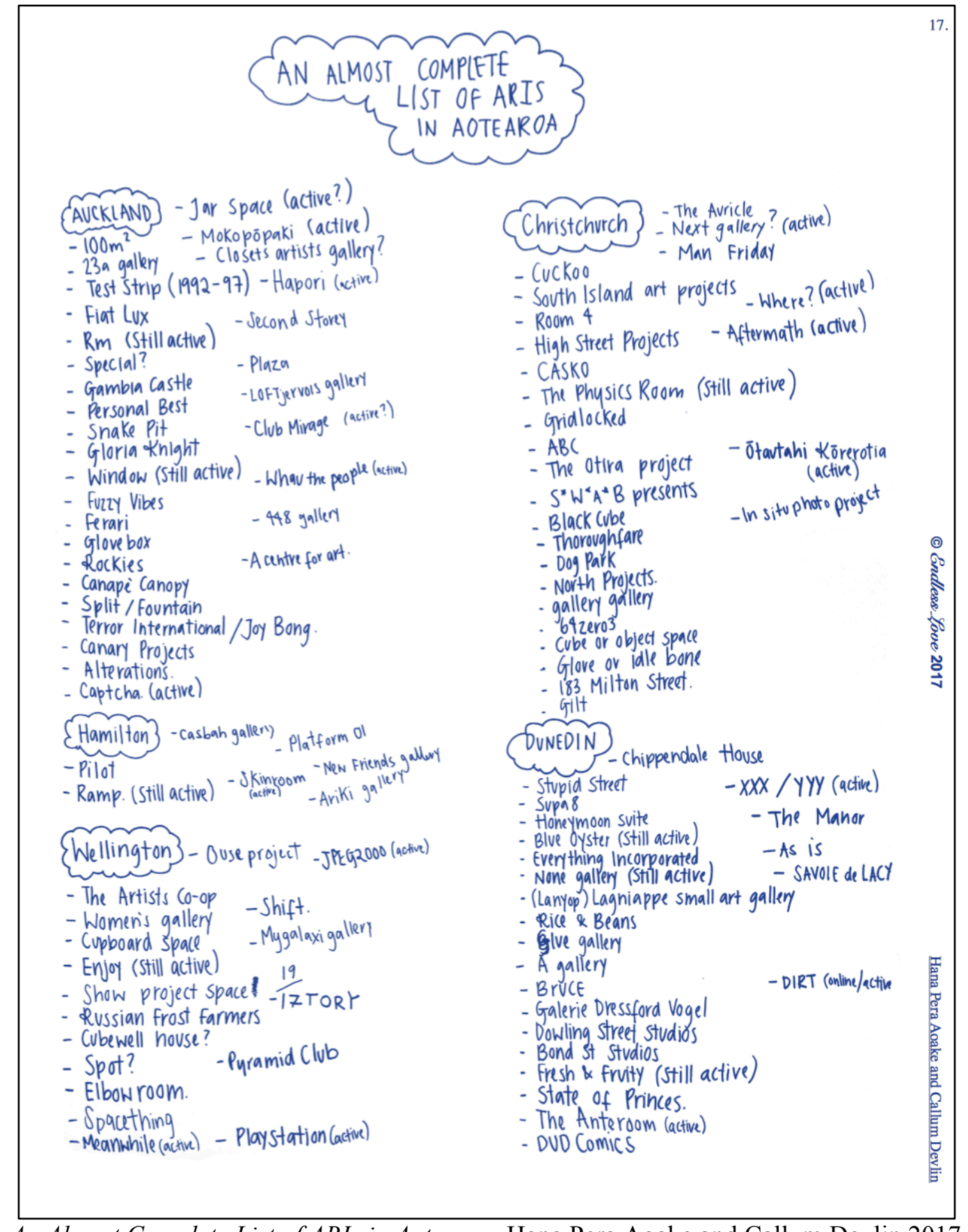

An Almost Complete List of ARIs in Aotearoa, Hana Pera Aoake and Callum Devlin 2017 
Clusters of artist-run spaces began to emerge more quickly in the 2000s, predominantly in Auckland, but also around New Zealand: Canary Gallery (Auckland 2004-2006), Special Gallery (Auckland 2003-2006), SHOW (Wellington 2004-2006), A Centre for Art (Auckland 2007-2010), Gambia Castle (Auckland 2007-2010), Newcall Gallery (Auckland 2008-2010), Russian Frost Farmers (Wellington 20082012). Some years are particularly fruitful, for instance, 2014 saw eight new spaces open: PILOT (Hamilton 2014-2015), LOFTjervois (Auckland 2014-2015), F U Z Z Y V I B E S (Auckland 2014-2015), Casbah Gallery (Hamilton 2014-2015), North Projects (Christchurch 2014-2016), Man Friday (Christchurch 2015), Canapé Canopy (Auckland 2016), Fresh and Fruity (Online/originally Dunedin 2013-Ongoing), Elbowroom (Wellington 2014-Ongoing), Whau the People (Auckland 2014-Ongoing) and Rockies (Auckland 2014-2017). Using the launch of SIAP, High Street Project and Teststrip in 1992 as a starting point, the only book to survey New Zealand artistrun space culture to date lists 58 spaces between 1992 and 2016 (Amodeo 2016c) .

Similarities of form are apparent across most of the spaces, a loose collective of practitioners emerging from art school and trying to find a place for themselves in the art world, a programme that starts with their own work and that of their friends, and a life span of generally between one to three years. In February 2018, a quick scan of active space aside from my case studies included $B O A G$ (1999, Dunedin), Play_Station (2016, Wellington), Skin Room (2015, Hamilton), Elbowroom (2014, Wellington), Mercy Pictures (2018, Auckland) and None Gallery (2003, Dunedin).

\section{Changes to the Wider Art Sector}

As artist-run spaces emerged to address perceived gaps within the art world, the wider terrain in which they operated began to change in response. Over the last 20 years, boundaries between public galleries, commercial galleries and artist-run spaces have eroded, leading writers to question if the distinctiveness of artist-run spaces has been lost as established institutions replicate "the practices and the modes of operation of [artist-run spaces]" (Blessi, Sacco and Pilati 2011, 142). As these boundaries continue to collapse, it is timely to consider New Zealand artist-run spaces within the broader remit of museum practice. 
In New Zealand, civic art museums are largely (although not exclusively) separate organisations to historical museums, and known as "public art galleries" rather than museums. Although linked by professional affiliations and adoption of the New Zealand Code of Ethics and Professional Practice (Museums Aotearoa 2013), public art galleries maintain their own formal networks (such as the Gallery Directors Group) as well as informal connections through touring exhibitions and the movement of staff between organisations.

New Zealand museum practice, in the European sense, began in the second half of the nineteenth century (Thomson 1981) and today constitutes a range of national, civic and private enterprises which have increasingly professionalised in structure and outlook (Luoni 2011; McCarthy and Cobley 2009; McCredie 1999, Wellington 2013; Legget 2006; Wilson 1999). During the 1970s, as art historian Roger Blackley documented, New Zealand galleries underwent a substantial process of modernisation "galleries had to modernise or wither and all rose to the challenge ... the focus of new collecting and exhibitions turned to contemporary New Zealand art and many galleries developed public outreach programmes" (Blackley 2014, n.pag.). As a result, curator Athol McCredie argues, "as provincial galleries grew, they tended to become more alike - to have similar exhibitions, to own similar collections, and to appear as simply scaled-down versions of the metropolitan galleries" (McCredie 1999, 259).

In her thesis examining stakeholder perspectives on museum accountability beyond financial performance, Jane Legget argues "by the 1990s, public museums had embraced, frequently reluctantly, business practices including the ethos, and associated vocabulary, of the market place" $(2006,9)$. Today New Zealand museums run the gamut of:

Museums, art galleries, whare taonga, tribal museums, cultural centres, historic places, science centres, interpretive centres and exhibition centres. They usually carry out a range of functions, which include but are not confined to, care of collections, public programmes including exhibitions, education, and community relationships. (New Zealand Government 1992)

While larger museums, in particular Te Papa, have received substantial research focus (Bayly-McCredie 2016; Farrar 2018; Hackett 2017; Hakiwai 2014; McCarthy 2004; Shannon 2013; Schorch 2013; Schubert-McArthur 2014; Tamarapa 2015; ) the sector predominantly comprises small and micro museums (Davidson and Shaw 2015), 
organisations with between zero to five full-time, paid employees. Under this system Meanwhile and RM are configured as micro (no paid staff) and Enjoy as a small museum (two paid staff).

Alongside the development of public galleries, the New Zealand commercial gallery network has increased substantially in the last ten years, expanding the commercial sector, to the extent that some of the most challenging and ephemeral exhibitions (for instance, inthisholeonthisislandwhereiam, by Luke Willis Thompson at Hopkinson Mossman, awarded the Walters Prize 2014) are now held by dealer spaces. Public galleries are also shifting, although less dramatically. In 2014, my master's thesis on change management at the Christchurch Art Gallery argues that the Gallery "found new methods of working that are both more reactive and more personal. The Gallery's changes ... can ... be understood in the wider context of international moves by galleries and museums" (Bugden 2014, 93).

The wider context demonstrates a repositioning of the gallery from the neutral white cube of modernist thought to a specific context which framed the visitor experience. Critic Brian Doherty's influential series of articles in Art Forum in the 1970s and 1980s articulates how the sociological, economic and aesthetic context within which an individual views art shapes their experience (Doherty 1986).

Understanding the gallery as both a physical and institutional site which moulds the presentation, understanding and reception of artwork was significantly shaped by the late 1960s practices of American and European artists like Michael Asher, Marcel Broodthaers, Daniel Buren and Hans Haacke, whose work examined and made visible the organisational structure and apparatus of the exhibiting institution itself. In the 1980s artists working consciously under the term Institutional Critique (Buchloh 1999), such as Andrea Fraser, Fred Wilson, Martha Rosler and the Guerilla Girls, provided critical challenges to the unseen structures and systems of the art institution (Welchman 2006).

Artists ... participate jointly in the maintenance and/or development of the ideological make-up of their society. They work within that frame, set the frame and are being framed. (Haacke 2016, 68)

The institution of art is not only 'institutionalised' in organisations like museums and objectified in art objects. It is also internalised, embodied, and performed by people ... if there is no outside for us, it is not because the 
institution is perfectly closed, or exists as an apparatus in a 'totally administered society' or has grown all-encompassing in size and scope. It is because the institution is inside of us, and we can't get outside of ourselves. (Fraser 2006, 130-131)

Institutional critique, as my literature review details, has played a major role in reshaping the relationship of the artist to the exhibiting institution. But if institutional critique was a challenge by artists to the institution, writers began to note a "co-option of so-called 'alternative' strategies by mainstream galleries and museums" (Rosati $2012,41)$ in the early 2000s, in texts identifying new institutionalism as an emerging curatorial construct. Curatorial new institutionalism is characterised by an emphasis on the transformation of the art institution from within and interest in "temporary/transient encounters, states of flux and open-endedness" (Doherty 2004, 71), which cast both artists and audience as active collaborators with the institution (Szeemann 1969). Curatorial new institutionalism values experimentation, hybridity and process (Hou 2002; Lind 2010), re-inscribing the gallery in the role of a laboratory (Bishop 2004; Bourriaud 2002; Obrist and Vanderlinden 2001; Szeemann 1969).

The curatorial shift had an impact on the practices of mid-scale to large civic art institutions, but simultaneously altered the ground for grassroots organisations, usurping "the traditional territory of artist-led initiatives" (Gordon-Nesbitt 2003, 78). "New Institutionalism responds to (some might even say assimilates) the working methods of artistic practice and furthermore, artist-run initiatives" agreed British curator Claire Doherty in 2004 (1). In 2016, New Zealand writer Gabrielle Amodeo suggested that, "as dealers and major public institutions in this country are increasingly led by curators with artist-run roots ... they take the strategies they tested in artist-runs with them" (Amodeo 2016c, 64). As signalled by Amodeo, this shift has been in part credited to the movement of artist-run practitioners to curatorial and directorial positions within conventional institutions (Anderson 2008; Heiss 2012, 66; Ingberman 2012) meaning "these more conservative structures are changing from the inside" (Anderson 2008, 17).

The co-option of artist-run practitioners and methods is often presented in the form of a benign yet effective takeover. Canadian historian of artist-run spaces Clive 
Robertson asserts that "public galleries ... responded to the intervention of an administration of art by artists by employing or contracting those curators or critics who gained cultural expertise working with or within artist-run centres" (Robertson 2004, 32). Ann Philbin claims, "the galleries and the museums learned from the alternative art spaces. At one point we were the red-hot centre of the art world, and then they basically adopted the practices of the alternative spaces to enliven their own programmes" (Rachleff 2012, 39).

What does this imply for artist-run spaces today? Do they, as Blessi et al. asked in 2011, "run the risk of being 'crunched' by such an expansion of the institutional mission of the museum?" $(2011,143)$. Many writers evoke a circular entropy in which individual spaces surface, practice and then end, where "for various reasons, ranging from personal to economic, from sociopolitical to strategical, these alternative spaces are constantly appearing, evolving, and disappearing" (Hou 2003, 37). The distinctiveness, or otherwise, of artist-run spaces is charted in the chapters ahead, through aspects of practice including the experiences of workers (paid and unpaid), how exhibitions and activities are framed by participants, and the wider networks through which the case studies operate.

\section{Neoliberalism and the Art World: The Rise of Creative Industries}

Artistic developments do not sit apart from society, and changes to artist-run space culture over the last 20 years have occurred against wider reverberations of cultural policy evolution, which in turn is the result of shifts in social and economic policy. During that time art has moved into the spotlight, both in New Zealand and elsewhere, as Danish art historian Maibritt Borgen proposes, "from a place in the margins or in opposition to society to a place in the centre of what society desires" (Borgen 2013, 46).

New Zealand art critic Jon Bywater argues that it is the coming together of a particular set of collective interests as well as the wider political, social and artistic setting which define an artist-run space [the] "combination of that generic selforganising, collaborative artist-run thing, and the environment that encouraged that, or that it responded to" (Bywater 2018). In charting cultural policy shifts of the last 20 years, the arrival time and circumstances of each case study emerges as a crucial 
factor in understanding what the space has become. When Enjoy opened in 2000 it was at a time of significant transition for the New Zealand arts sector, as a creative industries narrative first began to establish itself locally. By the time Meanwhile opened in 2016 the term 'creative industries' was deeply embedded in local culture, having migrated from formal policy into the casual language of artists.

Neoliberalism is not just a series of market-led economic policies, it straddles "a wide range of social, political and economic phenomena" (Saad-Filho and Johnston 2005, 1) that evokes a whole way of thinking about the self. Alfredo Saad-Filho and Deborah Johnston, in their introduction to Neoliberalism: A Critical Reader (2005) describe neoliberalism as global, influencing "the lives of billions of people in every continent" $(2005,1)$. While New Zealand has experienced a particular adoption of neoliberalism, beginning with the fourth Labour Government in 1984, the infiltration of neoliberalism from economic to cultural policy in New Zealand largely followed a path set by the United Kingdom's 'Third Way' agenda.

When, in 1997, Tony Blair was elected United Kingdom Prime Minister with New Labour's victory in the general election, it was on a mandate that "New Labour is neither old left nor new right ... instead we offer a new way ahead, that leads from the centre but is profoundly radical in the change it promises" (Blair 1997, 1). The centrist position suggested by Third Way strategies was first developed as an alternative to the bookends of neoliberalism and social democracy by sociologist Anthony Giddens (Giddens 1998) and adopted enthusiastically by the New Labour Government. The Third Way has sometimes been called "neoliberalism lite", and analysts have subsequently argued that, in reality, it "further established the approach of ... neoliberalism” (Martell 2004, 4). United Kingdom sociologist Luke Martell writes that the Third Way enabled "the centre-left to pursue an economically liberal agenda which under the right might have scared its electorates" (Martell 2004, 4).

Central to New Labour's utlisation of the Third Way was the alignment of culture with economic instrumentalisation, under the rubric of "creative industries", a powerful narrative which reconsiders art production through an instrumental value (Selwood and Davies 2015; Garnham 2005; Gordon-Nesbitt 2009). This saw "substantially increased funding to the cultural sector" alongside "unprecedented levels of policy guidance" (Selwood and Davies 2015, 43) . 
The term creative industries first came to prominence in the United Kingdom in 1998 with the publication of a Creative Industries Mapping Document (DCMS 2001) in which industry (architecture, design, advertising) and culture (visual arts, theatre, poetry) were brought together, "re-imagined as 'creative' and thought about increasingly in calculative terms while further blurring boundaries between 'culture' and "economy"' (Prince 2014, 751). The seemingly innocuous rewording saw artists burdened with new responsibilities: the arts would now be expected to stimulate economic growth as well as cultural (Blomkamp 2014, 2011; Prince 2010; Skilling 2005; Volkerling 2001). This policy shift was subsequently implemented in a range of other countries including New Zealand (Caust 2003; Cunningham 2002; Hesmondhalgh and Pratt 2005; Smith 2001; Volkerling 2001).

New Zealand's uptake of neoliberal economic policies had been embedded locally since 1984, as New Zealand's various governments on both the right and left adopted and maintained a more or less unwavering commitment to deregulated, neoliberal economics (Easton 1989; Jesson 1999, 1989; Kelsey 1995; Whitwell 1990). Neoliberalism was introduced originally by the fourth Labour Government (19841990) through a programme of deregulation and privatisation known as "Rogernomics", after Finance Minister Roger Douglas. Policies driven by neoliberal economic theory were continued after 1990 by the succeeding National Government (1990-1999) whose "Mother of All Budgets"8 in 1991, among other stringent measures, introduced substantial cuts to unemployment, sickness and welfare benefits (Kelsey 1995, Boston and Dalziel 1992).

My third case study, $R M$, opened in 1997, the year it was predicted "this generation of graduates run the very real risk of becoming the first generation in our nation's history who won't be better off than their parents" (Brett and Chamberlain 1997, 33). By 1997 neoliberal politics were well entrenched in New Zealand, but the impact on the arts was largely felt only through a general tightening of public funds. Peter Skilling argues "what is most noticeable through the 1990s is not so much a concerted attack as a concerted ignoring of arts funding policy ... Clearly, this was not a politically hot topic; elections would not be won or lost on this basis" (Skilling 2005, 26). 
Like me, the founders of $R M$, were part of the first generation of New Zealanders to acquire significant debt via the Student Loan Scheme, introduced in 1992 along with a tertiary education fee system. Loan debt has been a significant part of New Zealand student life since 1992, and continues to shape graduates' lives post-study (Shore 2013; Bill 2008), a period examined in greater detail in Chapter Three. Arguably Brett and Chamberlain's observation above is being borne out.

But, while neoliberalism initially focused on core social and economic agendas, the period of Helen Clark's Labour Government (1999-2008) saw a refocusing of the arts into a newly neoliberal agenda along Third Way lines (Bill 2008; Blomkamp 2014, 2009; Horrocks 2007; Jones and Boon 2007; Jones 2008; Lawn 2006; Major and Connell 2005; Prince 2010, 2009; Simmons 2007; Skilling 2008; and Volkerling 2001). The shift was signalled in 1999 when Clark assumed the position of minister for arts, culture and heritage — the first New Zealand prime minister to do so, "giving the portfolio unprecedented status at the heart of power" (Prince 2010, 130). Despite this role being, in part, titular (Judith Tizard as associate minister for arts and culture undertaking much of the logistical work for the role), it represented a strong symbolic stance, as Clark declared "my position as Prime Minister is one of leadership, and I choose to use that leadership to indicate that the government places a very high value on arts and culture" (Clark 2000).

The new Labour Government promised "a middle line" (Kelsey 1995, 309), rather than deploying the term Third Way, but Prime Minister Clark similarly claimed the era of neoliberalism in New Zealand was over (Clark 2002, 463). While commitment to neoliberalism softened in tone during this period of government, it has been argued by sociologists and political theorists to have entrenched itself more firmly (Roper 2011) remaining "acquiescent to the neoliberal faith in the formal freedom and vibrancy of the market economy" (Craig and Scott 2012, 151).

The first notable benefits to the art sector were delivered through the mechanism of the Cultural Recovery Package (Volkerling 2010) a multi-pronged programme that provided an initial boost to the art sector of more than eighty million dollars of public funding. Announcing the scheme in May 2000, Clark declared it "a significant injection of funding into the arts, culture and heritage sector which will allow New 
Zealand's arts and culture to flourish and create jobs and growth in the industry" (Labour Government 2000).

When museum professional Courtney Johnston aligned the launching of Enjoy in 2000 with the election of Helen Clark in late 1999 as prime minister in her essay Millennial Child, (Johnston 2016,13), citing "the warm glow of Clark's championing of the arts", she describes the moment when the arts discernibly, and very deliberately, shifted from marginal to centre stage. Like many in the art world at the time, Courtney Johnston felt positive about Clark's stewardship, perceiving her support for the arts as the minister for arts culture and heritage as an important repositioning for art nationally, "I could feel the concentration of energy and belief around the visual arts in Wellington ... this was the environment in which I came of age. It was one that made optimism around the visual arts feel natural" (Johnston 2016, 12). For myself, working as a young, arts professional at The Physics Room, an art project space which received a 40 per cent funding boost from Creative New Zealand as a direct result of the Cultural Recovery Package, Clark's support was tremendously significant, representing a sea change from a barely-there profession to feeling personally valued.

In this way the New Zealand Government, like the New Labour Government before them, repositioned cultural production as a major player in brand-building for both the nation-state and economic generation (Skilling 2008). Associate Minister for Arts and Culture Judith Tizard stated in 2000 that,

the arts and culture sector in New Zealand is not just about our hearts and our souls, and is not just about national identity and personal identity; it is also about jobs ... [it] is about how we describe ourselves and how we face the world in a globalising economy. (New Zealand Parliamentary Debates 24 May, 2000)

In this new environment Creative New Zealand (itself a telling rebrand from the Queen Elizabeth Arts Council) offered a "greater degree of market responsiveness into its funding systems and articulated a more rigorous and transparent statement of outputs and objectives" (Skilling 2008, 141). Such a shift echoed reforms throughout the public sector which, in general, privileged "generic management skills over sector-specific experience and expertise" (Skilling 2008, 141). 
There were a few public dissenting voices, for instance, Lydia Wevers warned "the creative industries are looming ever larger in the economy and the Labour government of Helen Clark has invested substantially in arts and culture, with at least some of the expected return being economic" (Wevers 2004, 118). In the same publication, Greg O'Brien worried that "a nationalistic organisation with a name like Creative New Zealand — and a hyperactive, go-everywhere logo to boot — might set about colonising its own country after the noisy, unself-critical manner of an operation like The Warehouse chain store, purveying a feel-good consumerism" (O’Brien 2004, 33).

Although criticism of the changes was levelled at an academic and informal level, few artists were prepared to openly write in protest at the changes, although senior Christchurch sculptor, Andrew Drummond, complained "the signals that CNZ (Creative New Zealand) and society are putting out, is that everything's got a price, got a dollar value, and so we have to behave that way or we're not behaving properly (Wood 2004, 42).

Russell Prince has argued that, while in 2000, Creative New Zealand was strongly identified with creative industries discourse, by 2006 they preferred to be seen as "primarily an arts agency [that] did not have a creative industries focus" $(2010,182)$. In November 2008 the Labour Government was replaced by a John Key-led National administration with the prime minister's symbolic portfolio choice falling on tourism rather than the arts, suggesting a shift in emphasis for the new government.

During that government's three terms (until 26 October 2017) "the approach towards the cultural agenda could be characterised as being fairly conservative, erring on the side of frugal public spending, and support for 'efficient' creative sectors" (Bieldt 2016, 24-25). Owen Hughes contends that "Key represents a moment in neoliberalisation where market logics become embedded almost beyond recognition, as a prosaic formation of rules and regulations for the practices of governing" (2013, 95-96). At the time of writing New Zealand has begun a new era under the sixth Labour Government, led by Jacinda Adern, like Clark the minister of arts, culture and heritage, which undoubtably will again bring a shift in emphasis. However, this research is not an analysis of the current government which falls outside my remit. 
Throughout the 2000s New Zealand tertiary institutions began to rebrand art and design schools into hubs for "creative industries"-University of Auckland brought its architecture, dance studies, fine arts, music and urban planning departments into the National Institute of Creative Arts and Industries (2004); Waikato Institute of Technology launched the Creative Industries Research Centre and Auckland University of Technology (AUT) established a Creative Industries Research Unit in 2007 (Bill 2008). In her $\mathrm{PhD}$ thesis examining the impact of creative industries rhetoric on New Zealand curatorial practice, Nemane Bieldt suggests that the implementation of creative industries thinking at policy level, "shows the naturalisation of creative industries discourses and the continuing influence of the concept, and that the comprehensive and intense adoption of the creative industries concept in New Zealand has brought about permanent change” (Bieldt 2016, 176).

Visual artists are, United Kingdom critical cultural policy researcher Kate Oakley argues, discriminated against by a creative industries rubric, which places emphasis on the economic value generated by creative labour (Oakley 2009). In New Zealand, a recent survey by Colmar Brunton for Creative New Zealand (2019) found that visual artists were one of the lowest paid art form practitioners, with a median personal annual income of just $\$ 25,500$, compared to an average of $\$ 51,800$ for all New Zealanders. Creative practitioners earning the most reflected the "industry" part of the terminology, with video game development and media production at the top of the income spectrum. As creativity comes to the fore, visual artists are both inside and outside the fold, celebrated for their creativity yet largely unable to capitalise on such interest financially. In tandem with the difficulty in generating commercial success, curator Ioana Gordon-Smith contests that arts funding in New Zealand is currently "crescending to a crisis point ... effects within Aotearoa have been too acute to hide" (Gordon-Smith 2019, n.pag.).

This section began with the histories of artist-run spaces, in New Zealand and elsewhere, and pulled back to consider a broader view of cultural and political shifts regarding the role of art in society. It is against these various histories of the last 30 years - of artist-run spaces, the wider arts sector, and the pervasiveness of neoliberalism through the creative industries narrative - that I have considered my case studies in the chapters to come. I've done so understanding that, through 
ethnographic research, I seek to "understand the interaction of individuals not just with others, but also with the culture of the society in which they live" (Merriam 2009, 23). Each case study has evolved through, and into, a world that has demonstrably changed over that time in its approach to artists. 


\section{Case-Study Snapshots}

In the Introduction I discuss the why and how of case-study research; the process of choosing each of my case studies and the ways in which I engaged with their histories, documents and people. This section shapes a narrative for all three case studies, intersecting with two points on each of their timelines: the moment of their founding; and February 2018, the point at which my research ceased and I started my analysis of the data gathered.

The first snapshot focuses on the establishment of each space. The beginning of any institution-“'finding a space, painting its walls" (Spratt 2018) is a time of intense interest to researchers, when early rituals and values are established. Focusing on the opening of each space enables me to understand both the motivations for starting, but also the way in which the beginning may have come to form organisational narratives (Weick 1995) that define or represent the gallery in some way.

The second snapshot in February 2018 captures the last moment in my active fieldwork, when my final interviews were conducted. Research of this kind can never be fully complete while organisations continue to evolve and I have had had to select a cut-off date. Between February 2018 and the time of writing, changes to personnel have occurred within each of the case studies, but, although I have tried to acknowledge subsequent changes, my research takes February 2018 as its focus point.

\section{$\boldsymbol{R M}$}

Currently 3 Samoa House Lane, Auckland CBD. Established 1997-ongoing.

In 1997 an unprecedented number of new artist-run spaces opened around New Zealand - rm3 and Fiat Lux in Auckland and The Honeymoon Suite in Dunedin. Rm3 was begun by a collective of six art students in their final year of study at AUT: Barbara Anderson, Lorna Bailey, Zoe Drayton, Vaughan Gunson, Nick Spratt and Joyoti Wylie. Nick Spratt recalled that "a conversation developed, so there was six of us. We got together and it all happened." The six did not all know each other prior to working together, but were united by their interest "in site-based work, and in the relationship between the space and the artwork" (Wylie 2018). 
We were very interested in mediums that weren't traditional, so painting was interesting but it was hoping for people to push the boundaries in that way. We just wanted to push beyond what was the mainstream, I guess, at the school. And so conceptually we were more interested in what was going on than aesthetically, I guess. (Drayton 2018)

They also sought to find room as emerging artists in a restrictive Auckland art scene, in which the more established art school, Elam School of Fine Art, Auckland University, held sway "we wanted to support our community but we wanted to support ourselves, as well" (Wylie 2018). Auckland in 1997 was a far smaller art scene than today, with commercial galleries clustered largely downtown near the Auckland Art Gallery and few alternative spaces for emerging artists. Artspace opened in 1987 in Federal Street and by 1997 was an established venue in Quay Street featuring artists who were beginning to make a name for themselves, such as Ani O'Neill, Ronnie van Hout and Gavin Hipkins.

$R M$ 's founders perceived that the existing artist-run spaces in Auckland weren't open to working with emerging AUT students, with Teststrip and Fiat Lux "heavily affiliated with Elam and Elam students ... there was a sense of us and them" (Spratt 2018). Teststrip and Fiat Lux provided "a model there that we see as relevant for us, but there's no opportunities there for us" (Spratt). Contributing to the sense of invisibility, there "wasn't the culture at AUT at that point ... of encouraging us to go out and go to openings and things" (Drayton 2018). Nick Spratt described AUT as "a young art school with not much of a history, very little in the way of a sense of the previous graduates and what they were doing ... there wasn't much of a clear direction for a career path".

None of the founders interviewed remembered it being difficult to find a space in downtown Auckland, with a room above Real Groovy Records on Queen Street suggested to them by artist and critic Danny Butt, who rented the accompanying office. Butt, along with their lecturer at AUT, Julian Dashper, would be an important early mentor for the collective. The space was not a traditional gallery white cube, being very small and rather idiosyncratic.

It was perfect, because it had horrible carpet and just one rectangular room that was like a perfect space and a big glass window that looked down onto Real Groovy. And it was so simple you felt that people could do lots of really different things in it. (Wylie 2018) 


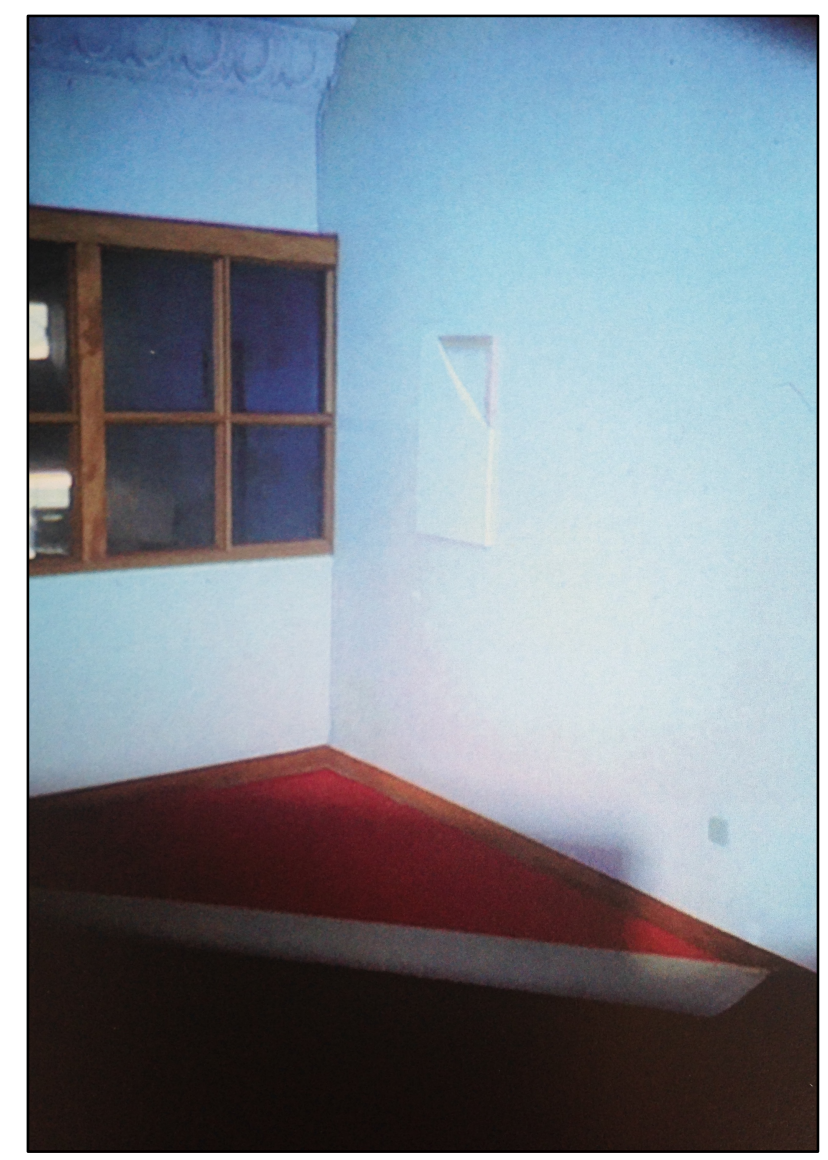

Vaughan Gunson (detail from inaugural exhibition), June 1997, rm3. Photo: RM archives

The title reflected the name on the office door and was unanimously decided on, when the group "came back for a meeting and we all had the same name. We had 20 names each, but we all had rm3 as one of them, with a little rm and a big 3" (Wylie 2018). The new collective opened a bank account together to manage the costs and "you had to put money in every two weeks ... I think it was about $\$ 60$ each, every two weeks" (Wylie 2018) with artists "charged a little bit for the show" (Spratt 2018).

Exhibition openings were held every two weeks- "we were nuts! We were constantly painting the walls, putting up shows and making invites. I didn't have a job at the time" (Wylie 2018) — with the initial shows featuring the members and their peers at AUT. At the beginning the collective had to be proactive to seek out exhibitors, “because we were doing shows every two weeks we just didn't have enough people. So we'd call people and say, 'we'd really like you to do a show'" (Wylie 2018). 
Wednesday night openings attracted a range of artists and art students, with a core group of friends who came to "every opening" (Wylie 2018). "But it was also artistdriven, if the artist knew a lot of people then there'd be lots of people there. If they didn't, it would just be their mum and dad and lots of sausage rolls!" (Wylie 2018). The gallery opened three days a week with the collective taking turns to invigilate.

The group made collective decisions on the exhibition programme, but did not operate with formal systems for decision-making at that stage, "we just talked about who would do what. We had meetings regularly, and we would sit down and go 'ok, we need to plan shows for the next six months"” (Wylie 2018).

I'd been a chef before, so I'd worked with teams of people in different ways, but not in a democratic way, you're always in a hierarchy, and so you tend to do what you're told. So this was a new situation for me to be in, in a democratic situation, and that was great. (Drayton 2018)

After a year, Zoe Drayton, Barbara Anderson and Lorna Bailey had left the organisation, "it was a lot of work, and a lot of money ... and Zoe and Barb had kids" (Wylie 2018) but the collective continued "we just got some new people and kept going" (Wylie 2018). The system for recruiting new members was largely based on friendship "it was very loose" (Wylie 2018) but over time the organisation began to be subtly reshaped "every time someone new came along they brought something different to it" (Wylie 2018).

Two and a half years after opening as a newsletter describes it, "our dysfunctional and dramatic run has finally been brought to a halt" ( $R M$ 1999, n.pag.), when the organisation's lease was not renewed because of the expansion of the landlord, Real Groovy Records. However, the newsletter went on to tease, "fear not, Auckland. Wipe the tears from your eyes. $r m 3$ might have finished writing this first chapter for the art history books, but there is still more to come" (Ibid.). In fact, the organisation had secured a new gallery space in a former dentists' office in downtown Auckland. The final show in their original premises in February 1999 featured the $r m 3$ directors, past and present, showing in the office space. 


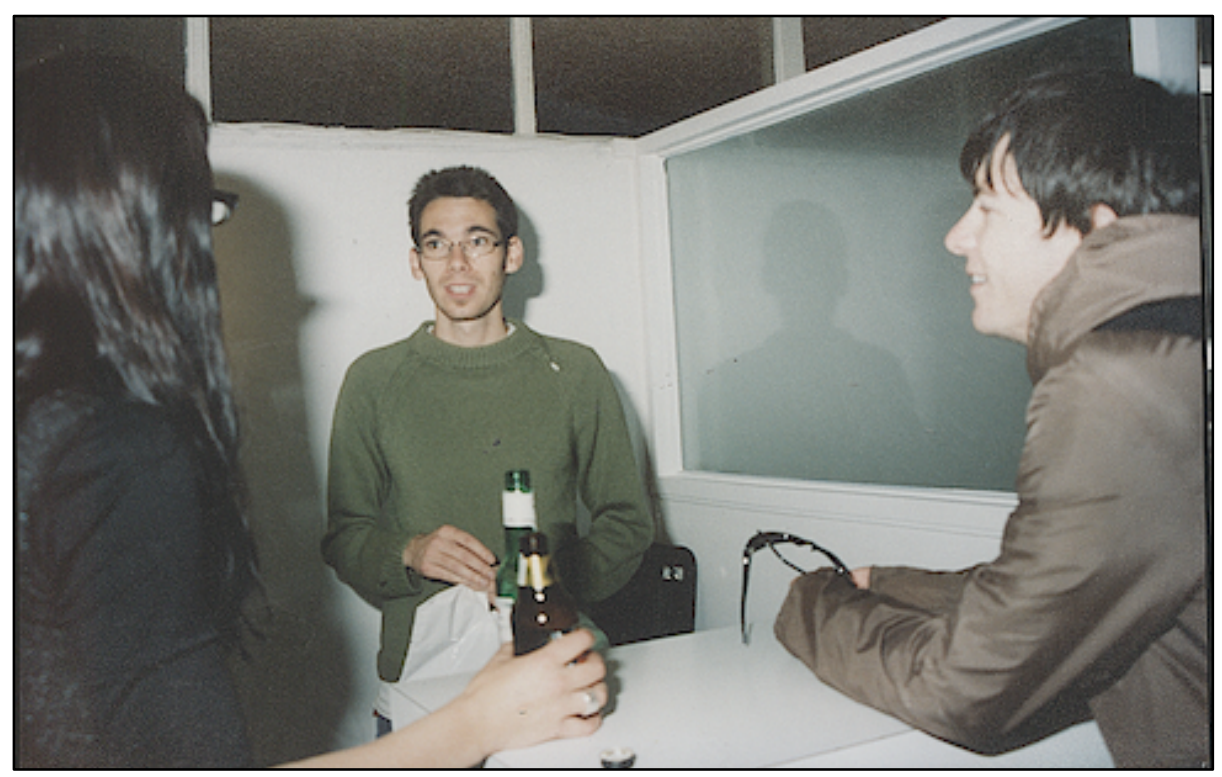

Andrea Wilson, Tim Checkley and Clint Watkins, Rm212, 2000. Photo: Joyoti Wylie

By February $2018 R M$ had established itself as New Zealand's longest running artistrun space, with over 20 years of continual operation as an artist cooperative. Over that time $R M$ had occupied a number of different industrial and commercial locations throughout the Auckland CBD, originally altering its name to reflect each physical shift ( $\mathrm{rm} \mathrm{3,} \mathrm{rm} \mathrm{212,} \mathrm{rm} 401$ and $\mathrm{rm} \mathrm{103)}$ and eventually settling on the moniker $R M$, signalling the time-bound nature of each occupancy.

The space has received Creative New Zealand funding regularly over the years through project funding, currently under the Arts Grant system, which provides them with financial support for rental and logistics as well as modest artist fees. In February 2018, the line-up of co-facilitators were Louisa Afoa, Jess Morgan, Deborah Rundle and Daniel Sanders.

We recently re-described ourselves as being a collective, rather than co-directors of the space, and we've done this I guess because ... we felt like "collective" kind of reflected all of us more than saying we're a group of co-directors. Because we do so many different roles from just volunteering in the space, just helping out at openings. And co-director I guess, for us, was ... it felt like a different role. Like we sit in a boardroom or something. (Afoa 2018)

The exhibition programme is developed jointly by the collective through an annual open call for proposals. Alongside the monthly exhibitions are regular public programmes (screenings, talks, performances) and an annual summer resident artist. Decisions are made by consensus among the group, which Deborah Rundle described 
as "deeply committed to different ways of decision making and processing, and challenging ourselves and each other and establishing a different voice and environment for artists to practice in".

$R M$ 's online mission statement describes their focus as a space which, places the work of local emerging artists alongside more seasoned practitioners. $R M$ seeks to engage with the practices, discourses and modes of presentation that aren't well-supported or easily accessible in Auckland. Though we might look like a white cube, we are more interested in the potentials of an empty room - a space to gather, to think, to talk, to make, to share ... (http://rm103.org)

My research into $R M$ as the longest surviving artist-run space in New Zealand is useful both because of that longevity and the relatively under-researched nature of $R M$ compared to other spaces such as BOAG (Amodeo and Enjoy Public Art Gallery 2016; Campbell and Wolf 2009) and Enjoy (Enjoy Public Art Gallery 2005, 2010, 2016; Amodeo and Enjoy Public Art Gallery 2016). In addition, capturing $R M$ in the period soon after the last founding member had departed meant I encountered them at a time of change.

\section{Enjoy Contemporary Art Space}

Level 1/147 Cuba Street, Wellington. Established 2000 - ongoing.

Enjoy opened in July 2000, founded by artists Ciaran Begley and Ros Cameron and policy analyst Rachel Smithies, in a rented space above a shop in Cuba Street, downtown Wellington. Previous not-for-profit art projects, such as Cubewell House (1992-1993) and The Concrete Deal (James Smith Carpark, 1996-1997) had been and gone, and Wellington's art scene at that time consisted of the major art institutionsCity Gallery Wellington, Dowse Art Museum, newly opened Te Papa Tongarewa Museum of New Zealand - and a handful of small but powerful commercial art galleries. There were not many opportunities for emerging artists to enter the scene and Begley "came to the conclusion that the only way I was going to get a show in Wellington was if I set up a gallery that would show the stuff that I would make" (2018).

Senior Wellington artist Stuart Shepherd bluntly sums up the Wellington scene entered by Enjoy as "awful. AWFUL. And dull, very dull ..." (Shepherd 2005, 20). 
He explains, "I was so delighted that there was finally a site for intelligent, anarchic investigation in this hopeless city that I volunteered to gallery sit. Something that essential in the community deserves support, I figured" (21).

The opening exhibition saw Begley and Cameron collaborate in a performance where the glass in the windows were removed. This simple gesture was metaphoric in its aim-letting fresh air in - and its fresh, sculptural insouciance set the tone for the programme to follow.

At that first opening, a bit to our surprise, there was suddenly this whole set of people. Because we told people that we were doing it and we made fliers and things but you never quite know what's going to happen and if anyone's going to turn up. And then we had this opening and there were 40 people and they all stayed and talked to each other for an hour and a half and everyone was really excited that it was happening. (Smithies 2018)

The space consisted of a white walled L-shaped room with three long windows at one end, which became the focus of the first series of shows, Viewfinder. The initial three weeks of rent were covered in exchange for Begley sanding the floors of the space and shop below, and, at that stage, the entire project was anticipated as temporary.

We were supposed to be five weeks and then we were another show, and then we did another five shows, and we did a fundraiser to try and recoup costs, and then we got Creative New Zealand [support] for the next six months. And I think when we did the next funding application for the following six months after that, so that was Damage and Control, and after those two, then we started thinking it was long-term. (Begley 2018)

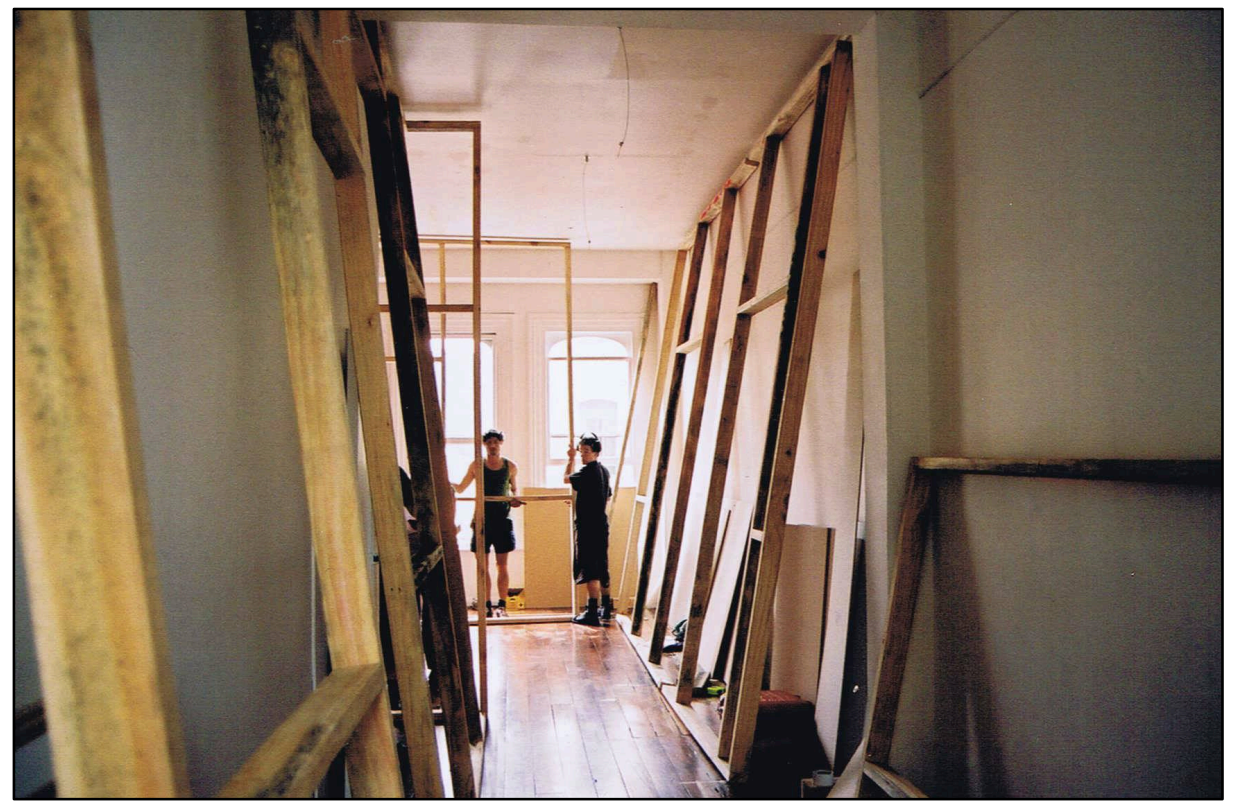

Enjoy Under Construction, 174 Cuba Street, 2000. Photo: Enjoy archives 
The three friends were unusual in that they were not recent graduates of a local art school-Begley and Cameron had studied fine arts together at Canterbury University, while Smithies studied public policy at Victoria University. Begley and Smithies were a couple. At that time, Massey University in Wellington offered design and photography courses, and, in 2000, was launching its first Bachelor of Fine Arts programme. There was, therefore, no obvious art school community at that point, but, "quite quickly, there was sort of a community of people that attached themselves to the space. Because they supported what it was trying to do" (Smithies, 2018).

This group drew together a diverse variety of grassroots communities; established artists working in the various departments at Massey University or who had working practices as painters, and filmmakers and experimental musicians. The wider environment was important in developing the early programme "if you have an active art school you have a dominance by that art school. And when we started, there was no dominant force on the programme" (Begley 2018).

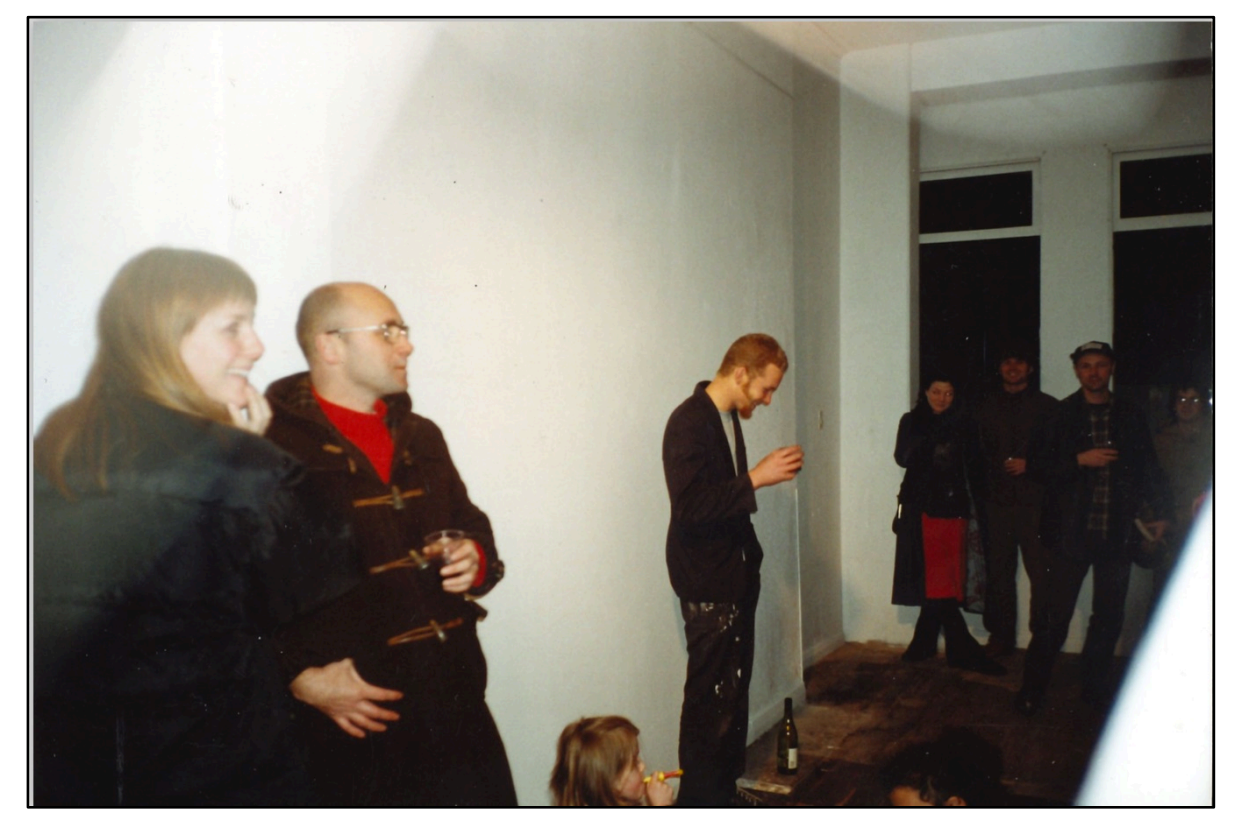

Ciaran Begley Speaking at Enjoy's Inaugural Opening, 2000. Photo: Rachel Smithies

The three participants worked closely together, operating largely with consensus, although Begley and Cameron were more hands-on and Smithies, who was working full time at the Ministry for Social Development, was mostly involved in behind-thescenes work such as establishing the organisational structure and applying for 
funding. The idea of three participants working together was not random, rather it was a deliberate strategy. Begley describes it as a pared-down governance structure,

with just three people involved at a maximum, it means you just can't get big, that you have this necessity of close communication that grows or fails and is immensely personal and emotional, but is also really grounded. So you have to front up for everything you do. (Begley 2018)

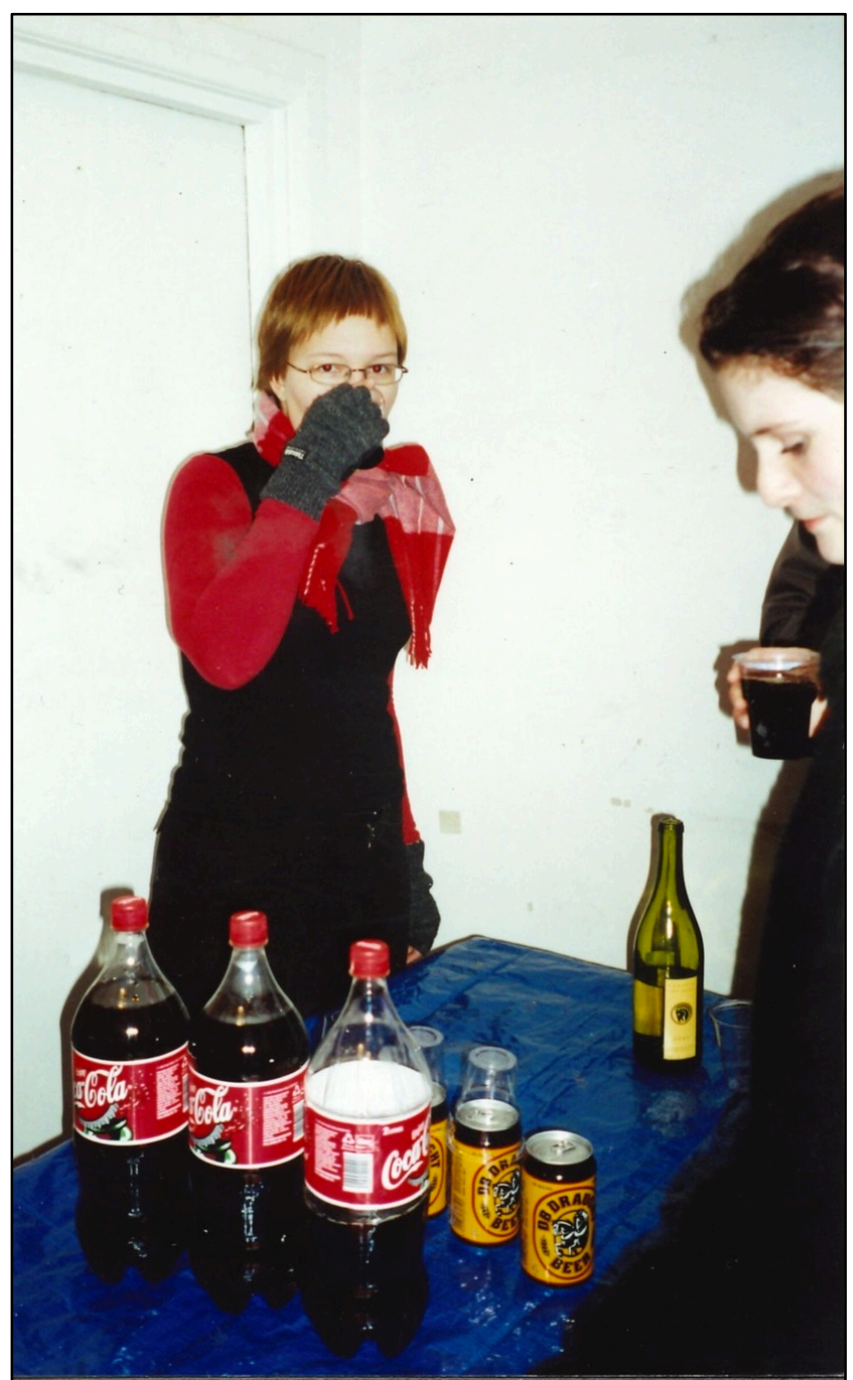

Rachel Smithies at Enjoy's Inaugural Opening, 2000. Photo: Rachel Smithies

The early phase was marked by a commitment to a particular and deeply felt curatorial approach. An open call invited artists to submit a very specific proposal, which they would then be held tightly to during the development of the show. This approach was an attempt to "have an open application process, judged on the merit of work rather than credentials" (Smithies 2002, 36) creating a more inclusive programme. 
I wanted something that was transparent, that you'd say, 'We want your proposal. We don't really care about your history, because we want to know what you want to do with us'. (Begley 2018)

The resulting exhibition programme was fuelled by enthusiasm and, at times, antagonism, with Enjoy, Begley stated, "very aggressive about holding people to their proposals". The first shows reflected the eclecticism of the arts community at that time, ranging from installation to performance to sound, and mostly focused on Wellington-based practitioners. The very first fundraising show, Buy Enjoy, was launched in August 2000, and remains an annual event, with artists donating works to sell at a fixed price.

Gradually Massey University's growing influence as a new art school began to have an impact, with the first ever graduates of the art programme beginning to exhibit. Notable exhibitions from this second phase included highly charged male endurance performances - Auckland artist Mark Harvey releasing a fire extinguisher in the gallery, forcing the audience to evacuate the building (Home Helper, 2003), Wellington artist Bryce Galloway setting fire to his own chest hair (Mr Pudding and the Bedroom Stars, 2003), while the smell of human urine festering for days in a paddling pool apparently generated complaints from neighbours (Ryan Chadfield and Tao Wells, 2004).

In February 2018 Enjoy had been in its second location since 2006, still on Cuba Street in a building rich with contemporary art significance-including close neighbour, Peter McLeavey Gallery, located there since 1968. Enjoy's current space is still modest in scale, but is part of a network of small spaces clustered in the lower Cuba Street precinct, including Hamish Mckay Gallery, Bartley + Company, $\{$ Suite $\}$, and Bowen Galleries. Around the mid-2000s Enjoy lost its full stop and at the time of my active research was officially Enjoy Public Art Gallery, although most of its community still seem to call it Enjoy. Over 20 years, more than 40 board members and 18 staff members have been involved in the trust, along with many more interns and volunteers. 
Enjoy, says current Curator/Manager Sophie Davis, "has been around for a long time and gone through several different stages and identities, and has developed into a mini-institution". She describes the remit of the gallery as:

to service a particular part of the sector, which is to develop artists while they're quite young, or to help artists who are more established to develop more experimental work. Enjoy only really shows new work, although there are cases where we show existing work as part of a curatorial project. We come in at that particular stage or that particular space of experimentation and we help to promote artists, we help to create critical dialogue around the work. (2017)

Exhibitions are developed by the curator/manager, who is employed on a three-year, fixed term contract. There is an emphasis on the personal curatorial take each curator/manager offers. They shape the programme in consultation with the board, with "definite shifts in what each curator has been interested in and I think that it's important for them to wear that openly" (Rutledge 2017). The exhibition programme is punctuated by an annual summer artist residency, held in 2018 by artist and graphic designer Ella Sutherland.

Enjoy in 2018 is a funding client of Creative New Zealand through the Toi Uru Kahikatea (Arts Development) programme, which provides "ongoing funding over serval years to support continuous programmes of activity and ongoing infrastructure" (https://www.creativenz.govt.nz/find-funding/funds/arts-development-investment27000203110662). Additional funding is received from the Wellington City Council and the Wellington Community Trust, and the Buy Enjoy fundraiser, first held in 2000, continues to feature every year. Enjoy's mission statement reads, “Enjoy generates and facilitates contemporary art projects to promote the discourse of contemporary art practice in all its forms" (http://Enjoy.org.nz/about/).

Chairperson Ann Shelton reflects on Enjoy's future,

I suspect, obviously I'm just surmising, but I expect Enjoy will grow, in terms of its size, and the group of professionals that support it. So I imagine Enjoy will get bigger, both in terms of the environment it operates in, I can see it having more staff, as I've said, I think it's mission and vision is still so relevant that it's alive as an organisation, it's not becoming obsolete in any way. (2018)

My initial interest in Enjoy was as a space with a high level of organisational structure and a commitment to actively recording and archiving their own history. My research 
coincided with a significant period of change for the organisation as it debated its next stage of development and tension arising from such change became a focus.

\section{Meanwhile}

Level 299 Willis St, Wellington. Established June 2016-ongoing.

Why are there no artist-run spaces here in Wellington? How do we begin? How do we keep running? What is the longevity? What is the gravity of a physical space? I left angry, knowing what I knew to be true but had ignored out of convenience, a critical mass of young artists are being underrepresented, unsupported, in need of a space. (Bragg in Bowling, Bragg and Devlin 2016, n.pag.)

After years of very little new artist-run activity in Wellington, 2016 saw the establishment of two new spaces, Play_Station and Meanwhile, both founded by recent graduates of Massey University's College of Creative Arts. The trajectory for Meanwhile is different to the usual opening narrative of the artist-run space, which $R M$ and Enjoy both followed. Instead of a group of people coming together with intent and seeking out a space to use, a venue became available to rent at 35 Victoria Street and a group emerged to occupy it. The potential building was identified initially by Auckland artist-run space Club Mirage, who approached Wellington artist Sonya Lacey, Enjoy Trust member and former member of Auckland artist-run space and studios, Newcall Gallery. While Lacey was originally intended to be involved, she did not end up taking an ongoing role, and Meanwhile was formed as a collective of three emerging artists, Jesse Bowling, Jordana Bragg and Callum Devlin.

I was at an art opening and someone handed me a key and said, you can probably do this ... I grabbed Callum and Jesse and said, someone's just handed me a key. That's not completely random, there's probably a very good reason why they thought me, potentially, but that's the start of it. (Bragg 2018, n.pag.)

The three founders had each graduated with a Bachelor of Fine Arts in 2015 and were still trying to establish a foothold in the Wellington art scene when the opportunity came up for studio space, which developed into the chance to run a gallery and studios. Initially Devlin and Bowling were committed, with Bragg shortly after becoming involved, "me and Callum asked Jordana to help us, because we'd worked together before ... and we were good friends at art school” (Bowling 2017). 


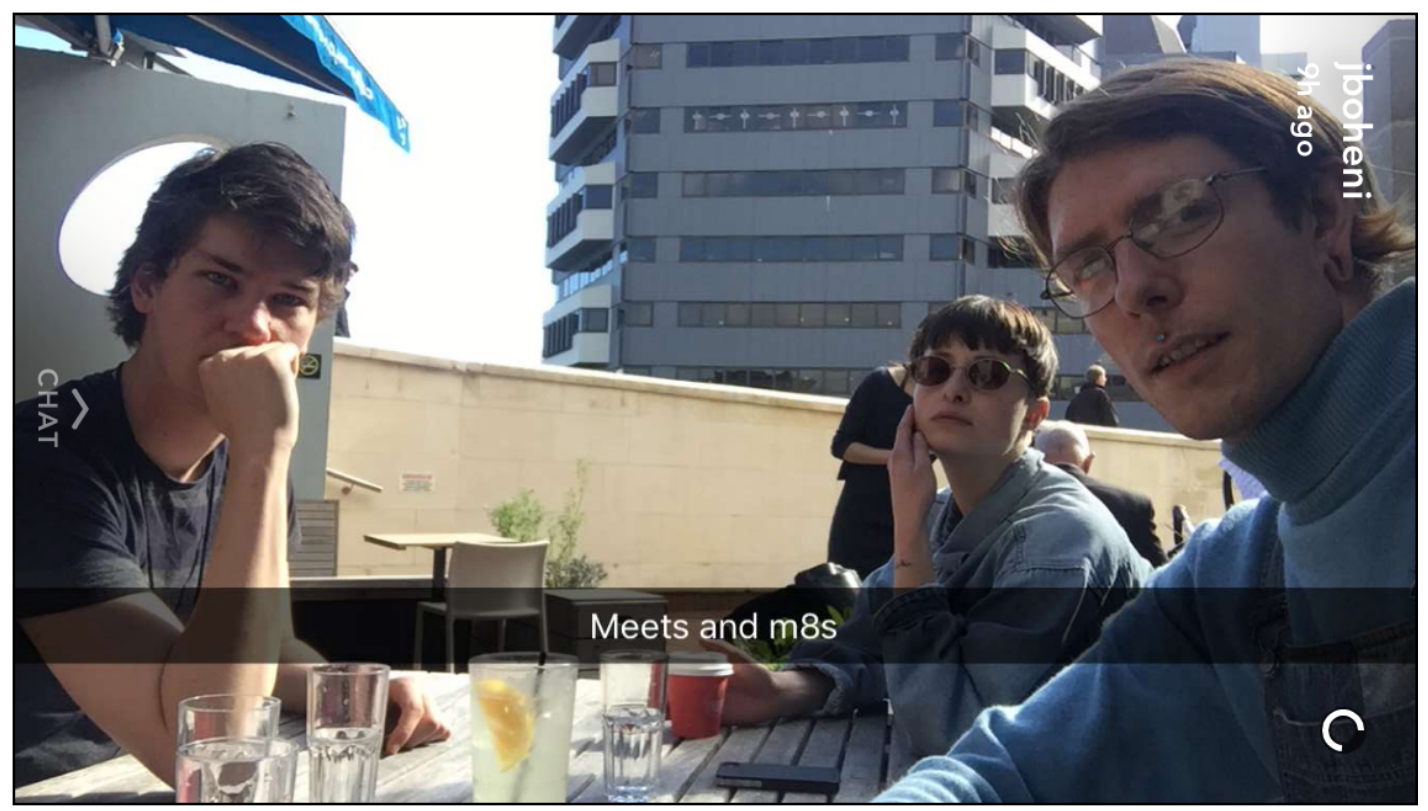

Callum Devlin, Jesse Bowling and Jordana Bragg, 2016. Photo: Meanwhile archives

As students in their final year at art school they'd collaborated, alongside fellow student Samuel Jackson, on Stay On. Pdf, an exhibition held at 8 Egmont Street, premises which would later become Play_Station. At this early stage, Meanwhile was intended as temporary, and the name reflected the provisional nature "the idea of enduring was not something we were ever thinking of-hence naming ourselves Meanwhile" (Bragg 2017). There was "no expectation whether this was going to be a several year project or just a few months" (Burn 2018).

The inaugural show was by Massey University graduate Josephine Jelicich, developed through a casual process by which the artist received an email from Sonya Lacey "asking if I had any existing work that I would like to install in the Meanwhile window in about a week. Having only one week notice made me feel relaxed about the content" (Jelicich 2016, n.pag.). The reality of the upcoming exhibition drove the next steps, as Callum Devlin recalls, "so we came up with the name Meanwhile, created a gmail account, made an invitation and sent it out" (Bowling, Bragg and Devlin 2016, n.pag.). This sense of serendipity was a strong current in Meanwhile's early development, writes Jesse Bowling, "we are indebted to the opportunity being presented to us, and it came to us because we were there" (Bowling, Bragg and Devlin 2016, n.pag.). 
Jordana Bragg recalls "Based on the success of that show, Sonya gave Jesse and Callum the reins to programme the window space until the end of the year" (Bowling, Bragg and Devlin 2016, n.pag.) and shortly after that, "something fell out there" (Bowling 2018) and "Sonya approached Jesse and I to ask if we wanted to take over Meanwhile permanently" (Bowling, Bragg and Devlin 2016, n. pag.). The first official meeting as the Meanwhile collective took place on 23 August, a month after first occupying the space, and the collective began to develop a sense of who and what it was. "We felt we were doing the right thing, instinctively, and decided to forgo answering why until we have had a little more time to figure out what our model was" (Devlin in Bowling, Bragg and Devlin 2016, n.pag.).

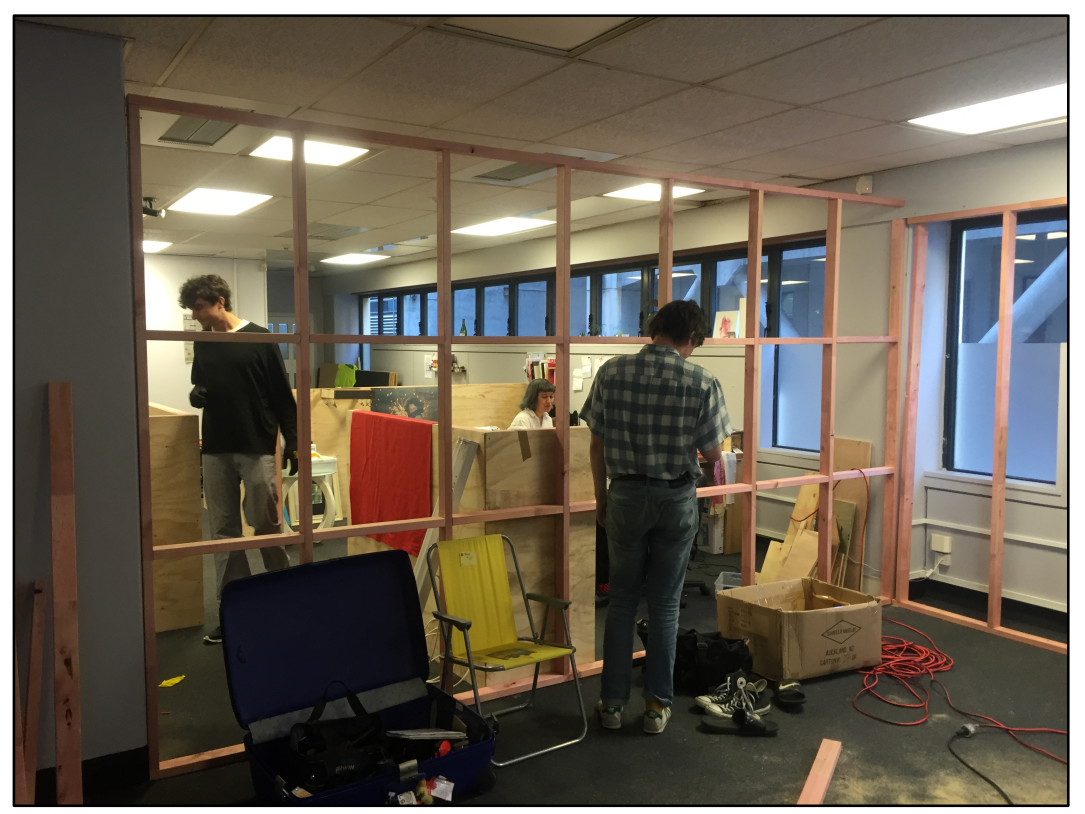

Building Studio Spaces, Meanwhile, 35 Victoria Street, November 2016. Photo: Meanwhile archives

The space initially featured a ground-floor window gallery and rented artist studios, and eventually a larger gallery space carved out in the building space. Initial work to create the environment included removing frosted vinyl from the windows and building dividing walls to create studio and gallery spaces. Looking directly onto busy Victoria Street, the window gallery allowed for playful interaction with pedestrian traffic and offered a public profile unusual for emergent artists. Exhibition openings were theatrical events spilling into both sides of the window divide. Writing about a performance by Digby Carter where the artist led a yoga routine (part of the 
exhibition Free Time, August 2016) Dilohana Lekamge describes this blurring of public and private as "an obscure spectacle to witness in the window of an office building in the middle of the CBD ... a peaceful disruption of habitual activities offering a moment of calm obscurity" (Lekamge 2016, n.pag.).

Callum Devlin described the Meanwhile community as "people that we trust, and [who] trust us.

And that's a big deal for us. We're also artists, so we want to work with artists in the way that we'd wanted to be treated, represented, and respected. So we're figuring that out. (Wardle 2016, n.pag.)

By February 2017 the Victoria Street building, which had only been available on a month-by-month lease, sold and Meanwhile was required to vacate the premises. The collective, which had developed organically in response to the opportunity of the space, was faced with the need to make decisions about the future.

We had to quickly think about whether we could or wanted to find a new space. But we had already done something that was beneficial for Meanwhile, but not so beneficial for us as co-founders, which was an open Call for Proposals - right before we found out we had to leave. So we felt dedication to those who had visited the space in 2016, our studio artists and those who'd applied [for the 2017 exhibition programme]. (Bragg 2017, n.pag.)

Making a decision to carry on, Meanwhile relocated to upper floor premises in Willis Street, where they continued the gallery/studio model developed at Victoria Street, evolving into "a pretty vibrant little beehive" (Bragg 2017). A small, street level window display space keeps the connection to a wider public begun by the original site, while the space upstairs is divided up into shared studio zones, or 'lots', and a small gallery space off a reception entrance. With white walls and a concrete floor, the gallery is modest but fairly traditional, apart from the insertion of a window view into the brick wall of an adjourning building.

The premises lease is covered by the rental paid by the studio artists, along with the contributions of collective members. The relationship between gallery and studio artists is considered crucial, both financially and also in the core community they provide "they are funding the space, but they also get space. You have a studio, you can make stuff, you're not here just giving us money to keep the thing going" (Bowling 2018). 
Studio artists, current and former, receive automatic inclusion in an annual show: Pool Party (2016), Slumber Party (2017) and Office Party (2018). For all members interviewed, the Party series is where the relationship between studio and gallery is celebrated and cemented "giving privilege and some power back to the studio artists, who essentially fund the space, and giving them the opportunity and the voice" (Bowling 2017). Bowling identifies the inaugural Pool Party as crucial to their development, "I reckon that really solidified our identity. It was a defining exhibition, for us, and it got talked about" (Bowling 2017). For Jordana Bragg it is important the series is accumulative, bringing together old and new studio artists, and, as such "carries with it every year the full significance of who we were and where we are now, displaying our history expanding as the space continues” (Bragg 2018).

The rest of the gallery programme is curated by collective members through an open call for proposals, driven by both personal interests but a larger sense of what is missing from the wider art scene.

We were, like, what don't we get to see in Wellington? Who are the artists that we look at, and they do really good work but they don't get to show, because one, it's not commercial enough, or two, there's no space for it. More conceptually driven, experimental projects. (Bowling 2017)

In the beginning Meanwhile documented their meetings by formal minutes, as Callum Devlin explains, "our process so far has involved a lot of meetings, plunger coffee, and ginger nuts. And talking about our feelings" (Wardle 2016). The minutes detail the logistics of upcoming exhibitions but also list snacks and drinks along with the emotional state of each member. In this early phase Meanwhile was highly conscious of the importance of documenting their temporal achievements, "to canonise ourselves ... so that it's known that we did that, and that this is how it happened" (Bowling 2017).

As they have evolved, the more formal qualities of minute taking have relaxed, although in 2018 the current iteration of Meanwhile developed strategic documents in the form of a Meanwhile Kaupapa and Safer Spaces Policy. Meetings are now held every three weeks, to discuss each upcoming show, but, with members juggling paid work and their own artistic practices, "we do a lot more instant messaging, or Facebook, talking on there. It's a lot of our communication” (Bowling 2017). 
To date, they are largely self-funded, using the gallery/studio model, although they have received a small amount of funding support from the Arts and Culture Fund, Wellington City Council and project funding from Creative New Zealand to enable them to travel and take part in the inaugural Hobienniale, a "festival bringing together artist-run initiatives and emerging artists from across Australia and New Zealand" (https://hobiennale.com). In 2016 they conducted a highly successful Pledge Me campaign which reached its target goal of $\$ 1,000$ in just 15 hours, to fund a book documenting their progress. A second crowd funding campaign in 2018, hosted on Boosted for ongoing maintenance and running costs, raised over $\$ 5,000$.

Callum Devlin left the organisation in early 2017, around the time of the move to Willis Street. At first Jesse Bowling and Jordana Bragg continued together and then Sean Burn, a designer who had developed Meanwhile's graphic identity, joined as a third facilitator, "we did different degrees but we were in the same group of friends, my partner, Maddy, studied with them, so I've kind of always known them" (Burn 2017). By February 2018 a new set of facilitators had joined, with Bowling leaving at the end of 2017 to take up additional study in Melbourne. Dilohana Lekamge, Simon Gennard and Laura Duffy had submitted applications in response to a Call for Facilitators, a formal process of recruitment that Sean Burn hoped would "open it up a bit more" outside of their usual networks.

To try and widen the scope of what we can do and the communities we can bring in. And it's a chance to try and keep Meanwhile running beyond just us. So it gives us an opportunity to step away if we like and know that there's still people that can keep it going. (Burn 2017)

At the point my research intersected with Meanwhile they were undertaking change in personnel as well as developing their first formal organisational documents. Although very new as an organisation, they were already undertaking crucial discussions about who they were and what was important to them, and the discussions generated by this work became a research focus.

\section{Conclusion}

This chapter identified the broader terrain in which my chosen artist-run spaces are situated, as a background against which the research builds. Artist-run spaces are, as 
this chapter has demonstrated, a global phenomenon, and the New Zealand experience has emerged in response to, and in parallel with, international developments.

Although most of my participants are focused primarily on their own activities and the activities of the art scene directly around them - "the whole time I've been involved in art I've never seen an artist-run initiative, never been to one, apart from if I went up to Auckland" (Bowling 2017) — this history, both national and international, has nevertheless shaped the culture in which they have emerged.

But, as this chapter has shown, broader cultural changes than that of the artist-run have had an impact on their development. Political and social forces have changed what it means to be an artist in New Zealand in 2018, compared to the situation in 1997 when my first case study began. The history of artist-run spaces in New Zealand is inseparable from a wider history of neoliberal thinking that has reworked our economic and social structures, and artist-run spaces today articulate themselves, knowingly or unknowingly, against this background.

New Zealand artist-run spaces, established originally in the 1990s to offer "some sort of resistance" (Bywater 2018) quickly became absorbed in the mainstream art project's relationship with neoliberalism, and today, Jon Bywater suggests, artist-run spaces are "advancing those forces as much as resisting them" (2018). Yet, insists Bywater, "I don't think that can be settled in the abstract and it certainly doesn't take away the value that there is in artist-run spaces". The push-me, pull-you tension between advancement and resistance is a key consideration in my research, and the relationship between art and neoliberalism is explored in different ways in the following chapters.

Although the thread of resistance is embedded deeply into the artist-run narrative, cultural organisations can never be truly neutral, representing "microcosms" of social activity where "beliefs about the order of the world" are publicly constituted (Duncan $2005,79)$. While many of the participants I interviewed argued they enact a form of organising that is "experimental and open and as free as we want" (Burn 2018), my research demonstrates they are also regularly embroiled in power relations, internal and external. The following chapters chart negotiations between participants, with each other and with the wider art ecology, in the process of making and remaking the artist-run space, and building their own identities as participants. 


\section{Chapter Two}

\section{Trust and Exchange: The Artist-Run Space Assemblage}

While the physical space leaves residues of encounters, it is as sites of activity where there is transformation, unpredictability and energy through a continual negotiation with the site (at once physical, social, cultural and historical), which produces spatial relations. This distinguishes artist-run organisations from the white cube model. (Attiwill 2007, 32)

\section{Introduction}

It's early November by the time I make it to an Enjoy opening. I'm there to meet Enjoy Trust Chairperson Ann Shelton, who doesn't show up. While I wait for her, I study the show - a series of photographs and videos by Auckland-based artist Ngahuia Harrison. Her show, I huti a Manaia i te ika and his heart was broken, considers the disjunct between the natural waters of Whāngārei Harbour and the large-scale apparatus that squats beside it, the Marsden Oil Refinery. Having grown up in Northland in the 1980s, at a time when the economy of Whāngārei was tightly entwined with the workings of the refinery, I pay the work particular attention. The exhibition is professionally framed and tight in execution. It's beautiful and thoughtful, and quite polished.

I'm slightly ill at ease, unsure of my role at the opening. Two years ago, as a Wellington-based curator, I would have been attending such events as a matter of course. However, I'm now a visitor from out of town, and, secretly, a researcher in the field. I take count of the number of institutional curators in the room-fivewhich seems a lot, at an event attended by around 30 people in total. (One of the curators tells me she is here because her institution has recently made a purchase of Harrison's work). There are, I later realise, probably fewer artists in general attending the opening because the exhibiting artist is from out of town. 
The number of institutional curators might have been particularly high, but it reinforced the enmeshed nature of the Wellington art scene. Writing about the Australian art world, Tessa Dwyer and Daniel Palmer describe artist-run spaces as, one stratum within a vast and intricately layered composite. International biennales, triennials and art fairs, commercial and not-for-profit galleries, national and state organisations, curators, critics and funding bodies alike rely to some degree on the networks and ideas generated by the humble artist-run space. ... In this sense, artist-run spaces are intrinsic to the life cycle or ecology of contemporary art in Australia. (Dwyer and Palmer 2007, 13)

This chapter uses assemblage theory to map the artist-run space in a holistic and expanded manner that acknowledges my case studies are not "completed or stable constructions ... they are better conceived as temporary and provisional connective arrangements" (DeLanda 2006, 10). Traditional methods for measuring cultural institutions focus on tidy outputs: audience footfall, visitor satisfaction, professional development or financial management. These data on their own can't account for the artist-run space's “complex and emergent collaborative settings" (Mar and Anderson $2010,48)$ that, as new participants and artists continuously enter and exit, reflect a constant "relational processes of becoming" (Sherlock 2013, 19).

In utilising the framework of an assemblage, I have taken a wider, messier view, extending to examination of the physical and social environment, the activities presented and the larger network in which the artist-run space is enmeshed. The assemblage therefore does not stop at the physical boundaries of the gallery but describes the interlacing of a loose community (of people, institutions and objects) in formal and informal unions that activate and support a single space. It provides a mechanism to track tensions, contradictions and ambivalence that might co-exist alongside experiences of connection and community.

My study grounds this process in real situations and descriptions, as Sharon Macdonald has noted, the assemblage "is not an abstraction, though it may contain abstractions. Rather, it is made up, variously, of constituent practices, affects and materialisations" (Macdonald 2013, 6). In particular, this chapter considers the physical space of galleries, exhibition programmes, visual identities and the broader network of institutions with which they intersect, particularly larger organisations that offer practical or professional support. I trace the 'space' of the artist-run, exploring 
how the spatial materiality of a given site impacts the nature of, and reception to, activities presented, as well as determining how participants experience the work of the space. I examine the exhibition as a form to understand the artist-run space itself, in particular focusing on how my three case studies, RM, Meanwhile and Enjoy describe themselves. What are the activities that speak to who they are as a space?

Beyond the spatial configuration of the gallery itself I describe the artist-run space within a broader network, tracking each space as a node within a larger assemblage, believing that "ARIs are only one technology within a complex landscape within which artists and artworks 'work"” (Coffeld 2015, 33). The assemblages emerge as a predominantly city-specific cluster of larger and smaller structures that together, create an arts ecology. This network is configured as a support system for smaller spaces, which, experiencing scarcity, depend on their larger counterparts to share resources, but also act as a feeder system to the larger institutions, for whom artist-run activity serves as test and training ground for emerging artists before they enter the public realm.

The relationships that define the support structure are variously described as both benefit and source of tension for participants, due to anxieties arising from questions of agency and independence. At the heart of this chapter lies my primary research question; to what extent does the artist-run space offer alternatives to current neoliberal orthodoxy in the art world? In addition, this chapter explores the impact of 'wider art networks', from my secondary research question; what impact have funding, policy and wider art networks had in shaping the New Zealand artist-run space? The chapter seeks to understand how, if the artist-run space is enmeshed within a wider assemblage, can the space locate itself outside a conventional art world mainstream?

\section{Space Matters: How Physicality Shapes the Organisation}

'Space', as Chapter One reported, has long been hooked up to 'artist-run' in New Zealand, and the physicality of site is tightly entangled into the identity formation of the artist-run. I used Suzie Attiwill's words as this chapter's epigraph to emphasise how the spatial politics of the artist-run are often evoked as rebuke and challenge, forming a counter narrative to the modernist convention of gallery as a white cube. In 
this reading, space is not just a material location but also a political choice which determines the artistic direction of the organisation. This is not to say that an artist-run space cannot have white walls and ceiling, but that, for many artist-run space participants, "the relation to space is not that of the white cube model, where space is understood as neutral, abstract, autonomous, isolated and void" (Attiwill 2007, 32).

Therefore, when co-founder Joyoti Wylie, quoted in Chapter One, describes RM's first location as "perfect, because it had horrible carpet" she is deliberately refuting the notion of a gallery as neutral foil against which artwork performs. She goes on to say,

If we'd wanted to, we could have turned the spaces into white cubes ... we were interested in site-based work, and in the relationship between the space and the artwork.

For Wylie, the space was an active agent in both the construction and reception of the artwork, and the idiosyncrasies of the physical environment part of the specific qualities of showing at $R M$. The gallery's first location, in a small office on Auckland's Queen Street above Real Groovy Records, set the tone with such oddities as a window in the back wall that allowed people to look down into the shop itself. This space, too small, as writer Gabrielle Amodeo has noted, "for the co-directors to invigilate within it" (Amodeo 2017, 45) was one of many of their premises characterised by, Nick Spratt recounts, "bad signage, closeted away in a dingy old building" (Amodeo 2017, 45). Spratt echoed Wylie when he noted "we came out of a way of thinking that was about site-specific responses, and so the gallery itself was always seen as having an influence" (Spratt 2018).

Space emerged as a major factor in $R M$ 's development from the perspective of its founders, a position that evolved into thinking about space as a marker of the collective's conceptual position. By the late 2000 s, over a decade after $R M$ had opened, the collective began to reconsider the gallery venue in terms of how it might generate “openness" (Spratt 2018).

the office space was a kind of conceptual boundary, not a physical boundary, necessarily, and the idea that we could take a more modular approach to the gallery, where the components, the office desk and the shelves, could be moved around, re-articulated, was really quite key for us in ensuring an openness. (Spratt 2018) 
In 2009 RM left downtown Auckland's Achilles House and moved to premises located within the existing arts community of Karangahape Road, alongside commercial and other independent art spaces. From their second location they had always invigilated the space in the gallery itself (the first space, as Amodeo pointed out, being physically impossible to do so) but this crystalised into a deliberate position.

It became a much more formal quality of $R M$ after that. We wanted to ensure that the office desk was a visible part of the space but also that we were an open, approachable space ... it became a political decision, rather than just, well, it's easy for us to work this way. (Spratt 2018)

$R M$ began to align themselves from this period with an increasing focus on hospitality, enacted physically, by being present in the space to welcome and acknowledge gallery visitors.

the intrinsic and particular sense of hospitality $R M$ has achieved is something that takes patience to cultivate and maintain ... One can say, 'Right, at this gallery, we're going to be hospitable!' But it is quite a different thing to embody hospitality and embed it into the framework of the institution. (Amodeo 2016a, 49)

One of the most distinct differences since Spratt's departure in 2016 has been an organisational realignment away from spatial politics as a defining conceptual framework. In $R M$ 's current incarnation the office is within the footprint of the wider space, but partitioned off with glass walls, creating a conceptual separation but not an entirely physical one. The archive is similarly housed in this office, rather than placed in the gallery where exhibitors must interact with it, as previously. Increasing the sense of distance now are the daily invigilators themselves, no longer collective members but a series of regular volunteers, with collective members only filling in roster gaps.

For most current members, this shift in mode was not significant, an operational matter rather than one of strategic relevance, and one driven by the new reality of life in Auckland for emerging artists, where "we've got people on the collective who've got their 40-hour jobs, and they're willing and enthusiastic, but it's all going to be after hours" (Rundle 2017). However, Jess Morgan feels their increased reliance on volunteer labour outside the collective is problematic, "I want to get them more 
involved in decision-making and stuff. It's a bit stink. You come sit here all day and you don't get a chance to be involved with what's going on".

The time of my active research was soon after the final co-founder had left, and the organisation was consciously evolving a new ethos for $R M$, seeking to "find our own voice and assert a philosophy and a framework" (Rundle 2018). Through this process hospitality has become less of an emphasis for the organisation by means of a combination of new interests and the rupture with institutional histories resulting from co-founder Nick Spratt's departure. This does not mean a lack of interest in spatial politics, rather a new focus on maintaining a physical presence for experimental art practices in a city that has increasingly pushed small and not-for-profit activity out into the suburbs.

I think the reasons why $R M$ exists now is different to why it started. I think because the political climate shifted, the economic climate shifted, even just being here on $\mathrm{K} \mathrm{Rd}$, it means something completely different now than it did a few years ago ...RM has kind of a responsibility as holding physical space which is quite rare in this climate ... Just the fact that it's a physical art space seems almost like a political action. (Sanders 2018)

$R M$ 's continuing occupation of rental property around and near Auckland's Karangahape Road certainly feels tenuous, as this area is scheduled for development for the Mercury Lane train station. The Upper Queen Street / Karangahape Road area hosts the most significant gallery cluster within Auckland, having supplanted both downtown and Parnell as earlier active centres. Within walking distance of $R M$ now are the independent project space Artspace along with commercial galleries Mokopōpaki, Michael Lett Gallery, Ivan Anthony Gallery, Melanie Roger Gallery, Starkwhite, and, a little further out, OREX, Fox Jensen Gallery, Two Rooms, Hopkinson Mossman and Tim Melville Gallery.

My interview subjects all reject the suggestion that $R M$ has moved closer to resembling a conventional gallery, the "continuing ethos of $R M$ has been that its been resisting being a white cube, and it's done that through different tactics" (Sanders 2018). For Sanders, the changes represented a strategic realignment towards the exhibition programme as the key site of resistance. He contends, "When I took on the job [as a co-director] there were quite a lot of exhibitions that were just so typical of what you might see in any other white cube structured gallery". Participants argue 
that a new focus on public programmes saw the gallery reconfigured towards events that were not necessarily hung directly off an exhibition programme "it can be quite flexible, in terms of being a space that offers book launches or conferences or workshops or all sorts of things, without measuring on return or attendance or any of those things" (Rundle 2017). Louisa Afoa describes a fluid approach where "we also we try and leave gaps in the year, so that if someone comes to us and wants to respond to something that's just happened, we have the space to do things like that. Whether it's just a screening, or a one-night screening, or it's like a workshop, or a little symposium" (2018).

Over 20 years of operation $R M$ has articulated shifting attitudes towards space, initially to accommodate various tactics of institutional critique, more recently as a gesture against the gentrified city. The way that bodies, desks and artworks inhabit or disrupt the space received particular scrutiny during the space's middle period, when members sought to position the physicality of these entities in the space as a political, conceptual act. Within the $R M$ assemblage, therefore, physical layout and occupation of space have been important players in building a specific constellation.

Increasingly, their focus has been twofold, growing the scale of the exhibitions to be "more ambitious with the way that we install and the way that we curate" (Morgan 2018) and a new focus on public programmes, "I think it keeps the space vibrant and alive. You can come do a writing workshop one day and then go and do a couture workshop the next week. That's cool” (Morgan 2018).

The withdrawal of Nick Spratt, longest-serving founder and a significant force within the organisation, signalled a retreat from positioning the gallery spatially. As the presence of the invigilator has been reconsidered, from a deliberate intervention in the space to the more traditional occupation of a semi-detached office, the gallery repositions itself as an emptied out, neutral zone, against which the art can perform. That can be seen as a return to the white cube of modernism and more conventional forms of cultural production, and a shift away from more conceptual tactics. Spratt's careful articulation of the strategies of engagement between space, artist and public provided a distinct and nuanced positioning which, while drawing heavily on international models, occupied a unique realm in the New Zealand art world. 
Current members disputed a reading of their present configuration as less political or considered, arguing that their focus remained on resisting and reshaping a mainstream narrative, but through a holistic approach to exhibition-making which situated "the exhibition like a bookmark in the bigger conversation" and "facilitating a whole conversation" (Sanders 2018). For the current members, spatial politics are not as resonant as the quality of responsiveness that on-off events provide them with, enabling the organisation to react swiftly to political or social change "because things happen and, you know, like, a lot of artists want to react" (Afoa 2018), and reflecting their commitment to observing and understanding "how power plays out" (Rundle 2017).

Enjoy is similarly located in a single room with two white walls, a wall of windows and a battered but glossy wooden floor. The office is located in one corner, demarked partially by a low standing shelving unit the gallery commissioned from furniture designer Andy Irving. The office is therefore part of the gallery, although exhibitors usually work outside and around the office element, leaving a dedicated space untouched just as though there was a physical boundary. Upstairs from the heart of Cuba Street, the gallery space historically had a former life as the Elva Bett Gallery ${ }^{9}$ and is half a floor above iconic commercial gallery, Peter McLeavey Gallery.

The two staff and Saturday volunteers work on desks pushed into this corner, on which sit the usual accoutrements of office life-computers, cups of coffee, pens and books and folders. The office is immensely public, yet also feels private, and it can be a disconcerting experience to enter the gallery, as staff, busy with work, don't always look up and welcome visitors. Etiquette in this situation isn't always clear, I've found, unsure myself whether to say hello or simply pretend the staff aren't present.

While the decision to situate the office inside the gallery was a deliberate ploy for $R M$, for Enjoy it was a matter of circumstances and represented a problem, rather than strategy. Both staff members expressed frustration with the set-up, as Communications and Publications Manager Louise Rutledge put it, "we have our backs towards our audience ... to talk to someone, we have to turn around in our chair 
and walk out of the office and it's quite a big gesture to make". Gallery Manager and Curator Sophie Davis described the competing demands of gallery and office, feeling obligated to engage with visitors yet complete her workload in public.

Sometimes people overstep that boundary a little. Lots of people will come and visit us on a Friday afternoon if they're finishing work early. It's their down time but for us it's the middle of our work day. It's nice to see them but if you in the middle of something or trying to have a phone call with CNZ - I've had lots of confidential phone calls in the bathroom.

If $R M$ 's office activities were for a long time tied into the larger conceptual project of art, for the two paid staff members of Enjoy the day-to-day routine of their roles is clearly work, and, as such, is framed by organisational expectations of outcomes. The frustration expressed about the conditions of the office were echoed, by most of the Enjoy staff and board members interviewed, a sense that the gallery has outgrown its physical space. Louise Rutledge stated “we've been in the current building for 11 years and it's very hard to physically install in a new way, although there's been all sorts of new iterations of the space".

Similarly, Sophie Davis called the gallery beautiful but complained "it's not necessarily set-up for contemporary practices in some ways, it's very hard to show video work for example, to a high standard. But also we are a publicly-funded gallery but people can't visit us if they have mobility issues". The gallery is up a flight of narrow stairs with no lift in the building, it's certainly very difficult to take a buggy up there, and a wheelchair would be extremely problematic.

Enjoy has been on a trajectory of growth in both its staffing and professionalisation (discussed in subsequent chapters) but, since moving to their current space in 2004 their gallery and office space has remained unchanged. My interviews took place in the midst of private board and staff discussions about moving, and dissatisfaction with their current space underscored all conversations I conducted with them. For Enjoy's participants the limitations of the physical space not only misrepresent the organisation as they perceive it currently (appearing more modest and less professional) but also hold Enjoy back from further, desired expansion.

Space, in the context of Enjoy, therefore, is constituted as a lack and a constraint. The aspirations of Enjoy's identity formation are tied into a growth narrative but this was 
not an uncomplicated stance. Interview subjects articulated tensions about the extent and pace of growth, particularly in relation to the demands it would place on an already busy staff, distracting them from their core mission.

that focus on infrastructure is always counterbalanced by other things, a shift away from programming, for example, to a greater amount of discussions on fundraising. So that's always a tension for me and probably for everyone involved in Enjoy. (Davis 2018)

Subjects also expressed the concern that some aspects of their audience would object to expansion, "I know that, if Enjoy did move, there would be support and excitement but it would also be people that didn't want change and didn't want us to move" (Davis 2018). Enjoy's relationship to space is currently threaded through anxieties and hopes around identity formation as they seek out new forms of space that will best represent who they see themselves as becoming. Staff members described a process of consciously re-articulating their role in a wider community, where as employees “you've stepped into 17 years of history and its weight and people are always going to have opinions about everything you do" (Davis 2018).

This section has used examples from two case studies to explore space as a marker of institutional values. The physicality of the artist-run space, therefore, can act as an active agent in its identity formation, whether positively, as a collaborator with exhibiting artists or, negatively, as a perceived impediment to organisational growth. Negotiations to do with space are ongoing, either, as $R M$ experienced, having to move regularly in response to a heightened property market, or, as in Enjoy, growing out of a space as the organisation develops and professionalises.

Certain patterns have emerged from the research discussed, emphasising that the occupation of space can never be neutral, and that space can operate as a node through which theories of identity formation are embodied and actualised. The artistrun space - in contrast to online or peripatetic projects - hinges on its relationship to physical occupation, but these two examples demonstrate that the strategic politicalisation of the space is never fixed, but is renegotiated according to the changing organisational goals of members. As my analysis of $R M$ demonstrates, spatial nodes are not static, but can change with the arrival of new individuals or new situations, such as the institutional rupture that occurred when Nick Spratt left the 
organisation. In a very different relationship to space, Enjoy's staff and board articulated the new identity possibilities that new space could offer them, as a way to facilitate their evolution into a larger, more public organisation.

\section{Finding the Gap: The Artist-Run Exhibition}

Exhibition-making isn't something that you can practice alone or in your head. There needs to be somewhere to experiment with realising exhibitions, both for curators and for artists ... artist-run spaces have the potential to push the exhibition format. (Gordon-Smith 2018)

In this section I examine the exhibition programme as a key node where the artist-run space situates artistic and political positions. I seek to understand how current practitioners of such spaces describe the exhibitions they show, why they consider the work important and how exhibition programme reflects underlying organisational values.

My starting point was the rhetoric of experimentation and risk, which form central tenets within artist-run literature, as outlined in the Introduction and Chapter One. Such narratives expect artist-run culture "to claim space for alternative critical practices" (Morley 2016,77). Amy Griffiths has argued "radical and avant-garde practice and praxis were integral to the formation of these early spaces and collectives" (Griffiths 2012, 12) and the early pioneer artist-run spaces, Gabriele Detterer contends, were linked by a common goal: "the basic idea of free affiliation and exchange between avant-garde artists in order to engage with experimental art practices" (Detterer 2012, 12).

It was my initial assumption that a belief in experimentation and artistic risk would be paramount to the identity formation of each case study. Because of this I tracked the usage of both terms, across interviews and written documentation. The supposition was also significantly based on personal experience with spaces as a younger practitioner, and the sense, as an established curator working in larger public institutions, that artist-run spaces could, and should, exhibit artwork edgier and more difficult than I was able to accommodate in a mainstream exhibition programme. 
I have felt personally invested in the concept of museums as "safe places for unsafe ideas," a museological approach since the 1990s. ${ }^{10}$ The artist-run space, it seemed to me, was the ideal location for such work to be undertaken, with its greater emphasis on artistic agency and less focus on audience development. However, I was surprised at the aversion to my use of the word 'risk' by participants in two of my case studies, and the move against notions of risk emerged as a significant finding. Yet, through this process of deep listening, other terms began to emerge as more relevant for my case studies, and it is through these terms that I began to understand each space's exhibition programme as nuanced and specific.

As Chapter One made explicit, artist-run spaces come in many forms, but the mechanism of the exhibition remains central. Each of my case studies have at least one additional activity they describe as significant - for Enjoy, it is publishing, for Meanwhile the studio programme and online gallery, and for $R M$, historically the artists' archive and more recently public programmes_-but showing art in a gallery space remains at the heart of what they do.

The three case studies all demonstrate established exhibition conventions deployed by smaller public galleries. In the description below Louise Rutledge details not only Enjoy's mode of operation but its prevalence amongst smaller spaces too,

The open call for proposals, the three and a half week shows, ten shows a year, solo presentations, artist talks, a few publications here and there ... I think there's an ease to that structure. (Rutledge 2017)

Despite this commonality, in examining the various official mechanisms by which case studies present themselves, such as online mission statements, different modes of representation are established that signal different strategic agendas. Meanwhile outlines a commitment to "emergent and experimental" art practices that are "exceptional", a value judgment that is ambitious, if only lightly sketched. Enjoy stretches beyond "emerging" to include "established practitioners" to facilitate 
artwork that is "innovative", a key term of artistic value used by Creative New Zealand. $R M$ similarly aims to span "local emerging artists alongside more seasoned practitioners" but instead seeks to engage with "practices, discourses and modes of presentation that aren't well-supported or easily accessible in Auckland".

What, then, does the exhibition look like and how was it described? My analysis took a close reading of 12 months of exhibition programming at each case study, from June 2017 to May 2018. Each space presented both solo and group exhibitions, featuring a range of disciplines, although installation and site-specific practices are most common. The artwork was usually, although not always, temporal in nature and casual in presentation style.

During the data collection period Meanwhile presented 13 exhibitions, all of which were installation, performance or mixed media, apart from one painting show. Their programme demonstrated the most casual display approach of all the spaces, perhaps because, as a collective, they offered the most hands-off approach to monitoring the exhibition as it developed. Sean Burn declared that most of the time the collective would know little about the show until it was being installed in the gallery.

Which makes it quite fun. We just trust them. Because why we've selected them or why we've given them the space to do what they want is because we like their work or even just the energy of what they've proposed, even if it wasn't exactly clear what the final result of the work was going to be, we just appreciated the energy of the ideas they wanted to bring. (Burn 2017)

Enjoy similarly conducted 13 shows, across a broader spectrum of media: one painting, one painting with sculpture, one photography, a group fundraiser, and the remaining nine shows were mixed media, installation or performance. The programme is set by the curator/manager, from a mixture of submitted proposals and direct invitations to artists, and signed off by the board. Bringing together a year's exhibition programme will take into account "where they're from, say Auckland or Wellington, so there's a lot of different things to consider, across [a range of] media" (Rutledge 2017). The process of working with artists was hands-on for both staff members leading up the exhibition, but while Louise Rutledge suggested that risk was largely something to be anticipated and mitigated, there remained the possibility of the unexpected. 
[An artist] might propose a project but in the proposal it might not state what the material outcomes of the work may be, so we take a chance on them, looking at their past work "that looks great, and the research looks really good".

$R M$ hosted ten shows and one summer residency without a public showing. All their shows took the form of installation, performance or mixed media group exhibitions. Each show is allocated a member as their key liaison, "you have to sort things out for that and delegate if you need to. You'll be in contact with the artist or artists. You'll be the support person for that specific show" (Morgan 2018). The level of involvement varies depending on the nature and experience of the individual exhibitor, "do you want my involvement or not? I think we should make the effort to suggest things, if we feel like that might be helpful" (Morgan 2018).

The $R M$ exhibition programme is generated from an annual or six-monthly open call for proposals, from which selections are then made at an all-day meeting of codirectors. Participants express particular support for artwork of a political and social nature "I think that a lot of people who have socially-based practices see $R M$ as politically aligning with and supporting their practices which it does" (Sanders 2018). Deborah Rundle describes their selection process as being "mindful for where power sits within the arts community and society in general" although she noted they would also seek "a diversity of programme for interest and for quality of the proposals and probably some elements of risk and exploration ... organic rather than structural, but with a framework for bringing our values to the fore."

Meanwhile were the only case study to use the word "experimental" in the official narratives quoted above and the word experimental was stressed by all participants, expressed, for example, in Sean Burn's statement that Meanwhile, "try and be as experimental and open and as free as we want and give people as much agency over the work that they do". Similarly, Louisa Afoa describes $R M$ as "a place where young artists can experiment, or even older artists that are working on new work, and take risks because they don't have the type of pressure, I guess from other galleries" (Afoa 2018).

Both Enjoy staff used the word experimentation in relation to Enjoy's activities but felt that it was less a priority than it had been previously. Louise Rutledge argues 
Enjoy is "a platform for experimentation, to test ideas, but perhaps less so than in the early days" (Rutledge 2017) and Sophie Davis notes "it's hard to be truly experimental sometimes when we've got a list of KPIs that we're trying to bang out" (Davis 2017). For each of them, experimentation was a concept tied to the early development of the space, before funding had formalised expectations.

Experimentation was a state they still personally aspired to, but it felt less attainable as the organisation had grown

Enabling artist risk-taking through exhibition making was the other element I questioned participants about, as I was surprised that only one subject directly used the term themselves without prompting. This was Louisa Afoa, who argues that $R M$ is "a place where young artists can experiment, or even older artists that are working on new work, and take risks". Other $R M$ co-directors interviewed said they did not personally use the term, but, when asked, felt that it represented a creative ethos they aspired to "we do talk about the fact that it's important that $R M$ has a different voice. And it can't be a voice as one" (Rundle 2017). RM's interview subjects were comfortable with the notion of risk attributed to their artistic strategies, although they did not feel a strong affiliation with the word.

Enjoy had a different perspective on risk, with most of the staff and board discussing the word in relation to health and safety, despite risk being highlighted in their most recent Creative New Zealand funding application, "we play an important role providing a 'safe space for risk taking"' (Enjoy Trust 2016, n.pag.). Louise Rutledge cites recent changes in the health and safety legislation as having impacted their programme, stating,

I think now, particularly with the changes in the health and safety legislation, I think the liability of boards and of board members is a lot more pronounced. It changed the responsibility that board members have and they're potentially more responsible if something happened. They've become more formalised in their approach to certain decisions. (Rutledge 2017)

Trust member Jess Hubbard brought a wider perspective to the notion of risk, considering it in relation to the age and established nature of the space.

I think, because we are a space for emerging artists, that has been around for a long time, and is so dependant on funding, we are probably more risk averse than if we were a brand new space that wasn't dependant on those things. We probably think about the risk of things that we do more and I think we're 
probably structured to a certain degree on needing to produce certain things over the year that, I think, if we had no funding and no measures to meet, we might do differently. (Hubbard 2017)

Jess Hubbard (in her 30s) identifies risk with younger practitioners, stating,

I think the younger you are, the more risk you're willing to take. The older you get the more you see what happens when things go wrong and you get more scared of taking risks. So if everyone on the Trust Board was young, I feel like it would probably be a very different gallery because I think people might be much more willing to go much more out. (Ibid.)

In sharp contrast, Meanwhile's co-founder, Jesse Bowling, became very animated when I asked him about risk, declaring that "I don't think Meanwhile's interested in risk. I'm not interested in risk, I'm more interested in supporting solid, emerging contemporary art, rather than taking risks, like we could do this really weird show. I think that's important now, to make sure your space is safe". At the time of our interview, Bowling and his fellow Meanwhile members were in the middle of generating a number of strategic, organisational documents, including a Safer Spaces Policy. This policy supports and reinforces his assertions that safety, of exhibiting and studio artists, is paramount for the gallery. In this sense, safety is less about a physical state of wellbeing but instead focuses on culture and identity.

As a visitor / volunteer / exhibiting artist / studio artist of Meanwhile we ask that you take responsibility for your behaviour and privilege by understanding the ways it can affect others. Meanwhile is a place of work and we ask that you respect our studio artists' space and productivity. We encourage innovative practice, but not at the cost of alienating or harming others ... People who are unwilling to discuss and correct their harmful behaviour will be immediately excluded from Meanwhile events (Meanwhile 2018, n.pag.).

Dilohana Lekamge describes the role of the policy: "if anything were to arise, interpersonally or whatever, if there was ever an issue, we have a guideline". Potential issues that might occur are listed as including

Racist, sexist, classist, transphobic, homophobic, ableist, fatphobic or religiously bigoted comments of any kind. Failure to respect the physical and/or emotional safety of others. Entering into studio artists space without consent. Sexual violence ... (Meanwhile 2018, n.pag.)

This emphasis is a new development in artist-run culture, running counter to a longstanding narrative about artistic freedom which has valued risk taking as a measure of "alternative art insurgency" (Goldbard 2002, 192). The policy reinforces 
participants' interest in challenging concepts of heteronormativity, and the ways in which normalisation processes can marginalise those who "have been deemed as deviating from the preferred societal norms of whiteness, heterosexuality and ablebodiedness" (McDonald 2015, 318). Meanwhile participant Dilohana Lekamge argued,

Meanwhile has always been a space that really cares about its audience and its artists. I think we have an opportunity here to expand Meanwhile ... I want us to support the artists that are doing the kind of work that expands audiences and makes galleries more inclusive. (Lekamge 2018)

Otherness, for Meanwhile, is strongly connected to notions of safety as a mechanism to enable conversations of difference to occur. Participant Simon Gennard has written of the development of "new strategies for survival, care and sexual encounter", positing that Aotearoa has experienced "a radical shift in societal attitudes towards queerness ... as well as an expansion of the vocabulary used to consider the complications, contradictions and subtleties of sexual identity" (Gennard 2018, n.pag.). The changes demonstrated by Meanwhile occur at a time when the international \#MeToo campaign and related questions around gender safety are changing wider cultural norms, much as the term "cultural safety" signalled a major shift in understanding of cultural identity in this country since the $1980 \mathrm{~s} .{ }^{11}$ This emerged as a significant finding of the research, pointing to a changing context for artist-run culture that is explored further in later chapters.

What, then, were the terms the spaces most commonly deployed to describe the exhibitions they programmed? Both $R M$ and Meanwhile participants utlised a spatial metaphor of 'a gap' when describing their selection process "being able to show what we felt wasn't being seen ... what wasn't being offered around us" (Spratt 2018) and "people who wouldn't otherwise have opportunities to show work". Meanwhile cofounder Jesse Bowling described a process of finding the gaps in the existing artistic landscape.

What don't we get to see in Wellington? Who are the artists that we look at, and they do really good work but they don't get to show, because one, it's not commercial enough, or two, there's no space for it. More conceptually driven, experimental projects. (Bowling 2017) 
Louisa Afoa similarly states, "I see $R M$ as a place that creates platforms for young artists, or for people that we feel need to be represented that aren't being represented in any other spaces that we're seeing”. Deborah Rundle agrees, arguing “there has to be a good reason for $R M$ to exist, otherwise it's a lot of work replicating something that could be elsewhere". Understanding and retaining gaps in the mainstream art narrative is therefore a major part of both galleries' sense of organisational identity. For Louisa Afoa, the discussion that happens when the group comes together is what enables those gaps to become visible,

because we all have different ways of seeing the world and having different practices that we want to advocate for, it becomes a really ... I don't really want to use the D-word, 'diverse', but you know, it becomes a programme that reflects all those different people. (Afoa 2018)

One of those gaps was in representation of a wider cultural diversity in exhibited artists, although this gap was only noted by New Zealand Samoan artist Louisa Afoa and New Zealand Indian artist Dilohana Lekamge. "Like me being Pacific, I'll always advocate for Pacific representation. People of colour in the space" (Afoa 2018). The gap for Lekamge was specifically in the Eurocentic nature of the art world, and, by extension, the artist-run space movement,

that's always been something I've tried to challenge, with my own practice and with my art writing. I chose to support and write for artists who have a similar vision to me in the sense of fucking with that standard and that hierarchy. And that's what I've always been passionate about and I want to continue to support artists who do that. (Lekamge 2018)

But the gap is not static. Instead, the art practices, and types of artists, that constitute a gap need to be constantly re-negotiated, as new spaces open and different exhibiting platforms emerge around them.

Artists being artists, they would tend to take whatever opportunity came their way. Sometimes it was really disheartening, to think we'd finally got this show that was coming up that we were really excited by, by this artist who offered something different, and suddenly they were popping up in a whole bunch of other galleries. (Spratt 2018)

The notion of a gap emphasises responsiveness to a wider community, and working within gaps requires regular assessment of the broader conditions within which artists are operating. Programming exhibitions and events only a short time ahead enables 
the galleries to be nimble and to readjust as the gap moves, "I'm seeing this happening now, and we have the space, let's put it on now. We have the freedom to do that" (Morgan 2018). In this way, for these two artist-run spaces, the idea of occupying an alternative position is heavily reliant on, and determined in relation to, the existing gatekeeping of the mainstream art world.

Enjoy did not use the terminology of filling a gap, instead, their focus was artist development, artistically and professionally, to "develop careers and enhance the reception and impact of the work of the talented artists, writers and curators, we engage with" (Shelton 2018). Development was a word used by interview subjects to describe both the artistic process an artist might undertake through them "we commission and develop new work" (Rutledge 2018) but it also underscored a mentoring relationship between staff and exhibiting artists "which is beneficial to them and their development" (Shelton 2018). Such development emphasised Enjoy's placement within a wider network and their ability to leverage opportunities for emerging artists.

Artists step up their ambition, as well, knowing that Wellington has such a supportive art scene and some of the dealers and all of the public gallery curators come and see the shows when they can. They're at the openings; they're at the talks. I think the artists that show at Enjoy know that they're getting their work in front of some good eyes. But I think those moments when you first get paid for your work, there's a real validation to artists at that level. (Lacey 2018)

The schism between the two positions, between finding and occupying the gap and getting artwork "in front of some good eyes", reached a particular nexus of tension in a recent exhibition which participants in both Enjoy and Meanwhile brought up in their interviews, using the exhibition as metaphor for larger positions. The Tomorow People, at Wellington's Adam Art Gallery, surveyed a generation of New Zealand artists born after 1990, seeking to highlight new modes of practice. The exhibition was co-curated by Gallery Director Christina Barton with Gallery Curator Stephen Cleland and younger freelance curator Simon Gennard, who subsequently became a member of Meanwhile. For Jesse Bowling, however, the process was simple: "Tina picked a lot of artists out of our shows and put them in the Adam show". Bowling argues that the exhibition drew directly on artist-run programming, co-opting grassroots activity for its own institutional means, and in doing so, did not acknowledge the environment that had nurtured that activity. Reviewer Chloe 
Geoghegan shared Bowling's concerns, writing in a review for Pantograph Punch that,

A great deal of the work in The Tomorrow People has been pulled straight from 2017 independent project space programmes... By lifting works from extremely recent debuts, these smaller commissioning spaces - fighting to be relevant in the niche nexus - start to function as nurseries for larger institutions to pick over without a further thought. (Geoghegan 2017, n.pag.)

But Enjoy's Louise Rutledge framed this situation quite differently, describing The Tomorrow People as an example of the impact Enjoy can enable, beyond the gallery space, "people look to us to see who [the new artists] are, that's really evident when works and artists are picked up and shown somewhere else". For Rutledge, the inclusion of a number of emerging artists from their programme in The Tomorrow People showed Enjoy's crucial importance as a development agency. 


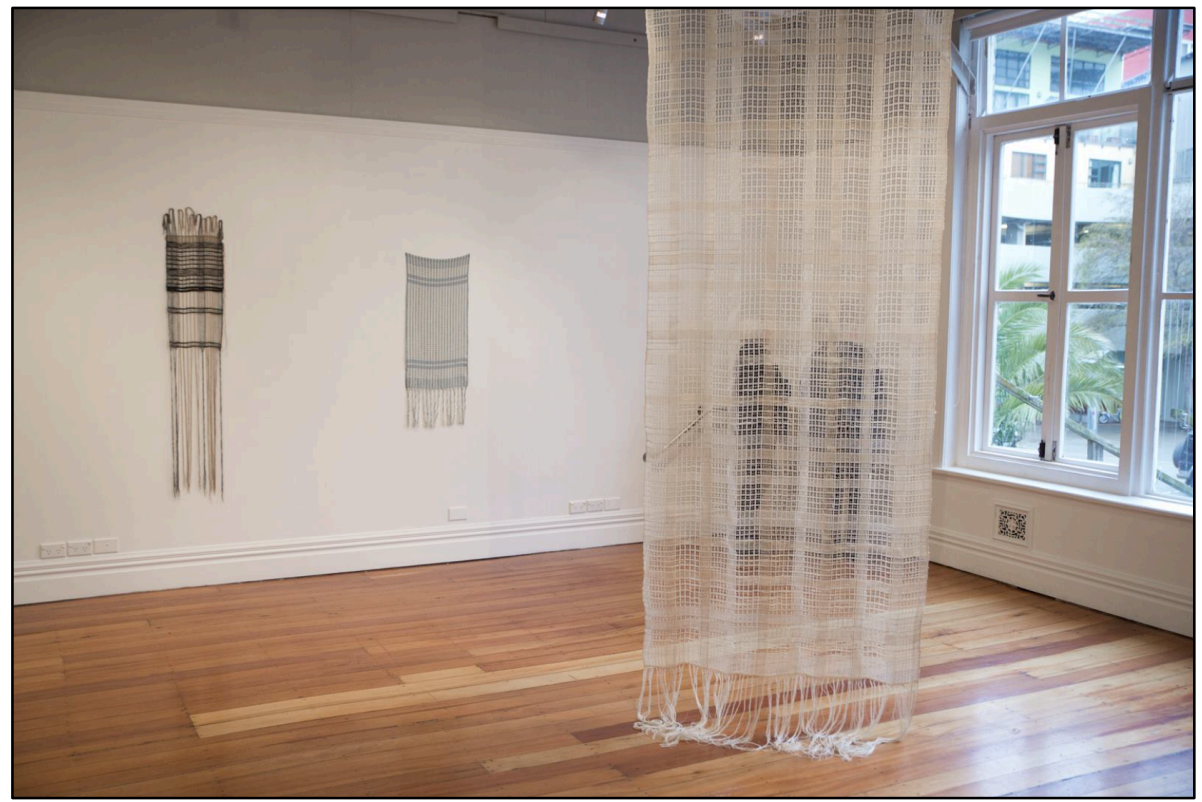

Walking Forwards Backwards, Annie Mackenzie, Enjoy, 2016. Photographer Shaun Matthews, Photo: Enjoy archives

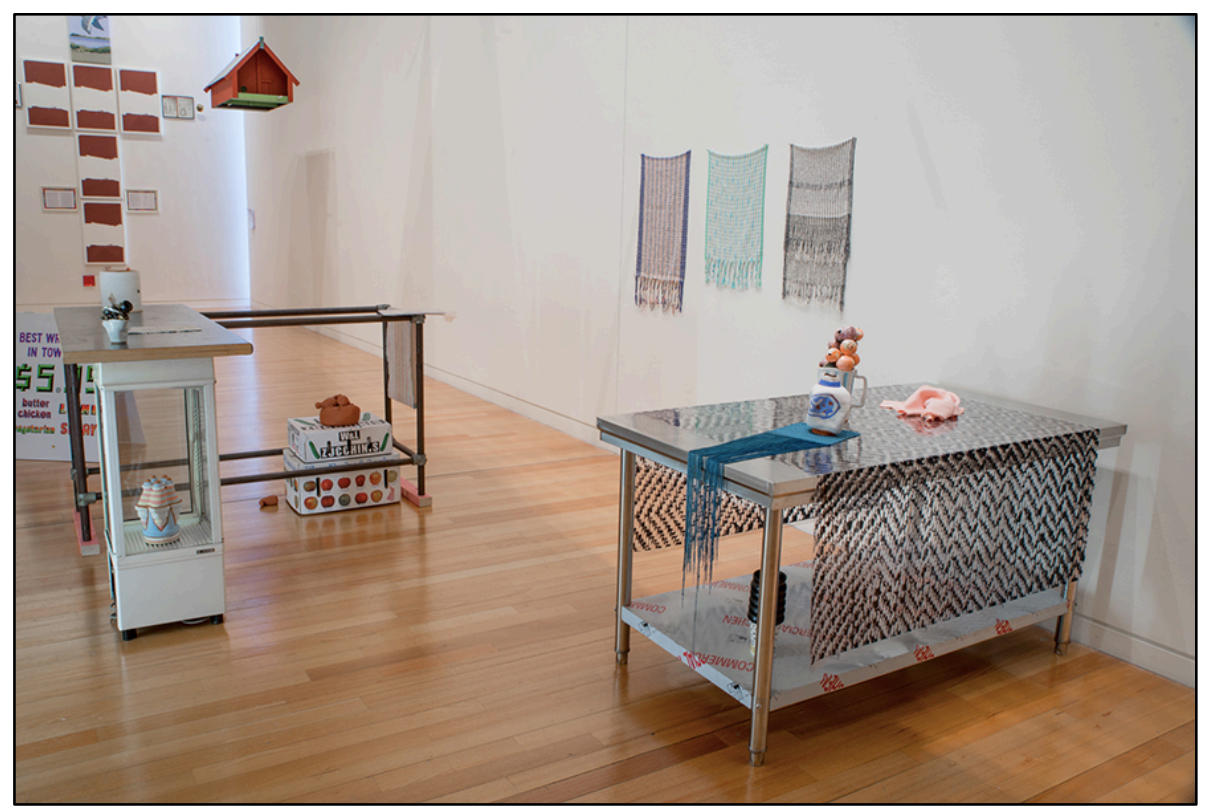

Annie Mackenzie and Dave Marshall (detail from The Tomorrow People), Adam Art Gallery, 2017. Photographer Shaun Mathews, Photo: Adam Art Gallery 
Certainly, the original exhibition context for each work was not acknowledged in the gallery texts, and discernible only to regular visitors to the smaller spaces. Cherrypicked from existing networks and stripped of their original context, The Tomorrow People demonstrated the way in which artist-run spaces have the potential to be rendered invisible as structures in the wider art project, despite the close relationship they might maintain with larger public institutions, as demonstrated in Chapter Two. Puerto Rican artist Papo Colo once described museums as hungry creatures "that use their influence, compete, and swallow small places like alternative spaces" (Colo 2012, 11).

$R M$ participants were similarly reluctant to connect the success of an exhibition at their space with resulting professional opportunities for the exhibiting artist. Daniel Sanders declared, "I'm personally really not interested in that game when it comes to this gallery" although he was quick to add, "it's fantastic for the artists if they picked up afterwards and get all these opportunities". Success, for Sanders, emerged from the exhibition itself, "as long as the actual work and the ideas around the show are fully realised, that is more what I'm interested in" (Sanders 2018). Fellow facilitator Louisa Afoa agreed, declaring, "we're not trying to make the next big thing. We are just trying to accommodate and create conversations. Conversations that we feel aren't really happening [elsewhere]" (Afoa 2018).

Such tactics can be read in the light of curator Maria Lind's call for "a certain strategic separation" (Lind 2010, 76) which argues for small institutions to "turn their backs upon the expectation to be constantly and immediately accessible" (78). When considered through the lens of a strategic separation I argue that RM and Meanwhile's stance can be understood, not as oversight or failure to operate strategically, but rather as a highly deliberate positioning which seeks to resist conventional career narratives, and which prioritises the artistic contribution of the exhibition to a community of users, rather than its generative possibilities for the individual artist's career.

For all participants, then, the wider art world is a dominant force in determining their exhibition activities, whether it is through defining their own absence through the mechanism of the gap, or through situating themselves as entry point or stepping stone in a broader ecology. But, while the exhibition mechanisms for all three spaces 
might appear the same (and indeed some of the same artists were to be found across all three programmes as detailed below) the intentions and goals for Enjoy were very different to that of $R M$ and Meanwhile. How they understood and measured success in their programming signals a larger shift in institutional values, which is discussed in detail in the following chapters.

\section{A Wider Network}

Intimate institutions based on kinship and sociability—clubs, neighbourhoods, domestic partnerships - require trust, a trust that has been significantly undermined by a capitalist system of overproduction that quantifies and commodifies all social relations and exchange. (Sherlock 2013, 19)

I visit $R M$ one morning in October, making my way down Samoa Lane to climb the steep stairs to the airy white space above. The volunteer in the office looks up from his laptop, and says 'hi', but does not initiate further conversation. Later, when I venture into the office to chat, he tells me he's Ary Jansen, an art student, with a regular weekly slot in the office at $R M$. Much later still, I realise I've just missed an exhibition of his work held here the month before, ${ }^{12}$ which co-facilitator Jess Morgan tells me was a defining exhibition for her. She enthuses "it was so responsive and so relevant. I think that really shows what we can do" (Morgan 2018).

I sit across the large table from Ary for the afternoon, working my way slowly through the shelves of boxes that comprise the $R M$ archive. The sun slants in, the room is quiet and only one other person makes the trip up the stairs to view the exhibition. I find several notebooks used in the mid-2000s and written in each day by the gallery invigilator. The books operate as a shared, virtual meeting place, with updates, queries and suggestions by members recorded. While entries are not usually signed, making it difficult to understand who is saying what, taken together they provide insight into the connectedness of gallery visitation, with not only daily numbers noted, but often individual details of each visitor. For example, Thursday 6 April 2006 records the following visitors, 
a guy who heard the interview on the radio with Margot and Fiona. John Reynolds and his assistant Elliot ${ }^{13}$. Simon McIntyre ${ }^{14}$. Fiona's dad ${ }^{15}$. Dodgy looking street guy. (RM 2006)

As the overall tally for the day's visitation is six, and each has been documented in some form, it constitutes a high level of audience mapping. I show one of the notebooks to Ary, who is intrigued, mostly, I think, at its acutely analogue nature. Nowadays, he muses, day-to-day communication on manning the space is largely conducted by text message or the Facebook messenger service.

13 Elliot Collins, now an exhibiting artist in his own right, worked for a period in 2006 with John Reynolds at his studio in Achilles House.

14 Painter and lecturer at AUT's School of Art and Design.

15 Probably Fiona Connor, artist and co-founder of artist-run spaces Special and Gambia Castle. 


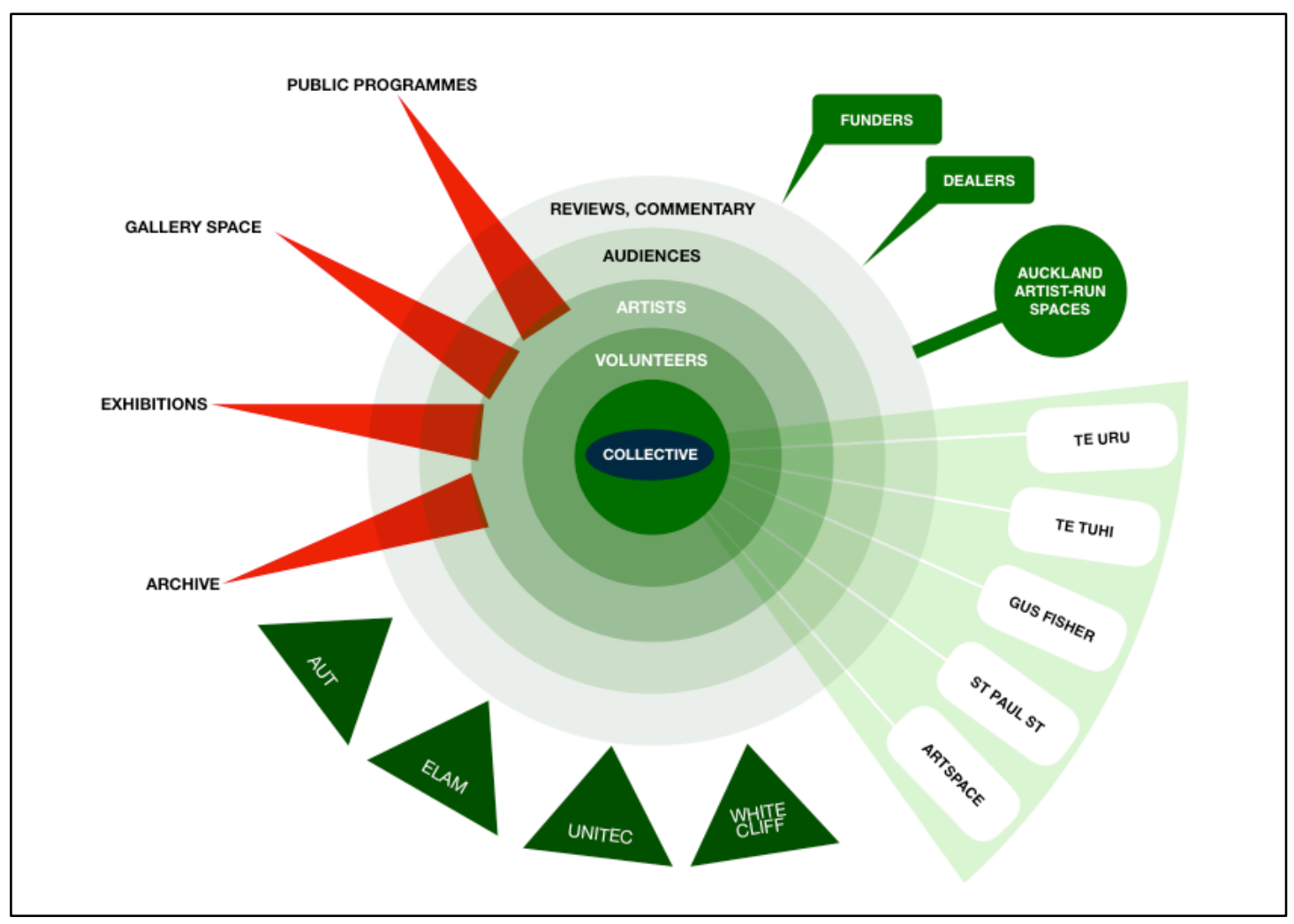

$R M$ Imagined as an Assemblage, 2018 
The intimacy implied between artist-run space and audience could be read as what cofounder of artist-run space Canapé Canopy (Auckland 2016) Daphne Simons dismissively calls "the feedback loop that some artist-run spaces create" (Simons 2017,20 ) but it's important to consider that this is an art world of connected and overlapping scenes, or, as New Zealand artist Gabrielle Amodeo has called them, "loosely connected nodes of self-determination" (Amodeo 2016, 64). An artist-run space doesn't stand alone, unconnected from a wider scene, at least not for long, as former Enjoy Curator/Manager Emma Ng noted, "artists move fluidly between art spaces, forming interconnected networks of related practices and spaces" ( $\mathrm{Ng} 2016$, 16). Similarly, New Zealand curator Abby Cunnane advocates for galleries to be considered, "not as a discrete entity but as a network, as a decentralised field within which our mobility as individuals is both possible and necessary" (Cunnane 2014, n.pag.).

Connections and overlaps, both in operations and exhibition programmes are apparent between my case study spaces. A few examples: over the last year, $R M$ co-Facilitator Daniel Sanders and former $R M$ co-Director Natasha Matila-Smith both exhibited at Meanwhile ${ }^{16}$ and co-founder of Meanwhile, Callum Devlin, exhibited at Enjoy. ${ }^{17}$ Australian artist, Shivanjani Lal opened the exhibition yahaan se dekhen at $R M$ in November 2017 and The Raft at Meanwhile in June 2018. Lal's exhibitions shared strong visual and conceptual similarities, floor-based installations that deployed scent and spices as a strong element (Meanwhile's show involving 15 kilograms of turmeric) and focused on narratives of cultural distance and belonging. My experience of the two exhibitions, however, felt quite different, her work spreading out in the light-filled spacious $R M$, while it was more compact and intense in the smaller, rougher environment of Meanwhile.

If the exhibition is the core of an artist-run space, the exhibition opening is the moment the work is activated by an audience. "People like to come to the openings" says Meanwhile's Dilohana Lekamge, “because there's booze and you get to see your mates". Curator Melanie Oliver agrees, stating, 
People just need to get together over a free glass of cheap beer, and talk about what they're looking at, about what they're making, about what they're reading, all of those things ... I think physical spaces are important. (2017)

The opening is usually held the night before the exhibition officially opens to the public with an invited list of guests that includes collective members, studio artists, exhibiting artists and their friends and families, and several layers of artists, curators, writers, people from other artist-run spaces and gallerists. Typically, an opening at an artist-run space is an informal occasion, with free alcohol ${ }^{18}$ and an absence of speeches or formal proceedings.

The exhibition opening is where central characters in an art assemblage come together, to view art, to talk about art, to see and be seen. Becker's analysis of the social networks of contemporary art (1982) emphasises hierarchies and boundaries among various players, and the accounts provided by participants in artist-runs reveal a complex meshing of community building and anxieties around access and belonging. As facilitators, board members or staff, the people I interviewed experienced a deep connection to their space's community, but a couple of participants expressed concern that "It's always been quite a welcoming space for me but I also understand that I'm a Massey [University] graduate and these are all my mates, so I'm pretty lucky to easily feel welcome here" (Lekamge 2018). Tensions regarding the audiences and participants for artist-run spaces are discussed in greater depth in Chapter Three. 


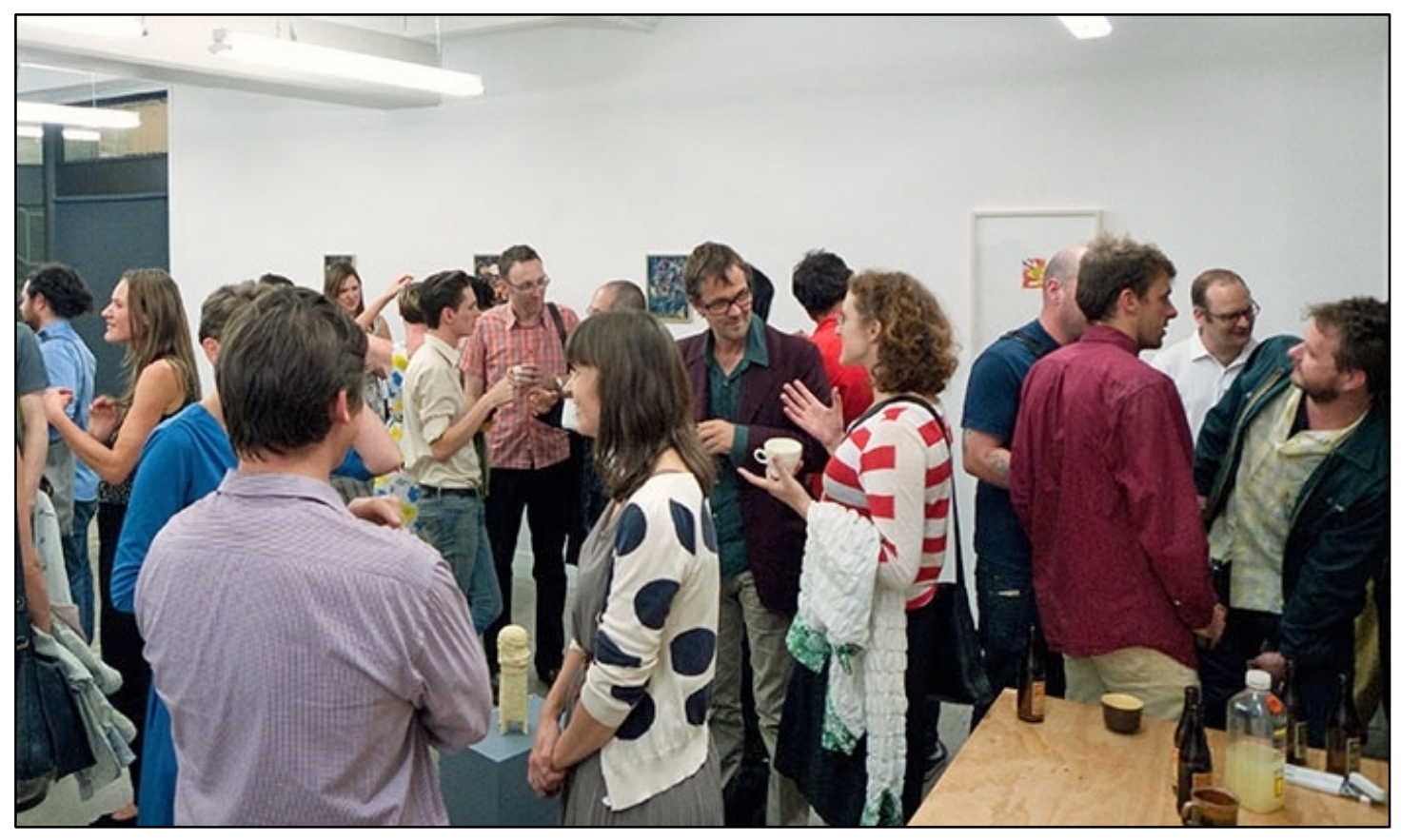

Opening of Timber Trophy: Kirstin Carlin and Carina Brand, RM, 2011. Photo: Sait Akkirman and Arts Diary

The social element associated with the life of an artist-run was affirmed by all interview subjects, who saw it as one of the most crucial elements in their participation. As curator Ioana Gordon-Smith notes, "artist-run spaces are fundamental in terms of sustaining artistic communities and ensuring that artists aren't working in isolation". Writing about her time as a staff member at Enjoy curator Bopha Chhay reflects,

it enabled a space where hospitality, impromptu gatherings and informal congregation held equal weight [with exhibition making] ... These temporal and spatial moments articulate a shared condition that are not always legible or accounted for formally. (Chhay 2016, 32)

While each space was started by a loose group of friends, its evolution reaches out beyond an inner circle, and the process of building a core community must be repeated each time. Both $R M$ and Meanwhile recently undertook an open call process to recruit new members, with the aim of opening up and expanding beyond their immediate networks. This was a significant departure for $R M$ for whom the process of succession had traditionally been conducted by more fluid methods "previously the person that would leave would kind of shoulder-tap or suggest a new person to take their place" (Afoa 2018). 
We made a decision, which I was really keen on, instead of shoulder-tapping or inviting people, I was really keen that we advertise, that we invite people to step forward with their enthusiasm, because I think that one of the things about an artist-run space is that it offers the opportunity to speak to difference and speak to a wider reach, and if you do it by invitation, then you speak to what you already know. (Rundle 2017)

Whereas like having an open call, it was great to just like give everyone an opportunity to be a part of the space. We didn't have interviews, we just kind of, like, vibed it off the proposals and picked our new members. (Afoa 2018)

At the time of interviewing, $R M$ had expanded from a group of three to a larger circle of seven, which was in the process of establishing itself "it was comfortable-ish with everyone, but we weren't all close. I think now we're getting more comfortable with each other" (Morgan 2018). "It's been awesome to have that kind of cross-learning between different people's experiences. It's been really cool" (Sanders 2018).

Relationships and systems were being reformed, with an upcoming day evaluating exhibition proposals identified as a significant moment in building a sense of community.

Because we've got such a great, a new team, I feel like it's going to be like a really great way of kind of, like, understanding where everyone else is coming from as well. Yeah, kind of like team bonding in a way. I'm actually looking forward to it. (Afoa 2018)

RM GALLERY AND PROJECT SPACE SEEKS INTERESTED PEOPLE TO JOIN THE RM COLLECTIVE

Established in 1997, RM is the longest running artist-run- space in Aotearoa/New Zealand. RM is a gallery that supports the work of local emerging artists as well as operating as an experimental site for more seasoned practitioners. Exhibitions, offsite projects, archive residencies and events that respond to contemporary political, social and artistic issues are all

part of the RM calendar. We actively engage with practices, discourses and modes of presentation that sit outside of a more mainstream conversation.

If you would like to contribute your energy to the running of RM, then we would very much like to hear from you. Please send a short application to info@rm103.org by midnight of Sunday 24th September. Please include a description of the interests and skills that you would like to bring to the collective. You are

welcome to include images, testimonial, references and anything else that you

consider to be relevant, but please ensure that you are succinct and that the

information is in the form of a PDF document.

We look forward to hearing from you.

Call to join the $R M$ Collective, $R M$ instagram post, 18.09.2017 
Meanwhile's open call was a more formalised process and represented the first major intake of new members since founding (Sean Burn had previously replaced Callum Devlin).

We did six interviews, we talked them through the weird contract-facilitator thing that we were trying to write, and then we posed some questions to them, like 'what would you bring to the space', 'what about the space interests you in applying here'. (Bowling 2018)

While this process was designed to reach outside the space's immediate networks, the three new appointments, Laura Duffy, Simon Gennard and Dilohana Lekamge, all had existing relationships with the space, Duffy and Lekamge through the studio artist programme and Gennard through curating an exhibition there.

Jordana asked me to apply. I didn't really think about it ... but I'd had the chance to work with Meanwhile, a few months prior, when I curated a show for them and I was really interested in the generosity they brought to working with artists and also in ways in that projects were artist-led.

While Meanwhile, from my perspective, represented a tight community of largely recent graduates from Massey University, who are friends, Jordana Bragg rejected this reading, stating "I feel that our community varies organically and dramatically from show to show". However, Bragg concedes, "one core I can absolutely identify would be the contemporary makers whom we have been lucky enough to support through offering studio space and use of Meanwhile for exhibitions". 


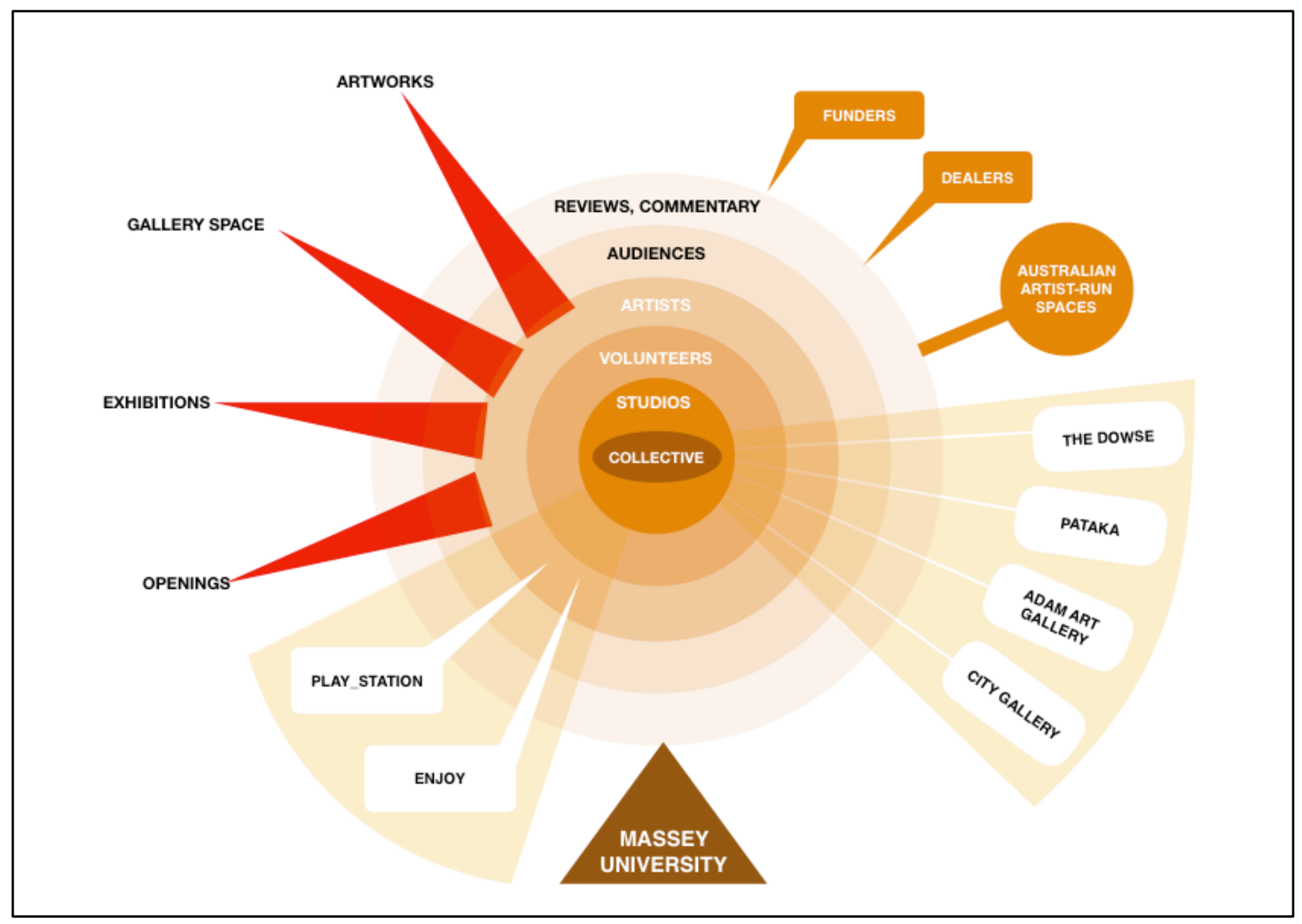

Meanwhile Imagined as an Assemblage, 2018 
Sean Burn outlined a multi-tiered approach to Meanwhile's community, with facilitators at the core, then studio artists, volunteers and after that the exhibiting artists and surrounding that, the audience. They positioned volunteering as a crucial way to gain access to the inner circle. "It's an opportunity to get a little bit closer, see behind the scenes ... we always try to connect them as much as we can, if they turn up to events we try and introduce them to people or bring them into the community".

Meanwhile cite multiple layers of community; first the collective members themselves, then the studio artists, volunteers, the people attending openings, then general audiences that come to the shows. The special relationship studio artists have with the gallery space was emphasised by all members of the collective interviewed, as Dilohana Lekamge comments, "it's important that they're heard, because they help pay the rent that helps us run the space ... they need to be a priority, so we also run all decisions past our studio artists" (Lekamge 2018).

Meanwhile participants interviewed reinforced the idea that studio artists represented a formal tier of membership which sat below the co-facilitators in terms of access and agency, but who must be consulted by facilitators about organisational decisions. Jesse Bowling highlighted the role of the annual 'Party' series of shows, featuring all studio artists, past and present, for "giving privilege and some power back to the studio artists, who essentially fund the space, and giving them the opportunity and the voice". Studio artists can, like Dilohana Lekamge, move from the role of partial insider to the position of co-facilitator, and this was perceived as strengthening Lekamge's position, because of her unique insight into the organisation.

The many-layered connections between spaces are typical of New Zealand's art ecology, where the geographic reach is small enough for artists to easily move between cities and, within a city, artists can operate as exhibitors and audience for a wide range of institutions. Framed largely by city boundaries, the relationships an artist-run space participate in can cut across hierarchies, with Enjoy staff and board citing close contact with City Gallery Wellington (where Jordana Bragg also works as a gallery attendant, as does Meanwhile's Simon Gennard), The Dowse Art Museum and Victoria University's Adam Art Gallery. 
Louise Rutledge identifies the recent emergence of two new artist-run spaces in Wellington (Meanwhile and Play_Station) as fleshing out the terrain and creating the possibility for more specialisation. "Having the new spaces", she argues, "has definitely taken some of the pressure off [Enjoy] needing to be all the things to a lot of different people" (Rutledge 2017). 


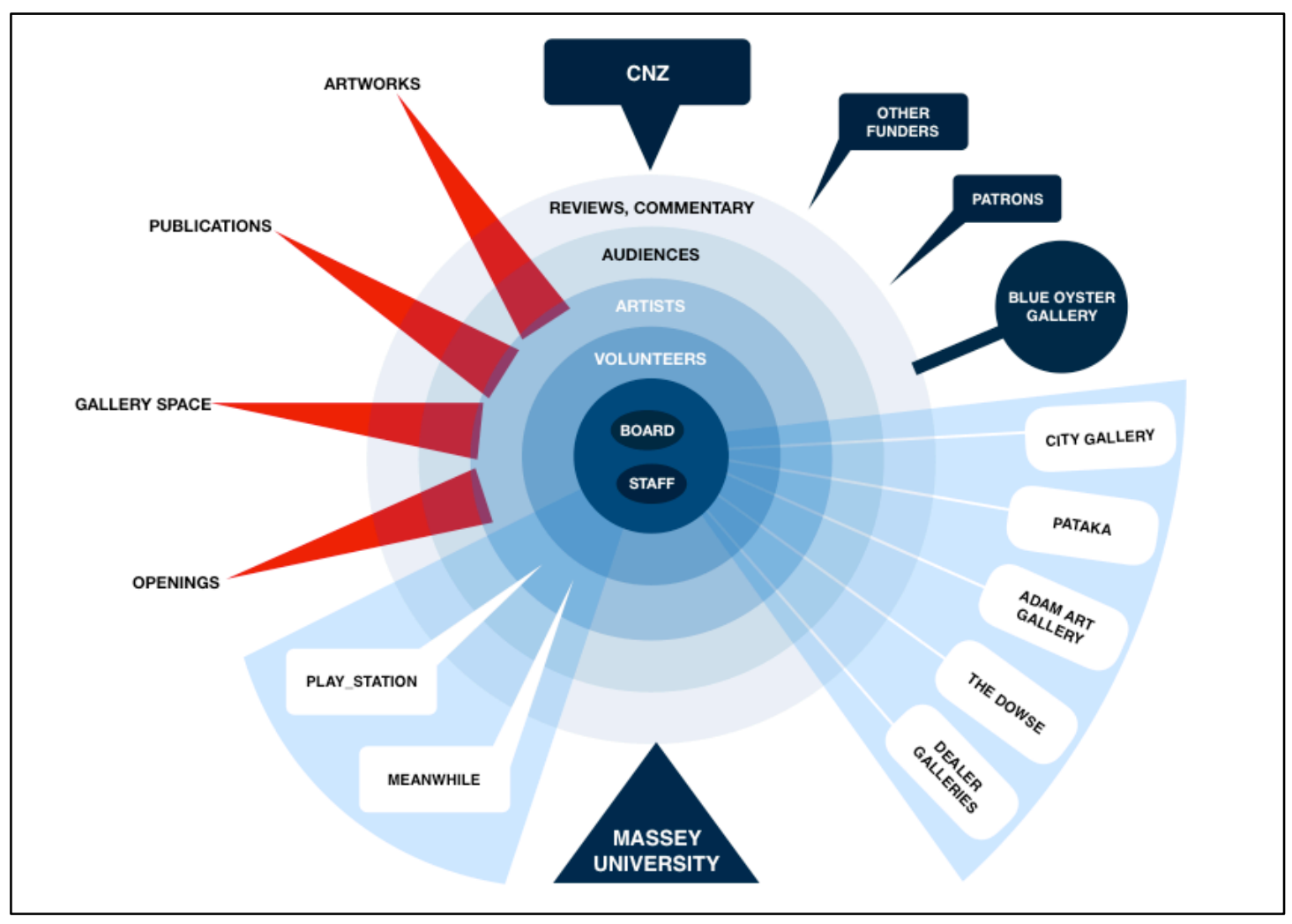

Enjoy Imagined as an Assemblage 2018 
Meanwhile are reluctant to term themselves as Enjoy's little sibling, most of the participants emphasising difference rather than similarities. Bowling is particularly critical, having previously stated "Enjoy seeks to fill that gap of 'ARI' but they have an agenda and a board they have to live up to, not to mention attract numbers through the door ... here at Meanwhile we are free of those institutional cobwebs" (Bowling 2016). What exactly constitutes institutional cobwebs for Bowling? In his interview he outlines the desire to "surpass Enjoy, if we can be a more progressive model". This translates for him as an emphasis on transparency and being "more open about how it functions" with a "more diverse range of facilitators ... who talk about all the fundamentals. It should be that everyone deals with everything”. (Bowling 2018)

Jordana Bragg, implicated in a very different way through their status as both cofounder of Meanwhile and current member of the Enjoy Trust, was guarded when asked about the relationship between the two spaces, their answer giving the impression of a more scripted response.

As a much younger space Meanwhile is connected to Enjoy by proximity and an admiration for such a sustainable, progressive and positive model for emerging artist run spaces in Aotearoa. (Bragg 2018)

In conversations prior to the formal interview Bragg was freer in their responses, and I speculated that they were mindful of the anxiety expressed by Enjoy Chairperson Ann Shelton, that staff and board members might speak out of turn, and sought to monitor their comments. Through the pressure of needing to speak about and for two artist-run communities (although I only interviewed them about their role at Meanwhile) Bragg appeared less able to speak for either.

As the youngest member currently serving on the Board of Enjoy, as well as its first non-binary member, Bragg occupys a position arguably less stable than their place as a co-founder of Meanwhile. Bragg's own art career is also entwined with Ann Shelton's, in that they had acted as the performer in an artwork by Shelton which was presented at the Christchurch Art Gallery, Bragg's first involvement at that institution (they would go on to be included in the exhibitions We Do This (2018) and The Devil's Blind Spot: Recent Strategies in New Zealand Photography (2017)). Bragg had only recently graduated from Massey University, where Shelton was a wellknown senior lecturer. 
I was mindful that Bragg had not been approved as an interview subject by Shelton, and was therefore only permitted to discuss any topic from their perspective as a Meanwhile facilitator ("I am hesitant to make a direct claim or comparison between what Enjoy has established and the model Meanwhile currently has"). Difficulties and struggles over power relations between the Enjoy Trust and staff, past and present, are discussed further in Chapter Four.

Members of both Meanwhile and Enjoy appeared more anxious to carefully mark out boundaries between their spaces than $R M$ 's members did—although, or perhaps because, $R M$ operates in a much larger city with a greater number of (historic and current) spaces located within it. In contrast, Jess Morgan spoke easily and enthusiastically of $R M$ 's relationship with their larger, and more influential neighbour, Artspace; “we need a ladder!” They'll be like, “yeah, that's fine” (Morgan 2018) while Louisa Afoa cheerfully said "they're like our aunty, basically".

Cause they're right across the road, and so they look out for us, and because with our CNZ funding, we can't really get equipment, and so they've been a really great help of, like, loaning equipment and they'll come to our exhibition openings and we'll go to theirs. (2018)

Meanwhile described a supportive relationship with larger, more established Wellington institutions, with The Dowse Art Museum and City Gallery Wellington regularly loaning equipment. While Meanwhile's openings may be less studded with institutional gatekeepers, close examination of their recent Boosted fundraising campaign reveals a significant level of support from institutional leaders, ${ }^{19}$ as Simon Gennard confirms, "older, more established people in the industry have supported us and shared our Boosted campaign with their networks".

Most current members interviewed didn't cite artist-run models they looked to as exemplar for their own practice. This was in contrast to founders of $R M$ who actively looked for spaces to emulate. Earlier incarnations of $R M$ had links to international spaces, which began with the mentoring relationship the gallery had with senior artist Julian Dashper (1960-2009) who sought to connect the gallery up with international counterparts. Spratt recounts, 
Julian was a massive influence, and a really proactive influencer, because he created opportunities for us ...He was really proactive in terms of creating those relationships and without doubt his death has left a gap there. He was a real loss for us as an artist, but without doubt as a connector he had this incredible network of artist-run spaces. With the loss of Julian is the loss of that network. (Spratt 2018)

$R M$ actively sought mentoring relationships with other galleries throughout the involvement of Nick Spratt, and captured on their website is an archive of writing from spaces around the world, which $R M$ looked to as an influence. Spratt describes this as a way of inserting themselves into a wider narrative, primarily as a way to manage their own development, "beginning to look at those models elsewhere that we saw resonance or potential in as a way of thinking about what we wanted or what wasn't being offered around us" (Spratt 2018).

For Enjoy founder Ciaran Begley, the establishment of the space was more about repudiating existing models and setting themselves up in opposition to what they knew.

In a weird way I'd been rejected by High Street [Project] the whole time I lived in Christchurch. So as much as I wanted that kind of space, that was not a model for me. We had this idea that being really open with the proposal system was a way of breaking through the - nepotism is unfair- the kind of networking that is how these communities function.

Jordana Bragg was unusual among current participants in describing Teststrip as an important forerunner, although they noted that their understanding of its impact came largely from photos and "of course they might not reflect how it really was" (Bugden 2017, 77). The biggest influence on Meanwhile, argued several of the participants, was an applied exhibition paper taught at Massey University, which all three founders had participated in.

we'd worked together before. We did an exhibition on Egmont Street, where Play_Station is, called Stay On.pdf in our fourth year, through the exhibition paper. And we were good friends at art school. (Bowling 2017)

The students coming up see what the fourth years are doing and they always try and best them, each year. It's amazing, each year, the food, the drinks, the sponsorship, the venues, the tone - just everything gets more formal, more professional and slicker, each year. Everyone is just pushing themselves. So I guess I can see that that stepping into people establishing their own spaces. (Burn 2018) 
Jon Bywater, a critic and academic who has regularly taught students about the importance of establishing artist-run spaces in his critical studies classes at Auckland University's Elam School of Art, reflects that,

I think when you're taking in the world through Instagram or whatever else online, it doesn't really matter that somebody had a room down the street and some things were shown in, 15-20 years ago. It's not a relevant reference point. (Bywater 2018)

As demonstrated in Chapter Two, artist-run spaces often emerge directly from an art school, and the resulting network remains a compelling force, at least for the organisation's early years. Senior artist Judy Darragh observes, "the best thing about art schools is your peers, and if you take those peers with you when you leave. Then you can keep making work, support each other" (Darragh 2018). Art schools feed new generations of emerging artists into artist-run spaces, as participants, exhibiters and audiences, and in turn, benefit from having such spaces to support their training.

$R M$ 's initially close ties with AUT loosened over the years (Spratt says, "in a very soft and gentle way" (Spratt 2018) as their circle broadened, and both the make-up of the collective and their exhibiting programme currently contain about equal numbers of Elam and AUT graduates along with graduates from the other Auckland art schools, Unitec and Whitecliff. Deborah Rundle insists that a blend of students is really important to maintaining a diverse culture within $R M$, stating,

it wouldn't be good if it was just one or the other [AUT or Elam]. I think it's really important to link across the two, and it doesn't really happen within the actual institutions, which is disappointing but understandable, in terms of their competitive structures, for finance and for students, but afterwards, it's really important. (Rundle 2017)

The artist-run space, then, can be a conduit for graduates of seemingly related but, in reality, very disparate institutions to connect with each other, through its informality and openness. Yet tensions were signalled when a space was considered too close to a single tertiary provider, an issue which came to the fore in Wellington, where Massey University is the major art school. Enjoy, as Chapter One demonstrates, was unusual in that its founders had not studied in Wellington and in their early days the Massey University art programme was embryonic. Co-founder Rachel Smithies was 
concerned that "it feels like it's quite strongly tied in now to Massey University", a situation she connects with institutionalisation. "It feels like the kind of gallery you might get attached to a university art school”, she argued, "it doesn't seem to have quite the messiness and experimentation and playfulness that we were able to have at the beginning" (Smithies 2018).

Back in 2005, when Enjoy had been running for five years, artist Stuart Shepherd (at that time a lecturer at Massey University) warned of a growing closeness between Enjoy and Massey, detailing his concern that "Enjoy will get used as a venue for career-focused artists bent on scoring points in the new Performance Based Research Fund culture" (Shepherd 2005, 21). Shepherd's concern echoes wider criticism of the impact of the PBRF programme in New Zealand by researchers who argue its impact on academic freedom can lead,

researchers to abandon certain research endeavours in favour of research more fitting with perceived criteria promulgated by the state through the peer review process. It can, for example, lead to risk-avoiding behaviour that means only outputs that are easily attainable and which are perceived safe, that is, are within the orthodoxy, are produced. (Butler and Mulgan 2013, 515)

The make-up of Enjoy's current staff and board, at the time of writing, certainly suggests that they are heavily enmeshed with Massey University, with one of the two staff members a recent Massey University graduate (Louise Rutledge) and Enjoy Chairperson Ann Shelton, a senior lecturer, along with board member and fellow lecturer, Shannon Te Ao, and two board members, Jess Hubbard and Jordana Bragg, who are Massey University fine arts graduates.

Current participants argue that the relationship with Massey University is two-way (“Enjoy [has] a strong connection to Massey University ... because it's the only university in Wellington [with a fine arts school]" Rutledge 2017) with the larger institution supporting Enjoy with logistical assistance and, in turn, Enjoy playing a vital role in supporting the development of emerging practitioners. Interview subjects stressed the fruitfulness of a productive relationship with larger Wellington cultural institutions. 
We have strong community relationships that are really important with the Adam Art Gallery and Massey's Whiti o Rehua and City Gallery [Wellington]. So we have those local relationships where we share equipment and facilities. We provide opportunities, for students from Massey, for professional development through internships and to get their first engagement with a contemporary art gallery. (Shelton 2018)

Meanwhile's links to Massey University began with its formation, with all three cofounders graduates from its arts programme, while current members are all Massey University graduates with the exception of Simon Gennard, an art history graduate from Victoria University. But, unlike Enjoy's participants, the tightness of the connection is one that some members of Meanwhile feel uncomfortable with. The point was made vehemently by incoming Meanwhile member Dilohana Lekamge, who declared a desire to shift outside a core audience of Massey University graduates,

Because it's so exclusive. It feels like it's some little club that is closed off and we don't want that. We also want to help Meanwhile expand the space and show a larger variety of artists from different perspectives and just have more varied work for a wider audience. (Lekamge 2018)

Within the wider network of art organisations, commercial, public and tertiary, the artist-run space is particularly enmeshed with the last two, through this complex set of relationships which are "temporary and episodic" (Grabher 2004, 104) and "better conceived as temporary and provisional connective arrangements" (Mar and Anderson 2010, 37).

Tertiary training institutions and public galleries are larger and more powerful than the artist-run spaces, and this imbalance of scale contributes to the anxieties expressed by former participants that the spaces will be consumed within a larger narrative. Yet, in turn, the artist-run space offers back a form of legitimacy to the tertiary institution which needs pathways for emerging artists by which to enter the art world. Jon Bywater, a lecturer at Elam School of Art, describes promoting the establishment of artist-run spaces to students as a fruitful mechanism for their development.

I've heard in one of Jon Bywater's lectures that they're launching pads ... I could do that, we should just get together and pay the rent on a room and show one another's work. (Bywater 2018) 
The need, then, is mutual, even if the relationship is not always equal. The artist-run space's contribution to a thriving local art scene provides a reason for emerging artists to stay in a city after graduating, or, potentially, to come to a city to undertake postgraduate study. The artist-runs provide a training ground and entry point for both commercial and public galleries, as well as sustaining larger organisations and their activities through the very practical mechanism of providing the part-time, flexible workers who are needed to run those institutions. The interface between the bigger organisation and the small artist-run space materialises through concrete outcomes (lending equipment, hosting interns) but also through less tangible arrangements of legitimising each other's practices.

\section{Conclusion}

This chapter has examined the importance and impact of space within artist-run culture. I began by mapping the physicality of the gallery sites which my case studies occupy. The research demonstrates that within spatial politics a significantly different divide emerges in the data between Enjoy as an organisation with a goal to expand, and $R M$, a space which has found a scale and format that fits.

For $R M$, my research has demonstrated, decisions about space have at times been highly politically attuned, from embracing locations that are idiosyncratic and require artists to negotiate the site, to conscious placement of the office and archive within the gallery, requiring artists to negotiate the institutional support of the gallery infrastructure. For a particular period of $R M$ 's development, details of the space and layout have been inherent in the holistic nature of the organisation and strongly connected with an ethos of hospitality. However, after the withdrawal of the last founding member, the relationship with spatial politics has been renegotiated, as a new set of members create a current working ethos for the organisation.

At Enjoy the members feel they have outgrown the physical limitations of their space, an attitude that reflects an early incarnation of the gallery. Their space is framed for them now in terms of what has already occurred, and the seeming restrictions that this has placed on future growth. Space, for Enjoy, is a conversation underscored by frustration but also one about possibility for change, to enable them to grow into the larger, more permanent institution they feel they have the potential to become. 
The exhibition remains essential to the activities of each case study space, although each organisation has other aspects to their practice. For each gallery the exhibition is the form that best allows them to serve their community and express what is unique about their activities. While I began my focus examining activities through the framework of two terms crucial to the founding narratives of artist-run historyexperimentation and risk - my findings, in the event, identified two very different sets of terrain.

For Meanwhile and RM it is about working into gaps left by the wider art network of commercial and public galleries, the artists and practices that are not currently acknowledged by this mainstream environment. Enjoy positions themselves very differently to focus on artist development, a process which seeks to nurture and elevate emerging artists into the wider arts system. Additionally, Meanwhile have developed a new approach to risk management that provides guidance for personal behaviours from exhibiting artists to visitors.

In addition, I traced the spaces within a wider assemblage of interconnected art nodes, detailing how each space is connected to a wider scene, which, in day-to-day terms, tends to be a citywide arts scene, although spaces might also have individual relationships with similar-scaled spaces in other cities. Artist-run spaces rely on practical support from bigger galleries, especially in regard to loans of equipment, but in return, the spaces can directly feed into the bigger galleries' programmes.

Questions emerging at this stage include; is there territory that's important for artistrun spaces to claim and keep? Could they work with bigger institutions so that their contributions to developing emergent talent might be better acknowledged by public galleries?

In this chapter artist-run spaces are revealed to be vulnerable to the external pressures of the city and the wider art network. They are, however, remarkably enmeshed in the wider art project which supports them in practical senses and draws on them to source programming and to generate wider cultural capital. Artist-run spaces can provide important support and infrastructure for artists at the very beginning of their careers, providing a reason for graduates to stay in a city and giving them a way into the wider art world. The role of artist-run workers is further explored in Chapter Three. 


\section{Chapter Three}

\section{'So Much Labour For Free': The Artist-Run Space Participant}

My occupation is as an artist, but because of the nature and forces of capitalism, my work is very separate from my occupation. And in order to continue to be an artist, I have to do all these really awful jobs. (Pera Aoake 2017)

\section{Introduction}

I'm standing in Meanwhile, looking at a pile of white rocks with words on them. 'A whole new set of problems' declares one and 'a way to deflect the mental problems you subconsciously know you're having' reads another. I'm alone in the space, but an intense conversation is filtering through the flimsy walls that delineate the gallery from the artists' studios. "She's super needy", a woman's voice declares, "I'm really over it. She's always pushing my boundaries". A man laughs and music starts up.

I cover my embarrassment by staring intently at a Robbie Hancock painting, a loose canvas depicting a man performing fellatio, as though I'm trying to decipher hidden meaning in its intimacy. It feels like there's a party going on, and I haven't been invited. The show is No one is Sovereign in Love, curated by Simon Gennard, who I would later interview as a new member of Meanwhile. His introduction details an interest in subjectivity as "first and foremost relational".

This vulnerability, though, can be transformative ... in sensing out and staying with the tensions produced by our different priorities might, if we let it, enable us to imagine different, exciting modes of being together ... If liberalism structures itself around the fantasy, or aspiration, of the autonomous, sovereign individual, then nonsovereignty is an attempt to attend to the ways subjects are acted upon as much as, or more than, they find themselves acting. Thinking of ourselves as nonsovereign foregrounds what is unbearable, overwhelming, and estranging about being around other people ... (Gennard 2017)

Why does Meanwhile feel so private in so many of my encounters? Is it that I have become conditioned to thinking of the public space of the gallery as neutral, a white cube where I can engage with art without the messy reality of personal lives? This is, 
after all, the case study that provided me with access to their internal online documents after only one meeting, and whose meeting minutes regularly archive Emotion Time_- “Jordana: fucking good today. Crazy and cool. won't last, but will ride wave" (Meanwhile 2016). Yet, conversely, contact is regulated within the space, as their Safer Spaces Policy states, the studio spaces, which are visible from the gallery and delineated only by partial walls, cannot be entered into without permission (Meanwhile 2018). Art and life are intermingled here, to an extent I'm sometimes uncomfortable with.

While the previous chapter takes a broad overview of artist-runs' activities, this chapter brings a tighter focus on the experiences of the people doing the running, asking how are the identities of participants shaped by their involvement in the space. In doing so, I focus on my supplementary research question: How are the identities of participants shaped by their involvement in artist-run spaces? I return to notions of creative subjectivity (Taylor and Littleton 2012; McRobbie 2016, 1998) and passionate labour (Lorey 2015, 2006; McRobbie 2016, 2010a; Gill, 2007) raised in the Literature Review, to chart the matrix of art, sociability and artistic identity that forms the subjectivity of the artist-run space participant, in a complex enmeshing of dependence and independence.

Passionate labour, my Literature Review argues, is where creative work and a sense of one's self collide (McRobbie 2016), and passionate labour plays a vital role in maintaining and perpetuating cultural precarity for artists and arts workers. Such labour positions the emerging arts worker, through their unstable, multi-faceted work portfolio and a strong personal identification blurring life and work, as an ideal neoliberal worker. To understand the complicit and embedded nature of the creative work as it has been articulated by my case-study participants, I turn, in particular, to the writing of Angela McRobbie, Isobel Lorey, and Stephanie Taylor with Karen Littleton.

As my Literature Review surveys, recent critical attention theorises creative work through the framework of cultural precarity, enabling a nuanced understanding of the contradictory ways in which creative workers experience their labour. Passion, rather than stability, is a narrative that fuels a discourse about neoliberalism and passion is at the heart of the artistic and creative narrative. Isobel Lorey argues that creative 
workers' belief in the value of their endeavour, outside of financial rewards, fuels an acceptance of uncertain work conditions. Such complicity demonstrates "the extent to which 'self-chosen' precarisation contributes to producing the conditions ... to become an active part of neoliberal political and economic relations" (Lorey 2006, 128). However, it's important to remember that the traditional career arc of a visual artist might not completely mirror the goals of neoliberalism nor fit entirely comfortably within the 'creative industries'. While the life of an artist might be underscored by uncertain labour conditions - “freelance, contract, self-employed, and intermittent" (Gordon 1991, 264) they often do not align with another key attribute of the neoliberal subject - the financial aspirations of the entrepreneur (Gordon 1991).

Increasingly, artists and arts workers have begun to both claim and interrogate their own relationships with passionate labour, and the literature demonstrates this trend emerging in exhibition practices as well as in written form. Emerging New Zealand curator Lucinda Bennett, a former member of artist-run space Window, wrote the first substantial New Zealand essay on cultural precarity which argues,

You may regard insecurity as the inevitable price that must be paid for following your heart and choosing to work in a field that excites you. Most of us are here because our love of art matters more to us than making money - or at least it did before we understood how low the pay could be, how long the hours, how precarious the lifestyle. (Bennett 2017, n.pag.)

In examining the experiences of artist-runs' participants I am interested in understanding how their sense of identity might be shaped by their involvement in and identification with artist-run spaces. How does participation in such a space affirm or, conversely, complicate their own sens of themselves as creative subjects?

The chapter is broken into three sections and a conclusion, which together trace the multiple realities experienced by an artist-run space worker in New Zealand. The first section, The Artist-Run's Precariat, introduces the worker and argues that passionate labour contributes to a strong sense of identity. As this chapter's epigraph suggests, artist-runs' participants juggle a frantic schedule of paid work, artistic practice, and the very real work of administering an artist-run space. For all of them, the difficulties of running the space are caught up in an act of belief. "People do it because they believe in the values, of having those opportunities to exhibit with more freedom, less constraint, all those things" (Oliver 2017). Beyond the commonalities of cultural 
precarity, significant difference has emerged between the experiences of operating in Auckland and in Wellington, the two cities covered in my case studies.

In an artist-run space fuelled by passionate labour, particular types of participants come to the fore. The second section, Insider's Club: Who is Included in the ArtistRun Space? outlines which kinds of participants are best supported by these systems and who might be excluded from such practices. I describe changes to artist-run culture that have occurred since it emerged in New Zealand in the 1990s. How has the artist-runs' network expanded or developed since that time? Do artist-run spaces now reflect wider societal changes in cultural and gender diversity? What artists are prioritised through this system and in what way might this reinforce or resist a neoliberal orthodoxy?

However, while this chapter acknowledges and describes the deep connection between passionate labour and all the artist-run spaces I have studied, in the third section, Career Paths, I argue that particular details in my findings suggest distinct differences in participants' involvement that significantly shape their experiences, that is, if their work is framed up as a job or as a form of community service.

Building on Chapter Two, Career Paths identifies two different scenarios for New Zealand artist-runs' workers: one situates itself as a stepping stone within a creative career, the other, firmly resisting this, locates itself outside the workplace and, instead, is embedded in an artistic and community practice. These two roles sit alongside each other but have different motivations and long-term goals, which reflects different organisational positioning between various artist-run spaces. This difference is rarely talked about in detail within the artist-run culture in New Zealand, but has significant implications for the future of artist-run spaces.

\section{The Artist-Run's Precariat}

As Hana Pera Aoake describes in the opening epigraph, most emerging artists balance an artistic practice, which is yet to pay off, with a variety of part-time and short-term positions, both within the arts or outside it, perhaps in hospitality, media or labouring. Artist-run space participants juggle the work of establishing and running the space with their own artistic practice and paid work. 
Chapter One describes the establishment of the case-study spaces, each story echoing the founding narrative that the early days are intense and exciting but also very exhausting "a lot of artist-run spaces have a two-year life span for that reason, because people get burnt out easily" (Gennard 2018). For founding members, bringing in new participants is seen as a way to lessen the workload or allow founders to move on. But the hard work of the space continues, and my conversations with participants were framed by stories of the lived reality of cultural precarity.

This was stressed particularly in relation to juggling artist-run space activities with an artistic practice, a scenario described as difficult, "we both work and we can't always meet up all the time, and we're doing a show every two and a half weeks, or every three weeks, it was quite full on" (Bowling 2018). The space is described as a void into which money and time can disappear, "it'll take whatever time you can give it. And because we've got our own jobs and our own art practices, you have to find a way to limit the time you give it" (Rundle 2017) and where exhaustion is a given, “it's hard fucking work and I'm so tired” (Devlin 2016, n.pag.). For Enjoy founder Ciaran Begley it was not just the physical demands on time but the creative input required that he found draining, and which took time away from his own art practice.

It took a lot out of you creatively ... it was killing me. The amount of personal investment. And now I understand it - if I don't go to the studio at least once a fortnight and get something done, the long-term psychological impacts of that are I get quite agitated. (Begley 2018)

However, along with tiredness, the accounts all stressed the passion and dedication the participants felt towards the space, along with a strong belief in the importance of artist-run spaces to the wider art ecology. Curator Melanie Oliver says, "people do it because they believe in the values ... more freedom, less constraint, all those things". Artist Judy Darragh describes her involvement with Teststrip as hectic but exhilarating, “it was like we were hyperactive. It was extraordinary”. Many participants emphasise the friendship and sociability that involvement in the space, beyond the physical production of the gallery, engineered for them.

It's so great to have the support ... making art can be quite isolating and can be lonely. A lot of art making happens by yourself, thinking and doing it. So, I think for me it was less of a space and more of a collective, a group of people that were supporting me and I was supporting them. (Wylie 2018) 
Emerging artist Hana Pera Aoake feels the collaborative nature of artist-run spaces acts as an antidote to the highly individualised nature of the art world as a whole, with its strong narrative of personal success.

Art school encourages this really toxic individualism, and I think it's the reason why so many young artists start up artist-run initiatives, because they're gutted, ripped apart from art school, and they need something. (Pera Aoake 2018)

A new focus on individualism within professional art training is stressed by Angela McRobbie, who argued that the new emphasis on creativity promulgates individualism as central to its remit- "passionate work is then inherently individualistic and conservative". McRobbie has described the rise of the "business school module" $(2015,40)$ which becomes "a key component of the 'art school' provision, but fierce competition among individual students figures more prominently as a pedagogic strategy ... the meaning of professionalism for art students is also now understood in terms of entrepreneurialism” (McRobbie 2015, 75-76).

While work for artist-run spaces was similarly not paid or underpaid, participants expressed no expectation that such spaces should or could deliver financially. "There's no money. No money, so it is an overwhelming task" (Lekamge 2018). Only one participant, artist Erica van Zon, distinguished between spaces that ran on volunteer labour of artists and those, like Enjoy, with paid staff members, arguing "if it's run by artists then it's a given that you just do it all off your own bat ... But when it comes to spaces like Enjoy ... they need to build [artist fees] into their budget" (van Zon 2017). The comment did, however, echo wider concerns raised by some members of the Enjoy staff and board that Enjoy is currently occupying an uneasy in-between space, neither big enough nor small enough. I expand on this later in this chapter as well as in Chapter Four.

Many participants felt that their current financial difficulties were likely to be longterm situations as a result of their identification as artists. For example, Dilohana Lekamge expressed the concern that her long-term goal "to be a sustainable artist that can afford to live and live reasonably comfortably [was] not very realistic" (Lekamge 2018). For the more established artists I interviewed, precarity was not seen as specific to artist-run culture, or emergent practices, but rather, was a wider reflection 
of the art world. This is echoed by the recent survey of creative professionals in New Zealand (Colmar Brunton 2019) which found that visual artists receive a median income of only $\$ 35,800$, in contrast to a nationwide median of $\$ 51,800$.

Interview subjects argued that there was a continuing expectation from larger institutions, like public galleries, that they would work for little or no money. Several made the point that staff at larger art institutions regularly expected them to work for limited payment, while they received a salary. Artist Erica van Zon described attending meetings with gallery staff about an upcoming exhibition, "Everyone else in the room is getting paid and you look at yourself and think 'oh, I'm getting paid in exposure, but how does that work?"' (van Zon 2017). Artist Judy Darragh, aged 60 when I interviewed her and with a successful exhibiting career in both public and commercial galleries, was blunt in her assessment.

We're using this language about the arts industry now. In an industry, workers get paid. Hello? I'm a worker in this industry and I don't get paid. But everyone above me gets paid. Even the gallery attendants get paid, you know? (Darragh 2018)

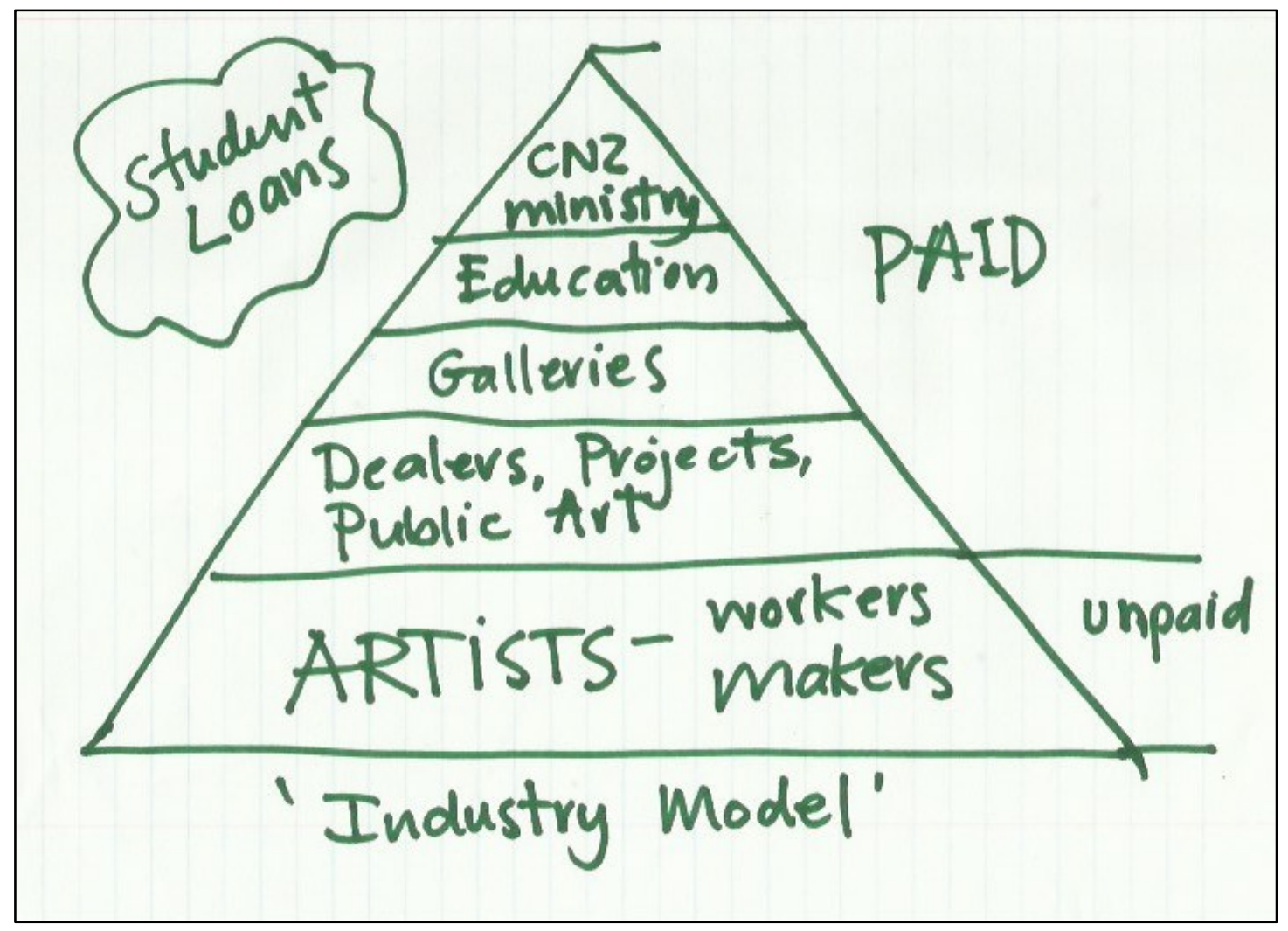

Art World Industry Model, diagram by Judy Darragh, 2017. Courtesy of Judy Darragh 
Some participants gave accounts of the difficulties experienced in validating their commitment to the artist-run space to people outside the art world, particularly family, who could see that involvement was not providing financial benefit and who struggled to recognise the more intangible benefits such as a sense of community.

Like, when I'm talking to my partner or my mum and I'm, like "I've got to do $R M$ ' and they're always kind of like, 'You do so much stuff. Like, are you getting paid for this?' And I'm, like, 'No, I'm not getting paid for this. I'm doing it because I want to.' And I guess, for them, they don't understand, but it's hard to understand if you're not part of, like, the art world, what would drive you to do something that's so much labour for free. (Afoa 2018)

As discussed in the Literature Review, Taylor and Littleton (2008) coined the phrase "double life" to describe a scenario where creative workers maintain an artistic practice alongside a waged job or jobs to support them. They describe the double life as one that necessitates "the continual balancing and accommodation of competing demands, and therefore requires considerable energy and effort" $(2016,69)$. The artist-runs' participants are juggling, in effect, triple lives, through the balancing of art practice, paid work and commitment to the volunteer work of the artist-run space.

Interview subjects described being pulled in different directions and experiencing fear that their artistic practice would be the element that suffered first, a tension frequently cited as a reason for participants to resign from artist-run spaces: "that's why I left [RM], because it started harming my ability to make art" (Wylie 2018). Dan Sanders reflected, "I've got personal life goals that I want to meet. And if it means that I might have to give up $R M$ to achieve them, I might have to" (2018). Personal art careers were seen as more important than the space, even for founders. Jesse Bowling argued "I still have my own ambitions and my own career that I want to do. I don't want to pour my soul into this one gallery for the next ten years just to make sure it goes the way I think it should go."

Relationships with the galleries were underscored by a sense of impermanence, with participants contributing to the space for a period of time and then moving on. This was not generally considered to be a negative, however, with participants framing short-term engagement as both being a necessity and having a wider benefit to the art community. 
I don't think I would want to be involved for longer than like, say three years ... I also feel that it's great to kind of make space for other people, cause that's what it was always about. And so, if I hold on to the position for such a long time, it's holding the position that someone else would learn so much from. (Afoa 2018)

Enjoy was the only space to have a suggested time span, with staff on fixed-term contracts of three years, and board members "asked that we could commit at least three years" (Hubbard 2018). That aim was not always achieved, however,

they've put people on for whatever reason and they've just not stuck around for very long. Could be that they're at the beginning of their arts career and they want to move to Germany, or maybe there's some kind of personality clash, or who knows. (Hubbard 2018)

Enjoy did not have an explicit term limit for board members, and Chairperson Ann Shelton had served ten years, coming onto the board after moving to Wellington in 2008 because, as she put it "I wanted to give back to the community I'm part of as an artist. And I've always been a person that's had a lot of energy"' (Shelton 2018).

An additional difference in the experience of New Zealand artist-run workers was the impact of their city. Auckland's property market pressures have financial implications for artist-run practice, not least in relation to the amount of time that workers can dedicate to their space. The narrative provided by Meanwhile's members conformed neatly to the stereotype of the neoliberal worker, juggling freelance and part-time paid work along with the work of running the space and their individual art practicesliving the "triple life".

Jesse Bowling and Jordana Bragg both worked as contract gallery technicians and, along with Simon Gennard, as gallery attendants for City Gallery Wellington. Sean Burn undertook website design contracts and Dilohana Lekamge was a freelance arts writer. Each of their individual experiences reinforced the contemporary understanding of the neoliberal worker as highly flexible and building a working week characterised by "self-employment strategies, the freelance work and the new modes of "self-entrepreneurship"” (McRobbie 2016, 35). 


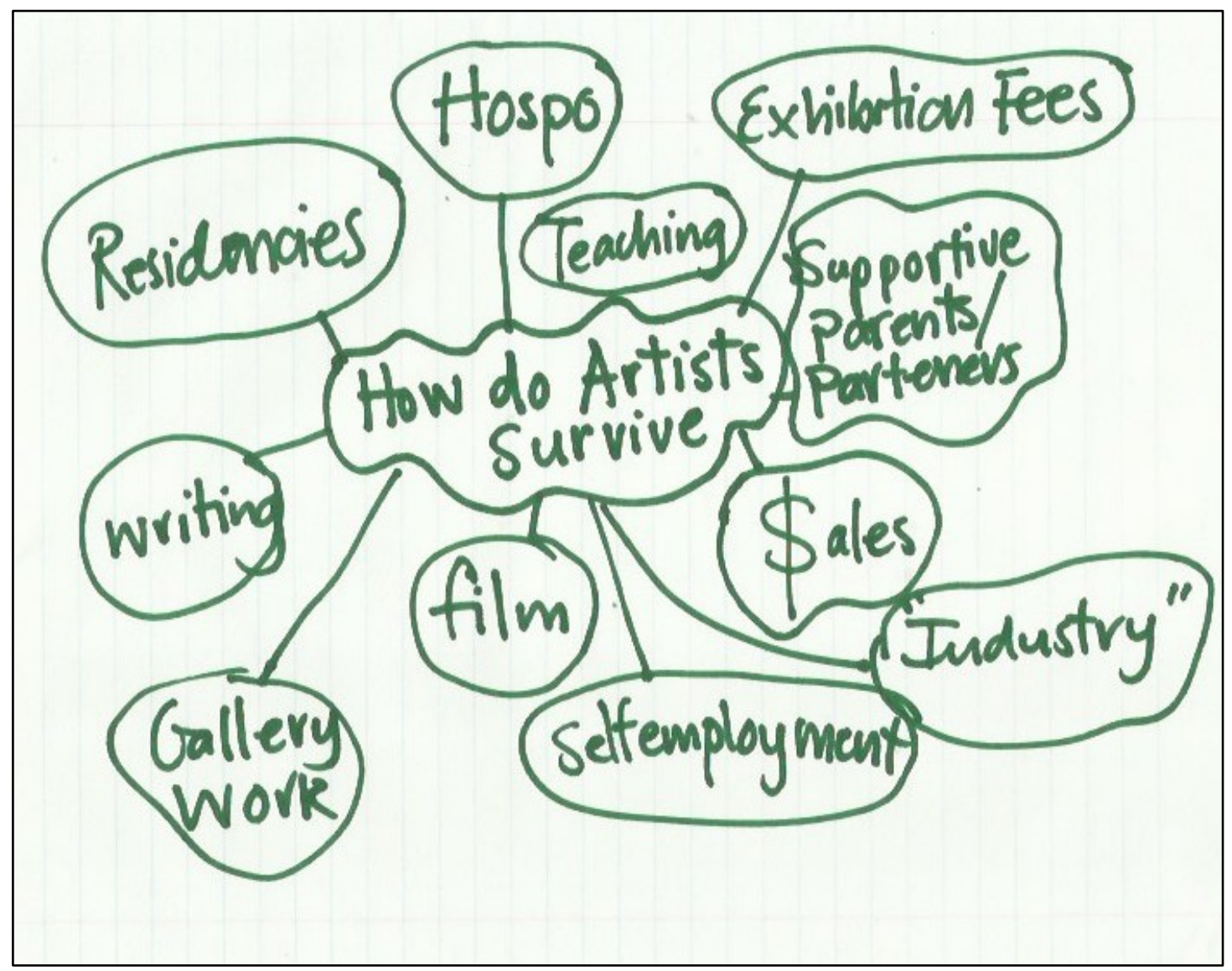

How Do Artists Survive, diagram by Judy Darragh, 2017. Courtesy of Judy Darragh

I've just been juggling art handling with all the galleries and then I had a sixmonth contract with Massey [University], so my work has been all over the place, plus doing Meanwhile. (Bowling 2018)

The early days of running $R M$ were very similar, with the collective members initially being students, and then, juggling a range of different freelance and part time jobs, as Nick Spratt describes it, "we always seemed to have people who were students or recent graduates who had the directorship of $R M$, so there was that extra space and time to be able to do things" (2018).

These experiences mirror the data provided by the Colmar Brunton survey of creative professionals in New Zealand, along with the Australia Council's economic study of professional artists in Australia (Throsby and Petetskaya 2017) which found,

employment conditions for artists have been changing radically, with increasing insecurity in contractual arrangements, and the replacement of steady employment with the emerging concept of the portfolio career, characterised by a variety of work arrangements - some involving original creative work, some applying skills more widely, some requiring team participation, some involving 
the artist in taking time out from creative work for further study, travel, research, and so on. In all of these trends we see a variety of ways in which the life of the artist is changing. (16-17)

However, argues Deborah Rundle, the experience of $R M$ today is very different. Some members of $R M$ are art students, and thus, according to Rundle, they are "more flexible, but it's on the basis of [student] loans". For the rest of $R M$, she suggests, their ability to live in Auckland now on part-time or contract work is limited.

People are having to get tough, non-flexible work now ... they're got more restrictive, possibly outside of the art world jobs that aren't sympathetic to the possibility of being able to just nip away or finish early. So, we've got people on the collective who've got their 40-hour jobs, and they're willing and enthusiastic, but it's all going to be after hours. (Rundle 2017)

Artist Erica van Zon, who moved from Auckland to Wellington in 2010, describes the environment she left in dramatic terms, concluding, "[artists] can't afford to live in Auckland anymore" and curator Melanie Oliver agrees, stating, "living in Auckland, it's so expensive". Nick Spratt, who left Auckland in 2017 to move to Wellington also, identified the shift in working and living conditions in Auckland as one of the most significant changes over the last 20 years.

The financial aspects of being a human being in Auckland, that really changed, the amount of money that was needed to sustain yourself. The idea that you could leave art school and do a part-time job and work on your art and run a space, and just pay the bills by doing some part time jobs, doesn't seem like it's a practicality anymore. (Spratt 2018)

Senior artist Judy Darragh also expresses concern about the financial conditions for emerging artists in Auckland. Having taught until recently at Elam School of Art, she left after the realisation that it was no longer a productive situation for those involved. Darragh calls it an "epiphany. I just looked around one day and I thought, I can't do this anymore. I can't support this structure. I can't support this art school". For Darragh, the increased reliance by students on student loans to acquire a qualification, with no guarantee of resulting financial sustainability, is making her very uncomfortable.

This is a game changer. These guys walk out with $\$ 60,000, \$ 40,000$ in debt. There's no way these guys are going to be able to pay their debt as an artist. There's no professional trajectory where you can go off and make money as an artist. (Darragh 2018) 
Although I have not examined case studies beyond Auckland and Wellington, it's reasonable to speculate that the situation in smaller urban areas remains more flexible for artists and arts workers, and that the severity of these pressures is a particularly Auckland problem. As demonstrated in Chapter Two, Auckland's loss is to some extent Wellington's gain, with Erica van Zon's statement that, as Auckland becomes increasingly out of reach for Wellington art graduates, they stay in the city to establish themselves, and in doing so, create new grassroots organisations. As the capital, and self-titled 'creative capital', Wellington has a higher number of large arts institutions per capita than Auckland (OECD 2014) and arguably generates a greater quantity of casual work, such as for gallery attendants and technicians.

What does this generational change to artist-run culture mean for the future of Auckland art graduates and their ability to continue to generate artist-run and grassroots activities? Auckland artist-run spaces have increasingly moved outside the central city to more peripheral and private locations, as curator Melanie Oliver remarks, "spaces like Ferrari, that were run out of a garage ... or spaces that are run out of people's homes". They are also, as the extensive artist-run archive listed in Assay / Essay (2016) demonstrates, existing for shorter periods of time, typically one year instead of two. Perhaps funding bodies need to understand spaces, not only by their individual characteristics, but by their city.

\section{Insiders Club: Who is Included in the Artist-Run Space?}

I think a lot of them [artist-run spaces], from my own experiences, almost seem self-serving from the outside. Because you're not in it, you can't see it, and I don't think they're that invested in being inclusive. (Pera Aoake 2017)

In general, Joan Acker argues, "work is organised on the image of a white man who is totally dedicated to the work and has no responsibilities for children or family demands" (Acker 2006, 448). When McRobbie identifies self actualisation as an outcome of creative labour under neoliberalism, she suggests that, while selfactualisation of creativity might especially appeal to those people who have felt excluded by traditional work (such as women or people of colour), these are also the very groups who will be marginalised, arguing "the gender of post-Fordism is female" (McRobbie 2016, 94). McRobbie contends that through post-Fordism and the rise of 
individualisation, the "older men of labour are being replaced by the younger women" (95) and the experience of being "a 'worker' is but one element in a more complex configuration of personhood" (95). This section explores the artist-run space as a space that both affirms and, at times, complicates the norms of the wider art world and the wider world again, in terms of who feels welcomed and who might feel excluded.

Asked what advice she would give emerging female artists, senior artist Judy Darragh is uncompromising: "I would tell the woman artist that I have to work twice as hard as the male artists. My work sells for a third of the male artists". ${ }^{20}$ Backing up the anecdote, a recent New Zealand survey of creative professionals (Colmar Brunton 2019) found there was a 21 per cent average difference in total personal incomes for men and woman and a 45 per cent difference when focused solely on incomes from their creative pursuits (rather than additional strands of income). However, the study warns, "more research needs to be done to determine how much of the gap is due to factors ouside of gender" (Colmar Brunton 2019, 21).

There is little New Zealand data on gender representation in the art world (Knox 2019; Jack 2018) but Australian data collected by both the Australia Council and the CoUNTess Report are relevant to the New Zealand experience. The CoUNTess Report, led by artist Elvis Richardson and undertaken regularly since 2008, tracks gender representation across the art world, from public institutions to commercial galleries, art prizes and artist-run initatives. The latest iteration of this study, from 2016, shows that "female artists may be claiming new ground" with the number of women showing in Australian galleries increasing, but that it is still the case that, "the closer an artist gets to money, prestige and power the more likely they are to be male and male artists' work sells for higher prices than female artists' work. These results are not surprising as they mirror those in almost all other areas of creative production as well as in almost all spheres of power and influence (CoUNTess Report 2016, n.pag.).

20 Relevant to my research is data on both art students and artist-run initiatives. The report shows that 74 per cent of all visual arts graduates are female, which, anecdotally reflects the New Zealand experience, where females significantly outnumber men. For example, female staff enrolled at Massey University's College of Creative Arts in 2012 comprised 67.67 per cent of the total student population (Ellen-Eliza 2013, 54). What neither of these studies tracks is the number of non-binary students, which, in New Zealand, is a small but rising number. The other statistic of relevance is that 48 per cent of artists exhibiting in artist-run initiatives are women, the highest representation of women for all of the gallery types surveyed. 
Women were prominent in the artist-run spaces I examined, both in the running of spaces and in the exhibiting programme, and this remains a point of difference between artist-run spaces and larger institutions. The artist-run space is therefore the last stage of an artistic practice where gender is not visibly a factor of success, although, due to its reliance on precarious labour, it remains a culture most easily accessible for young, single participants without significant financial burdens. It is, therefore, both a more open environment than the wider New Zealand art world, but simultaneously, still an arena that is more welcoming for some participants than others.

Artist-run spaces are also, Chapter Two argues, deeply enmeshed in the tertiary art institution, and it is very rare for an artist-run space to include participants who have not come through the art school system. Surprisingly, participants from both Meanwhile and $R M$ described a process of actively engaging with self-taught artists through their studio or gallery programmes, a relationship which Jesse Bowling described as containing an element of mentoring.

We have two studio artists who aren't formally trained, so they just make art but they don't know how to do that [move from the studio into an exhibition format] because they're just making it in their bedroom and they don't have this critical art framework where they can talk about it all the time. It gives them that opportunity. (Burn 2018)

We don't want to have any prejudice or bias based on their professional history. You don't have to have a degree and you don't have to have a master's or whatever. We're not going to exclude you. (Sanders 2018)

But the strong networks that run between artist-run spaces and art schools provide an easy mechanism for art graduates to interact with existing spaces as audience, exhibiting artists, and participants, as well as the encouragement, as Jon Bywater describes, to establish their own space. Artists who have not come through the art school system need to establish their own entry and connections with artist-run spaces, without the art establishment to validate them.

The emphasis on recent art school graduates or current students actively working in artist-run spaces_- "most of us are still studying or recently graduated. I think it's probably about 50/50 of people who are still students and people who are graduated" 
(Sanders 2018) — echoes the artist-run space literature. Australian artist-run space participant, Brett Jones, suggests that artist-run spaces are best suited for younger artists, because of the financial implications of artist-run involvement. "There is", Jones argues, "an implicit understanding that artists will only be able to maintain their involvement in an ARI for a set period of time before they must return to their individual practice" (Jones 2007, 19).

Nick Spratt was in his early twenties in 1997 when $R M$ opened, single and willing to pour all his energies into the project. By the time he left in 2017, he had a young daughter and "definitely work and family had begun to take more of my headspace". For Spratt, spending time with daughter Mina became a priority, and "I wasn't doing as good a job as I wanted with the gallery, didn't have the time and the resources to bring to the gallery that I wanted" (2018). Similarly, Zoe Drayton, who had initially juggled parenting with establishing an art career and an artist-run space, recalls "as time went on, and I got older, it did become problematic to work for free and I no longer want to do it ... I just got to the stage where I felt too old to be poor" (Drayton 2017).

That first incarnation of $R M$, like Teststrip before it, comprised a mix of artists in their early twenties who had attended art school straight from high school, and artists who were slightly older, with two of those, Zoe Drayton and Barbara Anderson, being parents. Co-founder Spratt suggests that the perspective of older participants, more aware of life outside of study, reinforced the need for a project that would bridge their time at art school with their professional careers, as he puts it, "Vaughan, Zoe and Barb were slightly older students, so maybe they were having the conversation about what next" (2018).

Drayton agrees saying, "being mature students, we did bring other things to it" but also reflects that, "I don't know if we were your average mature students either. For some reason we were all quite prepared to risk things perhaps that other people of our age wouldn't have" (2017). However, despite the support network of $R M$, the tension between parenting and the art world would continue, ultimately leading Drayton out of the art world, first into the niche environment of sound art (where events were held much later in the evening, at a time when children were sleeping) and later, into a new career as a therapist. 
I don't think there is ever an easy road when you're a single parent and an artist. You're always compromising one or the other. You're always compromising your parenting when you're being an artist and you're always compromising your artistic practice as well, being a mum. (Drayton 2017)

The current iteration of $R M$ represents a generational span among its seven members, with all members interviewed stressing this as an organisational strength, as Daniel Sanders notes, "it's been awesome to have that kind of cross-learning between different people's experiences". Older participant Deborah Rundle stated,

I think one of the things I like about that is that seems quite seamless to me. There doesn't seem to be issues that come up to do with difference across the age range. Because I think there are lots of isms in the art world and one that is particularly active is the agism. The new is often equated with the young. (Rundle 2017)

$R M$ 's open structure and gentler approach facilitates a wider ranger of participants than a more ambitious organisation might. Their refusal to locate career building as a priority, either for members or for exhibiting artists, means a greater emphasis on discussion rather than outcome and a focus on diversity over cohesion. 'Emerging artist', for $R M$, is a broader grouping that speaks to gaps within the mainstream art project.

Outside of $R M$, those interviewed mostly equated artist-run spaces with youthfulness. Looking into the future, Jesse Bowling, co-founder of Meanwhile, agrees, saying, "I think it's for young ideas and for people who are fresh out of university. Why would I start an ARI when I'm trying to push my mid-career art practice?" (2018). Co-founder of Enjoy, Rachel Smithies, agrees,

I think they are particularly a young people's endeavour. And that's because I think, in a sense, you don't have all the other choices yet. Trying to make a start in the arts, especially if you want to be a curator or you want to help run an art space, there's not that many jobs and it's a bit like doing an internship. (Smithies 2018)

However, Smithies qualifies this by pointing to the example of her partner, Cairan Begley, who has been involved in a number of artist-run initiatives since leaving Enjoy. His current space, Our Neon Foe, a Sydney-based gallery and studio complex, is run in collaboration with two other artists, including senior Australian artist Mikala Dwyer. Our Neon Foe is a very informal organisation, with no legal structures in 
place, and decisions made by the collective in casual consultation with each other.

Smithies, who is not a member but takes an active interest in the space, commented,

You can approach it a slightly different spirit I think. Because you know that you have other options and so you can use this for a vehicle for particular things like for trying stuff out, and for doing things that are a bit looser and for building community ... it's less of a reactive thing of not seeing a space for yourself in what's out there, because you can see a space for yourself, because you're that generation. Your mates are senior curators at places. (Smithies 2018)

Enjoy's paid staff are young, in their early to mid-twenties, and have been so throughout the gallery's history as an employer. Their board of trustees comprises a broader range of ages, from Chairperson Ann Shelton, in her early fifties, to trustee Jordana Bragg who is 24 , with the majority in their thirties. Trust member Jessica Hubbard reflected on the disjunction between the age and maturity of the organisation with the youthfulness and inexperience of the gallery staff.

Is having really new curators for an increasingly maturing gallery the right, continuing approach? But at the same time, if we were to hire curators with more experience, what would that turn the gallery into, and would that shift move the focus away from young and emerging artists? (Hubbard 2017)

While RM and Enjoy both span generations, Meanwhile's members were all born in the 1990s. They are, as the Literature Review began to detail, part of the cohort of 'Roger's Children', using Lawn and Prentice's term, and youthfulness, as argued in Chapter Two, is a significant element of their brand. However, they have only run for two years and their organisational structures are still emerging, an aspect further developed in Chapter Four. Meanwhile might change, and one of the most significant ways could be in its emphasis on youth (undergoing a similar transformation to Enjoy). Sean Burn was one of several members to speculate on the possibilities for change,

it could be possible for Meanwhile to last, say, ten years as it is, but I feel it's also just as easy for it to completely change into something else as new people are brought in and we all step away, new studio artists come in. (Burn 2018)

The difficulties of juggling artist-runs' work, paid work and an art practice suggest another barrier to participation, lack of access to external financial support from family or other sources. Social order, both Pera Aoake and Oliver argue, remains a crucial barrier for many emerging artists who might want to take part in an artist-run 
space, but must instead focus on activities that generate financial support. Class and money are inevitably linked to ethnicity and several participants expressed concern that artist-run spaces were not considered welcoming for people of marginalised ethnicity or class.

Since the 1990s, when the first artist-run spaces began to develop in New Zealand, New Zealand's cultural make-up has significantly diversified, particularly in Auckland, a city now defined by its "super diversity" (Spoonley 2009). ${ }^{21}$ Interviewees were variously optimistic and pessimistic about diversity within the New Zealand art ecology, often because they felt the changes in cultural diversity were not embedded deeply enough at a power structure level. It was notable that those who expressed optimism were predominantly Pākehā (all but one) and those who expressed pessimism were predominantly Māori, Pasifika or Asian (all but one).

in my final days at $R M$ it was super exciting to see those voices really present within the directorship, for sure. So, there's been some positive shifts, without doubt, in terms of how artists think about representation, but also where those voices are coming from. (Spratt 2018)

Similarly, senior artist Judy Darragh expresses enthusiasm about the new generation of emerging artists, stating, "that next generation, in their twenties: they're brown, they've brave, they're collaborative, they share, they're amazing. I'm knocked out by them" (2018). But Meanwhile's Dilohana Lekamge feels that, "artist-run spaces and the art industry in the first place, are very Eurocentric, have very Eurocentric standards and procedures of how things work" (2018), Curator Melanie Oliver agrees, suggesting that, 'one of the disappointing things about artist-run spaces is that they are predominantly Pākehā and middle class" (2017).

Artist Hana Pera Aoake, whose art practice in Fresh $n$ Fruity has consistently agitated for a more inclusive art world, describes art galleries as "spaces for upper middle class Pākehā people". While she acknowledges "it's starting to change, and I think some artist-run spaces are trying to address that, and provide space for other artists", she remains cautious. "I'm critical of their efforts I guess. Whether they walk the talk, I guess, or put their money where their mouth is" (Pera Aoake 2017).

21 Statistics New Zealand's most recent census in 2013 put Auckland as the most ethnically diverse region in New Zealand with only 59.3 per cent identifying as European, compared to a nation-wide percentage of 74 per cent. 
In New Zealand's most comprehensive book on artist-run culture to date, Assay/Essay, Editor Gabrielle Amodeo criticises her own publication for failing to tackle Māori and Pacific representation. "Along with the rest of society", she reflects, "the arts need to address the white-privilege still in operation", yet despite this stance she concludes, "this publication, regrettably, does not do that" (Amodeo 2016, 4). She does not provide a reason for this shortfall, beyond that "I wanted it to explore everywhere, but inevitably (actually, obviously) it couldn't' (4). In my interview with her, curator Ioana Gordon-Smith concludes that within the broader New Zealand art world "there is lots of work still to be done".

What types of artists are recognised, what types of audiences are prioritised, what types of communities institutions serve or don't serve. And I think it's really hard to talk being inclusive of culture and race without thinking about the class position that institutions occupy and how that does or doesn't feel exclusionary or intimidating. (Gordon-Smith 2018)

This notion of work to be done was one echoed by Enjoy Chairperson Ann Shelton, who stated, "at the moment, we're really keen to get more Māori and Pasifika trustees on board, so that's a focus for us right now". For Lekamge, diversifying Meanwhile's audiences beyond those traditionally comfortable with gallery going was her motivation to become a member.

I think we have an opportunity here to expand Meanwhile and make it an accessible space to wider communities. I would really like Meanwhile to have that criticality and be able to have those discussions. (Lekamge 2018)

For Louisa Afoa, whose own motivation is to "advocate for Pacific representation. People of colour in the space," the diversity of artists within the $R M$ collective is vital to generating a diverse exhibition programme, "we're all different artists and so we're interested in different practices and we'll all kind of advocate for different people".

Participants' age, gender and cultural identity all emerge as significant to the make-up of the artist-run. However, while several participants were highly critical of spaces as exclusionary of difference, artist-run culture was also claimed to have broadened locally since the early days of the 1990s, particularly in relation to cultural diversity. Despite this, artist-run spaces are still most often experienced as welcoming by middle class, single participants, graduates of an art school, who are comfortable in their navigation of the art world. 


\section{The Artist-Run Workplace}

The artist-run space, therefore, is hard work, but is it also considered to be Work? The capitalisation refers to the acceptance of artist-run activities as a job. A distinction between the input into artist-run spaces as a community endeavour or as a job is crucial to understanding the different expectations and experiences of artist-run workers.

Arguably the first New Zealand participant to receive a wage for his work was Daniel Malone, when he became a paid administrator for Teststrip in the mid-1990s. At that point Teststrip had run for several years through the combined efforts of a voluntary collective, but as co-founder Judy Darragh describes it,

We just sort of got to the point where we were getting exhausted. So we applied to CNZ for a computer. We got a computer. Then we applied to CNZ for some funding, so that Daniel could do part-time coordinating. So he became the person who would sit there and coordinate. (Darragh 2018)

Malone himself only undertook this role for a year, because, Darragh states, "we got to the point where we realised we were supporting other artists' careers and our own careers were suffering. I think that's the point where we all just went, 'No'". Teststrip closed, and its members went on to further develop their own careers, both in New Zealand and internationally. But the precedent set by the role, along with a similar paid position at Christchurch's High Street Project, both funded through the Task Force Green scheme ${ }^{22}$, provided a template for a number of New Zealand artist-run spaces to come.

For the participants of $R M$ and Meanwhile their work on the space was voluntary and given in the spirit of community participation. Interview subjects describe the work as time-consuming but rewarding, providing participants with a deep sense of connection and "becoming part of the community" (Burn 2018). While I argued above that such work formed the third leg of the "triple life", it was framed by interview subjects as separate but complementary to an artistic practice.

I feel about it the same way I would about me being an artist. We recently redescribed ourselves as being a collective, rather than co-directors of the space, 
and we've done this, I guess, because we don't get paid for [our work running the space], and we're just a group of people that, you know, a group of artists, we felt like 'collective' kind of reflected all of us more than saying we're a group of codirectors ... And co-director I guess, for us, was ... it felt like a different role. Like we sit in a boardroom or something. (Afoa 2018)

Surprisingly, a key finding in this research was the marked difference in attitude between the volunteer participants of $R M$ and Meanwhile, and the volunteer board members of Enjoy, who were more likely to describe themselves through the terminology of a job, albeit one they were not receiving financial compensation for.

It definitely is a job, because obviously a lot of work is involved and I deal with a fair amount of procedural and funding paperwork. It is voluntary, but that doesn't mean it's not hard work that has to be done well. It is an enjoyable role and I've got a lot out of it, I've learned a lot, but it is hard work that requires focus, follow up and future planning. (Shelton 2018)

Such framing results from trustees' need to position themselves away from artistic activities and towards "governance: employment issues, things like that, pragmatic differences ... as a Board member at Enjoy, I think you're dealing much more with infrastructure, the quieter stuff' (Lacey 2017). While their work is voluntary, it places them in the position of employer, "a lot of the time you're really looking from that financial point of view and so less from an art point of view, in a way" (Hubbard 2018).

Only the two staff members at Enjoy receive a wage for their artist-run labour, each employed by the Enjoy Trust on a three-year contract. Their salaries are modest but allow the participants to largely concentrate on their role at Enjoy, without the weekly juggle of additional work. Sophie Davis, as curator/manager, and Louise Rutledge, as publications and communications coordinator, both acknowledge this difference as significant. Rutledge stresses, “Sophie and I aren't artists ... [so] as well as supporting emerging artists, Enjoy is also supporting emerging arts administrators and curators".

For Sophie Davis, her role as curator/manager builds on, but is not the same as, her earlier experience founding and running the artist-run space North Projects. ${ }^{23}$ Her work at Enjoy is bounded and defined by the nature of her role as a salaried worker, as she explains, 
once you have a paid employee I think it's hard to translate that initial energy and enthusiasm, of setting something up and building something, if someone inherits something it's always going to be quite different, I think, quite a different dynamic. (Davis 2018)

For Davis, the differences between her role as paid worker and her previous experience as a volunteer participant highlights the divide, not in the nature of the work she is undertaking (requiring a mix of creativity, relationship management and project management skills comparable to that of $R M$ and Meanwhile) but in the power dynamics that occur in the shift from non-hierarchical collective to a governance model. Davis and Rutledge are employees, at the beginning of their careers, and for them both, a modest salary is out-weighed by the opportunities the role offers for their own development.

\section{Career Paths}

For Davis, the opportunity that Enjoy offers is almost unique in New Zealand, providing the bridge between her previous unpaid, grass-roots activity (such as North Projects) and her chosen career as a curator.

It's one of the few paying jobs of a length greater than an internship that you [can apply for] in New Zealand, because the opportunities are rare. That's why, when the job came up, I decided to apply and go for it. (Davis 2018)

She anticipates that, after her allotted three years at Enjoy, she will move on to other curatorial roles, climbing a professional ladder to bigger organisations or a more specialist position.

I think I'd like to go overseas. But I don't see myself going down the dealer gallery or commercial gallery context, I do like public galleries. I also like the idea of doing a curator-run initiative or something that's a more fluid space, not necessarily tied to a monthly exhibition structure, on the side of something else. (Davis 2018)

As Louise Rutledge points out, “traditionally it's usually a person's first job in managing this kind of space, for me it was my first job outside of uni". The positions that Enjoy offer, therefore, are aimed specifically at emerging arts workers, who are anticipated to gain experience and build networks, and, after three years, continue on to a position at a larger organisation, often a public institution. Rutledge confirms, 
looking at Enjoy's history, it's pretty clear to see how that's worked and benefited people ... It's quite interesting tracing not only the artists we've shown but who's worked here and gone on to careers from those early days. (Rutledge 2018)

Melanie Oliver, who, early on in her career worked as the curator/manager at Enjoy and is currently senior curator at The Dowse Art Museum, concurs, "I've benefited enormously from artist-run spaces myself, in different ways. Working in them, gaining my professional experience, professional development through those spaces" (2017).

In this section I examine the career paths that the artist-run space might contribute to, for those emerging practitioners who engage with it, either as paid staff, volunteer participants or exhibiting artists. Chapter Two argues that for Enjoy the success of an activity is measured not only in the reception of the artwork during the exhibition, but its subsequent circulation within a bigger art world. In this sense, Enjoy's role is not just as a laboratory or testing ground, but as a feeder to national and international networks. Louise Rutledge says, "it's further endorsement when the [art]work that we're investing is validated in that way. It's always pretty exciting when work pops up somewhere else."

This approach extends beyond the careers of exhibiting artists to Enjoy actively tracking the ongoing careers of their former staff and board members, along with the artists they exhibit, using this information as a measure of its impact for funding purposes.

Enjoy endeavours to develop the skills and practice of artists and practitioners with potential, and our success in doing so is evidenced in the recent achievements of our exhibiting Artists, Trustees and Staff. (Enjoy Trust 2016, n.pag)

The 2016 Creative New Zealand funding application by the Enjoy Trust details the opportunities her position with Enjoy has provided then Gallery Manager/Curator, Emma $\mathrm{Ng}$,

Enjoy has presented many new opportunities for Emma; allowing her to develop management, administrative, financial, and strategic experience as well as her curatorial interests through the development of the annual Enjoy programme. She has also built strong relationships with the Wellington arts community during her time at Enjoy. (Ibid.) 
and follows by charting the subsequent success of previous employees.

Former Enjoy Curator/Manager, Melanie Oliver has recently been appointed as Senior Curator at The Dowse Art Museum. Charlotte Huddleston now holds the Director position at ST PAUL St. Erica van Zon, also a former Curator/Manager has continued to secure residency opportunities (Asia NZ Foundation, Tylee Cottage Residency, Sarjeant Gallery), and has exhibited widely including at Dunedin Public Art Gallery, The Dowse Art Museum, City Gallery Wellington, and ST PAUL St. (Ibid.)

In contrast, Meanwhile's funding proposal to Wellington City Council in 2017 similarly tracks participants and exhibiting artists, but with very different framing.

As a young queer artist of Māori (Ngāti Porou Iwi) descent, whose practice concerns Mana Wahine $;^{24}$ the representation of and for marginalised positionality, it is integral I contribute to this wider discourse as a cofounder/facilitator to encourage Māori cultural practice and to provide both safety and visibility for these views. (Meanwhile 2017, n.pag.)

For Enjoy Chairperson Ann Shelton tracking the career paths of staff, board members and exhibiting artists is a crucial part of the space's strength, both conceptually and practically, and provides a mandate for their continued relevance.

Firstly because its important for us from a philosophical perspective. We've had the most amazing group of people come through the gallery and go on to do incredible things and we're really proud of that. Secondly, because it's one of the main areas that we sit within, in terms of CNZ funding. Developing curators and artists in the field is a key area for us, its something we are evaluated on.

(Shelton 2018)

The emphasis on the organisation as a platform for development, previously discussed in Chapter Two, emerges as a significant philosophical difference between Enjoy and my other two case studies, and, I would argue, needs to be understood as a major schism in institutional values between Enjoy and my other case studies, regardless of apparent overlaps in programmes and communities.

Therefore, while the members of Enjoy sees their support of emerging curators as a positive, Meanwhile's Jesse Bowling is concerned that the professionalisation of staff led to different priorities for the space. While Louise Rutledge cites curator Melanie 
Oliver's career trajectory as aspirational, Bowling uses the same example rather differently.

It's career-based curating. They are providing a service by giving people shows, but it's also in their best interests to be putting themselves in these spaces for their own careers ... it shouldn't be a career-based thing. (Bowling 2018)

Sean Burn agrees, stating Meanwhile's goals were "not about showing our own art or pushing our own agenda or pushing our idea of what a space might be”. Dilohana Lekamge is uncomfortable with the notion that personal career benefits might emerge as a result of her involvement, although she accepts that might come about.

I don't like the social climbing aspect of networking. But I'm very aware I'm in a very privileged position here ... the places I inhabit do have people who are quite high up in the industry, or established enough in the art industry. So we do make connections. but the social climbing aspect of networking, it just seems a bit greasy. (Lekamge 2018)

Participants from $R M$ echo these sentiments, acknowledging that their involvement might lead to subsequent career opportunities for themselves, but stressing that this should not be a primary motivation for becoming a member. Louisa Afoa, when asked if participation in $R M$ would benefit her personally, concedes, "I guess it's also benefited my career, by having this type of experience". But, she emphasises, "I don't really think about my career in that way. I think it really fits into what I'm interested in ... the kaupapa of $R M$ reflects things that I think about in my art practice as well" (2018).

This refusal can again be understood through Lind's description of the strategic separation $(2010,76)$, a rejection of a development narrative which perceives each temporary project as one more building block for the neoliberal worker, each contributing to, and affirming, the development of individualised careers — of both artist and curator. Enjoy's focus on exhibition outcomes is also driven, at least partly, by expectations from their major funding body. While both $R M$ and Enjoy are significantly funded by Creative New Zealand, $R M$ receives project funding rather than operating as a funding client through the Toi Uru Kahikatea strand, as does Enjoy. The impact of funding expectations will be examined in detail in Chapter Four. 


\section{Conclusion}

The blurred lines between work and passion, between labour and creativity, make the artist-run space a complex organisational environment. It is important to acknowledge the extent to which art world participants are complicit in perpetuating the narrative of passionate labour. Lucinda Bennett describes herself as feeling unable to complain, yet, she writes, "by clinging to the notion that we are doing what we love, what we are actually doing is self-exploiting, and allowing ourselves to be exploited by others (Bennett 2017, n.pag.).

The notion of the self-exploiting precariat is crucial to understanding the complexity of the artist-run space participant, whose labour may be given willingly yet knowingly. It's important not to devalue the commitment which artists and arts workers make to their work, while simultaneously recognising that such a commitment can lead to them adopting, seemingly by choice, neoliberal labour conditions. McRobbie, in her 1998 study of young fashion graduates, describes creative work as a "process of self-actualisation" $(1998,103)$ a trade-off between the freedom and status a creative worker might achieve and the poverty experienced.

In my research I have been struck by the knowingness of a community comprised of highly educated participants, who are acutely aware of "the amount of emotional energy and emotional labour" (Pera Aoake 2017) the art world demands of them, yet simultaneously hold to the notion that their work refutes societal expectations, because it is "radically different ... trying to be as free and experimental and for the artists as much as possible" (Burn 2018). To understand these dual positions is to acknowledge the complexity of operating within a neoliberal orthodoxy, where inside and outside are no longer clear boundaries, as Amanda Bill argues "multiple resistances and dominations ... are implicated in the formation of these new creative identities" (2008, 183). Following on from this, as I quote in the Literature Review, Bill suggests that "rather than trying to 'cure' students of creativity the goal should be instead to become aware of creative subjectification" (121).

Certainly, none of the participants I have studied would wish to be "cured", but several expressed their culpability in their relationships to arts reliance on unpaid labour. As Jon Bywater reflects, “it's a double bind, isn't it? You could refuse on 
principle to do it and nothing will happen. So it's good when people are conscious and critical about it. But that's not going to make it go away" (Bywater 2018). It's helpful to reflect on Taylor and Littleton's research approach to creative workers, which allows for experiences of both agency and dependency to coexist "as a constrained but not wholly dominated subject, negotiating 'who I am' out of the various possibilities and limitations giving by multiple meanings and positionings" (Taylor and Littleton 2012, 39). Taylor and Littleton describe the project of creative identification as "ongoing, complex and incomplete" $(2012,4)$ in which the process of developing a creative self is constantly "claimed and maintained" (7).

Although the art world conveys a strong rhetoric of being an alternative to the mainstream, in this chapter I argue that many of the tropes of the contemporary, neoliberal workplace are found in the artist-run scene. Financial uncertainty and exhausting schedules were a common thread among my interview subjects. Many juggle their work in the space with their own artistic practices and contract or parttime work, without an obvious end point to such activities. It is difficult for parents, particularly mothers, to prioritise child rearing in an event-heavy environment geared for young and mobile participants.

My case studies are linked by the deep passion and commitment to the work of their space expressed by all participants interviewed. Every interview subject believes strongly in the merit and significance of their space and the community they supported. They put up with long hours installing exhibitions and less than ideal office conditions because of their beliefs in a meaningful endeavour. In this way the work of the artist-run space contributes to the process of self-actualisation, or creating themselves through what they do (McRobbie 1998). The artist-run space contributes to a sense of who the participants are, but mostly represents a fleeting or transitional moment in their development, one to be valued and celebrated, but not expected to be permanent. Members of $R M$ and Meanwhile characterise their involvement as a special vocation rather than a job, whereas both paid and unpaid participants in Enjoy frame their activities through the language of a job.

The only members not juggling a triple life are the paid workers at Enjoy, for whom a creative practice, paid work and the artist-run space are one and the same. It is through these accounts that the chapter demonstrates two distinct types of artist-run 
space practices. I found significant distinction between the professionalised emerging arts worker and the artist volunteer, who, though subscribing to many of the same organisational rituals (exhibitions, public programmes, publications) are operating with very different goals and outcomes. The arts worker is paid a (modest) salary and the relationship with the organisation is that of an employee, which brings, as Sophie Davis words it, "quite a different dynamic" (2017) to that of a collective member. For the worker, the role is a stepping-stone in the development of a longer career as an arts-professional. In contrast, the artist volunteer frames involvement in the artist-run as a service to the community, albeit one, the volunteer is aware, that may be personally beneficial.

Differences are also emerging between the early artist-run spaces of New Zealand in the 1990s, and spaces operating today, particularly emphasised in this chapter through the difficulties experienced by artist-run spaces operating in contemporary Auckland. The economic conditions of the bigger city have created conditions that make involvement in an artist-run space more difficult, but, in a flow on effect, conversely have been more productive for Wellington. This builds on the generational differences detailed in Chapter Two, where I argue that newer spaces have a stronger sense of brand from their inception. In addition, the New Zealand artist-run community is, I contend, a more culturally diverse place than in the 1990s, and this diversity has widened the scope of exhibition programmes accordingly. Issues around who is included, and who might be excluded, were significant to members of $R M$ and Meanwhile. Despite these discussions, there is still further 'work to do', to echo Ioana Gordon-Smith, in order to reflect the wider diversity of contemporary New Zealand.

In this chapter, Enjoy once more reveals a more conventional form, where "neoliberal discourses assume that individual success should be a primary goal for all" (Nairn, Higgins and Sligo 2012, 175). In the Enjoy model, modest salaries are offset by the opportunity for professional development, and success for the organisation is strongly tied to subsequent individual successes of staff, board members and artists, extending beyond the activities of the exhibition programme. Success beyond Enjoy is actively tracked and celebrated, and reported both to funders and within the organisation.

In contrast, both Meanwhile and $R M$ have resisted prioritising individual development over a more holistic community experience. In Chapter Two I detail how both spaces 
are reluctant to measure success by long-term career outcomes for the artists as a result of exposure. There is no naivety shown towards the impact an artist-run can have on career development, but there is also a determination to prioritise the experiential moment of the exhibition and its immediate reception within a community, and in doing so to enact a "strategic separation" (Lind 2010, 76). This chapter has documented artists' desire to minimise the effect of running the space on their own careers, as Bowling said, "it's a providing space rather than a way to get a leg up. You obviously get that, anyway". $R M$ have a track record of operating like this for over 20 years, and continually re-commits to such practices. Meanwhile have taken a similar route but are still in an early stage of organisational formation - which will be discussed further in Chapter Four.

$R M$ and Enjoy are established as distinctly different models for artist-run practice in New Zealand with very different institutional values, even though they are often conflated from outside. In Chapter Four I will examine more structural differences between these spaces in their organisational make-up, and the impact of these factors on identity formation. 


\section{Chapter Four}

\section{Governing Ourselves: The Artist-Run Space Organisation}

The language that the institutions are required to implement in order to communicate with granting agencies has its effects. It leaks into mandates and press releases, into mission statements and directors' reports. Regardless of how genuine the grant applications and reports might be, they create a textural corpus and discursive habits that influence a spatial subjectivity that is focused on holding space and surviving in a permanent crisis. (Hilder, 2017, 23)

\section{Introduction}

On 2 June 2003, Charlotte Huddleston, then gallery administrator at Enjoy, posted a message to the public Enjoy message board titled 'Selling art, Selling out?'

After careful thought and considerable debate the Enjoy Trustees have decided to make an investigative foray into the area of selling art ... The Enjoy Trust is aware of the power that pricing art has to polarise, we are also well aware of the dangers of this territory. The success of the experiment remains to be seen ... What do you think, is selling art at Enjoy selling out? (Ciaran Begley personal archive)

Co-founder of the gallery Ros Cameron was the first to reply, with an emphatic "Yes". Conversation raged backwards and forwards online, ranging from robust criticism to personal attacks. Despite most of the participants writing under pseudonyms it was apparent that writers recognised each other.

Co-founder Ciaran Begley wrote,

I know I wanted to instill Enjoy with a capacity for change but I honestly never believed that anyone would attempt to change this aspect of the project.

Anon shut down the discussion with an aggressive post that tackled the founders, bluntly stating,

One should be wary of nostalgia, especially when it is uncritical, as is yours. You know what, I'm glad that you left Enjoy, it has taken a while for to actually make some headroom and get somewhere interesting, something that never happened when you were running your little ivory tower. So shut up! Go away! Stop wasting our time. 
Enjoy would not actually go on to undertake commercial sales, but as the above story demonstrates, guardianship of an artist-run space can be fraught, with multiple viewpoints on its direction. Over time, a space gathers many participants, from members, former members, exhibiting artists and audiences, all of whom may feel a sense of ownership over the organisation.

In this chapter my key research question, To what extent does the New Zealand artistrun space offer alternatives to current neoliberal orthodoxy is explored through the structures and systems that underpin artist-run practice. I examine the organisational forms of my three case studies and how the form impacts on issues of ownership and legacy. The chapter is concerned with organisational change and how the members of the artist-run space articulate and describe their experiences of a changing gallery.

Chapter One argues that artist-run spaces usually begin life collectively, operating with a de-centralised power structure and engaging in non-hierarchical decisionmaking. Yet, even in a group without formal hierarchy, power relations are always present, and the previous two chapters have charted some of the negotiations and tensions that engage collective-run spaces internally and with the wider art ecology. Here I investigate the significance of collectivism for my case studies, and the impact of formalisation and governance on identity formation, as individual members and as an organisation. The nexus between the social, the organisational and the individual (Nentwich, Tennhoff and Vogt 2015) is where tensions arising from organisational development emerge and is a crucial focus of my research.

The lifespans of most artist-run spaces, as demonstrated in the Literature Review, are short and fuelled by the energy and intentions of the founders. Many spaces are started by a group of friends as they leave art school, run with enthusiasm and flair, and naturally come to an end when the lease runs out, or key members get a full-time job or move away. Spaces which run longer eventually change personnel and often structure, reflecting Jo Freeman's argument that, "any group of people of whatever nature that comes together for any length of time for any purpose will inevitably structure itself in some fashion" (Freeman 2013, 232). Sometimes, as with $R M$, the structure is flexible, but, as with Enjoy, other spaces transform into a more 
conventional hierarchy of governance and management with a board, a chairperson and staff.

In this chapter I look beneath the visible activities to chart deeper currents of institutional structure, how and why decisions are made, bearing in mind Clive Robertson's assertion that "artist-run culture produces subjects who have to resolve the conflicting needs for social cohesion and cultural critique". I draw on the theory of governmentality (Bennett 2018, 2013, 2007; Foucault 1991 (1978); and Lemke 2002; Rose 1999,1990$)$ to understand how spaces might be shaped and changed by the expectations and incentives of a wider art world, articulated particularly through the funding body Creative New Zealand who play a powerful role nationally as generator and moderator of the 'conduct of conduct' for the arts sector. I, therefore, keep at the forefront of my examination the question of agency by organisational actors within the spaces, bearing in mind Gray and Hadley's account of a shift in understanding from "people to whom instrumentalism happens, to being active agents who manage instrumentalisation for their own ends" $(2017,95)$.

The chapter is divided into three sections, each of which examines a different element of organisational identity. First, the governance structure of each case study is considered, particularly how spaces have navigated the shift from founding members to a more permanent next stage. Second, I examine the impact of funding on each space, as they themselves articulate it. Using the theoretical framework of governmentality, I examine the discourse (spoken and written) by which artist-run spaces describe their relationship to funding and what part financial imperatives play in the conceptual project of the artist-run space for its members.

I go on to explore the role of organisational discourse used by the artist-run's participants to define themselves. How powerful are these stories in creating a sense of organisational legacy and how do they influence current direction? What relationship do the founding members have to a space, 20 years after they willed it into being? I also investigate the importance of an organisation's name as a talisman that articulates the scope and essence of the artist-run space for members and audiences. Who does a name speak to and for? When change occurs, should the name change to reflect it? The crossfire between these elements is where the crux of this chapter lies: ownership of the space; competing tensions between members (past and 
present) as to how the space should change and evolve; and tensions between where the space sits in relation to the wider art world. Especially, in this chapter, the elements relate to issues of agency.

\section{Come Together: A Collective of Artists}

As I have described previously, the early stages of an artist-run space are characterised by the coming together of a group of friends, most often recent graduates of an art school, who make collective decisions about the space. In its early days a group may make decisions informally, employing friendship and shared interests as a binding mechanism, or in some cases employing more defined methods of decision-making from the beginning.

In the Literature Review I have examined the political and social nature of collectivism in artist-run spaces, which runs counter to wider neoliberal narratives of individualism. The trajectory from non-hierachical group to more formalised entity is one followed by many artist-run spaces. What leads such spaces to make such a shift, and what is gained, and lost, in such a process?

Enjoy was, on paper, formalised from the very beginning, although the articulation of that formality was intended for funding purposes only. Co-founder Rachel Smithies, a social researcher (or self-described "bureaucrat"), set up Enjoy as a charitable trust to enable it to apply for grants.

I very quickly figured out, because of being a researcher and trying to find out what other money you could get, that most other money required us to fill in various forms and have a sort of formal structure. That that would be the best way to set ourselves up, in order to be able to tap into public funding. (Smithies 2018)

Because of their status as a trust, Enjoy solidified different functions from the start. Ciaran Begley explained, "to get charitable status you have to fulfil a series of roles within an organisation". The three members, Begley, Cameron and Smithies, took turns adopting the roles as needed, "a curator, a technician, a publicist ... we could chop and change within the organisation". The shifting nature of these roles emphasised for both Smithies and Begley that the governance structure was, as Begley points out, "titular as opposed to a practised thing". 
The structure of three people making up the early years of Enjoy was not accidental, but crucial to their understanding of the space. Begley explains,

With just three people involved at a maximum, it means you can't get big; that you have this necessity of close communication that grows or fails and is immensely personal and emotional, but is also really grounded. So you have to front up for everything you do. (Begley 2018)

After the first year, Enjoy was awarded funding support from WINZ to enable two members (Ciaran Begley and incoming member Charlotte Huddleston) to receive the unemployment benefit to work, through the PACE scheme ${ }^{25}$. It was not planned, but occurred through an accidental discussion with Begley's WINZ case worker,

[WINZ] caught me out. I said, "We're running a gallery". And the guy said, how many hours are you doing a week, and I did a rough calculation and said roughly about 70 hours. And he said, "that's not ok, but we can get another person on a work for the dole scheme to do the other half of that, and get you the second half'. Which meant we actually put out a job offer and got Charlotte [Huddleston]. (Begley 2018)

Despite this apparent formalisation through the introduction of (barely) paid staff, Enjoy continued to maintain a fluidity of roles. The membership expanded with the inclusion of artist Tao Wells along with arts worker Charlotte Huddleston. After two years, Smithies and Begley moved to London and Cameron became increasingly busy with study, so the three founders met to discuss the future of Enjoy.

There was, for the first time, slightly more substantial money and possibly future money. So we had a conversation about, as founders, do we kill this now, because we're all pulling out? Or do we hand it over to other people to keep going with the name and the structure?" (Smithies 2018)

Smithies' recollection was that she advocated strongly for its continuation.

It's been so much blood, sweat, and tears to get us to this point, it would be such a waste to just close this down. We should let other people use all the stuff. (Smithies 2018)

The founders all left and the space continued. As new people arrived, and originators left, the formalised structure, intended to function as "a shell” (Smithies 2018),

25 Pathway to Arts and Cultural Employment programme, which ran 2001-2012. This scheme enabled arts practitioners to register with Work and Income New Zealand as a job seeker with their primary job field as an artist, actor or musician, receiving the unemployment benefit and specific training programmes. https://www.pantograph-punch.com/post/difficult-history-of-pace 
gradually became organisational practice. By 2018, 18 years after it opened as a collective, Enjoy was governed by a board of trustees, with a chairperson, secretary and treasurer, and a paid staff of two, along with volunteers. Each has clearly demarcated roles. As Ann Shelton, chair of Enjoy, outlines,

We vote once a year on who we want to be Chair and who we want to be Treasurer, Secretary, etc. And we try to recruit to make up where we don't feel we have the right set of skills, as we perceive them, to achieve our mission and vision. (Shelton 2018)

As I described in Chapter Three, the staff of Enjoy are emerging arts workers rather than artists, hired on fixed term, three-year contracts by the Enjoy Trust. Enjoy board and staff members meet monthly, with formal minutes taken by an external minute taker. A manager's report is presented at each meeting, with updates on key performance indicators set by Enjoy in their current agreement with Creative New Zealand. An AGM provides the chief strategic planning tool for the space, with monthly objectives set for the year to come.

In many respects, therefore, the organisation is structurally very different to its early incarnation. But Ann Shelton argues Enjoy have retained their own individual take on governance which is significant to maintaining a connection to their past. While many arts organisations of the scale of Enjoy seek to recruit trustees from a range of backgrounds, like "lawyers, accountants and marketing and business people" (Nahkies 2014, 74) Enjoy has an emphasis on practising artists. This, Shelton says, is important "to keep those links to the artist-run space".

Obviously we operate in a completely different environment now, we have over $\$ 120,000$ of government money coming in every year, and we have responsibilities that we take very seriously, for that funding. We are this interstitial space; we're a bit liminal. We are probably more towards the institution and less towards the artist-run space now, but ... I like to remember those roots and what that means, and think about how that can be inflected in the organisation. (Shelton 2018)

For Shelton the presence of artists on the board is crucial to keeping a link with the past, particularly given a staff of emerging arts professionals. A board predominantly made up of artists demonstrates for Shelton that, despite its changes, Enjoy still places artists at the centre of the organisation. This is both a symbolic gesture towards the 
past and a statement that attests that artists will bring a different perspective to governance.

However, not all Enjoy members expressed the same commitment to an artist-centred board. For other participants this attitude excluded skills and experiences that could benefit Enjoy's complex needs as a mid-sized organisation. Board member Jessica Hubbard observed that "the skill of being an artist and the skill of being a successful trust member isn't necessarily a totally overlapping set of skills" although she also noted that "in order to be a successful artist, you actually have a lot of management you need to do". The view was echoed in interviews with current and former staff.

I think the board would be strengthened by having some more perspectives especially to support Louise and I, because, we're not artists. We've got other interests and it could be helpful to have more of that reflected more in the governance. (Davis 2018)

What I think should happen is that people on the board should be ... bringing in different skills, like lawyers, accountants, people bringing in skills that are useful to keeping the organisation running. (van Zon 2017)

The focus on artist representation, although emphasised by all of the interviewees, was not total. At the time of my active research two members of the board were not artists, Kate Ricketts (arts fundraising and administration) and Bruce E. Philips (curator and writer). They were not, however, on the list of board members I was given access by Shelton to interview, implying that artists were considered the most significant and relevant members of the organisation. 


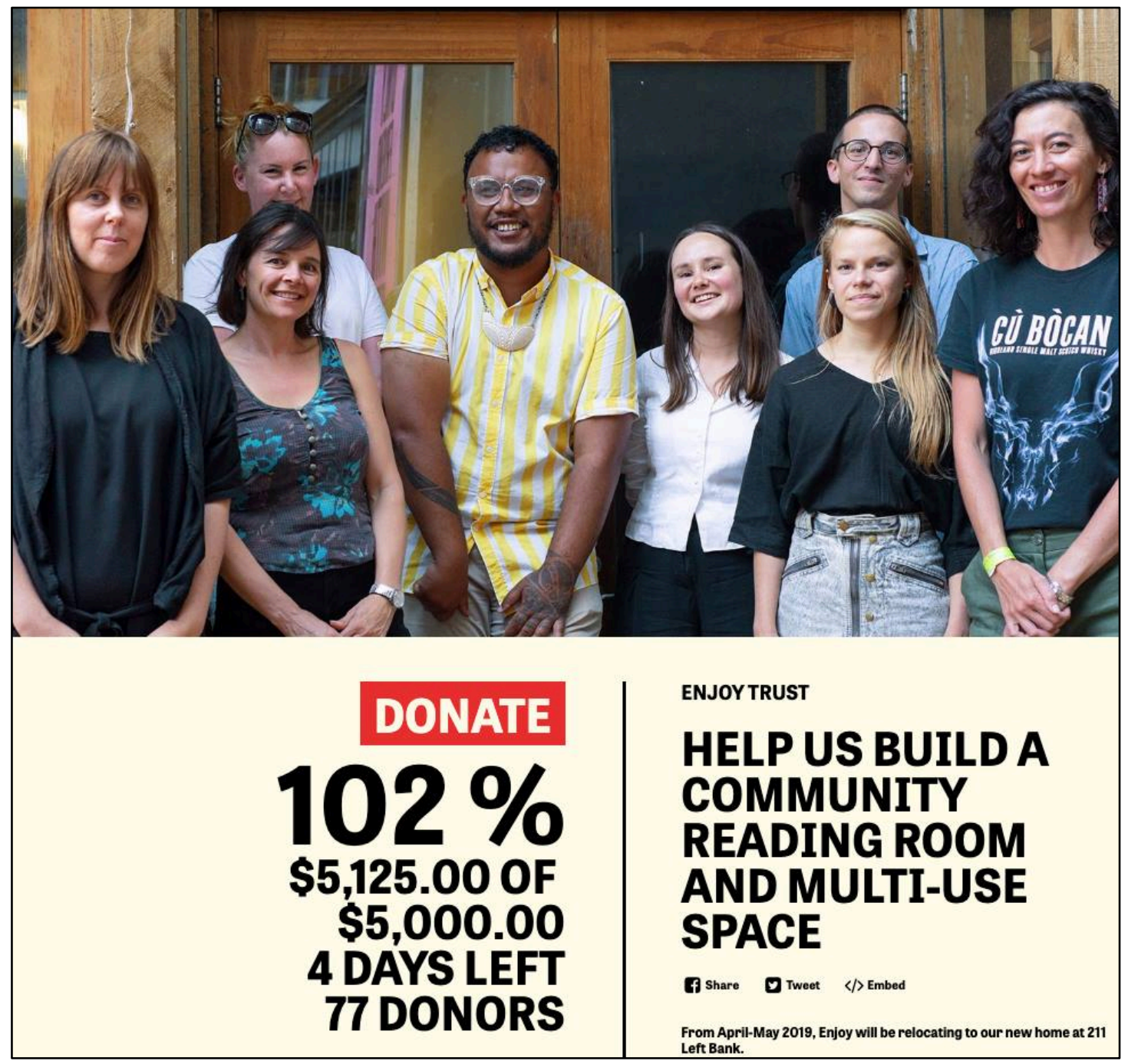

Enjoy Boosted Campaign 2019. Photo: Enjoy archives

Tension arising from the role of artists in the governance of Enjoy was representative of wider differences of opinion among staff and board members about where the organisation was heading. At the time of active research, Enjoy's members were discussing further expansion, with talks underway about a shift to a larger, more flexible space. In my interviews differing opinions emerged between members as to the extent Enjoy should develop. Chairperson Ann Shelton, argues expansion was inevitable, "I expect Enjoy will grow, in terms of its size, and the group of professionals that support it. So I imagine Enjoy will get bigger." Gallery Curator/Manager Sophie Davis is more cautious,

I don't think you need to grow, in the neoliberal sense of the word, where we're always trying to grow, to get more ... I think that comes up against that tension again, of change/growth vs. things staying the way they are to resist those external pressures from funders. (Davis 2018) 
The interviews conducted demonstrate that within the organisation there are mixed and contradictory perspectives towards funders as well as institutional scale, and that the issue of who, and how, they should be was a particularly live one for the organisation at that time. Such tensions demonstrate the ongoing pull between two core organisational desires for artist-run spaces; that is, as Clive Robertson describes, "to be both fluid movement and a lasting apparatus" (Robertson 2004, 4). Robertson is referring to competing impulses, both of which can be argued as crucial to an artistrun space's survival: to remain artist-focused and flexible to the changing needs of artists, and yet build an organisation which is stable and sustainable.

In contrast, $R M$ established three years earlier than Enjoy, has remained a collective for 21 years, with a revolving network of artists operating in an informal alliance. Throughout this time, they have used consensus as a decision-making process. Current member, Deborah Rundle, previously a professional mediator, says $R M$ 's reliance on collective practice is integral to her involvement.

[We are] deeply committed to different ways of decision making ... challenging ourselves and each other and establishing a different voice and environment for artists to practice in. Sometimes it might have its inefficiencies, but philosophically it's really important. (Rundle 2017)

$R M$ meet informally every two or three weeks to talk over the upcoming shows and allocate jobs to be done. They don't operate with set roles, so the meetings are run without a chair (although Rundle notes they "have a good number of people who are really good caretakers of meeting processes") and someone will volunteer to write meeting notes. Having entered the space at a time of particular upheaval, following the departure of the last co-founder, members are aware of needing to evolve their own systems "if there is a document that speaks to that particular issue we didn't find it" (Rundle 2017).

none of us had worked in a group of eight people like this before so we're still figuring out systems. Like who's checking emails that way we're not all responding. All these kind of things, but we're slowly putting in new systems and it's quite casual. (Sanders 2018)

Sanders acknowledges Deborah Rundle's important part in supporting this development period, having come from "a background in running her own businesses and has quite a thorough understanding of lots of more efficient processes and so 
many things that I wouldn't even know about" (Sanders 2018). New member Jess Morgan described the organisation as a work in progress "we're planning on doing a workshop day where we figure out roles and stuff. At the moment it's a little bit up in the air" (Morgan 2018).

It's not that $R M$ haven't considered formalising their governance structure (as Nick Spratt says, "it's hard to go for 20 years without having some of those conversations"), but each time the idea has come up, they have re-committed to the idea of collective practice. The closest they have come to changing to a more formal hierarchy was in 2016, when Spratt began the leaving process, and the collective explored formalisation in a serious way. In 2016 the then members of $R M$ (Nick Spratt, Taarati Taiarua, Ziggy Lever, Natasha Matila-Smith, Bridget Riggir and Melanie Kung) engaged in an intense period of self-examination, and decided to undergo transformation to form a legal board of trustees. Because of their long history of collectivism and the regular practice of sharing internal documents publicly, it was decided the process of formalisation should be shared actively with their community, rather than conducted in private.

They felt really strongly they wanted to be able to set up a platform or foundation for the gallery that could ensure some continuity, that could take those ideas that were key to what we were doing and continue to use some of the historical understandings that I had, so that I could potentially be in a space where I could be part of a brains trust, potentially as an advisor. We really wanted to do that in a way that was consultative and to involve others in the conversations. (Spratt 2018)

Their Creative New Zealand application in 2016 described the anticipated consultation process as follows.

Transcripts from a series of workshops around the concept of governance, history of $R M$ and other ARI's, and the development of a founding document will be compiled, and this new body of research will be made available to the public through transcriptions of the interviews in publications available onsite and online. (RM 2016, n.pag.)

The intention to be transparent followed on from $R M$ 's history of learning from other spaces and wishing to, in turn, share their own experiences with audience members and with other artist-run spaces. Yet, despite the detailed plan, the proposed consultation was never completed. Spratt explains, “for various reasons that didn't get anywhere, those conversations never quite happened in the way we wanted to, life got 
in the way for everybody". Current member Dan Sanders describes this tumultuous period as driven by a particular, individual, curatorial ethos,

The person who initiated that conversation left $R M$ to work in a gallery in a structure that she was envisioning for $R M$. So now everyone who is working for $R M$ is an artist. I think that's quite a big thing to maintain as well. This particular individual was from an art history background and so I think it was just a different view of how things work or something. (Sanders 2018)

This period was the closest $R M$ has come to formalisation, and can be seen as a significant moment in the space's development, a moment where they could have changed to become a more rules-based entity which distinguished between governance and staff. The identification of this possible change with a member from 'an art history background' is significant, demonstrating that the current members of $R M$ place a value in an artist-only membership.

we were thinking about some of those things around how power plays out, in those environments, and that the role of curatorial practice might better sit somewhere outside the artist-run space. It doesn't mean that no shows would be curated, but it's different from having curators on the collective. And that could change, but we did think about it really deeply, and I think it was an important question to address, and we ended up deciding that it was artists who'd run the space. (Rundle 2017)

Meanwhile are still relatively new as an organisation, However, in 2018 they made a shift from an original group of three art school friends (one of whom, Callum Devlin, had been previously replaced by Sean Burn through an informal process in 2017) to a more formalised collective, generated by an open call for new members. Much like $R M$, Meanwhile hold group meetings every three weeks to discuss upcoming shows and allocate tasks, however, a significant difference is the emphasis Meanwhile place on online space for much of their discussion and decision-making "it's a lot of our communication" (Bowling 2018) using Facebook chat or instant messaging.

Sean Burn describes the members as busy juggling work and art commitments, making online communication the easiest way to keep in touch. In addition, each member tries to invigilate the space one day a week, to ensure connection, although they also have volunteer gallery minders.

We're always in constant communication, just talking, a lot of the time it's just reminders - have you done that thing yet? We have a facebook group, we have a couple [actually]. We have a facebook group for the studio artists, that anyone can post to, any time, we often post updates up there, there's chats going on. And 
then we have another facebook group which is all the volunteers and we have an open communication with them, all at once. (Burn 2018)

The process of bringing in new members generated an active period of organisational document writing, resulting in the Meanwhile Kaupapa (2018), which includes information for each of their core communities (studio artists, exhibiting artists, volunteers) and a safer spaces policy. New member Simon Gennard is an art history graduate who is an emerging writer and curator. He stresses that the paperwork was less about documenting change than it was in capturing the intangible qualities of the space to date.

There was an intimacy between the three of them that allowed for things not to be set in stone. So one of the first things we did when we came here is write up a lot of that knowledge, have Sean and Jordana offer what they knew ... so that this knowledge that was transmitted orally was formalised. (Gennard 2018)

Dilohana Lekamge, an artist appointed at the same time as Gennard, agreed,

I think there was a lot of trust between the three of them, and it operated on good faith. Things can and did come up and we needed to create our own set of guidelines. So that we have a clear idea of how we want to run the space and what we want it to be like in future. (Lekamge 2018)

Gennard's appointment signals a shift from strictly artist-run to the introduction of arts professionals, but members refute suggestions that his appointment signals change. "Simon's been there from the beginning. I didn't even know him then, but I was looking in the archive a few weeks ago, and I saw a picture of him on the first night, and I was, like, it's fucking Simon" (Bowling 2017). Sean Burn, themselves a designer rather than an artist, prefers to use the term "creatives" to describe the wider community of facilitators and studio artists, and Lekamge argues "we all have different skills we bring to the team which makes it easier to run a space and also less stressful”.

A diversity of attitudes expressed by facilitators towards formalisation of governance structure, however, does signal a changing approach. Founding member Jesse Bowling is against it, but sanguine about the fact that, as a leaving member, interviewed just prior to his departure to study in Melbourne, he cannot control what happens in the future. Bowling argues that "longevity's a good thing, but I'm hoping it'll stay as a volunteer-based entity rather than going into a more board/curatorial, 
like Enjoy's done." All members of Meanwhile interviewed measured themselves in relationship to Enjoy (much as members of $R M$ defined themselves in relation to Artspace).

So much of the purpose of Meanwhile and embedded into our identity is that we're not these institutions, we're so radically different than that, and we're trying to be as free and experimental and for the artists as much as possible. (Sean Burn 2018)

But the more recent arrivals at Meanwhile articulated a position far more receptive to formalisation. Both Gennard and Lekamge perceive the formation of a trust enabling more transparency and a move away from personal decision-making, which Gennard explains as "there's an extra level of accountability with a Trust ... the organisation can be held to account".

Meanwhile was, at the time of my active research, poised at a moment of development. The influx of new members, which for $R M$ provided a time to reaffirm and recommit to collectivism, for Meanwhile triggered an interest in adopting a new structure. All members interviewed felt that they could undertake that change without "becoming the very thing you were trying to be different to" as Sean Burn explains. Jesse Bowling, interviewed as he was about to leave, cites anecdotal knowledge of tension among Enjoy's founders as to the evolution of the gallery, declaring that he was prepared for change he might not like.

Say in two years time it's still going, and the facilitators are completely different people and they start going for massive CNZ funding to commercialise it then it's just what happens. (Bowling 2018)

Meanwhile are shaping themselves in an environment with existing models, whether as mentors or examples to avoid, and their evolution may, accordingly, be different to the earlier generations of spaces, like Enjoy. Meanwhile's emphasis on their Kaupapa and Safer Spaces documents and conscious shaping of their brand through social media channels, demonstrate a highly attuned performativity. Perhaps this means they are less vulnerable to the regulations and practices through which funders groom funding clients, or perhaps the notion of 'selling out' is not so relevant to an organisation which is less wedded to the concept of being alternative. 
As my Literature Review argues, the question of whether artist-run spaces need to be run by artists is an ongoing source of tension within the sector. The argument pivots on the notion that there are unique artist-run values which sit outside or counter to wider art world positions, a belief that connects to broader conceptions of art first developed during eighteenth-century Romanticism, that construct the artist as a category with a "sacred calling" (Shiner 2001, 197) in which specific attributes of "inspiration, imagination, freedom and genius - [are] ascribed to the artist" (Shiner 2001, 111).

When $R M$ confirmed, in 2017, "it was artists who'd run the space" because of concerns "around how power plays out, in those environments" (Rundle 2017) the participants can be understood to be affirming Clive Robertson's argument that "artist-run is neither only nor simply a personnel question. It is an ethical refusal by artists not to 'anthropologise' other artists" (Robertson 2004, 57) a position that seeks to highlight the distinctiveness of the artist-run within the mainstream art project. Robertson argued "artist-run culture is a practice that aims to make a difference in the world, that has ... some points of difference or distinction which have to be staked out, which really matter" (Robertson 2004, 57).

The importance of an artist-only membership was positioned as crucial to their sense of identity by RM's current participants and by some of the participants in Enjoy, although differing opinions were held by other Enjoy participants. RM's participants identified a commitment to artists over curators as a tactic to resist the hierarchy of a wider art ecology, with curatorial power suggesting to them wider systems of institutional gatekeeping. For the chairperson of Enjoy, having a board predominantly comprising artists actively recalls the gallery's history as an artist-run collective, asserting artistic legitimacy by claiming its more experimental roots.

The younger organisation of Meanwhile were relaxed about their recent shift from an artist-only organisation to a wider mix of facilitators. Sean Burn's use of the neoliberal terminology of 'creatives' instead of 'artists' suggests less anxiety about such distinctions. Such slippage, I argue, is not insignificant, and echoes other differences between Enjoy and RM, organisations formed around two decades ago, and Meanwhile, a thoroughly millennial organisation inflected with the language and attitudes of its times. 


\section{Impacts of Funding}

To what extent have funding imperatives driven the decision to remain a cooperative or to formalise? This section examines the financial impact of the different paths $R M$ and Enjoy have chosen, as well as attempting to chart the external pressures placed on the spaces by funders.

Judy Darragh, talking about Teststrip, describes the conundrum of receiving public funding which enables an organisation to do more, but comes with expectations.

It definitely changed it. It sort of professionalised it, I would say. Then as soon as you're under the umbrella of CNZ that does give a bit of a different quality. Because you've got to report stuff. (Darragh 2018)

What did she mean by professionalised? Darragh sketched out a trajectory where funding contributed positively to Teststrip's development, not only enabling an increase in activity, but also providing a mechanism for the gallery to continue at all. But she was simultaneously critical of Creative New Zealand's funding system, which she described as top-down and overly focused on success.

They tend to fund stuff that's going to work. With good outcomes. They like their outcomes. They're not risk-takers. I think they need to think about how they're supporting artists more. And collectives that help ... Their role is to dish out money. They don't see their roles as being leadership or advocacy. (Darragh 2018)

Creative New Zealand "has increasingly focused on the professionalisation of arts practices" (Willis 2017, 86) through what she describes as "a neoliberal transformation" (ibid.). A key policy directive is ensuring stability in funded organisations, emphasising "efficiency and effectiveness" (Nahkies 2014, 8) in accordance with Creative New Zealand's governance manual, a stance which equates stability with longevity. Rachel Smithies, co-founder of Enjoy who went on to a career in policy at Arts Council England and the Australia Council for the Arts, believes public funding bodies track "A, individual success, and B, having some infrastructure" (2018).

In part this emphasis is because artist-run spaces are less successful at matching a third funding agency focus, being "audience focused" (Creative New Zealand 2010, 
2) due to the small audiences they garner. For many small spaces, emphasising they are "well managed, professional and accountable through the adoption of particular management styles" (Alexander 2018, 32) demonstrates sustainability that extends beyond gallery footfall. Enjoy's ability to demonstrate both organisational stability (particularly division between governance and management) and strength in career development (Chapter Three) has been central to funding increases over time.

In 2011 Creative New Zealand launched two new programmes for recurrent organisational funding, Totara for "leadership organisations" and Toi Uru Kahikatea for "development organisations" (Creative New Zealand 2011). These two strands support Creative New Zealand's flagship organisations, enabling funding beyond a project-basis over a multi-year period. Both Enjoy and its equivalent in Dunedin, $B O A G$, were accepted into the Toi Uru Kahikatea programme from the beginning, while $R M$, of similar scale and duration, is still in the project funding bracket.

Chair Ann Shelton identifies Enjoy's organisational stability as significantly driven by Creative New Zealand, who have encouraged and supported their organisational development.

Part of that is to do with the roll-out by Creative New Zealand of professionalisation for organisations like Enjoy. So there's been various initiatives to up-skill and train both staff and trustees, in things like "what is governance?" and "what is management?", so they ran courses about that sort of thing. And then they ran courses in fundraising, "what's the role of the Trust in fundraising, what's the role of the staff in fundraising?" Those sorts of programmes have really affected where we're at ... they played a role in our development as an organisation. (Shelton 2018)

As Shelton describes, Creative New Zealand's influence has been felt in both formal measures, such as setting key performance indicators for the gallery through funding acquittals, but also more intangible influences through professional development for staff and board. In effect, Enjoy now reflects, in miniature, the governance and management structure of a public art museum and, perhaps significantly, the structure of Creative New Zealand, in "a mirroring or even a confluence of strategies" (Jackson 2013, 114). They, like other long-standing artist-run space $B O A G$ in Dunedin, "have demonstrably moved beyond their artist-run space roots" (Amodeo 2017, 4). 
Yet Shelton's emphasis on an artist majority on the board of trustees runs counter to Creative New Zealand's emphasis on trustee recruitment from a range of professional backgrounds, for instance "lawyers, accountants and marketing and business people" (Nahkies 2014, 74). When pressed, Shelton admits that they might need to shift the make up of trustees if Enjoy were to significantly grow, "start looking at the trust's roles and the number of trustees".

$R M$ 's recommitment to operating with a non-hierarchical collectivism, without distinction between governance and staffing, was articulated passionately by all current members, but it comes at a literal price. Current participants stressed they are not able to shift from CNZ funding through the Arts Grant system, where the organisation's grant applications are assessed anew as individual projects in each round. In contrast, both Enjoy and BOAG, the two equivalent New Zealand spaces in scale and longevity to $R M$, have been on recurrent funding for many years, both currently through the Toi Uru Kahikatea/Arts Development Investment programme.

A shift by $R M$ to Toi Uru Kahikatea is, participants argue, contingent on adopting a more conventional, corporate structure of board and staff. ${ }^{26}$ "If we had a set-up similar to Blue Oyster [Art Gallery], we would be able to get bigger CNZ funding, or better funding from, say, Auckland Council because we'd be an incorporated enterprise" (Afoa 2018). None of the members interviewed expressed resentment at this stance, although all said they would prefer it if CNZ would recognise the importance and success of their own structure.

Receiving funding was an opportunity to be more proactive with what we wanted from the space, to be more thoughtful about what we showed, that changed the movement from making shows because of a necessity to keep things moving, to take the financial constraints off and be more responsive. (Spratt 2018)

The discussion about funding remained a live one for $R M$ - "we have talked about that a lot, whether it's in the space's best interest to kind of switch to get more funding" (Afoa 2018). But, so far, making the shift away from a collective to a 
conventional management / governance structure is perceived as compromising their commitment to consensus.

It feels like it compromises too much of what we do and who we are and what we like about the space ... It's always great to have more funding but when that means that you lose who you are in the process then it's not worth it. (Afoa 2018)

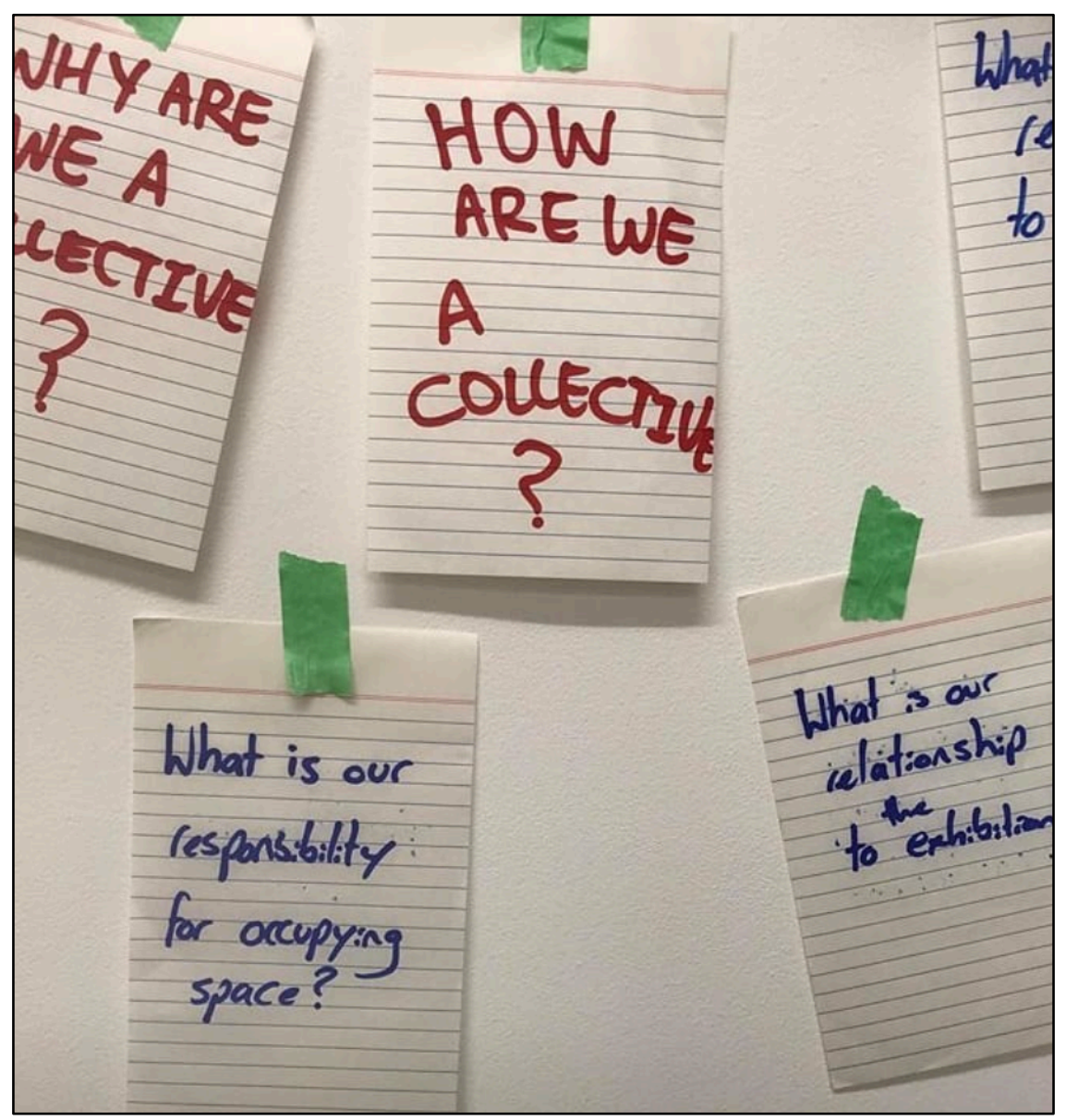

$R M$ Instagram Post, 30.04.2018. Photo: $R M$ archives

Consensus remained a central tenet for $R M$, not merely as a procedural element but also as a broader kaupapa or belief system, from which all decisions and activities should stem. Their exhibition programme, events and public archive were shaped by consensus and reflected deeply held institutional values. $R M$ 's renewed commitment to remaining a non-hierarchical collective was not framed up by members as a form of resistance explicitly to Creative New Zealand and their policies, but rather became a crucial element in a wider project of "resisting the white cube structure" (Sanders 2018). 
I argue that such a tactic demonstrates that $R M$ is again enacting a "strategic separation" (Lind 2010, 76), not by removing themselves from the funding imperative but rather through actively limiting the scale of funding they require to carry out their desired activities. By refuting the organisational imperative to continually grow, they remain at a static organisation and financial scale. Again, it's not that $R M$ as an organisation has been able to reject funding norms, but rather that they have found a space for themselves within the restrictions of funding that provides them with a level of agency that they are comfortable with, by limiting the extent of their financial ambitions.

Enjoy, seen through Shelton's lens, represents Clive Robertson's “good administrators, artists, workers" $(2004,3)$. The enthusiastic take-up of mentoring by the funding agency and the reframing of their discourse and practices through Creative New Zealand's terminology demonstrate the extent to which Enjoy has sought out their self-regulation. Enjoy's adoption of the policy discourse of organisational efficiency is, as Shelton describes, self-motivated yet encouraged and supported from above. Such a trajectory reflects the complexity of the governmental framework, as "a power which placed the people behind it, inveigled into complicity with it rather than cowed into submission before it" (Bennett 1988, 80). The creative agency of both $R M$ and Enjoy is therefore, I argue, a complex make-up of decisions and ambitions taken by individuals and by participants as an organisational whole, yet simultaneously framed within a larger system which supports and endorses a particular set of normative values and practices.

\section{Stories and Legacies: Organisational Ownership}

In this section I closely examine key stories told to me about one of my case studies, to understand how participants use narratives to describe and explain the space, for themselves and to others. When Jesse Bowling told me that they had archived online Meanwhile's text messages "to canonise ourselves, I guess, in our first six months. It was solely to say, "what have we done?" he is outlining the conscious development of organisational discourse. Inside an artist-run space, I began to realise, individual participants can hold a range of contradictory positions, and stories used by participants claim positions; to leverage status within the space, or narrate 
organisational power negotiations within the wider art world. This section asserts that there can be many levels of ownership of a space, from legal to historical to emotional, and stories about ownership are used to build and maintain institutional legacy.

Organisational discourse, as my Literature Review describes, has a wide range of functions, including: communication; managing change; sense-making; building and maintaining culture; and sharing knowledge and learning (Weick and Browning 1986). As the Literature Review shows, studies in organisational identity work follow how individuals within organisations construct identities through a series of ongoing stories (Giddens 1991) told by individuals who are in turn constantly negotiating their own identities (Brown 2015). Therefore, examining an organisational identity means understanding that organisations' identities interrelate with those of their participants and are managed by those participants (Elsbach and Kramer 1996). My growing understanding that "people in organisations actively and critically interpret discourses to construct and maintain a sense of self" (Weatherall 2018, 22) shifted me from considering each artist-run space as having a singular identity to acknowledging the space as an intersection between individuals, organisation and the social (Nentwich Tennhoff and Vogt 2015).

Curator Anselm Franke has described the act of an institution defining itself publicly as performing a series of gestures, vehicles to create difference and place an organisation within a taxonomy.

An institution has to perform itself, has to act out its own script until the script can be rewritten ... It is not about the content of the story as such, but about the act of telling it, and about its possibility and the options and practices it authorises and enables. (Buergel et al 2006, 40)

I wanted to observe, close up, a series of organisational gestures to explore how an artist-run organisational identity is actively constructed. This section focuses on one case study, Enjoy, to examine in detail tensions over its stewardship. My case study research found Enjoy to be the site where friction ran highest on issues of ownership and development, both between current participants, and between current and former participants. I examine narratives told by interview subjects about two formal, external organisational markers, the gallery's manifesto and its name. The, sometimes 
oppositional, accounts of the gallery's manifesto and name demonstrate the contradictory nature of organisational history.

Enjoy's Mission and Vision provides an important organisational narrative for the gallery, as the official representation of the organisation. The Mission and Vision's role is both private and public; to inspire and keep the gallery on track, and to stake a position for audiences and funders. It is used in funding applications and displayed on the website.

Enjoy generates and facilitates contemporary art projects to promote the discourse of contemporary art practice in all its forms. Enjoy is liberated from commercial constraints in order to provide both emerging and established practitioners with opportunities to develop innovative work. Enjoy works to provide the necessary critical support, resources, and audience development to realise quality projects in dialogue with contemporary practice both nationally and internationally. (Enjoy Trust 2018)

This Mission and Vision was developed very early in the gallery's development and Chairperson Ann Shelton is proud that it has remained relevant, years later. She cites it as a connecting thread, linking Enjoy back to "its history as an artist-run space".

We re-evaluated that mission and vision about five years ago, and when we work-shopped it with our community, nobody wanted to change it. We left it exactly as it was. So I think that the fact that that has endured, in that way for nearly two decades, and is still really relevant, really speaks to what a great job the founding trustees did of setting it up. (Shelton 2018)

Staff member Louise Rutledge agrees that the longevity was significant, "it's held very strong throughout Enjoy's history, which shows what forward thinking it was" but she felt it needed to be reconsidered to reflect organisational change, "it does still say we are an artist-run space, so it probably needs updating". The term "artist-run space" was rejected by all interview subjects in relation to Enjoy, Sonya Lacey arguing "it seems inaccurate" and Jessica Hubbard contending "I don't think we consider ourselves an artist-run space anymore". But for Shelton, the text was a powerful symbolic gesture, grounding the organisation and demonstrating a belief system that has transcended scale and time.

However, this notion of the text as an act of connection, unifying current and earlier iterations of the organisation was rejected by founding members, who disagreed that the manifesto had ever represented the spirit of the original space. Co-founder Ciaran 
Begley, echoing Smithies' description of the brand and structure, maintained that the manifesto was intended as "a shell", or a skin, that could be slipped on as needed for funding purposes.

Those manifestos were written because you had to for Creative New Zealand, for your funding application ... that's not to say that that wasn't us, it's just that our concerns were broader and more complicated ... you're having to codify it in terms that your art funding body will respond to. So you edit out stuff ... (Begley 2018)

For Begley, "there's a conversation about the spirit versus the letter of the law" and, again, a disjunction between the organisation's early reality and the version of itself performed to funding agencies. The rituals and energy that, to Begley, defined the space, were intangible and personal qualities which, over time, became invisible to new participants, and the incomplete truth of the documentation became established as fact.

The notion of maintaining an artist-run space for a period of time before handing it on to others to continue requires a delicate balance between new and old. Decisions about what of the past to bring with you, and what to discard, are complex, especially when a space has many former participants to try to honour. Sophie Davis describes this juggle as "an evolving beast".

You do feel ownership but it's not like the organisation is yours ... we're more like caretakers that set the direction for a period of time ... You need to work out what Enjoy means to a whole lot of people. You've stepped into 17 years of history and its weight and people are always going to have opinions about everything you do. (Davis 2018)

Many participants, once their time with the space has finished, feel no strong sense of connection with the continuing organisation. Interviews with the founders of $R M$ all stressed a distance from its current iteration ("I don't have any connection at all" Wylie 2018), both because the physical space was different "and the people changed so much as well" (Drayton 2018). For Nick Spratt, leaving $R M$ after 17 years was difficult, although he was ready to leave and had been open with his fellow members that he would go. "I guess", he concludes, "there's a bit of grieving”. Spratt, like Wylie and Drayton, felt disconnected from the gallery in its current state, although he 
had some contact with current members, ${ }^{27}$ "It's weird going back there. And there's that sense of wanting them to have ownership of what they do."

I experienced a relaxed quality in the accounts of $R M$ founders, a sense that they had benefited from their time with the organisation and did not seek more than that. To Zoe Drayton, the legacy of her involvement was skills and experiences learnt running the space- "rm3 gave me [a] model to build on"-which were useful later on in her role as Director of the Audio Foundation "it was a matter of placing the Audio Foundation skin on top of what I'd learnt". Joyoti Wylie, now working as a high school art teacher, is wary of the mainstream art world, but looks back on her time at $R M$ "really fondly. For me it was a lifestyle, running your own gallery was really fun. I really enjoyed it."

But for the founders of Enjoy, the artist-run space's continued existence was a source of ongoing regret and their accounts were underscored with displeasure and even antagonism. While the public debates about Enjoy's role that had characterised the mid 2000s no longer occur, both Rachel Smithies and Ciaran Begley expressed their dismay at the organisation's current form, with Smithies stating, "I would kill it, now, if I could” (2018). For Smithies, Enjoy's evolution into a conventional workplace with a professionalised staff and governance-focused board, suggested it had become "institutionalised". Infrastructural changes, she believes, have led to changes in brand and programming and "it doesn't seem to have quite the messiness and experimentation and playfulness that we were able to have at the beginning". In this respect she is critical of the funding space that Enjoy occupied in the local terrain, which she felt ensured that other, new spaces were not supported to emerge.

A space like Enjoy, in the context of very limited funding, ends up sucking up a lot of energy and money ... none of that funding is available for things like what we were doing. (Smithies 2018)

I think it's really important, when you're setting up these things, and you're making formal structures, to sit down, not when you do it, (because when you first do it you have no idea what you're actually doing) but if you're thinking about leaving, to talk about what it is you think should be left behind. It's making sure that, as the thing changes and develops, if it is appropriate, at this point, to change your name, to really engage with a new form. (Begley 2018)

27 One unanticipated consequence of my research is that my questions to current members of $R M$, has led them to contact Spratt to clarify elements of $R M$ 's history that my research identified as gaps in their knowledge. 
For Begley, the name linked the space to its past, and he expressed the wish for current members to engage in a dialogue with them about whether it was still appropriate to use.

I think there's these confused histories, where Enjoy is very much two, or even three, different bodies and galleries over its history. I just wonder why it needs to cling to that past. (Begley 2018)

Enjoy, named in ironic reference to a Coca Cola campaign at the time, ${ }^{28}$ originally had a full stop at the end. For Begley, the symbolism of the original name being tweaked to become less idiosyncratic represents the visual representation of a deeper shift to organisational conventionality. As he jokingly reflects, "it lost its point" (Begley 2018).

The name of an organisation is a powerful signifier of its brand, and the three artistrun spaces I studied all had very deliberate titles. The significance of minor elements of punctuation are reinforced by the experience of $R M$. The gallery started life as $r m 3$, and adopted the more general moniker of $r m$, in 2009, in acknowledgement of the shifting nature of their accommodation. The name reflected the pragmatic, yet political approach the organisation had to physical space. The lower-case letters and the hanging comma implied an informality and reluctance to commit to the notion of branding "it was political for us, to be lower case" (Wylie 2018). Wylie, herself, believes that $R M$ should consider changing their name to better reflect its variety of incarnations, arguing there are "probably seven or eight spaces that have come under the umbrella of $R M$. And that's not bad, but wouldn't it be interesting if they were all different, with different names and identities?"

28 “Coca Cola. Enjoy" was the Coca Cola slogan for Australia and New Zealand in 2000 https://www.coca- 


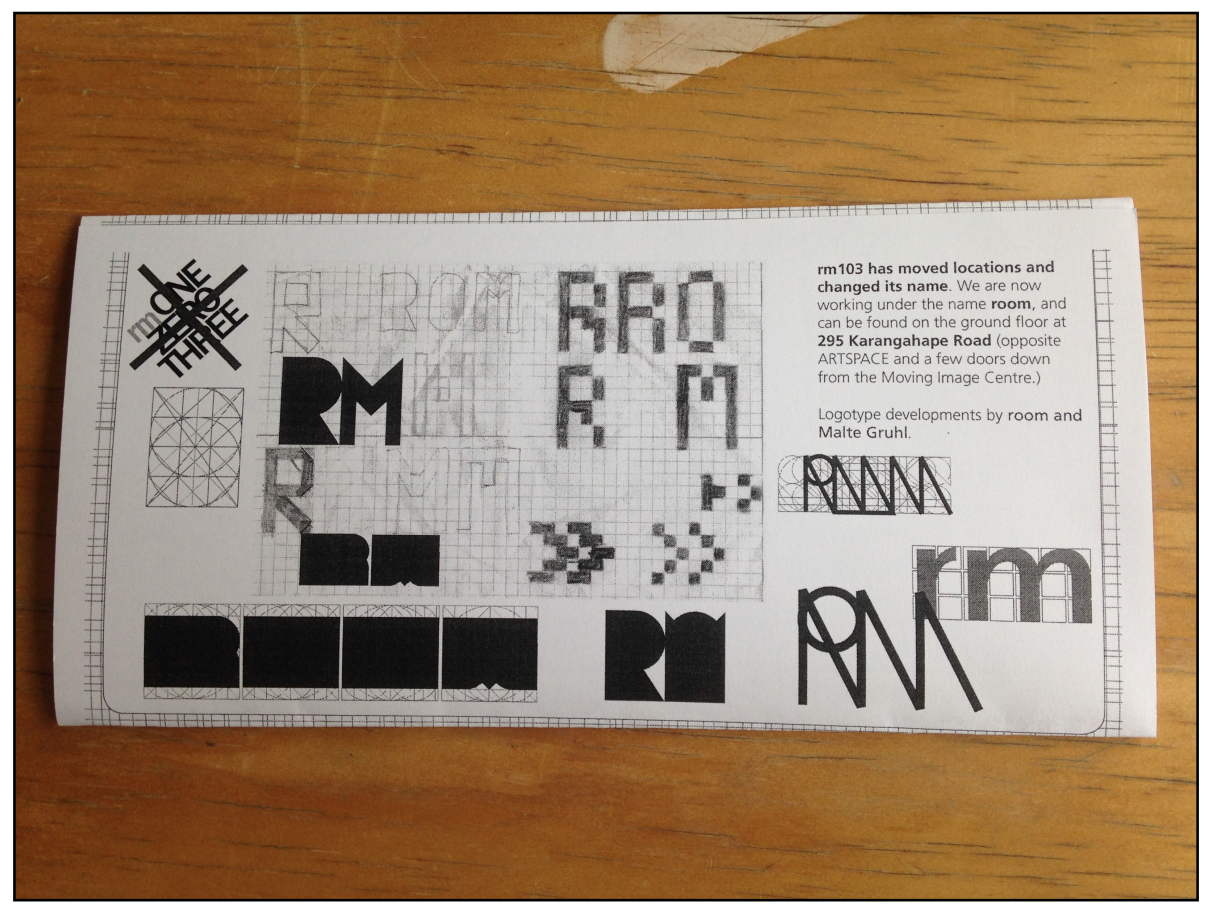

$R M$ Newsletter, 2009. Artists and Gallery Files, Fine Arts Library Special Collections, Auckland University Library

Following the departure of the space's last co-founder in 2016 the name morphed into the more definite upper case of ' $R M$,'. Current member Dan Sanders describes the shift as driven by the need to develop a logo for social media, and one that required significant discussion by the group before change occurred.

Another thing we're discussing is the comma on the end and we had a whole meeting about this comma and we still haven't come to any conclusion. It's quite fascinating. (Sander 2018)

For Sanders, the discussion around representation is "the $R M$ project. It's like the big question" and demonstrates a conceptual slippage, escaping obvious definitions "part of resisting the white cube structure and falling into this popular idea of branding" (2018). Similarly, Meanwhile's name was chosen to signal a temporal quality, as Sean Burn stated, "the word itself is quite transitory ... it's often used to connect two spaces in time" (2017). Designed when Meanwhile was intended to run only for a matter of months, the title takes new meaning as the space continues and establishes. Perhaps if Meanwhile continues to develop and formalise, the name will need to be revisited. 
Examining tensions around the ongoing use of Enjoy's name and manifesto demonstrate the power struggles that can occur in an organisation as it changes and develops. The findings analysed and discussed above demonstrate that, of my three case studies, Enjoy has altered the most from its original organisational form, and conflict among current and founding participants over those changes was more explicit than in the other two case studies. Enjoy's development over 18 years had not been anticipated by its founders, and their accounts expressed frustration that they had not prepared adequately for its stewardship beyond their active involvement.

The founders had willingly handed the organisation on without establishing protocols for continuing engagement, forfeiting legal and practical control. Should the organisation continue to consult with them, as founders? The positions outlined above demonstrate very different attitudes to institutional history and ownership. It is also important to note that a research strategy of interviewing only current and founding members leaves unexamined the possibility of other, dissenting accounts. But the informal quality of small art spaces means they are reliant on the goodwill and support of their wider community, as mapped out through the many strands and connections of the artist-run assemblage seen in Chapter Two. I argue that as Enjoy continues to build and develop, moving ever further from its artist-run roots, it is timely to re-engage with its own history and consider acknowledging publicly the tensions that punctuate and disrupt their development.

\section{Conclusion}

While the three artist-run spaces I have examined sprang into being from similar motivations - the desire to provide exhibiting space and support for the initial participants - it is when they move beyond the initial phase and widen their remit that they crystalise into different institutional forms. Those forms are never static, even when they appear to stay the same, as in the case of $R M$, who have repeatedly recommitted to a collective form, even as new members enter the group or funding pressures change.

Gene Ray suggests that despite the instrumentalism arts institutions might experience, in their desire to be compliant to neoliberal concerns, fissures and gaps still exist, through "which autonomous subjects can emerge" and my case studies demonstrate it 
is indeed so. In Chapter Three I argue that cultural precarisation, for my interview subjects, was simultaneously self-chosen and supported by a wider neoliberal framework, where subjugation and empowerment are entwined in apparent paradox (Lorey 2011).

Identity formation for the artist-run space, I contend, develops in the same contradictory way, which simultaneously suggests freedom and entrapment for the organisation and its participants. The contradiction of the spaces is that they occupy a scale small enough to remain nimble and to shape-shift, yet, are unescapably bound into a wider (cultural, social and policy) infrastructure that seeks to prescribe and determine their behaviour. Perhaps the largest, most pressing question for participants, is how to negotiate these oppositions and determine where on the continuum they want to locate their space: and it has to be resolved again and again throughout a space's life span.

This chapter argues that institutional efficiency is a key policy narrative that artist-run spaces have to grapple with in order to secure funding. Funding agencies' tangible procedural requirements and less tangible professional development philosophies encourage spaces to evolve from collectives into conventional business structures with strict divisions between governance and management. $R M$ and Enjoy demonstrate two distinct models of practice in response to the neoliberal orthodoxy promulgated by $\mathrm{CNZ}$.

Enjoy have been rewarded for their organisational compliance; accepted into Creative New Zealand's arts investment portfolio with consequent funding increases and funding security. Over time, they have proven their worth as, to draw on Robertson's quote again, "good administrators, artists and workers" $(2004,3)$ who have actively engaged with Creative New Zealand processes, particularly professional development opportunities that, as Ann Shelton describes, "played a role in our development as an organisation". Enjoy's point of resistance is not structural. Instead they work within existing, endorsed structures to enhance their artistic capacity to be "exciting and innovative and in dialogue with contemporary practice" (Shelton 2018). Despite this, Shelton argues that Enjoy enacts a form of resistance through a board comprised largely of artists, to ensure a connection with their artist-run roots. 
In contrast, $R M$, who have steadfastly maintained a collective by consensus over 21 years, remain outside the fold, perpetually pitching for one-off project funding through the Arts Grant scheme. Their relationship with CNZ is not antagonistic, Deborah Rundle stated, "last year we got a really good level of funding",29 rather, it is considered positively by all current members of $R M$. However, $R M$ 's resistance to adapting to the business structure CNZ require of investment 'clients' means they are unable to progress up the funding ladder. $R M$ 's members interviewed in this research perceived this as a matter of choice and have not agitated to change this relationship. The interview subjects enact gentle but firm forms of refusal against cultural policy orthodoxies, for as Rundle argued, “it's important that $[R M]$ asserts a different territory" (2017).

As the chapter demonstrates, Meanwhile are on a cusp, having recruited new members, including some who are not artists, developed a written constitution, and begun discussions about formalising into a trust for the purposes of funding. Where Meanwhile will go at this point is uncertain, with new members indicating greater enthusiasm for formalisation than the original founders. For many, the spectre of their Wellington neighbour Enjoy loomed, as both tension and motivator. As Simon Gennard described it, "that's always inevitable, that it will become more formalised, and more like somewhere like Enjoy" and Jesse Bowling stated, "I feel like we can surpass Enjoy if we can be a more progressive model".

The research presented in this chapter affirms that arts organisations operating in a time of neoliberalism are required to juggle "complex and sometimes contradictory expectations" (Robinson 2018, 5). The research has revealed significant tensions within Enjoy, both between current members, and between current and founding members. There was disparity between current members as to the extent and methods of growth the organisation should continue to undertake. More palpably, disagreement over what form Enjoy has taken meant that the founders felt disenfranchised from the organisation's move to hierarchy, and actively wished they had disestablished the space when they left. 
However, the data also reveals that the seeds for what Enjoy would become were planted by the founders themselves, in establishing a very different model as a "shell" for funding purposes. Over time, the paper model and the lived reality of the space converged into one cohesive organisation, with no distinction. There were other gaps in understanding between Enjoy founders and current members, which revealed very different institutional values.

My research has charted a shift from the early days, when the first funding grants were secured by whatever means possible, to the Enjoy of 2018, which operated with a sophisticated understanding of the funding policy dance. Observing this, I've come to understand that organisational behaviour might initially be "strategically practised" in order to secure funding until "over time it becomes passively followed" (Gray and Kendzia 2009, 165) as the organisation implements its formal self in institutional practice. Gray and Kendzia have described how organisations routinely self-censor themselves to secure short-term funding, but, in the "longterm, these types of practices accumulate and become normative" $(2009,165)$.

RM, Meanwhile and Enjoy, I argue, have quite different attitudes to external forms of power, as represented by normative funding discourses. Each organisation's embrace or rejection of formalisation and hierarchy can be read as a pointer to their relationship with neoliberal orthodoxies, and through this reading $R M$ provides an example of stepping away from the orthodoxy, or engaging in what Lind calls a “strategic separation" (2015). Yet, paradoxically, RM's separation hinges on receiving continual financial support from Creative New Zealand and, beyond that, as I argue in Chapter Two, their conceptual drive to find and occupy gaps in the existing artistic landscape still ties them inextricably into the wider art world.

Similarly, some of the participants of Enjoy, who have arguably embedded neoliberal orthodoxy deeply within their systems by complying with funding imperatives through a range of practices and discourses, spoke out against the possibilities of their own instrumentalism, with Ann Shelton attesting that commitment to an artist-focused board of trustees represents a living thread to the experimentation of the past.

Enjoy's behaviour as "good administrators" (Robertson 2004), Shelton argues, has enabled Creative New Zealand to trust Enjoy to "function effectively", creating the 
base conditions against which they can be "critically successful in artistic terms" (Shelton 2018). But staff members feel the regulation required by funding has constrained the experimental nature of programming, "it's a system that's difficult to reconcile with artistic/curatorial experimentation" (Davis 2018). To further echo Robertson, the gaps between various participants in their view of the relationship with Creative New Zealand demonstrate "the creation of fractured subjectivities" $(2004,3)$ within Enjoy.

Differing understandings among some of the interviewed members demonstrate tensions and ambiguities that can co-exist alongside deeply held beliefs in shared practice, and show that the idea of what constitutes an 'alternative' is contested. The production of artist-run culture, therefore, is not static, but complex, sometimes contradictory and continually changing with each new iteration of membership. The question of whether changes to an organisation at a structural level changes it at a deeper, more conceptual level, is one discussed more thoroughly in the following chapter. 


\section{Chapter Five}

\section{Relative Autonomy: The Artist-Run Space within a Neoliberal Discourse}

Institutions are not merely abstract formations that are either dominant or marginal, but remain rigid opponents to the agents within them. They are more like antagonistic force fields in which agency is balanced with other social fields. (Mader 2013, 41-42)

\section{Introduction}

It's November 2018 and the first time I've visited Enjoy since the retirement of longstanding Chairperson Ann Shelton. Enjoy's gallery set-up is unusually minimal. A trestle table in the centre of the room displays two piles of A4 paper, inviting participants to fill out a survey, and a noticeboard is pinned with responses from the survey to date.

The survey is very simple; a series of open-ended phrases and words, not even really questions. "A contemporary art space in Whanganui-a-tara Wellington is" it begins, then, simply: "could", "should" and "would". All replies are anonymous, and most are aspirational in their approach.

... Could be a space for difficult conversations and debate ...Would support artists, take risks, be open to change and development, advocate for experimental and non-commercial art practices. Respond to changes in society (political and social) and critique normative values, structures and assumptions. Be welcoming and self-reflexive.

While many entries take a general tone to talk about possibilities, others explicitly address the existing presence of Enjoy, with one calling for it to "cater to all of the art groups in Wellington because it has public funding." Enjoy could, it goes on to say, "be a lot broader in scope. Embrace other art groups.” It finished, rather desolately, with "would: won't".

The exhibition, It Follows, is by the Taipei Contemporary Art Centre, a space founded in 2010, and seeks to "prompt reflection and discussion in subsequent events 
and programmes". Perhaps it is easier for Enjoy to invite another gallery into their space and ask questions on their behalf, but the exhibition is notable in Enjoy's recent programme for its inclusion of dissent and critique. For the first time in a long time the impermeable, if invisible, wall I experienced over the last year has gone. With this exhibition Enjoy appears to be reaching out and asking for opinions, without filtering or mediating.

Meanwhile member Simon Gennard is now working in his new role as Enjoy's communications and publications manager. Sitting at his desk, he tells me he will be stepping down from Meanwhile at the end of the year, because it is becoming too difficult to juggle involvement with two spaces. Enjoy has provided him with a modest salary, while Meanwhile requires him to pay a weekly rental contribution. The equation is obvious and difficult to criticise. Gennard, after all, had said when I interviewed him “my practice is so young I still haven't figured out what it is, and I also have only been able to entertain art writing as supplementary to whatever else I was doing, because it's not going to sustain me". Here, finally, Gennard, has a job which, although modestly paid, puts writing about art at the forefront of its mission.

Could, should, would: this chapter builds on the previous chapters to engage in a larger discussion about what artist-run spaces currently are, and their possibilities for the future. The previous three chapters have each taken a strand of artist-run practice - the space, the workers, and the organisational structure - as their focus, examining in depth the differences and connections between my three case studies. In this chapter I look across those themes to examine the data closely against my research questions: to what extent does the artist-run space offer alternatives to current neoliberal orthodoxy in the art world? What impact have funding, policy and wider art networks had in shaping the New Zealand artist-run space? How are the identities of participants shaped by their involvement in artist-run spaces?

When Nikolas Rose, building on Foucault's work on governmentality, argues that, through neoliberalism, we have experienced a shift from being the "subjects of government" to "individuals who are to be active in their own government" (Rose 1996, 330) he describes a complex reconfiguration of our relationship to authority, as subjects instrumentalised through notions of "self-motivation, self-responsibility and 
self-reliance" (Rose 1996, 335). We are, therefore, rendered complicit in our own reframing.

Writers, including Isobel Lorey and Angela McRobbie, argue that for artists emphasis on individuals as active agents in their own governance is both affirming and alarming, because it seductively aligns with so many of the tropes of the modern art world: notions of freedom, flexibility and creativity. The method by which precarity underscores and produces the conduct of conduct in the art world, that is: the social governance of creative workers and the ways in which organisations voluntarily regulate themselves in social discourse and structures, is, Lorey argues, connected to deeply held beliefs in matters of "sovereignty, autonomy and freedom". Thus, do citizens "voluntarily subject themselves to the conditions of society" (Lorey 2015, 27). The nuanced blend of coercion and freedom that our current moment offers us enables the individual to become "not only a subject, but also a specific, modern, 'free' subject” (Lorey 2015, 75).

This thesis has focused on one area of cultural production, when artists mobilise to form their own art institutions, to better understand how the broader conditions of neoliberalism determine "how we are governed and keep ourselves governable specifically through precarisation" (Lorey 24). How truly free are institutions led by artists, who established them precisely to create new forms of organising? I began this research in agreement with Anthony Davies' argument that a "crisis of legitimation [has opened] up as institutions are subjected to neoliberal agendas" (2007, n.pag.) and my thesis has sought to determine if such a crisis has seeped from larger, mainstream arts institutions to smaller, more informal spaces.

However, while my research charted tensions within the artist-run space network, exhaustion among its workers, and awareness by participants that they were navigating within a wider neoliberal system, I have not experienced my subjects as defeated. Instead, their passion for the work is palpable, as well as a strong belief that participants have found ways to claim agency, even within a neoliberal orthodoxy. Lorey suggests that the question is not about overthrowing the system but seeking "where, within these governing mechanisms, cracks and potentials for resistance are to be found" (Lorey 2015, 24). This chapter explores the cracks and potentials for 
resistance that emerge in the artist-run space of today, bringing together, and extending, research detailed in the previous chapters.

To understand the question of how and where agency — cracks and potentials - might occur within an art world that, like the wider political and social environment, seeks to guide and prescribe its subjects, I explore further ideas of independence and interdependence. In his essay Culture Industry and the Administration of Terror Gene Ray describes a state of potential that offers "a focal point for possible practices of resistance" (Ray 2011, 174) for artists within neoliberalism, calling this condition "relative autonomy". Relative autonomy offers a way to understand resistance to hegemonic narratives through means that are subtle or ambiguous, understanding the situation as not a binary one, but one that is simultaneously inside and outside.

This chapter takes as a guiding principle Rachel Mader's description in the introductory epigraph of art galleries as "antagonistic force fields in which agency is balanced with other social fields". The question of agency within a neoliberal discourse is contradictory and complicated, not black and white, and the three artistrun spaces studied have each taken a very different stance to the idea of agency and where they sit in relation to the wider art ecology. The following discussion seeks to uncover, through specific details of artist-run space practices, the nuances of how participants articulate and aspire to notions of their own agency.

\section{Offering an Alternative: The Artist-Run Space and Neoliberal Orthodoxy}

We have moved beyond the artist as a figure in the margins, hidden away in their garret and removed from society by means of their precarious existence. Within the mainstream social narrative of most of the twentieth century, with its premium on stability and longevity, the artist's existence was too fractured, and temporal for acceptance. However, Chapter Three argues that artists have become tied to neoliberalism's narrative, migrating from the margin to the mainstream through the new orthodoxy's increased emphasis on creativity (Gill and Pratt 2008, Lorey 2015, 2011, 2006; McRobbie 2015, 2010, 2003, 1998; Taylor 2015; Taylor and Littleton 2012). 
The neoliberal project is both structural and implicit, woven so deeply into the fabric of contemporary society that it is hard to see from without. Neoliberalism, which began as an economic system, has, as the literature details, wound itself so tightly into cultural and social practices that it must now be considered a holistic environment rather than a specific or distinct policy. The artist-run space has been reconfigured accordingly within neoliberalism and can no longer credibly claim to be an alternative to the mainstream art project (Robertson 2004, 2006; Waugh 2016). In the strictest sense, it cannot stand outside current neoliberal orthodoxy. But, within this totality, glimmers of difference_-Ray's relative autonomy—remain, and this provides a rich area of possibility to "recompose, reorganise and link struggles, through practical alliances and strategic fronts" (Ray 2011, 176).

The artist-run space, I argue in Chapter Two, is linked deeply to the wider assemblage of the art sector, acting as a feeder to larger institutions and commercial galleries. If the artist-run space has been reshaped through neoliberalism, it is only following in the footsteps of the larger institutions, as "creative industries concepts are now accepted as standard practice in New Zealand museums and galleries" (Bieldt 2016, 175), and tertiary art training has been similarly structured by neoliberal rhetoric. Museum and gallery culture has led the way in embracing neoliberalism's coupling of creativity and managerial efficiency, as part of a wider cultural shift towards valuing business procedures (Abernethy 2016; Bieldt 2016; Leggett 2006). While museums have adopted a business aspect in attempting to woo and win corporate sponsorship, a similar transition for artist-run spaces has come about through public funding pressure. The new emphasis on fundraising has been driven both by major capital building projects and, increasingly, by the ongoing cost of exhibition development.

In Nemane Bieldt's 2016 thesis on the impact of neoliberalism on curatorial practices in New Zealand museums, she argues it is impossible,

to escape the conclusion that the changes brought about by creative industries concepts have forever changed the presentation of culture and have produced a form of 'bounded creativity' that exists within, and is legitimised by, the policy environment. (178)

Such a reading presupposes that creativity is otherwise inherently unbounded and free, and it is only the new limits of neoliberalism that have rendered it otherwise. Yet art, and wider cultural production, I argue, has always had to work within and against 
the limits of the policy environment of the time. However, I am in agreement with Bieldt's contention that the naturalisation of creative industries has filtered from policy level into the sector and that such "comprehensive and intense adoption of the creative industries concept in New Zealand has brought about permanent change" (Bieldt 2016, 176).

Shortly before they first become involved with an artist-run space, most emerging artists have graduated with significant student debt, built up through immersion in an environment which has become increasingly "more economical, accountable, flexible and more responsive both to industry and to government itself' (Shore 2008, 1). The art school, reconfigured into a training facility for creative industry and increasingly staffed by a roll call of temporary appointments, sets up the graduate to expect a neoliberal art world. The graduate, or "Creative Girl" as Amanda Bill describes her, in her thesis on the New Zealand fashion graduate, "occupies a subject position fitted to after-neoliberalised social and economic arrangements" (Bill 2008, abstract).

After leaving art school, the graduate described in Chapter Three might work in a part-time capacity at a public art gallery, as visitor host or exhibition preparator, as did Pera Aoke, Sanders, Bragg and Bowling, embedding them further in the institutional logic of the art world. Or, like Simon Gennard, they might undertake an internship at a public art gallery, which recompenses them with a small financial payment but provides an entry to institutional curatorial experience. Within the work of running the artist-run space they will regularly engage with the public art galleries within their immediate environment, which provide them with practical means of support (lending equipment, for example) but also draw on their programming for their own ends, as Chapter Two argues.

The broader contemporary art assemblage, which I argue is steeped in the neoliberal rhetoric of rationalisation and market responsiveness, provides the ground upon which the artist-run space must form and perform. The artist-run space cannot be removed from the wider art ecology, but must be acknowledged as a player within the environment, subject to its own self-precaritisation and self-regulation (Lorey 2011). Certain spaces, such as $R M$ and Meanwhile, engage in strategic measures to limit or manage their collusion with the wider art world, which will be discussed in more depth later in this chapter. 
To what extent did interview subjects frame their narratives through a neoliberal discourse? Most did not refer explicitly to neoliberalism in their accounts, although some did-Sophie Davis describes an institutional impulse to grow in "the neoliberal sense of the word" (2017) and Melanie Oliver reflects that "a neoliberal society encourages things to become more monetarised and more financially accountable" (2017). Instead, they were more likely to talk about "resistance", a notion framed as the rejection of mainstream art values. Daniel Sanders argues that $R M$ 's remit was to "serve (the art scene) creatively, in a way that it is quite resistant" (2018) and Deborah Rundle frequently referred to an ongoing process by the organisation to examine and refute "how power plays out" (2017).

Subjects interviewed who were outside my case studies were less positive about the ability for artist-run spaces to resist the mainstream, Ioana Gordon-Smith contends the "discourses that are happening in the larger institutions are filtering down to younger people in a way where all the signs and signifiers that they want to work with have already become tainted" (2018). Similarly, Hana Pera Aoake describe the difficulty of speaking out against inequality because "if you're critical you're against the community" (2017).

Interview subjects were clear about the benefits their involvement with an artist-run space offered them and this demarked a distinction between involvement in Enjoy compared to that of the other two spaces. Enjoy's participants saw the space as an entry point to a wider art world, through which they, as well as the emerging artists whose work they were championing, would professionally benefit. To that end, participants stressed deep connections between Enjoy and other areas of the art world, including public, commercial and tertiary institutions. $R M$ and Meanwhile's participants, who expressed the desire to situate their practices in the gaps within the existing system, while expressing an appreciation of the sense of wider community, were more likely to stress discomfort with notions of sector networking. 


\section{Governmentality and Neoliberalism: The All-Consuming Policy Narrative?}

The public support of small and diverse arts organisations must be sustained because their variety is precisely what maintains an open and nuanced arts sector. However, the decrease of public funding for both arts organisations and artists, as well as the narrowing and leveling of funding criteria, promotes only sameness. (Cruz 2016, 5)

In the previous three chapters I argue that spaces must navigate and take a position on key policy discourses once they begin to receive public funding. Here, three distinct narratives can be understood to provide the lens through which artist-run spaces are considered by funding agencies; audience development, professional development for artists and participants, and organisational efficiency. These are neoliberal concerns, fuelled by a larger governmental shift towards economic neoliberalism since 1984 and now intangibly but inexorably bound into the governmental contract. Organisations seek legitimacy (Alexander 2017) and the spaces studied have approached these expectations in very different ways, leading to different funding outcomes for them.

In Chapter Three I quote senior artist Judy Darragh who remarks on the impact of funding on Teststrip, New Zealand's seminal artist-run space of the 1990s. While Darragh stated that funding changed Teststrip, she is neither wholly negative or positive about this outcome, describing it both in terms of opportunities ("to expand the programme") and obligations ("you've got to report stuff ... that does give a bit of a different quality" (2018)).

Darragh's stance reflects a broader ambiguity in the art world towards public funding, in which grants are positioned as both an enabler of public good (both to artists and a broader community remit) and a restriction on artistic freedom. Artists and art administrators often express simultaneous gratitude and unease towards funding bodies, a relationship, as Sophie Davis describes it, perceived as both a privilege and a threat. But what is really at stake in the funding dance between artist and agency? And how does the experience of artist-run spaces mirror that of the larger museum environment?

As my Literature Review argues, New Zealand cultural policy has aligned itself with wider neoliberal policies since 1984 , a broad focus that makes little distinction 
between traditional Left and Right parties. But within that consensus there have been distinct shifts in focus, with Helen Clark's Labour Government (1999-2008) strongly emphasising a nationalistic focus on the arts — 'telling our stories ${ }^{30}$ — while John Key's post-GFC National Government (2008-2017) refocused on a dichotomy of "need to haves" and "nice to haves", which further emphasised streamlining and efficiency (Hughes 2013).

However, within this overarching narrative, close examination of Creative New Zealand literature over the last ten years reveals subtle shifts in language, notably an increase in hyperbole and emotive rhetoric. The 2007 Annual Report, for example, describes the organisation in relatively straightforward terms:

Other values important to Creative New Zealand include our commitment to a collaborative approach based on partnerships and our commitment to clarity, integrity, transparency, excellence and professionalism. Underpinning this is the value we place on artistic expression and the contribution of the arts to society. (Creative New Zealand 2008, 8)

Ten years later, in contrast, the Annual Report deploys a far more enthusiastic, even hyperactive, tone of voice,

We are forever passionate about the arts - actively championing the intrinsic beauty they possess and the transformative instrumental power they wield. Each day, members of the Arts Council and Creative New Zealand staff see the arts change lives. We want dynamic and resilient New Zealand arts, valued in Aotearoa and internationally through stronger arts communities, artists and organisations and greater public engagement with the arts. (Creative New Zealand 2017, 2)

For all cultural organisations, the need to reshape their narratives to align them with current government policy can be exhausting, demanding research and time. For smaller organisations like artist-run spaces, without specialist staff whose role is to manage such relationships, decoding and adjusting to subtle shifts in policy discourse can be baffling. There is, of course, the ever-present fear of defunding, as Deborah Rundle notes, "every year we hear about someone [who] could suddenly lose their funding" (2017).

30 "We are seeing a strong and confident cultural identity emerging and this investment will help our leading arts organisations continue to produce world-class performances with a uniquely New Zealand flavour" (media release, New Zealand Government 19 May 2006 https://www.beehive.govt.nz/release/budget-06-support-arts-and-culture-increase ) 
The majority of my interviews with artist-run space participants were conducted immediately after a significant Creative New Zealand restructure, ${ }^{31}$ which replaced sector-specific advisor roles (such as visual arts advisor) with generic funding advisors and sector-specific arts practice directorates and shifted all assessment to external peer assessors rather than the previous mixed system. The personal relationship with former Visual Arts Advisor Kate Montgomery (whose role has now moved to the arts practice directorate, a position which takes a more strategic, less hands-on stance) was cited as important by almost all of the members of Enjoy and $R M$, interviewed, indicated by this comment by Sophie Davis, "I always felt that Kate understood ... I know that she worked at The Physics Room for so many years she knows what it's like to work in that space" (2017).

Many of my interview subjects were wary of the changes, as Enjoy gallery manager/curator Sophie Davis indicated, “there's been a little bit of confusion about that recently because CNZ are always changing their system”. Rundle expressed concern that the peer assessors might not be familiar with $R M$; "there won't be the ability to call on the history of past successes, I mean, some of those people will definitely know about $R M$ but they might not, they might be from the South Island and have less familiarity" (2017).

The distinct policy narratives to emerge through my research that have impacted on artist-run spaces are audience development, professional development for artists and participants, and organisational efficiency. It's significant that none of these discourses specifically targets artistic programming, which has, until recently, been described in aspirational yet open-ended terms such as "high quality achievement" (Creative New Zealand 2018, 3), and "artistic excellence" (Creative New Zealand 2017, n.pag.). These two key phrases are the most commonly utilised by Creative New Zealand to describe the intangible elements of artistic programming, both vague and broad enough to enable buy-in from the arts sector.

Instead, the policy discourse focuses on elements aimed at improving and strengthening the organisation. The expectations, therefore, from the funding agency of artist-run spaces, are not aimed at changing the artistic aims of the organisation, but 31 Announced October 2017 http://www.creativenz.govt.nz/news/changes-at-creative-new-zealand 
merely fine-tuning the structural elements that scaffold creative work. This is an important distinction, allowing funding representatives to reassure concerned members of the arts sector that its core work will not be affected, merely better supported.

Such normative forces (DiMaggio and Powell 1983) are difficult to argue against, not least because of their presentation as sensible and pragmatic. However, looking at the organisation in a more holistic sense, it is clear that adjustments to one aspect of organisational practice significantly impact on the whole. Victoria Alexander argues that it is the seemingly innocuous nature of the changes required by arts funderssurface only and peripheral to core business - that enables them to penetrate through practices, "perhaps more deeply than they would if they focused on trying to influence content" $(2018,34)$. Further to that, Alexander contends that "enacting neoliberal practices through funding and operations management, changes arts institutions, moving them away from a more autonomous realm focused on the intrinsic merits of the arts to a heteronomous realm where customers, marketing and financial planning are 'naturally' more important” (Alexander 2018, 38).

I argue this is the case with Enjoy, in its shift from a fluid, grassroots organisation to one highly attuned to funders' needs. The degree to which Enjoy has framed its activities through a narrative of accountability and aspiration, is told through funding acquittals, publications and its online presence, and has largely eradicated counter narratives to present a seamless institutional façade.

Alexander's argument that changes to operational behaviour become inflected in the creative aspects of the organisation, is supported by claims of founding members of Enjoy, who suggest the institution has tilted on its axis, away from its alternative roots to an organisational stability at the expense of experimentation. For those interview subjects, the adoption of neoliberal practices had changed Enjoy significantly, to the extent that the exhibition programme is impacted. As mentioned previously, Rachel Smithies contends, "Enjoy now feels much like it's become very institutionalised ... it doesn't seem to have quite the messiness and experimentation and playfulness". 
Organisational stability, as I argue in Chapter Four, can lead to organisational homogeneity. In an article for the Aotearoa Ethnic Network's journal, Creative New Zealand employees Helen Bartle and Catherine Nesus call for greater organisational diversity. "We are already living in a diverse society. It is important that organisations reflect that. Organisations must take flexible approaches to defining diversity" (Bartle and Nesus 2006, 33). Bartle and Nesus were referring to cultural diversity at a time of growing multiculturalism in New Zealand, yet such diversity did not acknowledge differing cultural experiences of organising which might speak against Western systems of management. In the 12 years since that article, Creative New Zealand has implemented further steps to embed organisational homogeneity among its funded organisations, ${ }^{32}$ revealing a disconnect between policy discourse and Creative New Zealand's outward representation of its practices in particular public forums.

At the time of writing, November 2018, Creative New Zealand released a review suggesting a new set of guidelines for investment programmes, indicating a possible shift in direction towards a more qualitative, open-ended approach to measurement, encouraging "diversity and reach, dynamic arts and a resilient arts sector" (Creative New Zealand 2018). In addition, changes specifically to the Toi Uru Kahikatea programme mean that organisations funded at the lower end of the spectrum (under $\$ 75,000$ per annum) will be subject to "fewer requirements" (Creative New Zealand 2018, 2).

On the surface, this represents a major shift in policy discourse, and one that could be deployed by $R M$, to argue their shift from project support to recurrent funding as an investment client.

[it] would be cool if there were more types of funding and it was more flexible. But for the time being, I don't think it's going to happen unfortunately. But that would be fantastic. Yeah, it would be, it would be really cool. (Morgan 2018)

\footnotetext{
32 Creative New Zealand launched Move On Up in 2007, a strategic change coaching programme taken up by a significant number of investment organisations since it was launched in 2007, including Centrepoint Theatre (Palmerston North), Fortune Theatre (Dunedin), Chamber Music New Zealand (Wellington), Taki Rua Productions (Wellington), Circa Theatre (Wellington), The Physics Room (Christchurch), Govett-Brewster Art Gallery (New Plymouth), Artspace (Auckland), Footnote Dance Company (Wellington), Toi Maori (Wellington) and Auckland Writers and Readers Festival. Creative New Zealand currently offer four coaching programmes specifically for "investment clients" (Creative New Zealand's terminology), Growth Package, Extension Package, Refresher Package and Change Package, all working with external providers to deliver "capability building and training opportunities" (https://www.creativenz.govt.nz/development-and-resources/workshops-webinars-andtraining/investment-client-packages).
} 
But $R M$ 's current participants do not seek to substantially change the relationship with Creative New Zealand, while they might appreciate the possibilities such change could bring. The complex juggle of life, work, art and artist-run space detailed in collective members' accounts, means, on a practical level, they would struggle with the time required to make a detailed and ambitious pitch to renegotiate their Creative New Zealand status. But, more significantly, participants expressed deep uncertainty towards notions of professionalisation that extend beyond a commitment to collectivism to wider concern about artistic compromises, such as when Daniel Sanders objected to "being strategic about programming ... meeting [audience] numbers and getting bums on seats".

\section{Independence and Interdependence: The Internal and External Forces that Shape the Artist-Run Space}

Independence is associated with theories and reference points that are no longer significant; it is no longer synonymous with alternative or not-for-profit since both self-organised projects and established institutions depend on a wide range of complex support systems, ranging from funding to networking. (Jackson 2013, 168)

Over 21 years, $R M$ has articulated its own version of independence, which is, in fact, narrated by the members in terms of connectedness. They describe their role as providing space for gaps in the mainstream art world, that is, they see their practice very clearly in terms of the wider art ecology, yet this distinction is never antagonistic, they are never fighting against something. Rather, in defining their difference they are also describing how closely connected to the wider art project they are. Historically, they have looked to international models for inspiration, again seeking to connect themselves into a larger conversation.

However, they are, of course, not independent financially, because they receive public funding to enable them to continue. They have chosen a method of funding which they believe places the lightest of restrictions upon them, and one that allows them to practise the organisational form that is most meaningful to them, which enables them to "surrender the individual to the idea of how you function as the multiple" (Rundle 2017). $R M$ deliberately seek not to grow in size or scale, they want to "stay with the 
structure we've got, even though it has its vulnerabilities and its burdens in terms of workload" (Rundle 2017).

$R M$ could be understood to be leaders within the New Zealand art scene because they have carved out a unique position which could be used as a model for other spaces, much as they have sought out models elsewhere. Their history of sharing internal discussions with audiences gives them a framework to do so, and the confidence that such openness does not necessarily expose them, but provides an opportunity to learn in public. But $R M$ does not have a history of taking a leadership role within the Auckland or national art community. Instead they have a reputation as "this really quiet and reflective space" (Afoa 2018), and a gallery situated at the margins. Gabrielle Amodeo describes $R M$ as a space that "does not reveal itself quickly; it takes time to get to know... maybe it is RM's unassuming form of significance" (Amodeo 2016a, 46).

As the Literature Review demonstrates, the written art history of New Zealand artistrun spaces is limited and $R M$, is largely absent from the narrative. The space is invisible in the only book to survey New Zealand artist-run space culture (Amodeo and Enjoy Trust 2016), a missed opportunity to explore its unique and long-lived model of collectivism. Instead, the most public documentation of $R M$ 's history so far has been an article in Art New Zealand which marked Nick Spratt's stepping down as the last remaining co-founder (Amodeo 2016a).

Why has $R M$ remained so largely invisible? The regular turnover of collective members - over 40 in 20 years — clearly has had an impact. But perhaps most significantly, as Chapter Three demonstrates, those members do not seem to be attracted to $R M$ for career-building purposes. The identity formation that $R M$ contributes for its participants is, by all accounts, a deeply personal one, which prioritises sociability, connection and the sense that they are playing an important role in the community.

Consequently, there is less impetus for individual members to invest time into developing a public narrative for $R M$, writing it into art history. Art historians in this country, as the Literature Review reveals, have largely ignored the impact of artistrun spaces, so the onus has been on members to cement their space in the narrative. 
Enjoy's regular yearbooks and their partnership in the Assay/Essay publication, put them centre stage in the artist-run history, ensuring that their contribution is told and retold to new generations of emerging artists.

Chapter Four describes Enjoy's evolution from a space with two distinct identities. Day to day, I argue, early Enjoy assumed an informal, idiosyncratic form, fuelled by individual personalities and their desire to provide a space which reflected their strong belief in how organisations should operate. At the same time, they presented a different organisational narrative on paper, one that sought to meet more conventional expectations. Over time the two identities merged into one cohesive form, which, I have argued, resembles the on-paper version far more than the original collective. In doing so, they willingly remodelled themselves into Clive Robertson's "good administrators, artists, workers" $(2004,3)$.

They have reformatted their planning and working systems to incorporate Creative New Zealand's KPIs and frame their acquittals in the language of the funding discourse. The early eccentricities have disappeared, remaining only in ghost form through the emphasis on artists forming the predominant component of the trust board. Yet, it appears to me that, while serving on the board, the artists tend to behave in a highly compliant and conventional manner, seeking as, Sonya Lacey explained, to manage "the finances very prudently" because "the Trust cares about the longevity of the institution and keeping it going ... you don't want it to be your watch that brings it down".

Enjoy, I argue, have traded the strong personality of their early years for financial security and growth. From the distinctive characteristics of its founding era the organisation has become more conventional in both structure and tenor. They have done so consciously, aided, as Ann Shelton explained, by guidance from Creative New Zealand towards “professionalisation”. The space's value is repeatedly defined by participants in terms of the wider art ecology, as a 'feeder' space. It seeks to be a stepping stone for artists into both public and commercial gallery spheres, to "develop careers and enhance the reception and impact of the work of the talented artists, writers and curators" (Shelton 2018). 
In doing so Enjoy's participants endorse the wider system within which art circulates and the broader notion of individualism perpetuated by neoliberalism. However, this stance is not total, as individuals among the staff and board expressed concerns about the extent to which Enjoy might be compromising its ability to experiment and take risks, through the embedded nature of the funding relationship. Nevertheless, the organisation is still seeking to extend that funding in their plans for future growth.

It is important to note that there are still many meeting points between $R M$ and Enjoy, in their shared commitment to supporting contemporary art practice through elements like the production of small-scale exhibition programmes, the similar physical scale, the exhibition spaces tucked up a flight of steps, the summer residency. These are the familiar accoutrements of artist-run organisations that Louise Rutledge earlier ticked off as "the open call for proposals, the three and a half week shows, ten shows a year, solo presentations, artist talks, a few publications here and there" (Rutledge 2018). Each is populated by passionate advocates for the work they present who clearly and with enthusiasm articulate the importance of their project to its community.

But, within this generic form, there are deep differences in the subtleties of organisational shape and culture. Both exist to support a wider art network, but see that support operating in very different ways. $R M$ work to provide exposure for what's not there_- "that aren't being represented in any other spaces"—while Enjoy back artists whom they believe have potential for larger success down the track, a process of deferred investment that Louise Rutledge described as paying off through “endorsement when the work that we're investing [in] is validated" (Rutledge 2018).

$R M$ and Enjoy, although they seek to occupy different positions within the art world, are linked by two significant elements - the length of time they have been running and the ages of their participants. Both have evolved over time and are the sum of their histories. The age range brings a level of diversity to their mix. Most of the $R M$ members described the diversity of ages as an important element in keeping their dialogue vital and vibrant, but Enjoy's Jessica Hubbard expressed concern that a predominantly older trust board (in their thirties and forties) governing a much younger staff meant "we're possibly more conservative in a way, or maybe more structured" (Hubbard 2018). 
Opened at the turn of the millennium, both spaces are marked by the imprint of Generation X's wilful independence and Teststrip's parental status, even as they have moved ahead. The antagonism of Enjoy's founders towards its current incarnation reflects in part the looser environment in which they opened, when eccentricity and humour were emphasised by their immediate predecessors, The Honeymoon Suite and Fiat Lux, as well as Teststrip and RM. While the strong personality of the early era has been submerged within the more polished corporate brand of today, the gallery is determined by its timeline, evolving into what Jessica Hubbard described as "an increasingly maturing gallery" (Hubbard 2018).

\section{Finding Agency in Compromise: How the Identities of Participants are Shaped by their Involvement}

What are we doing? Whatever we want. Whatever you tell me to do.

This statement, made by Jordana Bragg in Meanwhile's inaugural publication, What Have We Done? (2016, n.pag.) contains an implicit contradiction, of independence coupled with compliance. A seemingly throwaway line, I've come to understand this remark as a highly charged description of the complexity of Meanwhile's position as a truly millennial, neoliberal space. If Enjoy and $R M$ can be understood as two oppositional and deliberate poles of practice, Meanwhile is a space whose participants embrace its complicity.

In the same essay, Callum Devlin wrote,

We have actively practised communication, talking not only critically about work and process, but also about our feelings. We have emotion time and we take minutes. Assimilate business strategies for our organisational synergy. (Devlin 2018)

Wilfully personal and idiosyncratic, Meanwhile still has a remarkably homogenous identity as an organisation, despite having moved beyond its initial line-up of founders. It is a space forged by a particular blend of young people: gender fluid digital natives, as comfortable performing to camera as they are talking about their feelings. 
The members of Meanwhile, past and present, were all born in the 1990s and grew up in a world of digital connectedness. For them, authenticity is an outmoded concept, given their entrenchment in selfie-culture and interest in challenging binary assumptions. Their distinctive exhibition documentation - a curious mix of posed and deliberately random shots, cutting off people's heads or torsos to focus on feet or showing glimpses of artworks instead of carefully framed images - is one of many visual aspects which reveal a highly crafted, yet playful sense of identity.

The question about the construction of a persona often leads to the idea that it's false. I'm not particularly interested in the idea of authenticity or being genuine. But the persona that I put on is not less true. I'm not hiding behind it. It's not a mask, it's more honest. (Bragg in Duncan 2018, n.pag.)

The members of Meanwhile also came of age at the same time as the rhetoric of creative industries. The art world they inhabit has always been underscored by free market ideology, reflected in Devlin's statement that they “assimilate business strategies for our organisational synergy" (Devlin 2017). By contrast, RM and Enjoy have had to confront and navigate the continuing legacy of spaces developed at the end of the twentieth and beginning of the twenty-first centuries', a markedly different time in terms of attitudes.

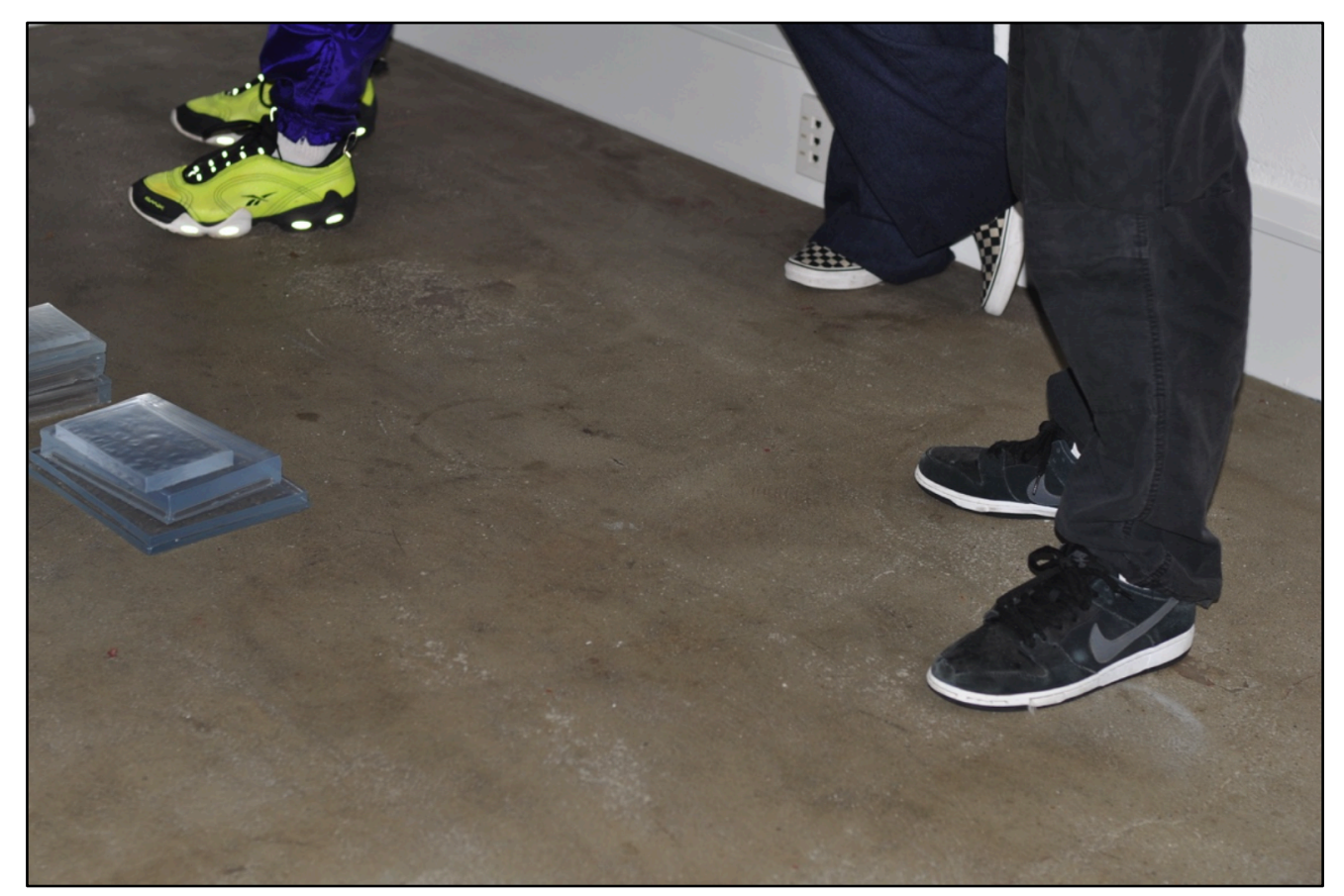

Opening of No One is Sovereign in Love, Meanwhile, 2017. Photo: Meanwhile archives 


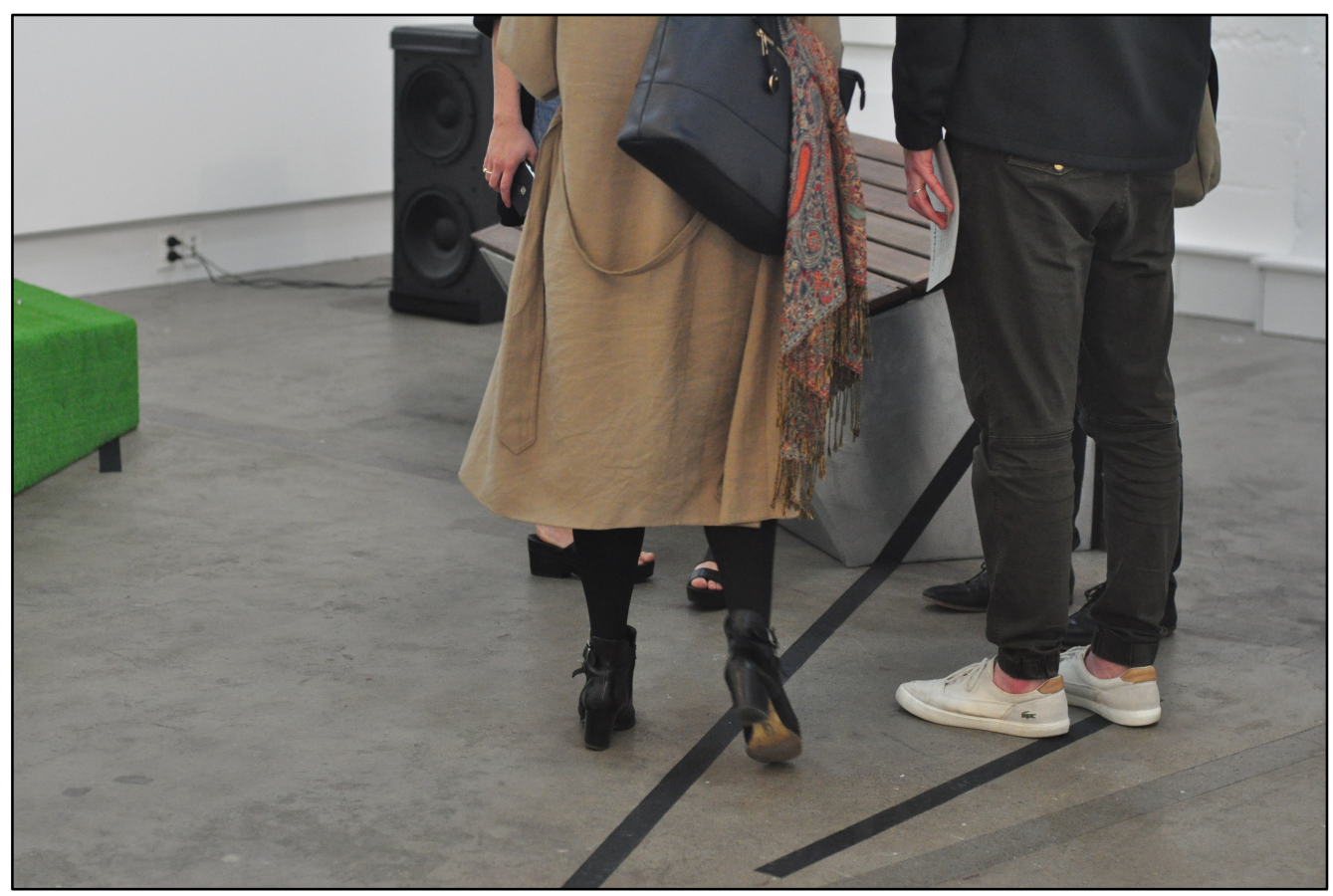

Opening of It's a Pond, Not a Moat, Meanwhile, 2017. Photo: Meanwhile archives

It is not just that the participants in Meanwhile happen to be young. The organisation is imbued with attitudes particular to youth at the current moment, which will be tied into whatever the space becomes. They are the generation of artist-run spaces which writer Emma Ng (born in 1990) describes as "spaces born of a different time and run by artists who've been steeped in the digital since childhood — who not only understand the digital environment they operate within, but understand the digital as a part of their physical environment" $(\mathrm{Ng} 2016,16)$. As inhabitants from birth of a New Zealand infused with neoliberal rationalities, I argue they are more comfortable than earlier generations with an art world that has embedded within it both neoliberal orthodoxies and Romantic and Modernist attitudes that position artists as special. Rather than acting as the "passive recipients of neoliberal rationality", claim Nairn and Higgins, the generation of Roger's Children instead "have been involved in actively crafting their identities, making use of the resources that neoliberal and other discourses provide" $(2007,278-279)$.

It's useful here to recall Ray's argument that, "pure autonomy, we can agree, is a myth. For 'autonomy' we have to read 'relative autonomy'. The culture industry subverts artistic autonomy and tends to absorb it, but never does so entirely" (Ray 2011, 175). Meanwhile are, I argue, more easily able to embrace the concept of 
"relative autonomy" because of the millennial nature of their organisation, where slippage and compromise is par for the course in a neoliberal era, the generation who are, von Osten argues, "experts in the very contradictions inherent to relations of production and contemporary governance" (von Osten 2010, 68).

As noted in Chapter Three, Jon Bywater describes the situation for artist-run spaces within the current discourse as a "double bind", stating "it's good when people are conscious and critical about it. But that's not going to make it go away". For Bywater, the organisational form of the space can't be considered alone, because the nature and quality of programming is paramount when considering a space. However, ultimately, he states, "there's no prescription you could give except to say, be aware of it and try and see a way out of it or be critical about it".

The practical organisational tactics pursued by my case studies have been detailed in the previous chapters, demonstrating the varying ways in which individuals and their spaces attempt to support the mainstream art narrative while also negating or subverting it, ranging from exhibition programmes to how they structure their organisation. However, they proceed more often via small aspects of practice than by grander acts of radicalism or antagonism. $R M$, for example, continues to actively practice decision by consensus while accepting Creative New Zealand project funding. Enjoy's recent invitation to applicants for their 2019 exhibition programme offered a far less prescriptive agenda than the previous year, with "scope to pose lateral responses and projects that serve their specific practices" (Enjoy 2018).

There is a degree of acceptance towards their situation reflected by each of the spaces I have studied. They reflect Mader's contention that such a space can be considered to "have developed a substantial, reflective awareness of its complexity, as well as a multiplicity of strategies, tactics and arguments to position themselves within this tangled and ambiguous constellation of interests" (Mader 2017, 22). However, it is Meanwhile that actively seeks to position itself as a space which might operate through Austrian philosopher Gerald Raunig's “constant struggle on the plane of immanence" (Raunig 2009, 4). What is needed, Raunig continues, are "practices that conduct radical social criticism, yet which do not fancy themselves in an imagined distance to institutions, their complicity" (4). 
However, complicity itself can be argued as a position of resistance, particularly in relation to difference. Natalie Oswin, the Literature Review demonstrates, calls for complicity to be taken more seriously within difference studies (2005), writing, "instead of thinking of complicit space as total and negative, we might reconceptualise it as ambivalent and porous, as an underdetermined set of processes that simultaneously enables both resistance and capitulation" (Oswin 2005, 84). Similarly, Heather McLean argues that "contradictory sites of feminist and queer complicity open up new opportunities for re-working and resistance in an era of neoliberal creativity” (McLean 2017, 52).

Meanwhile's self-conscious posture coupled with a deep emotional sincerity, are outward demonstrations of an organisation with gender fluidity at its heart and acknowledgment of the complicity of their position, not simple critique but a practice that contains critique within it. Meanwhile participant Simon Gennard writes that queerness as a position might provide a means to bring communities together.

Historically, queerness - as a political programme, and as a framework of analysis - has maintained an ambivalent and contested position in relation to identity and identification. Queerness' negativity relates both to a rejection of the inheritance with which queerness is recognised and interpreted as deviant, antisocial, and dangerous, as well as thinking through how that very symbolic negativity might provide a basis for solidarity, for world-making, for survival, and even flourishing. (Gennard 2017, 77)

Meanwhile's insistence on safety above all else, for participants, exhibiting and studio artists, argues that experimentation is best facilitated in an environment that supports and nurtures difference. Their emphasis on creating "an accessible space" (Lekamge 2018 ) is a position simultaneously about opening up and yet mediating their space to its users. Notions of public-ness are reconfigured into an openness moderated through concepts of privacy and restraint.

\section{Working Together: Possibilities and Speculations}

We must collectively ask: How to achieve diversity without creating division? How can variation and dissidence be present in equal measure to excellence and loyalty? Can there be a form of solidarity beyond the oppositional model of 'us' versus 'them', small-scale arts organisations versus large ones, private versus public funding bodies? Solidarity, in its reflective model, refers to a mutual expectation, a responsible orientation to relationships; it is aware of the potential of 'we' and how it can be constituted in relation to inclusion and exclusion 
without solidifying its limits and scope and explore our capacity to work together to articulate what arts organisations provide and need - to propose new ways of doing and being. (Cruz 2016, 9)

As the discourses of creative industries can no longer be separated from the contemporary art assemblage "its pathos of pessimism threatens to become paralysing" (Ray 2011, 174). Ray notes, "It tells us why there is less and less space for resistant subjects and practical resistance, without telling us what can be done about it". Curator Ioana Gordon-Smith agrees, stating, "it's difficult for resistance to take place, when resistance has cultural capital, as a value within larger institutions who are trying to become more inclusive".

More optimistically, von Osten has written, "there is still space to influence and change the discourse, even our own" $(2011,134)$. For participants in artist-run spaces, knowing the system's problems does not prevent their participation. Each space, in its own way, undertakes work that is of deep significance to their organisation, as well as being impactful in a wider sense. Within $R M$ 's quiet productivity a community of active resistance is regularly carved out, much of its power arising from its lack of visibility. Meanwhile's slippery experimentation with forms of practice, creating new rules which "ask that you take responsibility for your behaviour and privilege by understanding the ways it can affect others" (Meanwhile 2018) shows the artist-run space consciously modelling itself within a paradigm of sustainability, on the space's own terms.

Enjoy has been much more clearly subsumed within a narrative of governmentality, but, using Ray's description of "relative autonomy" (Ray 2011) one can still understand Enjoy's contribution to the wider art project, both through areas of deep compliance (professional development and training for both artists and curators, for example) and in the glimpses of anarchy and experimentation still found in their exhibition programme (Enjoy Feminisms 2015, Riff Raff's Trust Us Art Telefon 2017). Through Enjoy's support of emerging artists and curators many find a pathway into the larger art world, developing relationships with commercial and public galleries which, hopefully, will support them to enable an ongoing, life-long career. 
Enjoy shows us that relative autonomy can enable productive innovation to co-exist within governmentality's pull to behave. They play a vital role offering emerging artists entry to the larger art world, and without such pathways emergent artists would struggle to engage with public and commercial galleries, to "get their work in front of some good eyes" (Lacey 2018). Their role as a training ground to develop emerging artists and curators is important if the wider 'job' of being an artist is to be viable.

What are the possibilities for wider change in the sector, for artists and for artist-run organisations? Here I reiterate Rebecca Gordon-Nesbitt's call that "small visual arts organisations might instead come together to act as an advocacy group to devise KPIs more appropriate to their way of working $(2012,13)$. What changes could artist-run spaces engineer from Creative New Zealand, were they to activate as a sector, rather than negotiating with the funding agency one-on-one?

The only recent local publication to focus on funding issues for small art spaces, was published by Artspace with the aim of "stimulating thought which in turn might prompt appropriate actions on the part of individual small-scale visual arts organisations" (Post 2014, 4). The report relies heavily on United Kingdom reports covering similar terrain, meaning it does not provide much specific detail on the New Zealand situation, but it does offer an analysis of the difficulties small art spaces face when it comes to working to influence and change policy.

Firstly, arts organisations which have the resources (people and time) to dedicate to maintaining a relationship with funders, will have more influence on policy. This tends to be the larger more established organisations, where it is possible to identify a staff member (often the Director) who can make time available for a relationship and advocacy role with funders. In smaller organisations, the Director is generally responsible for creative and curatorial direction, strategic and administrative direction, fundraising, communications, marketing, strategy, planning and a fair amount of the day to day administration. It is not therefore surprising that advocacy tends to be squeezed out other than when applying for funding. (Post 2014, 12)

The last year has seen the only New Zealand mainstream arts organisation with sector advocacy as its primary mission, Artists Alliance, close due to decreased funding levels, after losing its place as a Creative New Zealand investment organisation under the Totara funding scheme. During its twenty-seven-year history, Artists Alliance focused on professional development for individual artists, through a variety of 
mentoring and internship programmes, and did not substantially engage in sector level discussions about wider issues, such as pay parity, gender representation or other structural concerns. Writing about their demise, critic Mark Amery suggests that the current form of Artists Alliance was not valued by CNZ however, he questions, "given the significant growth in the visual arts beyond dealer representation and the variance in the way artists get treated by public galleries, is the lack of such an organisation an issue for our artists' welfare?” (Amery 2018, n.pag.)

The possibility for artist-run spaces to play a role in shaping the national conversation about the roles and lives of artists is full of potential. My research argues such spaces are vital contributors, affirming the wider art world by developing new generations of artists and curators, but also in providing space for other conversations, locating and filling gaps ignored by the mainstream narrative. The more official, public end of the art world, from funders to tertiary providers, could gain greater understanding of the challenges and possibilities emerging artists face, at the current moment, by listening to the experiences of artist-run spaces.

In Australia small- to medium-scale art spaces have established the All Conference network, an online resource as well as events focused on tracking and capturing current trends and concerns within the sector. All Conference has enabled cross talk between more established organisations and very small and fluid spaces and is beginning to build a national voice for advocacy. It is possible that it might provide a model for a New Zealand sector organisation. However, many of the factors that come into play in the Australian situation - scale, longevity of multiple organisations — are arguably not as effective here.

An emphasis on solidarity does have the potential to be a useful tool, however. Collaborations and partnerships have tended to exist within the Creative New Zealand funding boundaries, so, for example, Enjoy has collaborated regularly with $B O A G$, because they both sit at the investment level of funding. Sophie Davis says of her connection with $B O A G$ Manager Grace Ryder,

Grace and I keep in touch a lot to support each other, and to bounce ideas around as well, because it can be hard to generate ideas by yourself. It's nice to have that collegial thing going on. (Davis 2018) 
But collaboration across the funding barriers is less common, and $R M$ and Enjoy, despite co-existing for 18 years, have not often collaborated. A perception of commercial sensitivity has led to a tradition of privacy around funding negotiations in New Zealand, which also contributes to spaces keeping quiet about funding hopes and losses.

One might argue that Enjoy currently have no incentive to collaborate as they are benefiting from the current system. But my research has revealed a degree of internal tension between staff and board members, some of whom are uncomfortable with the restrictions and limitations offered by the current KPIs. Enjoy has, in recent years, created a highly managed and seamless public persona. If they were to break out of this, as their recent call of proposals might suggest, they could take a role in examining and interrogating the policy discourse.

\section{Conclusion}

But that's the tricky thing about that history. That as much as it's resisting larger forces, it's also swept along by them. I think as that context has developed, it's not just that the basic form of an artist-run space has lost its surprise value or cachet, but that the subtleties of how actual programmes and particular works and shows and the other business of artist-run spaces have to be read against that contradiction. (Bywater 2018)

This chapter has pulled back somewhat to view the art sector as a whole, the complicated assemblage that knits together to create an art scene. Charting the internal and external forces that together form the artist-run space, the research reveals rich and particular detail emerging through the case study research.

Over the previous chapters I have argued that identity formation of each artist-run space is not static, as spaces change over time, with the influx of new participants and as the terrain around them shifts. But, even within the snapshot or window provided by my active research, conflicting views on the organisation were provided by participants, particularly notable in the case of Enjoy. Individuals involved in Enjoy expressed very different views about where Enjoy should or did sit, in the wider art world, and in particular in relation to funding agencies. Tensions resulting from these different viewpoints were palpable among my respondents, and served to enrich and complicate my understanding of how a space might be formed and presented. Central 
to these tensions were value judgements about the special role that artists might play, with participants from every case study arguing that artists bring a unique perspective to organisations.

As Jon Bywater's epigraph indicates, the wider environment of neoliberalism has impacted on the artist-run scene, but has not yet rendered it impotent. Instead, Bywater stresses, the focus must be on "the subtleties of ... actual programmes and particular works and shows" (2018). Resistance, then, is in the internal workings and everyday operations of an organisation, the specific qualities and strategies they embody. Being an artist-run space doesn't automatically mean you're critical or resistant to the hegemony, even maintaining the pure collective form is not the magic bullet for a space's autonomy. Katherine Waugh has stated, as noted in my Introduction, “we need to keep in mind that 'self-organisation' is in no way transformative in itself (suggesting a form of essentialist virtuousness)" (Waugh 2016, 153).

There is no black or white, as I have previously explained, there is only relative autonomy. But on this scale, RM, I argue, offers an overlooked model fundamentally different to that of Enjoy, and while currently positioned by funders as being in the developmental stage in a process ultimately geared towards formalisation, could instead be understood as a valid and useful model which plays its own important role in developing, and gently disrupting, the mainstream art world. I contend that $R M$ offers a model of organisational practice that is loose enough to change, but thoroughly committed to core elements of discussion, consensus and smallness of scale. Meanwhile are young and new, and in time, I think, they could offer a different model again, based more on fusion and conscious compromise while holding space for difference.

In some respects, it might be that the imprecision of New Zealand's cultural policy rhetoric has inadvertently allowed a more diverse range of art practices to take shape than its promoters intended. While Creative New Zealand may be investing in collectives such as $R M$ and Meanwhile as part of an institutional drive to support individual career development, they are in fact investing in collectivism. And artists sitting in the heart of the mainstream art world continue to build structures that support alternative practices. 


\section{Conclusions}

Art worlds change continuously_-sometimes gradually, sometimes quite dramatically. New worlds come into existence: old ones disappear. (Becker 1982, 300)

This study has asked what it means for artists and arts workers to be involved in an artist-run space today. At the forefront has been the desire to capture how participants in artist-run spaces understand and articulate their own values and experiences. Therefore, the thesis has asked the following questions. To what extent does the New Zealand artist-run space offer alternatives to current neoliberal orthodoxy in the art world? What impact have funding, policy and wider art networks had in shaping the New Zealand artist-run space? How are the identities of participants shaped by their involvement in artist-run spaces?

\section{Reviewing the Research Process}

I began the thesis with a story from my own experience in artist-run spaces, and in doing so sought to demonstrate that I was situated at the heart of my research. This was a story about my world; one I had forged new ground in over 20 years ago. Yet, as my study developed, I became aware that this was not, really, my own tale. Instead, my research has described a generation of participants operating in vastly different conditions to the New Zealand art world of the 1990s, and these participants have, collectively and individually, developed tactics to successfully navigate a neoliberal climate.

Qualitative research has enabled me to focus on the stories and experiences of the artist-run's participants, privileging their voices and building up a picture of each case study. My intention was not to provide a detailed history of each case study but rather to analyse the information provided by the case studies through a series of connecting frameworks, which considered together provide a way of understanding and articulating the artist-run space at this moment in time. 
Over three chapters I have deployed three distinct theoretical frameworks through which to view the artist-run space, each enabling me to understand different facets of professional practice. I began in Chapter Two by viewing the artist-run space as an assemblage, enabling me to describe its expanded form. Chapter Three uses the notion of creative labour to understand the artist-run's participant, detailing how participation in the artist-run contributed to identity formation. In Chapter Four I have utlised the concept of governmentality to investigate pressures that are brought to bear on an artist-run space, with particular focus on the way Creative New Zealand, as the key funder, has influenced the artist-run sector. In my final discussion chapter, I have brought the three strands together, reaching across the cases and frameworks to find connections and counterpoints.

\section{Findings}

In Chapter Two assemblage theory provided an expanded lens to understand artistrun culture as a wide and flexible network. Taking into account the broad spectrum of activities and elements that comprise artist-run culture, my research understood the artist-run assemblage as a complex mix of people, relationships, artworks, rooms, systems and events that together form a fluid, porous but robust entity. The assemblage is both relational and spatial, developed through the conversations that occur when people gather together in a physical space to view artwork, dialogues that are sparked by encounters with artwork, just as, in turn, the artwork emerges in response to the (physical, historical and social) context of the site.

The artist-run space, therefore, is in no way an artistic island, nor can it be argued that it remains free of the trappings of the wider art world. It is entrenched through various social and material networks, practical requirements like the need to borrow a projector for an exhibition, through overlapping skills, such as when participants are hired to work as public gallery front-of-house or exhibition preparators, and through the inherent sociability with which the art world is hard-wired, as when Artspace staff attend an opening at $R M$. It is also deeply embedded into the system as a launching pad, such as when emerging artists are selected for exhibition elsewhere through their artist-run exposure. 
Although this description suggests a sequential process, in reality it arises from interchanges between people, space and artwork that are highly fluid and shifting. While physical location is significant, the assemblage is not bound by the limitations of space, it spills across the city to intertwine with other arts organisations, whether they are similar spaces or institutions with vastly different holdings of art world power; public galleries, commercial galleries, art schools and funders.

In mapping the assemblage, I wanted to understand how notions of power and value were experienced and described by partipants operating within the assemblage. The artist-run space is generally the smallest, least powerful member of this cluster (Louisa Afoa describes Artspace as "like our aunty" (Afoa 2018)) but they are increasingly acknowledged as a vital "stepping stone" (Bowling 2017) that is "career building" (Davis 2017) for both artists and curators. Reaction to this positioning was markedly different between spaces, and emerged as a crucial talisman of institutional value.

In Chapter Three I have argued there are two distinct strands of participants - paid staff and artists working within a volunteer collective. Both share a deep passion and belief in what they do along with conscious knowledge of the complexity of working in the arts during the neoliberal turn to creativity. But the two kinds of participants are motivated to take part by different goals and they describe success in very different terms.

The wider art world often collapses these two identities into one, usually resulting in a dominant narrative based on the aims and ambitions of paid staff. That tendency can miss crucial aspects of how the space is shaping the identity of the participant. For the worker engaged in building a long-term career, time working at the space and learning on the job serves to develop strategies and networks they can utilise later in larger institutions. For volunteer artists juggling the role with an art practice and paid employment, the space offers a supportive way to engage with others and a community to activate their own research. When funders do not distinguish between these two positions, they can fail to recognise the particular quality of support each offers the art ecology. 
Chapter Four argues that New Zealand's artist-run spaces have evolved since the 1990s into two distinct models, each with different motivations and ideals. One, operating collectively and without hierarchy_coming out from the research in the form of RM and Meanwhile - is consistently positioned by CNZ as an emergent form, a state which an entity is expected to outgrow as it matures, rather than a valid organisational form in its own right. The other, with a separation between governance and staff and represented here by Enjoy, is prioritised by them and held up as a model of good practice. The two models of practice have been embodied over time in long running spaces $R M$ and Enjoy, forming oppositional poles in relation to the question of agency.

My findings have demonstrated Enjoy's participants intentionally assembling themselves within this system, narrating Enjoy into a wider story of art world success, highly attuned to the needs of its funders. In contrast, $R M$ participants talked about searching for the gaps, a separate conceptual space they try to occupy through tactics that resist and dismantle funder narratives of development and progression. I have argued that $R M$ 's resistance was not framed by participants as the negation of external forces, but instead as an active process of affirming their own values. Taking a position to deliberately not align oneself with funding priorities can be interpreted as naïve, and during my research I had to listen carefully to understand their stories instead as conscious and strategic.

My study has found that a third position is emerging through Meanwhile's work in self-institutionalism, as they establish organisational guides that prioritise very different values from those of the normative forces. When Jesse Bowling told me "we're making our own institutional structure" I caught myself listening with indulgence to what I considered to be youthful rhetoric. However, I watched Meanwhile develop and implement a very detailed kaupapa for the space which articulated markedly new ethical goals compared with those promulgated by previous New Zealand spaces. I began to consider that that might be exactly what they were doing.

The normative forces exerted by the key funding agency's top-down guidance were found to be highly influential, yet not all-encompassing. Spaces like Enjoy could choose to comply with funding narratives and be rewarded, but, as my study of $R M$ 
has demonstrated, it is possible to resist the narrative and continue to thrive by placing emphasis on staying small and rejecting the impulse for continual growth. None of these positions is static; they are constantly and consciously being recommitted to and can and will change with new participants.

In Chapter Five I have argued an additional finding, which does not negate, but does complicate the three points above. When, on page 235 I use the term oppositional poles to describe differing positions between spaces, it provides a handy device for understanding difference, but does not fully allow for the particular and complex nuances at play. At the beginning of my research I asked to what extent does the artist-run space offer alternatives to current neoliberal orthodoxy in the art world? Chapter Five has argued that the notion of 'alternatives' is inadequate for the task at hand, suggesting as it does, an inside and an outside. My findings demonstrate that participants in artist-run spaces generally don't identify themselves through such binary modes and the notion of an alternative is less relevant within a neoliberal orthodoxy.

The three spaces studied, no matter their positioning on the sliding scale of compliance, must be understood as operating with an acute self-awareness of their own complicity within a wider, neoliberal context. All have evolved their own toolkits of strategies and tactics to navigate an environment which seeks to remake them in its own image. Ambiguity and criticality were readily present in all my case studies, co-existing alongside deep sincerity and belief in the organisational purpose.

Therefore, in Chapter Five I turned to Gene Ray's description of "relative autonomy" to describe the complex system of relationships within which an artist-run space must navigate, a state somewhere between independence and institutionalisation. While it could be easy to locate Enjoy as subsumed within, and compliant to, a neoliberal orthodoxy and $R M$ as a hub for resistance, I have argued that this is too simplistic a reading. Each of my case studies consciously works within a neoliberal paradigm, each in their own way articulating how they simultaneously affirm yet negate neoliberalism through their actions. The notion of relative autonomy offered a different perspective from the binary notion of inside/outside; helping me to frame my research in terrain neither wholly independent nor completely shaped by the art world. 


\section{Answering the Research Questions}

To what extent does the New Zealand artist-run space offer alternatives to current neoliberal orthodoxy in the art world?

Artist-run spaces, I have argued, are deeply embedded in the mainstream art world through two key external forces; networks of reciprocity with larger institutions and funding imperatives which frame value through the narrow rhetoric of development. The nuances and complexities that constitute an individual space can get lost in the need to demonstrate value to funders. Moreover, the way in which a space perceives its own value can be broader and messier than its increasingly official role as a training ground for professional development and stepping stone to mainstream galleries. However, within, and despite the limitations of funding imperatives and art world expectation, artist-run spaces can, and do, carve out space for the marginal, the unplanned and the unknown.

Crucially, I have found that what constitutes an 'alternative' is always shifting, as the mainstream constantly and hungrily expands to absorb new developments. However, when an artist-run space is small and flexible enough to be nimble, as I argue $R M$, over 20 years, has proven to be, it can shift focus regularly to maintain a commitment to the less visible. Yet, as my research developed, I came to argue that the term 'alternative', while not invalid, proved too binary a concept and the thesis has therefore sought to complicate and problematise what alternative means. Never truly outside, artist-run spaces, to varying degrees, can work from deep inside the art world to provide space for otherness, simultaneously feeding and resisting neoliberal machinations in a myriad of small and subtle recalibrations, both conscious and unconscious.

How are the identities of participants shaped by their involvement in artist-run spaces?

In this thesis I have argued that identity formation for all participants of artist-run spaces has emerged as a significant element in the research. The research demonstrates that the identities of participants are bound up tightly with their work for the space, as well as their personal identification as artists. However, the identity 
formation of participants was, I have shown, similarly compromised, confounding simplistic readings. Participants found their involvement in the space both artistically and socially satisfying and believed strongly in the importance of their work. Many of them identified deeply with the artist-run space itself, finding in it both a symbolic gesture and a tangible example that represented their personal ethos about art and community. For example, for the members of Meanwhile the organisation is a vehicle to explore their personal commitment to supporting minority identities underrepresented in the art world.

Simultaneously, all participants were acutely aware of the problems and limitations in their unpaid or under-paid labour and of the need to quantify their activities in reductive form to funders. Recognising and acknowledging the difficulties didn't make them want to give up on the artist-run space (although all accepted that at some stage they would), nor did it solve the problem. The acute awareness of their own complicity in perpetuating what they saw as structural problems within the art world was understood as part of the paradox of being an artist.

What impact have funding, policy and wider art networks had in shaping the New Zealand artist-run space?

In this thesis I have proposed that artist-run spaces are under continual pressure from funders and broader shifts in cultural policy to formalise, reshaping from a loose collective to a business model of governance and management. Additionally, the mainstream gallery system seeks to launch an endless selection of new, emerging artists. Artist-run spaces are expected, by both funders and the wider art world, to act as a laboratory to nurture new artists.

My research has demonstrated that Enjoy's compliance has seen them adopt a narrative of development, not just for the individual artists whose artwork they champion but at a deeper, structural level which means the organisation is continually seeking to grow.

$R M$ and Meanwhile also embody a deep connectedness to the wider art world, and rely at least partially on external grants, but I point out their relationships to both funders and art networks are negotiated more on their own terms. 


\section{Research Limitations}

A close-up analysis of three case studies, all based in the cities of Auckland and Wellington, has meant that other locations were not considered in this research. In particular the role of artist-run spaces in regional sites, such as Skin Room, Hamilton; $B O A G$, Dunedin and Space Gallery, Whanganui is not covered to any extent. Nor have I focused on artist-run spaces in post-earthquake Christchurch, another very specific environment. I have held a strong focus on the nature of exhibition spaces, which gave continuity to my research and grounded it in the physical. As a consequence, I have left out new forms of artist-run initiatives such as online and popup spaces. However, as part of my wider contextual scan, the "boundary spanner" interviews include two participants in such spaces; Hana Pera Aoake (Fresh $n$ Fruity) and Ioana Gordon-Smith (Whau the People).

While my three case studies have included a broad overview of the spaces, the research considered only two moments in their organisational histories in any depth; their founding and the period of my active research (2017-2018). The research is not intended to trace an art history of those spaces or of New Zealand's wider artist-run history, although this is lightly sketched for context in Chapter Two. And, while my study looked at the impact of Creative New Zealand-funding on artist-run spaces in detail, it did not consider in depth the impact of regional funding, crowd funding, fundraising through artwork sales or private patronage. The tensions that arise within an organisation as it attempts to juggle some or all of these different funding streams, each with differing accountabilities, would be a relevant area to focus on in the future.

Finally, while I found two of my spaces, $R M$ and Meanwhile, highly receptive to my research, Enjoy presented a contrast, with restricted access to both documents and participants. As a result, I had less knowledge to draw from in some areas, but the experience shaped and coloured my understanding of Enjoy, meaning I witnessed it as less welcoming and concerned with controlling their brand, in contrast to my other case studies.

As the first New Zealand doctoral research to consider artist-run spaces as its subject, my study constitutes a beginning point from which research can build, with further theoretical issues to explore. As indicated above, a wider geographical span, a focus 
on non-sited initiatives and the impact of other forms of funding are all areas which further research could address.

\section{Contribution to the Literature}

Throughout the research I have followed Anthony Shelton's call for critical museology to "locate the contradictions and areas of tensions and contestations that play a fundamental role in institutional change and transformation” as my Literature Review has detailed. This study is important because it fills in knowledge about an under-researched area of the museum sector in New Zealand, but it also contributes to the international literature on art galleries, artist-run spaces and visual artists. Within the realities of negotiations around institutional growth and career development for emerging artists and art workers are larger questions of how culture is understood and managed.

The findings from this study make contributions to the current literature on artist-run spaces as well as within museum studies. While my research is nuanced and specific to artist-run spaces, seeking to speak to that community in particular, there are lessons for the museum sector, as a whole, regarding how a new generation of artists and cultural workers position themselves. Many of the specific concerns of my researchformalisation of infrastructure, the impact of policy on grassroots practice, the influence of neoliberal thinking on artist-run spaces - feed into broader questions about museum and art gallery practice, against the current moment of cultural neoliberalism.

This thesis represents research both at a micro level, shining a spotlight on some of the smallest and least visible art institutions, but also points to the future, in that participants of artist-run spaces today will become the senior curators and established artists of tomorrow. In doing so, as I quoted Gabrielle Amodeo in Chapter One, they will bring with them "the strategies they tested in artist-runs" $(2016 \mathrm{c}, 64)$. The reshaping of the artist-run space today, therefore, has significant implications for the development of the mainstream art world of tomorrow.

Within artist-run literature I have brought New Zealand experiences into engagement with a body of work dominated by European, United States and Canadian examples. 
This is particularly useful for New Zealand readers, providing them with data grounded in real-life, local experiences. But I have also brought new knowledge to the global literature, diversifying and complicating creative industries' literature beyond stories of 'industry' to focus on the experiences of visual artists and NGOs. In addition, focusing on New Zealand data offers a particular example of a small, contained country that has experienced enthusiastic take up of neoliberalism since the 1980s, alongside the adoption of many of the United Kingdom's methods of cultural policy.

The study also provides a nuanced and particular understanding of cultural precarity within the artist-run sector which differentiates between paid and volunteer workers and the different conceptual and practical implications. Much writing about cultural precarity examines either different aspects of the (more profitable) creative industries or, when focused on visual artists, addresses the trajectory of individual career development rather than tackling a broader consideration of grassroots structures. The findings in this thesis therefore sit alongside, and build on, research into the impact, on distinct fields of the New Zealand cultural sector, of neoliberalism's turn to creativity such as fashion (Bill 2017, 2012, 2008), music (Scott and Craig 2012), museum curatorship (Bieldt 2016) and film (Boon, Jones, and Curnow 2009; Jones 2008).

The longitudinal nature of my study has provided unique insight into the evolution of artist-run spaces over time and demonstrated that institutional values are not a static entity but a fluid notion that need to be repeatedly reconfirmed. Enjoy's experience shows how a space can move dramatically away from its core values, while continuing to use rhetoric that positions itself within that history. $R M$ 's experience shows that values need to be regularly recommitted to and that consensus can function as a useful mechanism for members who are deeply engaged in a process. $R M$ 's apparently loose systems were revealed as a less visible but very deliberate structure that has proved it can operate long term. A significant finding was the need for researchers and funders to recognise this system, although it might not resemble conventional management structures that prioritise efficiency and effectiveness.

While differences between Enjoy and $R M$ have emerged as major findings, each space has been shaped by the time in which they initially evolved, the late 1990s and early 
2000s. Meanwhile is a new entity and its members have consciously articulated very contemporary values - highly networked, performative, binary-fluid and committed to dismantling normative power in a very active way. Data generated from the space's participants suggests new and evolving systems that may operate long term in a very different way to either Enjoy or RM.

\section{Professional Implications of my Research}

This first $\mathrm{PhD}$ research into artist-run spaces in New Zealand serves to highlight an overlooked area of study, a part of the sector that has significant input into the wider art ecology but has not received the same scrutiny as the public art gallery system. I anticipate this work will contribute to greater understanding in both museum studies and art history of the impact grassroots cultural practices can make on the sector.

For the artist-run space community, I hope the research both validates their work and supports further critical discussion. While my writing is situated in an academic rather than sector forum, I hope that it contributes to dialogue with the existing, if limited, writing about New Zealand artist-run spaces, as well as writing that is yet to come. While, as PhD student I am acutely aware of writing within a specific discipline, I have also undertaken this work for the community of artists, who, on graduating art school come together to establish new iterations of the artist-run space. It is their work I seek to celebrate, analyse and understand, because, despite the tensions and contradictions I have detailed above, I still fervently believe in its power as a model to activate and rejuvenate artistic practice.

My thesis reinforces and extends the international writing to date on artist-run space culture. While most of the existing writing has taken a conceptual, theoretical approach, mine has used theoretical frameworks to map real spaces, real people and real situations. My methodological focus has been research that is applied and enriched by qualitative data, not just broadly abstracted. Grounding my thesis in casestudy research means that I sought to be "attuned to the complex, emotional and affective processes that are experienced and embodied through our lived experience" in order that my study contributes to the complex process of "recognising ourselves as cultural-political subjects, and exploring the ways in which we are caught up in 'webs 
of meaning' and relations of power of our own re-making" (Shear and Hyatt 2015, 12).

Therefore, this thesis sits alongside a small number of other theses internationallyincluding PhD work by Deborah Jackson, Emma Coffield, Clive Robertson, and other critical writing - that seek to understand the artist-run space through case study research. My work builds on Robertson's research employing the theory of governmentality and Jackson and Coffield's work with identity formation, bringing together these two bodies of research and synthesising them in new knowledge.

As I have written within an academic context, to acquire knowledge rather than to prescribe, the study is speculative and does not seek to make direct recommendations to practice. However, acknowledging that my work addresses new knowledge, and in keeping with the wider literature of critical museum studies that undertakes "new research methods that are practice-led and embedded" (McCarthy 2015, 206), I wish also to signal potential opportunities for change to the conditions for funding and regulating artist-run culture, as well as to the relationship a space might have to their own history.

Firstly, in cultural policy, the obligations required by funding agencies have been demonstrated as potentially restrictive, favouring compliant clients who are prepared to change to meet funding expectations around governance. I argue that Creative New Zealand could, and should, expand their definition of a successful organisation, enabling them to listen and respond to a diverse community that embraces a far wider range of organisational kaupapa. Such a shift has considerable potential to enable funding structures to more closely resemble the communities of practice they are established to support. As well as benefiting the artist-run sector such a change has implications for a much wider network of practices, particularly taking into account non-Western forms of craft collectives such as Pasifika customary craft circles.

Secondly, I argue that there is potential for artist-run spaces to mobilise as a sector, forming a loose arrangement like All Conference, the national network for artist-led organisations in Australia. Such co-operation could enable sector-led discussions with funders rather than the current one-on-one negotiations which encourage competition. A grouping of small, independant spaces would also cut across the distinctions 
generated through funding discourse, which separate organisations into divergent funding streams, and, in doing so, create artificial divisions in the sector. Working together, artist-run spaces could create a national platform for advocacy, meaning the experiences and aspirations of emerging artists actively contribute to policy negotiations, rather than operating as the passive recipients of decisions made on their behalf.

A final recommendation of this thesis is that, during this significant moment of change for Enjoy, as it further repositions itself into a larger, more resourced and public organisation, it might use this shift in scale as an opportunity to re-engage with organisational founders. An open-ended conversation might reconnect the gallery with its history in a more grounded way than the nostalgia it currently employs. It could also enable the gallery to revise the boundaries of its role, with one possible outcome of this process resulting in an institutional name change, in acknowledgement of the major transformation Enjoy has undergone during almost 20 years of operation. However, after I first wrote this, in mid-2019, Enjoy rebranded from Enjoy Public Art Gallery to Enjoy Contemporary Art Space, suggesting that such a move is unlikely.

\section{Conclusion}

In answering my three research questions I have come to a much deeper understanding of participants in today's artist-run spaces and the pressures they face from the art sector and its response to significant shifts in the social and economic conditions of neoliberalism. My thinking throughout the research has undergone significant change, from trying to define the artist-run in terms of alternative practices to understanding that the notion of 'alternative' is loaded with rhetoric of inside/outside that harks back to a pre-neoliberal era.

Through interviews and other qualitative research my findings have suggested that the participants operate in a high-stepping policy dance. The predominantly younger members, born into neoliberalism, embrace their complicity or their "relative autonomy" (Ray 2011). In these spaces, practitioners do not seek the same forms of rebellion that their predecessors might have, but that does not mean they are not enacting a form of resistance. Their resistance, however, is articulated differently, co- 
opting a language of entrepreneurship and inclusion. As practitioners working inside the machine, they see themselves as an integral part of a wider art ecology and don't feel compromised by their position. For them, compromise is an integral part of their professional practice.

While charting generational differences within artist-run culture has formed an important part of my thesis research, I have understood them as relevant both to participants and the spaces themselves. Artist-run spaces opening today are emerging into a very different artistic and social landscape from that confronting the spaces of 20 years ago. Their participants are "pushed, pulled, and reshaped in conflicting ways, even as [they] engage in activist research, critical pedagogy, and collective struggles" (Shear and Hyatt 2015, 12). The work of the artist-run space is continually developing, even as the basic structure recurs. It is with the intimate realities of artistrun space life that my thesis has engaged, mapping the distinct practices, negotiations, and interpretations that are re-shaping the artist-run space. 


\section{References}

Abernethy, Anna. 2016. "Innovative and Nontraditional Revenue Generation in New Zealand Museums.” Master's thesis, Victoria University of Wellington.

Acker, Joan. 2006. "Inequality Regimes: Gender, Class, and Race in Organisations." Gender and Society 20, no. 4: 441-464.

_. 1990. "Hierachies, Jobs, Bodies: A Theory of Gendered Organisations." Gender and Society 4: 139-158.

Adams, Tony, Carolyn Ellis, and Stacy Holman Jones. 2017. “Autoethnography.” In The International Encyclopedia of Communication Research Methods, edited by Jörg Matthes, Christine Davis, and Robert Potter, 1-11. New Jersey: John Wiley \& Sons.

Albiston, Catherine. 2000. "Reframing Arts and Cultural Policy Designs in Aotearoa New Zealand." Master's thesis, University of Auckland.

Allen, Brenda. 2004. Difference Matters: Communicating Social Identity. Illinois: Waveland Press.

Alexander, Victoria. 2018. "Heteronomy in the Arts Field: State Funding and British Arts Organisations." The British Journal of Sociology 69, no. 1: 23-43.

Altheide, David and John Johnson. 1994. "Criteria for Assessing Interpretive Validity in Qualitative Research." In Handbook of Qualitative Research, edited by Norman Denzin and Yvonna Lincoln, 485-499. California: Sage Publications.

Amery, Mark. 2018. "Sparks Fly in Funding Fireworks." Lowdown 18 https://www.thebigidea.nz/stories/lowdown-18-sparks-fly-in-funding-fireworks

—. 2016. "On their own terms." https://www.thebigidea.nz/stories/on-their-ownterms

Ames, Michael.1992. Cannibal Tours and Glass Boxes: The Anthropology of Museums. Vancouver: University of British Columbia Press.

—. 1991. "Biculturalism in Exhibitions." Museum Anthropology 15, no. 2: 7-15.

- 1988. "The Democratisation of Anthropology and Museums." AGMANZ Journal 19, no. 2: 33-35.

Amodeo, Gabrielle. 2016a. "Eighteen Years, Six Rooms: Nick Spratt and RM." Art New Zealand 157 (Autumn): 44-51.

—. 2016b. "Playing in Gorse." In The Third Enjoy Five Year Retrospective Catalogue, edited by Louise Rutledge, 16-19. Wellington: Enjoy Public Art Gallery. 
-. 2016c. "Preface." In Assay/Essay: Artist-run in Aotearoa New Zealand, edited by Gabrielle Amodeo, 4-5. Wellington: Gabrielle Amodeo and Enjoy Public Art Gallery.

-2016d. "On gravity and fridge magnets - an afterword." In Assay/Essay: Artist-run in Aotearoa New Zealand, edited by Gabrielle Amodeo, 62-69. Wellington: Gabrielle Amodeo and Enjoy Public Art Gallery.

Anfara, Vincent and Norma Mertz, eds. 2015. Theoretical Frameworks in Qualitative Research. California: Sage.

Anderson, Heather. 2008. "Untitled." In Decentre: Concerning Artist-Run Culture, edited by Elaine Chang, Andrea Lalonde, Chris Lloyd, Steve Loft, Jonathan Middleton, Daniel Roy and Haema Sivanesan,17-18. Toronto: YYZ Books.

Aoake, Hana Pera and Myra Middleton. 2017. "Ki Piki: Snakes and Ladders." Runway Australian Experimental Art 33 http://runway.org.au/ki-piki-snakes-ladders/

Apple, Jacki. 1981. Alternative in Retrospect: An Historical Overview 1969-1975. New York: The New Museum.

Aranda, Julieta, Brian Kuan Wood, and Anton Vidokle, eds. 2011. Are You Working Too Much? Post-Fordism, Precarity and the Labour of Art. Berlin: Sternberg Press.

Ashcraft, Karen. 2014. "Feminist Theory." In The SAGE Handbook of Organisational Communication: Advances in Theory, Research and Methods, edited by Linda Putnam and Dennis Mumby, 127-150. California: Sage.

Atkins, Robert. 2010. "Alternatives \& Aphorisms, Salon \& Spectacle.” In Playing by the Rules: Alternative Thinking/Alternative Spaces, edited by Steven Rand and Heather Kouris. New York: apexart. Kindle.

Attiwill, Suzie. 2007 "Spatial relations." In Making Space: Artist-run initiatives in Victoria, edited by Din Heagney, 30-34. Melbourne: VIA-N — the Victorian Initiatives of Artists Network.

Ault, Julie. 2010. “Of Several Minds Over Time." In Playing by the Rules: Alternative Thinking/Alternative Spaces, edited by Steven Rand and Heather Kouris. New York: apexart. Kindle.

-. 2002. Alternative Art New York, 1965-1985. Minneapolis and London: University of Minnesota Press and the Drawing Centre, New York.

Bagdadli, Silvia, and Chiara Paolino. 2006. "Institutional Change in Italian Museums: Does the Museum Director Have a Role to Play?" International Journal of Arts Management 8, no. 3: 4-18.

Baines, Penelope. 2015. "Non-Core Business? An Examination of University Art Galleries in Aotearoa New Zealand.” Master's thesis, Victoria University of Wellington. 
Baker, Kirsty. 2016. "Inhabiting the Threshold: The Women's Gallery as Liminal Space in New Zealand's Feminist Art History." Master's thesis, Victoria University of Wellington.

Barber, Bruce. 2008. "ARC to ICA, or Whatever...” In decentre: concerning artistrun culture, edited by Elaine Chang, Andrea Lalonde, Chris Lloyd, Steve Loft, Jonathan Middleton, Daniel Roy and Haema Sivanesan, 21-24. Toronto: YYZ Books.

Bartle, Helen, and Catherine Nesus. 2006. "Creative New Zealand, Cultural Diversity and the Arts." Aotearoa Ethnic Network Journal 1, no. 2: 31-35.

Barton, Christina. 2005. "Enjoy and the Artistic Mode of Production." In Enjoy Five Year Retrospective Catalogue, edited by Melanie Hogg (Oliver), 56-59. Wellington: Enjoy Public Art Gallery.

Bayly-McCredie, Lillian. 2016. "Museum Diplomacy: Developing cultural partnerships between New Zealand and China." Master's thesis, Victoria University of Wellington.

Beck, Martin. 2002. “Alternative: Space.” In Alternative Art New York, edited by Julie Ault, 165-1985. New York: Drawing Centre.

Becker, Howard. 1982. Art Worlds. Berkeley: University of California.

Bedoya, Robert. 1993. "Hardware Stores." In Manual: Art in General, 1992 and 1993, edited by Ruth Libermann and Naama Oppenheim-Kovner, 5-6. New York: Art in General.

Beech, Dave. 2006. "Institutionalism for All.” Art Monthly 294: 7-10.

Begley, Ciaran, Ros Cameron, and Rachel Smithies. 2005. "Now, if you'll only attend, Kitty, and not talk so much, I'll tell you all my ideas about Looking-Glass House." In Enjoy Five Year Retrospective Catalogue, edited by Melanie Hogg, 7-13. Wellington: Enjoy Public Art Gallery.

Bennett, Tony. 2010. "Culture, Power, Knowledge: Between Foucault and Bourdieu." In Cultural Analysis and Bourdieu's Legacy Settling Accounts and Developing Alternatives, edited by Elizabeth Silva and Alan Warde, 102-116. London and New York: Routledge.

—. 2009. "MUSEUM, FIELD, COLONY." Journal of Cultural Economy 2: 99-116.

- 1995. The Birth of the Museum: History, Theory, Politics. London and New York: Routledge.

—. 1992. "Putting Policy into Cultural Studies." In Cultural Studies, edited by Lawrence Grossberg, Cary Nelson, and Paula Treichler, 23-37. London and New York: Routledge. 
—.1988. "The Exhibitionary Complex.” New Formations 4 (Spring): 73-102.

—. and Chris Healy. 2009. "Assembling Culture." Journal of Cultural Economy 2, no. 1-2: 3-10.

Berg, Bruce and Lune Howard. 2012. Qualitative Research Methods for the Social Sciences. New York: Pearson.

Bieldt, Nemane. 2016. "Creativity and Curatorship: Creative Industries Policy and the Changed Face of the Curatorial Sector in Aotearoa New Zealand." PhD diss., Auckland University of Technology.

Bill, Amanda. 2017. "Counter-Conduct in Creative University Research:

Deliberations on Freedom." Higher Education Research and Development 36, no. 2 (February): 241-254.

—. 2012. "Blood, Sweat and Shears": Happiness, Creativity, and Fashion Education." Fashion Theory 16, no. 1 (March): 49-65.

—. 2008. "Creative Girls: Fashion Design Education and Governmentality." $\mathrm{PhD}$ diss., University of Auckland.

Bishop, Claire. 2004. "Antagonism and Relational Aesthetics.” October 110, no. 30: 51-80.

Blackley, Roger. 2014. "Art Galleries and Collections." Te Ara, the Encyclopedia of New Zealand. https://teara.govt.nz/en/art-galleries-and-collections/print

Blair, Tony. 1997. "Introduction.” In New Labour: Because Britain Deserves Better, n.pag. London: Labour Party.

Blazwick, Ioana. 2006. "Temple/White Cube/Laboratory." In What Makes a Great Exhibition? Edited by Paula Marincola, 118-133. Philadelphia: Philadelphia Exhibitions Initiative.

Blessi, Giorgio, Pier Luigi Sacco and Thomas Pilati. 2011. "Independent Artist-Run Centres: An Empirical Analysis of the Montreal Non-Profit Visual Arts Field", Cultural Trends 20, no. 2: 141-166.

Blomkamp, Emma. 2014. "Meanings and Measures of Urban Cultural Policy: Local Government, Art and Community Wellbeing in Australia and New Zealand." PhD diss., University of Auckland and University of Melbourne.

—. 2009. "Framing Short Film: Cultural Nationalism and Economic Rationalism in New Zealand Film Policy.” Master's thesis, University of Auckland.

Bloom, Brett. (n.d.). Radical Space for Art in a Time of Forced Privatization and Market Dominance. http://www.temporaryservices.org/reading_material.html.

Boeije, Hennie. 2010. Analysis in Qualitative Research. London: Sage. 
Bolton, Lissant. 2003. "The Object in View: Aborigines, Melanesians and Museums." In Museums and Source Communities: A Routledge Reader, edited by Laura Peers and Alison K. Brown, 42-54. London and New York: Routledge.

Bonin-Rodriguez, Paul. 2015. Performing Policy: How Contemporary Politics and Cultural Programs Redefined U.S. Artists for the Twenty-First Century. London: Palgrave Macmillan.

Booth, Jeremy. 2010. "Foreword". In The Second Enjoy Five Year Retrospective Catalogue, edited by Jeremy Booth, 6-7. Wellington: Enjoy Public Art Gallery.

Borgen, Maibritt. 2013. "The Inner and Outer Form of Self-Organisation.” In SelfOrganised, edited by Stine Hebert and Anne Szefer Karlsen, 37-49. London: Open Editions.

Boston, Jonathan, and Paul Dalziel, eds. 1992. The Decent Society? Essays in Response to National's Economic and Social Policies. Auckland: Oxford.

Bosworth, Albert Brian. 1988. Conquest and empire: The reign of Alexander the Great. Cambridge: Cambridge University Press.

Bouquet, Mary. 2012. Museums: A Visual Anthropology. London: Berg.

Bourdieu, Pierre.1993. The Field of Cultural Production: Essays on Art and Literature. Cambridge: Polity Press.

—. 1990. The Logic of Practice. California: Stanford University Press.

-. 1986. Distinction: A Social Critique of the Judgement of Taste. London: Routledge.

Bourcheix-Lapote, Marianne. 2013. "Interrogating the 'Artist-Curator-as-Artist' in After Finitude." Decoy Magazine http://www.decoymagazine.ca/interrogating-theartist-curator-as-artist-in-after-finitude/

Bourriaud, Nicholas. 2002. Relational Aesthetics. Dijon: Presses du Réel.

Bowling, Jesse, Jordana Bragg, and Callum Devlin, eds. 2016. What Have We Done? Wellington: Meanwhile.

Bragg, Jordana. 2018. Radio Active interview. https://www.mixcloud.com/Radioactive_FM/c-a-interview-with-Meanwhilefacilitator-jordana-bragg-2018/?fbclid=IwAR01-bar6yw1FxrNHFLd4d3h_9uzrr0bApOtycysIp6_xyg-q3bt9jQhjc

—. 2017. "On Creating Enduring Artist-Run Space with Jo Randerson and Jordana Bragg." Urban Dreams Podcast, November 1. http://urbandreambrokerage.org.nz/urban-dreams-podcast/2017/11/1/on-creatingenduring-artist-run-space-with-jo-randerson-and-jordana-bragg 
Brennan, Stella. 1995. "Testing Ground: Artist-Run Spaces in New Zealand.” New Zealand Listener, 7 February, 73.

Brett, Cate, and Jenny Chamberlain. 1997. “Generation Debt: Our Students' \$1.8 Billion Burden." North and South 131: 32-42.

Bromley, Denis. 1986. The Case-Study Method in Psychology and Related Disciplines. Chichester: John Wiley \& Sons.

Bronson, A. A. 2012. "The Transfiguration of the Bureaucrat." In Institutitons by Artists, edited by Jeff Khonsary and Kristina Lee Podesva, 25-47. Vancouver: Fillip Editions/Pacific Association of Art Run Centres.

—. 1983. "The Humiliation of the Bureaucrat: Artist-Run Centres as Museums by Artists". In Museums by Artists, edited by A. A. Bronson and Peggy Gale, 29-37. Toronto: Art Metropole.

Brown, Andrew. 2015. "Identities and Identity Work in Organisations." International Journal of Management Reviews 17, no. 1: 20-40.

Brown, Michael. 1995. "Discourse Analysis and Policy Formation: A Case Study of the Queen Elizabeth the Second Arts Council of New Zealand." Master's thesis, Victoria University of Wellington.

Buergel, Roger; Anselm Franke, Maria Lind and Nina Möntmann. 2006. "Curating with Institutional Visions: A Roundtable Talk." In Art and its Institutions: Current Conflicts, Critique and Collaborations, edited by Nina Möntmann, 28-59. London: Black Dog Publishing.

Bugden, Emma. 2016. "Hybrid Practices-Artist-Run Spaces and Money." In Assay/Essay: Artist-Run in Aotearoa New Zealand, edited by Gabrielle Amodeo, 5257. Wellington: Gabrielle Amodeo and Enjoy Public Art Gallery.

—. 2014. "Fly by the Seat of your Pants": Building Resilience through Collective Narrative at the Christchurch Art Gallery 2006-2013." Master's thesis, Massey University.

—. 2005. "I don't Like That Thing You Do: Blood and Guts on the World Wide Web.” In Enjoy Five Year Retrospective Catalogue, edited by Melanie Hogg, 66-69. Wellington: Enjoy Public Art Gallery.

Bui, Quoctrung. 2017. "Almost Half of Young Adults Get Rent Help from Parents." New York Times, February 9.

https://www.nytimes.com/2017/02/09/upshot/a-secret-of-many-urban-20-somethingstheir-parents-help-with-the-rent.html?_r=0

Burchell, Graham, Colin Gordon, and Peter Miller. 1991. The Foucault Effect: Studies in Governmentality. Chicago: University of Chicago Press. 
Butler, Paul. 2008. “11.” In Decentre: Concerning Artist-Run Culture, edited by Elaine Chang, Andrea Lalonde, Chris Lloyd, Steve Loft, Jonathan Middleton, Daniel Roy and Haema Sivanesan, 42-43. Toronto: YYZ Books.

Butler, Petra, and Roderick Mulgan. 2013. "Can Academic Freedom Survive Performance Based Research Funding?" Victoria University of Wellington Law Review 44, no. 3: 487-520.

Butt, Danny. 2008. "TeststRIP.” In Teststrip: A History of an Artist-Run Space, edited by Teststrip Board, 157-160. Auckland: Clouds.

Butts, David. 2007. "Māori, Museums, and the Treaty of Waitangi: The Changing Politics of Representation and Control." In Museum Revolutions: How Museums Change and are Changed, edited by Simon Knell, Sheila Watson and Suzanne MacLeod, 215-27. London and New York: Routledge.

—. 2003. "Māori and Museums: The Politics of Indigenous Recognition." PhD diss., Massey University.

Byrt, Anthony. 2001. “Artspace 1987-2000.” Master's thesis, University of Auckland.

Campbell, Jo, and Erika Wolf, eds. 2009. Old, New, Borrowed, Blue: 10 years at the Blue Oyster. Dunedin: Blue Oyster Art Project Space.

Cameron, Fiona, and Conal McCarthy. 2015. "Museum, Field, Colony: Collecting, displaying and governing people and things." Museum \& Society 13, no. 1: 1-6.

Carrotworkers' Collective. 2010. "On Free Labour." In Precarious Labour in the Field of Art, edited by Zoran Eric' and Stevan Vukovic'. On Curating 16: 22-25.

Caust, Jo. (2003). "Putting the Art back into Arts Policy Making: How Arts Policy has been Captured by the Economists and the Marketers." International Journal of Cultural Policy 9, no. 1: 51-63.

Chartrand, Harry and Claire McCaughey. 1989. "The Arm's Length Principle and the Arts: An International Perspective-Past, Present and Future." In Who's to Pay for the Arts? The International Search for Models of Support, edited by Milton Cummings and Mark Davidson Schuster, 43-80. New York: ACA Books.

Chatham, Rhys. 2012. "The Kitchen.” In Alternative Histories: New York Art Spaces 1960-2010, edited by Lauren Rosati and Mary Anne Staniszewski, 49-52. New York and Massachusetts: Exit Art and The MIT Press.

Chhay, Bopha. 2016. “An Appendix.” In The Third Enjoy Five Year Retrospective Catalogue, edited by Louise Rutledge, 30-35.

Christianson, Marlys, Maria Farkas, Kathleen Sutcliffe, and Karl Weick. 2009. "Learning through Rare Events: Significant Interruptions at the Baltimore and Ohio Railroad Museum," Organisation Science 20, no. 5: 846-860. 
Clark, Helen. 2002. "Arts, Culture and Public Policy: A lecture in the Winter Lecture Series on the State of the Arts," 22 August. https://www.beehive.govt.nz/speech/artsculture-and-public-policy-pms-speech-winter-lecture-series

Coffield, Emma. 2015. "Artist-Run Initiatives: A Study of Cultural Construction." PhD Diss., Newcastle University.

Colmar Brunton. 2019. "A Profile of Creative Professionals.” A report commissioned by Creative New Zealand and NZ On Air.

https://www.creativenz.govt.nz/assets/paperclip/publication_documents/documents/7 15/original/20052019_a_profile_of_creative_professionals_report_final.pdf? 1558318 144

Conlin, Peter. 2006. "The Pragmatics and the Promise of Working With and Not For: Policy and Canadian Artist-Run Culture." Topia 20: 225-230.

Cooke, Jacqueline. 2006. "Heterotopia: Art Ephemera, Libraries and Alternative Spaces." Art Documentation Journal of the Art Libraries Society of North America 25, no. 2: 34-39.

Creative New Zealand. 2018. "Review of investment categories: Toi Tōtara Haemata and Toi Uru Kahikatea investment programmes."

https://www.creativenz.govt.nz/assets/paperclip/publication_documents/documents/5 58/original/final_web_review_of_investment_categories.pdf? 1526254225

—. 2017. "Annual Report of the Arts Council of New Zealand Toi Aotearoa for 2016/2017."

https://www.creativenz.govt.nz/assets/paperclip/publication_documents/documents/5 44/original/g.11_creative_new_zealand_annual_report_2017.pdf?1515969376

—. 2014. "Visual Arts Review Final Report,"

http://www.creativenz.govt.nz/assets/paperclip/publication_documents/documents/36 4/original/visual_arts_review_final_report_2014.pdf?1408489087

—. 2011. "Creative New Zealand Implements Overhaul of Funding Programmes," https://www.creativenz.govt.nz/news/creative-new-zealand-implements-overhaul-offunding-programmes

—. 2008. "Annual Report of the Arts Council of New Zealand Toi Aotearoa for 2007/08."

https://www.creativenz.govt.nz/assets/paperclip/publication_documents/documents/2/ original/annual-report-2008.pdf?1322079819

Crenshaw, Kimberlé. 1991. "Mapping the Margins: Intersectionality, Identity Politics, and Violence against Women of Color." Stanford Law Review 43, no. 6 (July): 12411299.

—. 1989. "Demarginalising the Intersection of Race and Sex: A Black Feminist Critique of Anti-discrimination Doctrine, Feminist Theory and Anti-racist Politics." University of Chicago Legal Forum: 139-167. 
Crighton, Anna. 2012. "The Selection and Presentation Culture of the Robert McDougall Art Gallery, Christchurch, New Zealand, 1932-2002." PhD diss., University of Otago.

Crossley, Nick. 2002. Making Sense of Social Movements. Philadelphia: Open University Press.

Cruz, Carla. 2016. "Practicing Solidarity." A Report Prepared for Common Practice. https://sca-net.org/downloads/57fcdf6a1c3ea-commonpracticepracticingsolidary.pdf

Cullen, Mark. 2016. "Dallas Projects/Studios.” In Artist-Run Europe:

Practice/Projects/Spaces, edited by Gavin Murphy and Mark Cullen, 56-71. Dublin: Pallas Projects.

Cunane, Abby. 2014. "Introductory Remarks: We, the institution." Papers from ST PAUL St Gallery 2014 Curatorial Symposium: 4. https://stpaulst.aut.ac.nz/_data/assets/pdf_file/0007/9754/In-practice-models-ofcultural-exchange-and-reciprocity.pdf

Cunliffe, Ann. 2010. "Retelling Tales of the Field: In Search of Organisational Ethnography 20 Years On." Organisational Research Methods 13, no. 2 April: 224239.

Cunningham, Stuart. 2002. "From Cultural to Creative industries: Theory, industry, and policy implications." In Media International Australia Incorporating Culture and Policy: Quarterly Journal of Media Research and Resources 102, no. 1: 54-65.

Czarniawska, Barbara. 2012. "Organisation Theory Meets Anthropology: A Story of an Encounter." Journal of Business Anthropology 1, no. 1: 118-140.

Davidson, Lee, and Iain Shaw. 2015. "Museums Aotearoa 2014 Sector Survey Report."

https://www.museumsaotearoa.org.nz/sites/default/files/documents/museums_aotearo a_sector_survey_2014_report_-_final_draft_oct_2015.pdf

Davies, Anthony, 2007. “Take Me, I'm Yours.” Mute Magazine 2, no. 5: 101-113.

—, Stephen Dillemuth, and Jakob Jakobsen. 2006. "There is no Alternative: the Future is Self-Organised, Part 1." In Art and its Institutions: Current Conflicts, Critique and Collaborations, edited by Nina Möntmann, 176-178. London: Black Dog Publishing.

Dacin, Tina. 1997. "Isomorphism in Context: The Power and Prescription of Institutional Norms." The Academy of Management Journal 40, no. 1: 46-81.

Deephouse, David. 1996. “Does Isomorphism Legitimate?” The Academy of Management Journal 39, no. 4: 1024-1039. 
Degot, Ekaterina. 2015. "The Artist as Director: 'Artist Organisations International' and its Contradictions." Afterall (Autumn/Winter): 20-27.

Deleuze, Gilles and Claire Parnet. 1987. Dialogues. New York: Columbia University Press.

della Porta, Donatella, and Mario Diani. 2006. Social Movements: An Introduction. New Jersey: Wiley Blackwell.

Denzin, Norman and Yvonna Lincoln. 2011. The Sage Handbook of Qualitative Research. Los Angeles: Sage Publications.

Department for Culture, Media and Sport. 1998. "Creative Industries Mapping Document," http://www.creativitycultureeducation.org/creative-industries-mappingdocument-1998

de Peuter, Greig. 2011. "Creative Economy and Labour Precarity: A Contested Convergence.” Journal of Communication Inquiry 35, no. 4: 417-425.

Detterer, Gabriele. 2012. "The Spirit and Culture of Artist-Run Spaces." In Artist-Run Spaces: Nonprofit Collective Organisations in the 1960s and 1970s, edited by Gabrielle Detterer and Maurizio Nannucci, 10-49. Zurich: JRP/Ringier.

—. and Maurizio Nannucci. 2012. "Introduction." In Artist-Run Spaces: Nonprofit Collective Organisations in the 1960s and 1970s, edited by Gabrielle Detterer and Maurizio Nannucci, 4-9. Zurich: JRP/Ringier.

Dickson, Malcolm. 1998. "Another Year of Alienation: On the Mythology of the Artist-Run Initiative." In Occupational Hazard: Critical Writing on Recent British Art, edited by Duncan McCorquodale, Naomi Siderfin, and Julian Stallabrass, 80-89. London: Black Dog Publishing.

DiMaggio, Paul, and Walter Powell. 1983. "The Iron Cage Revisited: Institutional Isomorphism and Collective Rationality in Organisational Fields." American Sociological Review 48, no. 2 (April): 147-160.

Doherty, Claire. 2004. "Critical Context: The New Situationists.” In Contemporary Art: From Studio to Situation, edited by Claire Doherty, 7-14. London: Black Dog Publishing.

Drabble, Barnaby. 2013. "On De-Organisation.” In Self-Organised, edited by Stine Hebert and Anne Szefer Karlsen, 17-26.

Dubois, Vincent. 2014. "Cultural Policy in Western Europe." In The International Encyclopedia of the Social and Behavioral Sciences, 460-655. Amsterdam: Elsevier.

Dwyer, Tessa, and Daniel Palmer. 2007. "Doing It For Themselves: Artist-Run Alternatives and Contemporary Australian Art." In Making Space: Artist-run initiatives in Victoria, edited by Din Heagney, 30-34. Melbourne: VIA-N-the Victorian Initiatives of Artists Network. 
Dyson, Michael. (2007). "My Story in a Profession of Stories: Auto Ethnography - an Empowering Methodology for Educators." In Australian Journal of Teacher Education 32, no.1: 36-48.

Easton, Brian. 1997. The Commercialisation of New Zealand. Auckland: Auckland University Press.

—. 1989. The Making of Rogernomics. Auckland: Auckland University Press.

Einarsson, Kim, and Emily Pethick. 2011. "Beyond Representation: Conversation Between Kim Einarsson and Emily Pethick." In Circular Facts, edited by Mai Abu Eidahab, Binna Choi, and Emily Pethick, 50-61. Berlin: Sternberg Press.

Eisner, Elliot. 1991. The Enlightened Eye: Qualitative Inquiry and the Enhancement of Educational Practice. Toronto: Collier Macmillan Canada.

Eland, Steve. 2002. "Minding Your Own Business: Part B." In Space Traffic: ArtistRun Spaces Beyond a Local Context, edited by Brett Jones and Leung Chi Wo, 48-49. Melbourne and Hong Kong: West Space and Para/Site Art Space.

Ellen-Eliza, Natalie. 2013. "You and I Aren't So Equal: The Visual Representation of Gender Inequality in the Contemporary New Zealand Workforce and the Visual Manifestation of Inequality in Wellington's Southern Suburbs." Master's thesis, Massey University.

Elsbach, Kimberly, and Roderick Kramer. 1996. "Members' Responses to Organisational Identity Threats: Encountering and Countering the Business Week Rankings." Administrative Science Quarterly 41, no. 3 (September): 442-476.

Enjoy Public Art Gallery. 2018. “Open Call to The Future.” Online call for exhibition proposals, http://Enjoy.org.nz/about/opportunities

Enjoy Trust. 2018. "Mission and Vision Statement.” http://Enjoy.org.nz/about/

—. 2016. "Application for Toi Uru Kahikatea (Arts Development) Investment Programme.” Enjoy Archives.

Farrar, Sarah. 2018. "On the Internal Front Lines: Curatorial Activism and Collection Exhibitions.” PhD diss., Monash University.

Feeny, Warren. 2018. "The Physics Room Gallery Relocating to Worcester Boulevard." The Press, January 29. https://www.stuff.co.nz/the-press/christchurch-life/art-andstage/visual-art/100952894/the-physics-room-gallery-relocating-to-worcesterboulevard

Ferreri, Mara, and Valeria Graziano. 2014. "Passion without Objects. Young Graduates and the Politics of Temporary Art Spaces," Recherches sociologiques et anthropologiques 2: 85-101. 
Fesch, Gil. 2014. "From Kant to Raymond Williams: An Outlook of Western European Cultural Policy." Lusophone Journal of Cultural Studies 2, no. 2: 23-33.

Flew, Terry, and Stuart Cunningham. 2010. "Creative Industries after the First Decade of Debate." The Information Society 26, no. 2: 113-123.

Florida, Richard. 2002. The Rise of the Creative Class: And How it's Transforming Work, Leisure, Community and Everyday Life. New York: Basic Books.

Foucault, Michel. 1982. The Archaeology of Knowledge and the Discourse of Language. New York: Vintage Books.

Fraser, Andrea. 2005. "From the Critique of Institutions to an Institution of Critique." In Institutional Critique and After, edited by John C. Welchman, 123-135. Zurich: JRP Ringier.

Freeman, Jo. 2013. 'The Tyranny of Structurelessness.' Women's Studies Quarterly 41, no. 3-4 (Fall/Winter): 231-246.

Frenander, Anders, and Martin Jönsson. 2007. "What Are They Doing, the Cultural Policy Researchers? Or the Theoretical Universe of Cultural Policy Research (Part 1)." Centre for Cultural Policy Research University, College of Borås, Sweden. https://www.diva-portal.org/smash/get/diva2:886664/FULLTEXT01.pdf

Friesen, Wardlow. 2009. "The Demographic Transformation of Inner-City Auckland." New Zealand Population Review 35: 55-74.

Frye Burnham, Linda. 2011. "The late '70s Alternative: Artist-Run Art Spaces." In Collaboration Labs: Southern California Artists and the Artist Space Movement, edited by Nicole Gordillo, 86-93. Santa Monica: 18th Street Arts Centre.

Furlong Borders, Elizabeth. 2012. "Working in an Artist Collective in Portland Oregon: The Artistic Benefits of Cooperation and Place in an Underground Art World." Master's thesis, Portland State University.

Gablik, Suzi. 1992. "Connective Aesthetics.” American Art 6, no. 2 (Spring): 2-7.

Gabriel, Yiannis. 1993. "Organisational Nostalgia: Reflections on the golden age." In Emotion in Organisations, edited by Stephen Fineman, 118-141. London: Sage Publications.

Garnham, Nicholas. 2005. "From Cultural to Creative Industries: An Analysis of the Implications of the "Creative Industries" Approach to Arts and Media Policy Making in the United Kingdom." International Journal of Cultural Policy 11, 1: 15-29.

Gawronski, Alex. 2012. "Out of the Past: Beyond the Four Fundamental Fallacies of Artist Run Initiatives". In We Are Here, edited by Brianna Munting and Georgie Meagher, 70-73. Sydney: National Association for the Visual Arts.

Geertz, Clifford. 1973. Interpretation of Cultures. New York: Basic Books. 
Georges, Jane. 2005. "Linking Nursing Theory and Practice: A Critical Feminist Approach." Advances in Nursing Science 28, 1: 50-57.

Giddens, Anthony. 1991. Modernity and Self-Identity. Stanford: Stanford University Press.

—. 1998. The Third Way: The Renewal of Social Democracy. Cambridge: Polity Press.

Gill, Rosalind and Andy Pratt. 2008. "In the Social Factory? Immaterial Labour, Precariousness and Cultural Work." Theory, Culture and Society Annual Review 25, no. 7-8: 1-30.

Goldbard, Arlene. 2002. "When (Art) Worlds Collide." In Alternative Art New York: 1965-1985, edited by Julie Ault, 183-200. New York / Minneapolis :The Drawing Center/University of Minnesota Press.

Gordon-Nesbitt, Rebecca. 2009. “The Culture of Capital” Critique 37, no. 4: 553-564.

—. 2007. "False Economies: Time to Take Stock." In Curating Critique: Special

Issue on Curating, edited by Barnaby Drabble and Dorethee Richter, 9, no. 11: 32-38.

-. 2003. "Harnessing the Means of Production." In New Institutionalism, edited by Jonas Ekeberg, 59-88. Oslo: OCA.

Gray, Clive. 2016. "Structure, Agency and Museum Policies." Museum and Society 14, no. 1: 116-30.

—. and Steven Hadley. 2017. "Hyperinstrumentalism and Cultural Policy: Means to an End or an End to Meaning?" Cultural Trends 26, no. 2: 95-106.

Gray, Garry, and Victoria Kendzia. 2009. "Organisational Self-Censorship: Corporate Sponsorship, Non-profit Funding, and the Educational Experience." Canadian Review of Sociology 46: 161-177.

Gregg, Jane. 1996. “Creating New Zealand.” Output 18 (Autumn): 11-13.

Grenfell, Michael. 2008. Pierre Bourdieu: Key Concepts. Durham: Acumen Publishing.

Griffith, Alison. 1998. "Insider/Outsider: Epistemological Privilege and Mothering Work.” In Human Studies 21: 361-376.

Griffiths, Amy. 2012. "From Then to Now: Artist Run Initiatives in Sydney, New South Wales." Master's thesis, University of New South Wales.

Grosz, Elizabeth. 1994. Volatile Bodies: Toward a Corporeal Feminism. Allen \& Unwin: New South Wales. 
Grossberg, Lawrence. 1997. Bringing it all Back Home: Essays on Cultural Studies. Durham and London: Duke University Press.

Gutsell, Lauren. 2016. “On Board-The Blue Oyster Art Project Space.” In Assay/Essay, edited by Gabrielle Amodeo, 24-29. Wellington: Gabrielle Amodeo and Enjoy Public Art Gallery.

Haacke, Hans. 2016. Working Conditions: The Writings of Hans Haacke. Cambridge, MA: The MIT Press.

Habermas Jürgen. 1984. The Theory of Communicative Action. Boston: Beacon.

Hackett, Amy. 2017. "Trash or Treasure? Te Papa and the Collecting of Everyday Material Culture.” Master's thesis. Victoria University of Wellington.

Hakiwai, Arapata. 2014. "He Mana Taonga, He Mana Tangata: Māori Taonga and the Politics of Māori Tribal Identity and Development." PhD diss., Victoria University of Wellington.

Halberstam, Jack. 2012. Gaga Feminism: Sex, Gender, and the End of Normal. Boston: Beacon Press.

Halperin, David. 1995. Saint Foucault: Towards a Gay Hagiography. Oxford: Oxford University Press.

Hanru, Hou. 2003. "Initiatives, Alternatives: Notes in a Temporary and Raw State." In How Latitudes Become Forms: Art in the Global Age, edited by Michelle Piranio, 36-39. Minneapolis: Walker Art Center.

Hanson, Eugene and Jenny Gillam. 2009. SHOW. Wellington: SHOW.

Harlow, Anne. 2006. "Art, Craft and Hip Hop: A History of The Dowse 1971-2006." Master's thesis, Victoria University of Wellington.

Hartley, John. 2005. Creative Industries. Oxford: Blackwell Publishing.

Hassler, Rob. 2013. "The Other Art World: Alternative Spaces and the New Model of Sustainability for the Future of Cultural, Economical and Community Growth." Master's thesis, University of the Arts London.

Hebert, Stine, Anne Szefer Karlsen and David Blamey. 2013. "Foreword." In SelfOrganised, edited by Stine Hebert and Anne Szefer Karlsen, 10-16. London/Bergen: Open Editions/Hordaland Art Centre.

Heiford, Dean. 1993. "Arts Funding in New Zealand: A Review of Governmental Structures and a Case for Reform." Master's thesis, Victoria University of Wellington.

Hein, Hilde. 2000. The Museum in Transition: A Philosophical Perspective. Washington: Smithsonian Institution Press. 
Heiss, Alanna. 2012. "Interview with Alanna Heiss: PS1/Clocktower Gallery/Idea Warehouse." In Alternative Histories: New York Art Spaces 1960-2010, edited by Lauren Rosati and Mary Anne Staniszewski, 62-66. New York and Cambridge, MA: Exit Art and The MIT Press.

Helguera, Pablo. 2010. "Alternative Time and Instant Audience (the Public Programme as an Alternative Space)." In Playing by the Rules: Alternative Thinking / Alternative Spaces, edited by Steven Rand and Heather Kouris, n.pag. New York: apexart. Kindle.

Hellawell, David. 2006. "Inside-out: Analysis of the Insider-outsider Concept as a Heuristic Device to Develop Reflexivity in Students Doing Qualitative Research." In Teaching in Higher Education 11, no. 4: 483-494.

Hesmondhalgh, Dean, and Pratt, Andy. 2005. "Cultural Industries and Cultural Policy." International Journal of Cultural Policy 11, no. 1: 1-14.

Heumann Gurian, Elaine. 2006. Civilising the Museum: The Collected Writings of Elaine Heumann Gurian. London and New York: Routledge.

- 1995. Institutional Trauma: Major Change in Museums and its Effect on Staff. Washington: American Association of Museums.

Hewitt, Andy. 2012. "Art and Counter-Publics in Third Way Cultural Policy." PhD diss., University of the Arts London.

Hilder, Jamie. 2017. "Cultural Policy: A Problem of Metaphysics." Canadian Art 16, no. 3: 14-30.

Hoffman, Jens. 2004. "Introduction." In The Next Documenta Should be Curated by an Artist, edited by Jens Hoffman, 6-7. Frankfurt: Revolver.

Hogg, Melanie. 2005. "Introduction.” In Enjoy Five Year Retrospective Catalogue, edited by Melanie Hogg, 3-5. Wellington: Enjoy Public Art Gallery.

Hooper-Greenhill, Elaine. 2000. Museums and the Interpretation of Visual Culture. London: Routledge.

Hou, Hanru. 2002. On the Mid-Ground. Beijing: Timezone 8.

Howell, Martha, and Walter Prevenier. 2001. From Reliable Sources: An Introduction to Historical Methods. Ithaca: Cornell University Press.

Hughes, Owen. 2013. "Discourses of Neo-Liberalisation in New Zealand: From the 'Managed Economy' to the 'Mum and Dad Investor', Prime Ministers' Speeches of 1987-2011 (a Critical Discourse Analysis).” PhD diss., Victoria University of Wellington. 
Hunt, Scott and Robert Benford. 2004. "Collective Identity, Solidarity, and Commitment." In The Blackwell Companion to Social Movements, edited by David Snow, Sarah Soule and Hanspeter Kriesi, 433-60. Oxford: Blackwell.

Ingberman, Jeanette. 2012. "On Creating the Exhibition.” In Alternative Histories: New York Art Spaces 1960-2010, edited Lauren Rosati and Mary Anne Staniszewski, 14. New York and Massachusetts: Exit Art and The MIT Press.

Jack, Fiona. 2018. "Issues of Representation." Counterfutures: Left Thought and Practice Aotearoa 5: 53-57.

Jackson, Deborah. 2013. "The Shifting Focus of the Traditional Centres of Contemporary Art: Scotland's Evolving Position from Periphery to Prominance." $\mathrm{PhD}$ diss., University of Edinburgh.

Jackson, Mark. 1995. "Alternative Spaces to Critical Spaces." In The Changing Critical Role of Artist-Run Initiatives Over the Last Decade, edited Mark Jackson, 3056. Sydney: First Draft.

Janes, Robert. 2014. "Museums and Change: Some Thoughts on Creativity, Destruction and Self-Organisation.” Museum International 261: 114-159.

-. 2012. "Museums, Corporatism and the Civil Society." In Museum Studies: An Anthology of Contexts, edited by Bettina Messias Carbonell, 549-561. Oxford: WileyBlackwell.

—. 2009. Museums in a Troubled World: Renewal, Irrelevance or Collapse? New York: Routledge. Kindle.

-. 1995. Museums and the Paradox of Change: A Case Study in Urgent Adaptation. Calgary: University of Calgary Press.

Jelicich, Josephine. 2016. "Josephine Jelicich." In What Have We Done? edited by Jesse Bowling, Jordana Bragg and Callum Devlin, n.pag. Wellington: Meanwhile.

Jesson, Bruce. 1999. Only Their Purpose is Mad: The Money Men Take Over New Zealand. Palmerston North: Dunmore.

- 1989. Fragments of Labour: The Story Behind the Labour Government. Auckland and New York: Penguin Books.

Johnston, Courtney. 2016. "Millennial Child." In The Third Enjoy Five Year Retrospective Catalogue, edited by Louise Rutledge,10-13. Wellington: Enjoy Public Art Gallery.

—. 2004. "Peter Tomory: The New Zealand Years, 1956-1968." Master's thesis, Victoria University of Wellington.

Jones, Amelia. 2012. Seeing Differently: A History and Theory of Identification and the Visual Arts. London: Routledge. 
Jones, Brett. 2007. "Space Traffic and Networking." In Space Traffic: Artist-Run Spaces Beyond a Local Context, edited by Brett Jones and Leung Chi Wo, 129131Melbourne and Hong Kong: West Space and Para/Site Art Space.

Jones, Deborah, Bronwyn Boon, and Bradley Curnow. 2009. "Out of the Blue: The Dark Side of Creative Enterprise." Culture and Organisation 15, no. 3-4: 361-377.

Jones, Deborah. 2008. “'Ring Leader': Peter Jackson as 'Creative Industries' Hero.” In Studying the Event Film: The Lord of the Rings, edited by Sean Cubitt, Thierry Jutel, Barry King and Harriet Margolis, 93-99. Manchester: Manchester University Press.

—. and Bronwyn Boon. 2007. "The Voice of the Creative Economy," paper presented at Critical Management: The Fifth International Critical Management Studies Conference, July 11-13, 2007.

https://www.mngt.waikato.ac.nz/ejrot/cmsconference/2007/proceedings/apolloantepor tas/jones.pdf

Kelly, John. 2010. "Seeing Red: Mao Fetishism, Pax Americana and the Moral Economy of War." In Anthropology and Global Counterinsurgency, edited by John D. Kelly, Beatrice Jauregui, Sean T. Mitchell, and Jeremy Walton, 67-83. Chicago: University of Chicago Press.

Kelsey, Jane. 1995. The New Zealand Experiment: A Model for World Structural Adjustment? Auckland: Auckland University Press.

Kelm, Bonnie. 1987. “Art Openings as Celebratory Tribal Rituals.” PhD diss., Ohio State University.

Kennedy, Christopher. 2010. "The Artist-Run Space of the Future." Institute for Applied Aesthetics http://www.applied-aesthetics.org/wpcontent/uploads/2012/01/artistrunspaceofthefuture_lores.pdf

Kester, Grant. 2012. "The Game is Up: Programmers, Patronage and the Neo-Liberal State." In Gallery as Community: Art, Education, Politics, edited by Marijke Steedman, 10-17. London: Whitechapel Gallery.

-. 2011. The One and the Many: Contemporary Collaborative Art in a Global Context. Durham: Duke University Press.

King, Anthony. 1999. "Legitimating Post-Fordism: A Critique of Anthony Giddens' Later Works." Telos: Critical Theory of the Contemporary 115: 61-77.

Knell, Simon, Suzanne MacLeod, and Sheila Watson. 2007. "Introduction." In Museum Revolutions: How Museums Change and are Changed, edited by Simon J. Knell, Suzanne MacLeod and Sheila Watson, 28-47. London: Routledge.

Knell, Simon. 2007. "Museums, Fossils and the Cultural Revolution of Science: Mapping Change in the Politics of Knowledge in Early Nineteenth Century Britain." 
In Museum Revolutions: How Museums Change and are Changed, edited by Simon J. Knell, Suzanne MacLeod and Sheila Watson, xix-xxvi. London: Routledge.

Knox, Anna. 2019. "Gender Bias and Art in Aotearoa: A Spinoff Survey Reveals the Harsh Reality." The Spinoff https://thespinoff.co.nz/art/30-09-2019/gender-bias-andart-in-aotearoa-a-spinoff-survey-reveals-the-harsh-reality/

Kraus, Chris. 2011. Where Art Belongs. Los Angeles: Semiotext(e).

Kraus, Annette and Casco. 2015. "Site for Unlearning (Art Organisation)." Casco, Office for Art, Design and Theory. http://casco.art/casco-case-study-2-site-forunlearning-art-organization-0

Labossière, Robert. 2008. "Leadership." In Decentre: Concerning Artist-Run Culture, edited by Elaine Chang, Andrea Lalonde, Chris Lloyd, Steve Loft, Jonathan Middleton, Daniel Roy and Haema Sivanesan, 144-145. Toronto: YYZ Books.

Larroa, Argella. 2015. "Sustainability in the Film Industry: External and Internal Dynamics Shaping the Wellington Film District." PhD diss., Victoria University of Wellington.

Lawn, Jennifer, and Chris Prentice. 2015. "Introduction: Neoliberal Culture/The Cultures of Neoliberalism," Sites: a Journal of Social Anthropology and Visual Culture 12, no. 1: 1-29.

Lawn, Jennifer. 2006. "Creativity Inc: Globalising the Cultural Imaginary in New Zealand." In Global Fissues, Postcolonial Fusions, edited by Clara Joseph and Janet Wilson, 225-245. Amsterdam: Rodopi.

Lee, Im Sue. 2013. "Away from the Mainstream: Three Alternative Spaces in New York and the Expansion of Art in the 1970s.” PhD diss., University of Florida.

Lee-Duncan, Ellie. "The Edited Self: An Interview with Jordana Bragg." https://www.pantograph-punch.com/post/interview-jordana-bragg.

Lefebvre, Henri. 1991. The Production of Space. Oxford: Blackwell.

Legget, Jane 2006. "Mapping What Matters in New Zealand Museums: Stakeholder Perspectives on Museum Performance and Accountability." PhD diss., Massey University.

Lemke, Thomas. 2002. "Foucault, Governmentality and Critique," Rethinking Marxism 14, no. 3: 49-64.

Lind, Maria. 2010. "The Future is here." Selected Maria Lind Writing, edited by Brian Kuan Wood, 73-79. Berlin: Sternberg Press.

Lopesi, Lana. 2016. "Young Mums, the Arts Ecology, and 'Being Radical'." Pantograph Punch http://pantograph-punch.com/post/young-mums-arts-ecologybeing-radical. 
Lorey, Isobel. 2015. State of Insecurity: Government of the Precarious. New York: Verso Books.

—. Lorey, Isobel. 2011. "Virtuosos of Freedom: On the Implosion of Political Virtuosity and Productive Labour." In Critique of Creativity: Precarity, Subjectivity and Resistance in the "Creative Industries," edited by Gerald Raunig, Gene Ray and Ulf Wuggenig, 79-91. London: MayFly Books.

-. 2006. "Governmentality and Self-Precarisation: On the Normalisation of Cultural Producers." In CAPITAL (It Fails Us Now), edited by Simon Sheikh, 117-139. Berlin: B Books.

Luoni, David. 2011. "Museum Leadership in Practice: A New Zealand Case Study." Master's thesis, Victoria University of Wellington.

Macdonald, Sharon. 2013. Memorylands: Heritage and Identity in Europe Today. London: Routledge.

—. 2011. "Reassembling Nuremberg, Reassembling Heritage." In Assembling Culture, edited by Tony Bennett and Chris Healy, 113-130. Oxford: Routledge.

—. 2006. "Expanding Museum Studies: An Introduction." In A Companion to Museum Studies, edited by Sharon Macdonald, 1-12. Oxford: Blackwell Publishing.

—. 2002. Behind the Scenes at the Science Museum. Oxford: Berg.

Mader, Rachel. 2013. "How to Move In/An Institution.” On Curating 21 (December): $35-45$.

Magnusson, Warren. 1993. "Social Movements and the State: Presentation and Representation." In A Different Kind of State? Popular Power and Democratic Administration, edited by Gregory Albo, David Langille, and Leo Panitch, 122-130. Toronto: Oxford University Press.

Major, Suzette and Anna Connell, A. 2005. "From Arts Management to Creative Industries." Paper presented at the 8th International Conference on Arts and Cultural Management, Montreal.

http://www.acpcultures.eu/_upload/ocr_document/NEW\%20ZELAND_FromArtsMn gmentToCreaInd.pdf

Mar, Phillip, and Kay Anderson. 2010. "The Creative Assemblage: Theorising Contemporary Forms of Arts-Based Collaboration." Journal of Cultural Economy 3: $35-51$.

Marshall, Catherine and Gretchen Rossman. 2010. Designing Qualitative Research. California: Sage Publications. 
Martell, Luke. 2004. "Introduction." In The Third Way and Beyond: Criticisms, Futures, Alternatives, edited by Sarah Hale, Will Leggett and Luke Martell, 3-8. Manchester: Manchester University Press.

Mason, Richard, James McKenney, and Duncan Copeland. 1997. "A Historical Method for MIS Research: Steps and Assumptions." In MIS Quarterly 21, no. 3: 307320 .

McCall, Vikki, and Clive Gray. (2014). "Museums and the 'New Museology': Theory, Practice and Organisational Change." Museum Management and Curatorship 29, no. 1: $19-35$.

McCarthy, Conal. "Historicising Museums: Approaches to the History of Colonial Museums.” Museum History Journal 13, no. 1: forthcoming 2020.

—. 2018. Te Papa: Reinventing New Zealand's National Museum 1998-2018. Wellington: Te Papa Press.

—. 2015. "Book Reviews.” Museum Worlds 3, no. 1: 202-207.

-. 2009. "Postcolonial pasts and post-indigenous futures: a critical genealogy of "Māori art." In Crossing Cultures: Conflict, Migration, Convergence, edited by Jaynie Anderson, 829-34. Melbourne: The Miegunyah Press.

—, and Joanna Cobley. 2009. "Museums and Museum Studies in New Zealand: A Survey of Historical Developments." History Compass 7, no. 2: 395-413.

—. 2006. "Hailing the Subject: Māori Visitors, Museum Display and the Sociology of Cultural Reception.” New Zealand Sociology 21, no. 1: 108-130.

-. 2004. "From Curio to Taonga: A Genealogy of Display at New Zealand's National Museum, 1865-2001." PhD diss., Victoria University of Wellington.

McLean, Heather. 2017. "Hos in the Garden: Staging and Resisting Neoliberal Creativity." Society and Space, 35 no. 1: 38-56.

-. 2014. "Digging into the Creative City: A Feminist Critique." Antipode 46, no. 3 : 669-690.

McCray, Kelly. 2002. "YYZ Artists' Outlet.” In Space Traffic: Artist-Run Spaces Beyond a Local Context, edited by Brett Jones and Leung Chi Wo, 110-111. Melbourne and Hong Kong: West Space and Para/Site Art Space.

McCredie, Athol. 1999. "Going Public: New Zealand Art Museums in the 1970s." Master's thesis, Massey University.

McDonald, James. 2015. "Organisational Communication Meets Queer Theory: Theorising Relations of 'Difference' Differently." Communication Theory 25: 310329. 
McKee, Francis. 2011. "Losing Control." In Circular Facts, edited by Mai Abu ElDahab, Binna Choi and Emily Pethick, 44-49. Berlin: Sternberg Press.

McKenzie, Stuart. 1993. “Teststrip To Cubewell.” Stamp (April): 34.

McRobbie, Angela. 2015. Be Creative: Making a Living in the New Culture Industries. Chicester: Wiley.

—. 2010a. "Everyone is Creative: Artists as New Economy Pioneers?" In Precarious Labour in the Field of Art, edited by Zoran Eric' and Stevan Vukovic, On Curating 16: $58-61$.

-. 2010b. "Reflections on Feminism, Immaterial labour and the Post-Fordist Regime." New Formations 70 (Summer): 60-76.

—. 2007. “TOP GIRLS?”, Cultural Studies 21, no. 4-5: 718-737.

—. 2003. Postmodernism and Popular Culture. London and New York: Routledge.

—. 2002. "Fashion Culture: Creative Work, Female Individualisation." Feminist Review 71: 52-62.

—. 1998. British Fashion Design: Rag Trade or Image Industry? London and New York: Routledge.

Meanwhile. 2018. Kaupapa and Safer Spaces. https://www.meanwhilegallery.com/about

—. 2017. "Application to Creative Communities." Meanwhile Archive.

Meinhard, Agnes, Mary Foster and Ida Berger. 2004. "The Process of Institutional Isomorphism in Ontario's Voluntary Sector. Working Paper Series, 3. http://www.ryerson.ca/cvss/working_papers/

Melucci, Alberto. 1996. Challenging Codes: Collective Action in the Information Age. Cambridge: Cambridge University Press.

-. 1995. "The Process of Collective Identity." In Social Movements and Culture, edited by Hank Johnston and Bert Klandermans, 41-63. Minneapolis: University of Minnesota Press.

Menger, Pierre-Michel. 1999. "Artistic Labour Markets and Careers.” In Annual Review of Sociology 25: 541-574.

Merriam, Sharan. 1988. Case Study Research in Education: A Qualitative Approach. San Francisco: Jossey-Bass.

Merton, Robert. 1972. "Insiders and Outsiders: A Chapter in the Sociology of Knowledge." In American Journal of Sociology 78, no. 1: 9-47. 
Message, Kylie. 2009. "Museum Studies: Borderwork, Genealogy, Revolution." Museum and Society 7, no. 2: 125-132.

Mey, Vera. 2010. "Towards a Post-Ethnic Understanding of Identity and Representation of Asian New Zealanders for Museum Practice." Master's thesis, Victoria University of Wellington.

Miller, Peter. 2008. "Examining the Work of Boundary Spanning Leaders in Community Contexts." International Journal of Leadership in Education 11, no. 4: 353-377.

Miller, Toby, and George Yudice. 2002. Cultural Policy. London: Sage.

Möntmann, Nina. 2006. "The Enterprise of the Art Institution in Late Capitalism." http://eipcp.net/transversal/0106/moentmann/en.

Morley, Megs. 2016. "The Artist-Led Archive.” In Artist-Run Europe:

Practice/Projects/Spaces, edited by Gavin Murphy and Mark Cullen, 75-77. Dublin: Pallas Projects.

Morrill, Calvin, and McKee, Cindy. (1993). "Institutional Isomorphism and Informal Social Control: Evidence from a Community Mediation Centre." Social Problems 40, no. 4: 445-463.

Morris, Aldon, and Mueller, Carol, eds. 1992. Frontiers in Social Movement Theory. New Haven: Yale University Press.

Müller, Martin. 2015. “Assemblages and Actor-Networks: Rethinking Socio-material Power, Politics and Space.” Geography Compass 9, no. 1: 27-41.

Murphy, Gavin. 2016. "What makes Artist-Run Spaces Different? (And Why it's Important to have Different Art Spaces)." In Artist-Run Europe:

Practice/Projects/Spaces, edited by Gavin Murphy and Mark Cullen, 4-17. Dublin: Pallas Projects.

Museums Aotearoa. 2013. "New Zealand Code of Ethics and Professional Practice." https://www.museumsaotearoa.org.nz/sites/default/files/ma_code_of_ethics_br_2014 _v5_web_0.pdf

Nahkies, Graeme. 2014. Getting on Board: A Governance Resource Guide for Arts Organisations. Wellington: Creative New Zealand.

Nairn, Karen, and Jane Higgins. 2007. "New Zealand's Neoliberal Generation: Tracing Discourses of Economic (Ir)rationality." International Journal of Qualitative Studies in Education 20, no. 3: 261-281.

—. and Judith Sligo. 2012. Children of Rogernomics: A Neoliberal Generation Leaves School. Dunedin: Otago University Press. 
Nemiroff, Diana. 1985. "A History of Artist-Run Spaces in Canada, with Particular Reference to Vehicle, A Space and the Western Front." Master's thesis, Concordia University.

Nentwich, Julia, Wiebke Tennhoff, and Franziska Vogt. 2015. "Doing Gender and Professionalism: Exploring the Intersectionalities of Gender and Professionalisation in Early Childhood Education." European Early Childhood Education Research Journal 23, no. 3: 340-350.

New Zealand Parliamentary Debates 24 May, 2000. Hansard. https://www.parliament.nz/en/pb/hansard-debates/rhr/

New Zealand Government. 1992. "Museum of New Zealand Te Papa Tongarewa Act." http://www.legislation.govt.nz/act/public/1992/0019/latest/dlm260204.html

Ng, Emma. 2016. "gallery.net." In Assay/Essay: Artist-run in Aotearoa New Zealand, edited by Gabrielle Amodeo, 12-17. Wellington: Gabrielle Amodeo and Enjoy Public Art Gallery.

Noordegraaf, Julia. 2004. Strategies of Display: Museum Presentation in Nineteenthand Twentieth-Century Visual Culture. Rotterdam: NAI.

North Projects. 2016. "The Problems of Being 'Post-Quake'.” In Assay/Essay: ArtistRun in Aotearoa New Zealand, edited by Gabrielle Amodeo, 36-38. Wellington: Gabrielle Amodeo and Enjoy Public Art Gallery.

Oakley, Kate., and Sara Selwood. 2010. Conversations and Collaborations: The Leadership of Collaborative Projects between Higher Education and the Arts and Cultural Sector: Final Report. Arts Council England and the Cultural Leadership Project https://www.lfhe.ac.uk/en/components/publication.cfm/Oakley2.5

Oakley, Kate. 2009. "The Disappearing Arts: Creativity and Innovation after the Creative Industries." International Journal of Cultural Policy 15, 4: 403-413.

O'Brien, Gregory. 2004. 'Creative' New Zealand? In Writing at the Edge of the Universe: Essays from the 'Creative Writing in New Zealand' Conference, University of Canterbury 2003, edited by Mark Williams, 33-48.

Obrist, Hans Ulrich and Barbara Vanderlinden. 2001. Laboratorium. Cologne: DuMont.

O'Doherty, Brian. 1986. Inside the White Cube: the Ideology of the Gallery Space. San Francisco: The Lapis Press.

OECD. 2014. "Society at a Glance." http://www.oecdilibrary.org/deliver/fulltext?itemId=/content/book/soc_glance-2014en\&mimeType=freepreview\&redirecturl=http://www.keepeek.com/Digital-AssetManagement/oecd/social-issues-migration-health/society-at-a-glance2014_soc_glance-2014-en\&isPreview=true 
O'Leary, Zina and Jennifer S. Hunt. 2016. Workplace Resarch: Conducting Smallscale Research in Organisations. London: SAGE Publications.

O’Leary, Zina. 2004. The Essential Guide to Doing Research. London: SAGE Publications.

Oliver, Melanie. 2009. "My One and Only Prayer, is that Someday, You'll Care ... But it's Only Make Believe." In Old, New, Borrowed, Blue: Ten Years at the Blue Oyster, edited by Jo Campbell and Erica Wolf, 24-27. Dunedin: Blue Oyster Art Project Space.

Oswin, Natalie. 2005. "Towards Radical Geographies of Complicit Queer Futures." ACME: An International Journal for Critical Geographies 3, no. 2: 79-86.

Pacquette, Jonathan. 2012. "Mentoring and Change in Cultural Organisations: the Experience of Directors in British National Museum." The Journal of Arts Management 42, no. 4: 205-216.

Panickar, Paul. 2006. "Cultural Policy and Changing Governments: A New Zealand Perspective." Asia Pacific Journal of Arts \& Cultural Management 4, no. 2: 307-313.

Paolino, Chiara, and Silvia Bagdadli. 2006. "The Institutional Change of Italian Public Museums between Legitimacy and Efficiency: Do Museum Directors have a Role?" International Journal of Arts Management 8, no. 3: 1-23.

Pearce, Susan. 1994. Interpreting Objects and Collections. London: Routledge.

—. 1992. Museums, Objects and Collections: A Cultural Study. Leicester: Leicester University Press.

Petryshyn, Demian. 2005. "An Amoebic Urge: Artist-Run Centres in Canada as Minor Practice.” Master's thesis, University of Western Ontario.

Philbin, Ann. 2012. "Interview with Ann Philbin: Drawing Centre." In Alternative Histories: New York Art Spaces 1960-2010, edited by Lauren Rosati and Mary Anne Staniszewski, 75-77. New York and Massachusetts: Exit Art and The MIT Press.

Post, Stephanie. 2014. "Staying Alive: Some Thoughts on Opportunities for Private Funding for Small Scale Visual Arts Organisations in New Zealand." Commissioned by Artspace Aotearoa.

http://web.archive.org/web/20180305193659/http://artspace.org.nz/doclibrary/public/ Artspace_A4_ReportPublicFunding_Website.pdf

Potts, Jason, and Stuart Cunningham 2008. "Four Models of the Creative Industries." International Journal of Cultural Policy 120, no. 1: 163-180.

Powell, Walter, and Paul DiMaggio. 1991. The New Institutionalism in Organisational Analysis. Chicago: University of Chicago Press. 
—. 1983. "The Iron Cage Revisited: Institutional Isomorphism and Collective Rationality in Organisational Fields." American Sociological Review 48, no. 2: 147160.

Prince, Russell. 2010. “Globalising the Creative Industries Concept: Travelling Policy and Transnational Policy Communities." Journal of Arts Management, Law and Society 40: 119-139.

—. 2009. "Assembling the 'Creative Economy': Epistemic Communities, Policy Transfer and the Geography of Expertise.” PhD diss., University of Bristol.

Pryde-Jarman, Daniel. 2013. "Curating the Artist-Run Space: Exploring Strategies for a Critical Curatorial Practice.” PhD diss., Coventry University.

Rachleff, Melissa. 2012. "Do It Yourself: Histories of Alternatives.” In Alternative Histories: New York Art Spaces 1960-2010, edited by Lauren Rosati and Mary Anne Staniszewski, 23-39. New York and Massachusetts: Exit Art and The MIT Press.

Rae, Jude. 1992. “Editorial.” South Island Art Projects Newsletter 1 (May): n.pag.

Raunig, Gerald. 2011. "Creative Industries as Mass Deception." In Critique of Creativity: Precarity, Subjectivity and Resistance in the "Creative Industries" edited by Gerald Raunig, Gene Ray and Ulf Wuggenig, 191-203. London: MayFly Books.

Ray, Gene. 2011. Culture Industry and the Administration of Terror. In Critique of Creativity: Precarity, Subjectivity and Resistance in the "Creative Industries" edited by Gerald Raunig, Gene Ray and Ulf Wuggenig, 167-181. London: MayFly Books.

Ribas, João. 2016. "On the Solo Show: From Resistance to Repression." In The Curatorial Conundrum: What to Study? What to Research? What to Practice? edited by Paul O'Neill, Mick Wilson and Lucy Steeds, 85-94. New York: LUMA Foundation and The Centre for Curatorial Studies.

RM. 2016. "Application to Creative New Zealand Arts Grants/General Arts Fund." RM archives.

RM. 1999. “The End of Part One.” Newsletter (December). Auckland: RM.

Richardson, Elvis. 2016. The Countess Report. http://thecountessreport.com.au

Robertson, Clive. 2006. Policy Matters: Administrations of Art and Culture. Toronto: YYZ Books.

-. 2004. "Movement and Apparatus: A Cultural Policy Study of Artist-Run Culture in Canada (1976-1994).” PhD diss., Concordia University.

Robertson, Susan, and Roger Dale. 2002. "Local States of Emergency: The Contradictions of Neoliberal Governance in Education in New Zealand." In British Journal of Sociology of Education 23, no. 3: 463-482. 
Robinson, Helena. 2018. "Cultural Policy, Local Government and Museums: An Australian Perspective.” Local Government Studies 44, no. 5 (September): 719-738.

Roper, Brian. 2011. "The Fifth (Key) National Government's Neoliberal Policy Agenda: Description, Analysis and Critical Evaluation." New Zealand Sociology, 26, no. 1: 12-40.

Rosati, Lauren. 2012. "In Other Words: the Alternative Space as Extra-Institution." In Alternative Histories: New York Art Spaces 1960-2010, edited by Lauren Rosati and Mary Anne Staniszewski, 41-43. New York and Massachusetts: Exit Art and The MIT Press.

Rose, Nikolas. 1999. Powers of Freedom: Reframing Political Thought. Cambridge: Cambridge University Press.

-. 1996. "The Death of the Social? Re-Figuring the Territory of Government." Economy and Society 25, no. 3:327-356.

Rosoff, Nancy. 2003. "Integrating Native views into Museum Procedures: Hope and Practice at the National Museum of the American Indian." In Museums and Source Communities: A Routledge Reader, edited by Laura Peers and Alison K. Brown, 7280. London and New York: Routledge.

Rothenberg, Julia and Gary Alan Fine. 2008. "Art Worlds and their Ethnographers." Ethnologie Française 1, no. 38: 31-37.

Rumens, Nick, Eloisio Moulin de Souza, and Jo Brewis. 2019. “Queering Queer Theory in Management and Organisation Studies: Notes Toward Queering Heterosexuality." Organisation Studies 40, no. 4: 593-612.

Rutledge, Louise. 2016. "Foreword." In The Third Enjoy Five Year Retrospective Catalogue, edited by Louise Rutledge, 6-7. Wellington: Enjoy Public Art Gallery.

Ryder, Grace. 2016. "North Projects." In Assay/Essay: Artist-Run in Aotearoa New Zealand, edited by Gabrielle Amodeo, 6-9. Wellington: Gabrielle Amodeo and Enjoy Public Art Gallery.

Saad-Filho, Alfredo, and Deborah Johnston. 2005. Introduction. In "Neoliberalism: A Critical Reader," edited by Alfredo Saad-Filho and Deborah Johnston, 1-6. London: Pluto Press.

Sallee, Margaret, and Julee Flood. 2012. "Using Qualitative Research to Bridge Research, Policy, and Practice.” In Theory into Practice 51, no. 2: 137-144.

Sanders, Courtney. 2016. "This Art Collective is Challenging Gender Discrimination in the Art Industry." Catalogue https://www.cataloguemagazine.com.au/feature/thisart-collective-is-challenging-gender-discrimination-in-the-art-industry

Schorch, Philipp. 2013. “The Experience of a Museum Space.” Museum Management and Curatorship 28, no. 2: 1-16. 
-. 2010. "Te Papa, A forum for the World? A Narrative Explanation of a Global

Public Sphere.” PhD diss., Victoria University of Wellington.

Schubert-McArthur, Tanja. 2014. “'Walking the Talk?' An Ethnography of Biculturalism at Te Papa." PhD diss., Victoria University of Wellington.

Schwandt, Thomas. 1997. Qualitative Inquiry: A Dictionary of Terms. London: Sage.

Scullion, Adrienne, and Beatriz Garcia. 2005. "What Is Cultural Policy Research?" International Journal of Cultural Policy 11, no. 2: 113-127.

Selwood, Sara, and Stuart Davies. 2015. "Policies, Frameworks, and Legislation: The Conditions Under Which English Museums Operate." In The International

Handbooks of Museum Studies: Museum Practice, edited by Conal McCarthy, 43-68. New Jersey: Wiley \& Sons.

Sharon, Batia. 1979. "Artist-Run Galleries: A Contemporary Institutional Change in the Visual Arts." Qualitative Sociology 2: 3-28.

Shear, Boone W., and Susan Hyatt. 2015. "Introduction: Higher Education, Engaged Anthropology, and Hegemonic Structure." In Learning Under Neoliberalism: Ethnographies of Governance in Higher Education, edited by Susan Hyatt, Boone W. Shear and Susan Wright, 1-29. Oxford: Berghahn Books.

Sheik, Simon. 2012. "Burning from the Inside: New Institutionalism Revisited." In Cultures of the Curatorial, edited by Beatrice von Bismarck, Jörn Schafaff and Thomas Weski, 361-373. Berlin: Sternberg Press.

Shelton, Anthony. 2013. "Critical Museology: A Manifesto." Museum Worlds: Advances in Research 1: 7-23.

Shepherd, Stuart. 2005. "Five Years of Joy." In Enjoy Five Year Retrospective Catalogue, edited by Melanie Hogg, 20-21. Wellington: Enjoy Public Art Gallery.

Sherlock, Diana. 2013. "Institutions by Artists: Resistance or Retreat?" C: International Contemporary Art 117 (Spring): 16-20.

Shiner, Larry. 2001. The Invention of Art: A Cultural History. Chicago: University of Chicago Press.

Sholette, Gregory. 2011. "Speaking Clown to Power: Can We Resist the Historical Compromise of Neoliberal Art?" In Imagining Resistance: Visual Culture and Activism in Canada, edited by Keri Cronin, Kirsty Robertson, 27-48. Waterloo: Wilfrid Laurier University Press.

—. and Elena Sorokina. 2006. "Specters of Collectivism: A Conversation between Gregory Sholette and Elena Sorokina." http://www.gregorysholette.com/wpcontent/uploads/2011/04/SholetteSorokinaInterview.1.pdf 
Shore, Chris. 2015. "After neoliberalism? The Reform of New Zealand's University System." In Learning under Neoliberalism Ethnographies of Governance in Higher Education, edited by Susan Brin Hyatt, Boone W. Shear and Susan Wright, 30-55. Berghahn Books: New York and Oxford.

Siciliano, Julie. 1997. "The Relationship Between Formal Planning and Performance in Nonprofit Organisations." Nonprofit Management and Leadership 7, no. 4: 387403.

Simon, Nina. 2010. The Participatory Museum. Santa Cruz: Museum 2.0.

Simons, Daphne. 2016. "How we Turned our Backyard into a Short-Term'Project Space - Canapé Canopy." In Assay/Essay: Artist-run in Aotearoa New Zealand, edited by Gabrielle Amodeo, 18-23. Wellington: Gabrielle Amodeo and Enjoy Public Art Gallery.

Simons, Helen. 2012. Case Study Research in Practice. London: Sage.

Skilling, Peter. 2008. "Brave New Zealand: the Construction of a New Zealand Identity." PhD diss., The University of Auckland.

Smelser, Neil. 1962. Theory of Collective Behaviour. New York: The Free Press.

Smith, Jason. 2010. "The Creative Country: Policy, Practice and Place in New Zealand's Creative Economy 1999-2008.” PhD diss., Auckland University of Technology.

Smith, Terry. 2001. "The Visual Arts: Imploding Infrastructure, Shifting Frames, Uncertain Futures". In Culture in Australia: Policies, Publics and Programmes, edited by Tony Bennett and David Carter, 66-88. Cambridge: Cambridge University Press.

Smithies, Rachel. 2002. "Is Less More? A Response from an Art Project Space." In [ArtForum] Series 2001, edited by Kate Griffin and Zara Stranhope, 36-37. Wellington: Adam Art Gallery.

Snider, Jennifer. 2015. "Art Administration as Performative Practice/Organising Art as Institutional Critique.” Master's thesis, OCAD University.

Spoonley, Paul. 2009. "Mana Tangata: Conceptualising Cultural Diversity-A Review Essay." New Zealand Journal of Sociology 24, no. 1: 78-86.

Stake, Robert. (1995). The Art of Case Study Research. California: Sage.

Stanley, Michael. 1996. "The Mid-Life Crisis and Artist-Led Initiatives," a-n: 11.

Steane, Peter. 2001. "Governance: Convergent Expectations, Divergent Practices." Corporate Governance 1, no. 3: 15-19. 
Stimson, Blake, and Gregory Sholette. 2007. "Introduction: Periodising Collectivism." In Collectivism after Modernism: The Art of Social Imagination after 1945, edited by Blake Stimson and Gregory Sholette, 1-15. Minnesota: University of Minnesota.

Suchy, Sherene. 2004. Leading with Passion: Change Management in the 21st Century Museum. Walnut Creek: AltaMira Press.

Swartz, David, and Vera Zolberg. 2004. After Bourdieu: Influence, Critique, Elaboration. Dordrecht: Kluwer Academic Publishers.

Szeemann, Harold. 1969. When Attitudes Become Form: Works, Concepts, Processes, Situations, Information. London: Institute of Contemporary Art.

Szefer Karlsen, Anne. 2012. Self-Organisation as Institution?

http://www.szefer.net/index.php?/projects/self-organisation-as-institution/

Tamarapa, Awhina. 2015. "The Role of a Museum (Te Papa) in the Rejuvenation of Taonga Puoro.” Master's thesis, Victoria University of Wellington.

Tarrow, Sidney. 1989. Struggle, Politics, and Reform: Collective Action, Social Movements and Cycles of Protest. Ithaca: Center for International Studies, Cornell University.

Taylor, Stephanie. 2018. "Beyond Work? New Expectations and Aspirations." In The New Normal of Working Lives: Critical Studies in Contemporary Work and Employment, edited by Stephanie Taylor and Susan Luckman, 327-345. London: Palgrave Macmillan.

—. 2015. "A New Mystique? Working for Yourself in the Neoliberal Economy." Sociological Review 63, no. 1: 174-187.

—. and Karen Littleton. 2012. "The Meanings and Problems of Contemporary Creative Work." Vocations and Learning: Studies in Vocational and Professional Education 5, no. 1: 41-57.

—., Karen Littleton and Anneli Eteläpelto. 2011. "Special Issue Introduction: Creativity and Creative Work in Contemporary Working Contexts." Vocations and Learning 5, no. 1: 1-4.

- 2011. "Negotiating Oppositions and Uncertainties: Gendered Conflicts in Creative Identity Work." Feminism and Psychology 21, no. 3: 354-371.

-. 2008. "Art, Work or Money: Conflicts in the Construction of a Creative Identity. Sociological Review 56, no. 2: 275-292.

Teststrip Board. 2008. Test Trip: A History of an Artist-Run Space (1992-1997). Auckland: Clouds. 
Throsby, David., and Katya Petetskaya. 2017. Making Art Work: An economic study of professional artists in Australia. Report commissioned by Australia Council for the Arts.

Trahan, Carl. 2008. “92.” In Decentre: Concerning Artist-Run Culture, edited by Elaine Chang, Andrea Lalonde, Chris Lloyd, Steve Loft, Jonathan Middleton, Daniel Roy and Haema Sivanesan, 242-244. Toronto: YYZ Books.

Tuhiwai Smith, Linda. 2012. Decolonising Methodologies: Research and Indigenous Peoples. Dunedin: Otago University Press.

Van Maanen, John. 2011. "Ethnography as Work: Some Rules of Engagement." Journal of Management Studies 48, no. 1: 218-234.

Ventura, Patricia. 2012. Neoliberal Culture: Living with American Neoliberalism. New York: Routledge.

Vergo, Peter. 1989. The New Museology. London: Reacktion Books.

Vickery, Jonathan. 2012. "Location Production: the urban politics of contemporary art space," paper presented at Curator's Lab, DETOURS IV: Modus Locandi-modes of production/modes of exhibition, reciprocal influences, Fábrica ASA, Guimarães, November 1-3 2012. https://metapractice.wordpress.com/public-states/locationproduction-the-urban-politics-of-contemporary-art-space/

Vidokle, Anton. 2012. “Art without artists?” In Cultures of the Curatorial, edited by Beatrice von Bismarck, Jörn Schafaff and Thomas Weski, 217-227. Berlin: Sternberg Press.

Volkerling, Michael. 2010. "The Helen Clark Years: Cultural Policy in New Zealand 1999-2008," The Journal of Arts Management, Law, and Society 40, no. 2: 95-104.

—. 2001. "From Cool Britannia to Hot Nation: 'Creative Industries' policies in Europe, Canada and New Zealand," Cultural Policy 7, no. 3: 437-455.

-. 2000. "The Necessity of Utopia: Lessons from the Culture of Economics," International Journal of Cultural Policy 7, no. 1: 29-46.

- 1976. Cultural Research in New Zealand: A Report Prepared for the Queen Elizabeth II Arts Council of New Zealand. Wellington: Queen Elizabeth II Arts Council of New Zealand.

Von Osten, Marion. 2010. "Another Criteria ... Or, What is the Attitude of a Work in the Relations of Production of its Time?" Afterall: A Journal of Art, Context and Enquiry, 25 (Autumn): 56-6.

Wahyuni, Dina. 2012. "The research Design Maze: Understanding Paradigms, Cases, Methods and Methodologies." In Journal of Applied Management Accounting Research 10, no. 1: 69. 
Wai, Jim, and Alice Ming. 2002. "Premising Art in Hong Kong." In Space Traffic: Artist-Run Spaces Beyond a Local Context, edited by Brett Jones and Leung Chi Wo, 115-120. Melbourne and Hong Kong: West Space and Para/Site Art Space.

Wallace, Keith. 1991. "A Particular History: Artist-Run Centres in Vancouver.” In Vancouver Anthology: The Institutional Politics of Art, edited by Stan Douglas, 2344. Vancouver: Talon Books.

Wallis, Brian. 2002. "Public Funding and Alternative Spaces." In Alternative Art New York, 1965-1985, edited Julie Ault, 161-181. Minneapolis and New York: University of Minnesota Press and The Drawing Center.

Wardle, Lucy. 2016. "Hey Meanwhile." Salient (September) http://salient.org.nz/2016/09/hey-Meanwhile/

Waugh, Katherine. 2016. "Delicate yet Deadly." In Artist-Run Europe:

Practice/Projects/Spaces, edited by Gavin Murphy and Mark Cullen, 144-157. Dublin: Pallas Projects.

Weatherall, Ruth. 2018. "I am Undone by these Women: Identity and Change in a Feminist Domestic Violence Organisation." PhD diss., Victoria University of Wellington.

Weedon, Chris. 1987. Feminist Practice and Poststructuralist Theory. Oxford: Blackwell.

Wei, Li. 2019. "Ethnography: Origins, Features, Accountability, and Criticality." In The Routledge Handbook of Research Methods in Applied Linguistics, edited by Jim McKinley and Heath Rose , 154-164. London: Routledge.

Weick, Karl and Larry Browning. 1986. "Argument and Narration in Organisational Communication." Journal of Management 12 no. 2: 243-259.

Welchman, John C. 2006. "Introduction." In Institutional Critique and After, edited by John C. Welchman, 11-20. Zurich: JRP/Ringier.

Wellington, Shannon. 2013. "Building GLAMour: Converging Practice Between Gallery, Library, Archive and Museum Entities in New Zealand Memory Institutions.” PhD diss., Victoria University of Wellington.

Wevers, Lydia. 2004. "The Politics of Culture." In Writing at the Edge of the Universe: Essays from the 'Creative Writing in New Zealand' Conference, University of Canterbury 2003, edited by Mark Williams, 109-122.

Whelan, Andrew. 2015. "Academic Critique of Neoliberal Academia." Sites 12, no. 1: 130-152.

White, Anna-Marie. 2006. "Māori Curatorship at Auckland Art Gallery Toi o Tāmaki 1998-2001." Master's thesis, Massey University. 
Whitwell, Jan. 1990. "The Rogernomics Monetarist Experiment." In The Fourth Labour Government, edited by Jonathan Boston and Martin Holland, 101-122. Auckland: Oxford University Press.

Williamson, Stephen. 1990. "Sectoral Shifts, Labor Market Sorting, and Aggregate Fluctuations." International Economic Review 31, no. 4: 935-52.

Willis, Emma. 2017. “A Rare Opportunity to Fail: STAB's Legacy of the Actual Experimentation.” Australian Drama Studies 70 (April): 86-112.

Wilson, Sarah. 2009. "Pearls need true grit: the origins and evolution of the Blue Oyster." In Old, New, Borrowed, Blue: 10 years at the Blue Oyster, edited by Jo Campbell and Erika Wolf, 47-55. Dunedin: Blue Oyster Art Project Space.

Wong, Paul. 2008. “100.” In Decentre: Concerning Artist-Run Culture, edited by Elaine Chang, Andrea Lalonde, Chris Lloyd, Steve Loft, Jonathan Middleton, Daniel Roy and Haema Sivanesan, 263-265. Toronto: YYZ Books.

Wood, Andrew Paul. 2004. \& Ampersand: A Catalogue of Art and Essays: the High Street Project. Christchurch: High Street Project.

Yin, Robert. 2014. Case Study Research: Design and Methods. California: Sage Publications.

—. 2012. Application of Case Study Research. California: Sage Publications.

Zoran, Eric and Stevan Vukovic, eds. 2013. "Precarious Labour in the Field of Art." On Curating 1, no. 16. http://www.oncurating.org/files/oc/dateiverwaltung/old\%20Issues/ONCURATING_Issue16.pdf

Zsreder, Kuba. 2015a. "How to Radicalise a Mouse? Notes on Radical Opportunism." In Mobile Autonomy: Exercises in Artists' Self-Organisation, edited by Pascal Gielen and Nico Dockx, 183-205. Amsterdam: Valiz.

—. 2015b. "Politicising 'Independent' Curatorial Practice under Neoliberalism:

Critical Responses to the Structural Pressures of Project-Making". PhD diss., Loughborough University.

\section{Interviews}

Afoa, Louisa. Interviewed by Emma Bugden, Auckland. (22/01/2018)

Begley, Ciaran. Interviewed by Emma Bugden, Whanganui. (11/01/2018)

Begley, Ciaran. Interviewed by Emma Bugden, Sydney. (20/02/2018)

Bowling, Jesse. Interviewed by Emma Bugden, Wellington. (10/12/2017)

Burn, Sean. Interviewed by Emma Bugden, Wellington. (25/10/2017)

Bragg, Jordana. Interviewed by Emma Bugden, over email. (05/06/2018)

Bywater, Jon. Interviewed by Emma Bugden, over Skype. (18/06/2018)

Darragh, Judy, Interviewed by Emma Bugden, Auckland. (26/01/2018)

Davis, Sophie. Interviewed by Emma Bugden, Wellington. (11/12/2017) 
Drayton, Zoe. Interviewed by Emma Bugden, Whanganui. (18/10/2017)

Gennard, Simon and Dilohana Lekamge. Interviewed by Emma Bugden, Wellington.

$(18 / 02 / 2018)$

Gordon-Smith, Ioana. Interviewed by Emma Bugden, Auckland. (24/01/2018)

Hubbard, Jess. Interviewed by Emma Bugden, Wellington. (10/12/2017)

Lacey, Sonya. Interviewed by Emma Bugden, Wellington. (10/12/2017)

Morgan, Jess. Interviewed by Emma Bugden, Auckland. (23/01/2018)

Oliver, Melanie. Interviewed by Emma Bugden, Wellington. (25/10/2017)

Pera Aoke, Hana. Interviewed by Emma Bugden, Wellington. (25/10/2017)

Rundle, Deborah. Interviewed by Emma Bugden, via Skype. (11/01/2018)

Rutledge, Louise. Interviewed by Emma Bugden, Wellington. (10/12/2017)

Shelton, Ann. Interviewed by Emma Bugden, Wellington. (18/01/2018)

Sanders, Dan. Interviewed by Emma Bugden, Auckland. (23/01/2018)

Spratt, Nick. Interviewed by Emma Bugden, Wellington. (18/02/2018)

Smithies, Rachel. Interviewed by Emma Bugden, Sydney. (23/02/2018)

van Zon, Erica. Interviewed by Emma Bugden, Whanganui. (09/10/2017)

Wylie, Joyoti. Interviewed by Emma Bugden, Auckland. (23/01/2018)

\section{Archives}

In addition to the individual documents provided by case studies above, I was given access to the following archives.

Artists and Gallery Files, Fine Arts Library Special Collections, Auckland University Library

Ciaran Begley Personal Archive

Rachel Smithies Personal Archive

Joyoti Wylie Personal Archive

Meanwhile Archives

$R M$ Archives 


\section{Sample Case Study Information Sheet}

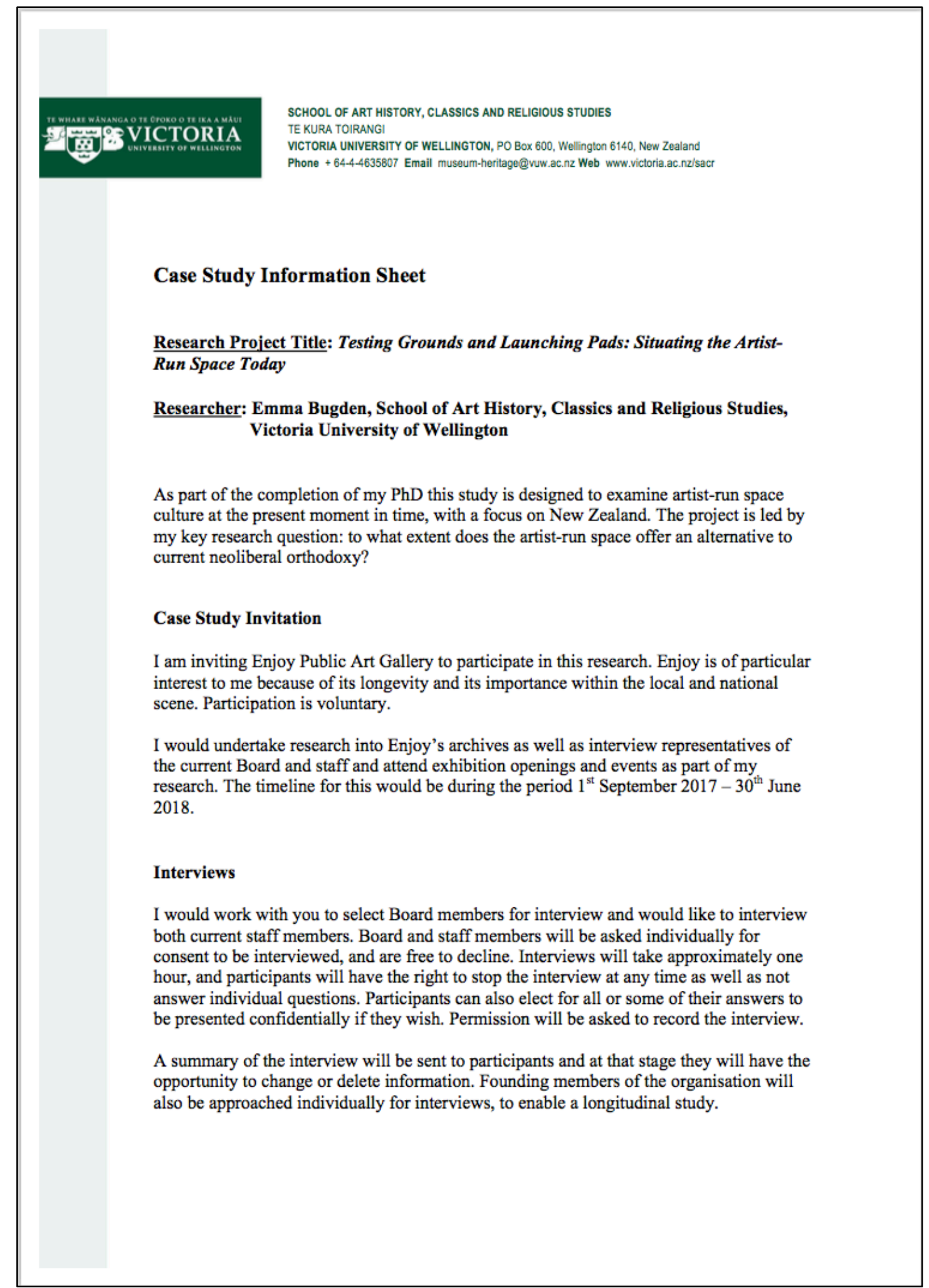




\section{Archival Research}

I would like to undertake research into aspects of Enjoy's archive. This would involve you recommending and providing me with internal documents that you believe best represents the organisation. I am particularly interested in Strategic Plans, funding proposals and Board Meeting minutes, both recent and historic. I am also interested in reading relevant correspondence, memos and notes that document discussions about development of mission and vision statements as well as the development of funding proposals.

\section{Attending events and openings}

During the period of my research I may attend Enjoy events and openings. The focus of this aspect of my research is to map the kinds of people and institutions who are represented at such events and to gain a better understanding of the community that supports Enjoy. As I will not be identified publically at the event as a researcher I will not be recording conversations. If aspects of conversations at any event (both overheard or engaged in personally) are relevant to my research, I will ensure that I use these confidentially, with the speakers only identified by broad type (such as "senior public gallery curator" or "young art student".

\section{Withdrawal from Research}

Should Enjoy agree to participate in my research as a case study, you will have the right to withdraw up until $1^{\text {st }}$ March 2018 and all data collected up to that point destroyed. Additionally, any individual participant that wishes to withdraw from the project, they may do so until $1^{\text {st }}$ March 2018 and their personal data will be destroyed. All data collected from participants will be destroyed within one year after the completion of my thesis.

\section{Research Outcomes}

My completed thesis will be submitted for marking to the School of Art History, Classics and Religious Studies and subsequently deposited in the University Library. It is my hope that my research will contribute to the wider body of knowledge about artist-run culture in New Zealand. At this stage I anticipate offering an informal presentation of my research to the board and staff of Enjoy as well as providing you with a short summary of my research as well as a copy of my completed thesis for your library. I may also publish reworked sections of my thesis as essays in other publications or presentations, and if so, will supply Enjoy with a copy of these as well. 


\section{Further Information}

If you have any questions or would like to receive further information about the project, please contact me at emma.bugden@vuw.ac.nz or telephone 0273117008 or you may contact my supervisor Dr Conal McCarthy, at the School of Art History, Classics and Religious Studies at Victoria University, PO Box 600, Wellington,

Conal.McCarthy@vuw.ac.nz and 4637470.

This research has been approved by the Victoria University of Wellington Human Ethics committee (approval number 24637). If you have any ethical concerns about the research they should contact Dr Allison Kirkman (Allison.Kirkman@vuw.ac.nz), ph: 04463 5676, Chair of the Human Ethics Committee, Victoria University of Wellington. 


\section{Sample Boundary Spanner Participant Information Sheet}

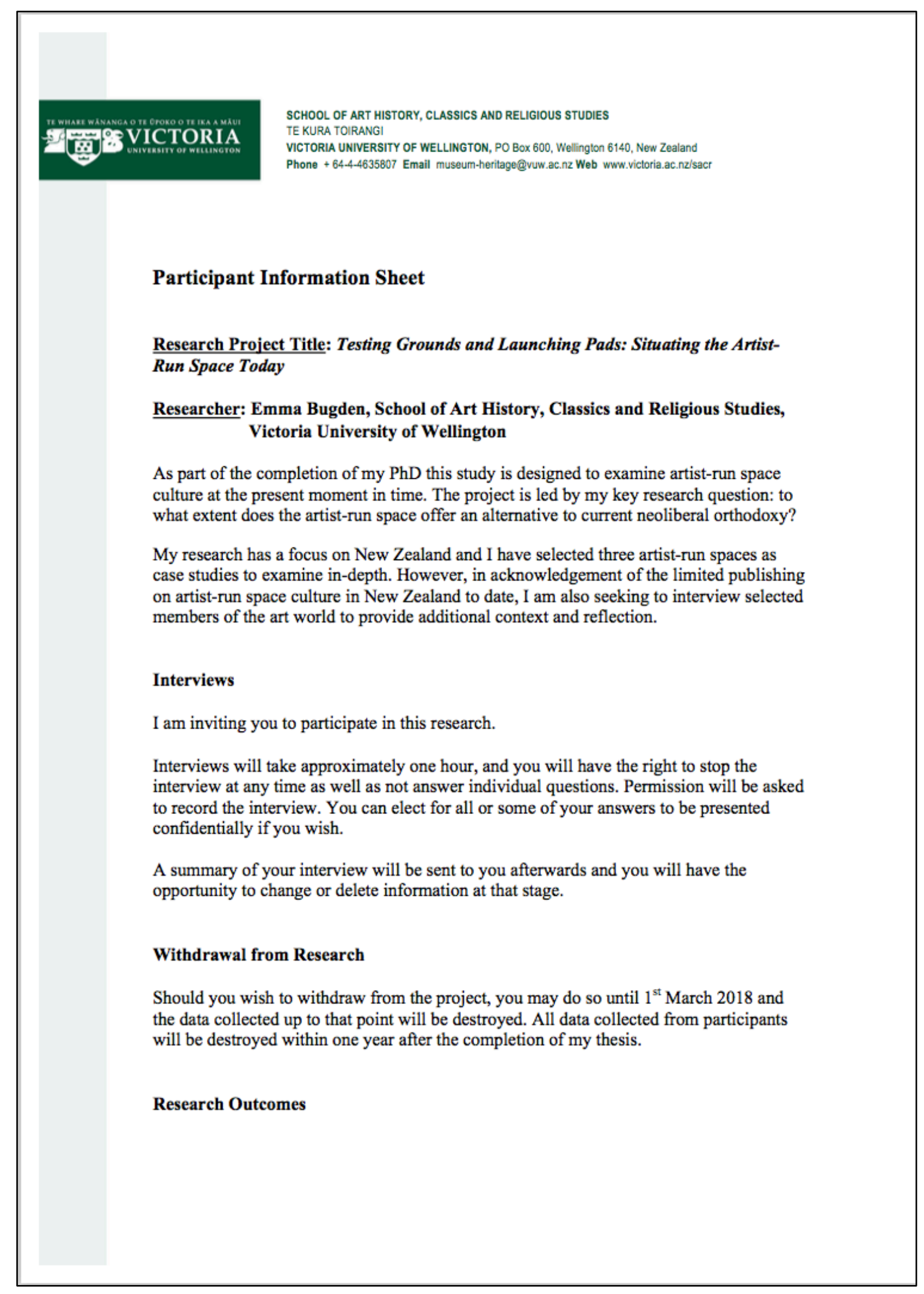


My completed thesis will be submitted for marking to the School of Art History, Classics and Religious Studies and subsequently deposited in the University Library. It is my hope that my research will contribute to the wider body of knowledge about artist-run culture in New Zealand. I may also publish reworked sections of my thesis as essays in other publications or presentations, and if so, will notify you of these as well.

\section{Further Information}

If you have any questions or would like to receive further information about the project, please contact me at emma.bugden@vuw.ac.nz or telephone 0273117008 or you may contact my supervisor Dr Conal McCarthy, at the School of Art History, Classics and Religious Studies at Victoria University, PO Box 600, Wellington, Conal.McCarthy@vuw.ac.nz and 4637470.

This research has been approved by the Victoria University of Wellington Human Ethics committee (approval number 24637). If you have any ethical concerns about the research they should contact Dr Allison Kirkman (Allison.Kirkman@vuw.ac.nz), ph: 04463 5676, Chair of the Human Ethics Committee, Victoria University of Wellington.

Emma Bugden 


\section{Sample Case Study Research Agreement}

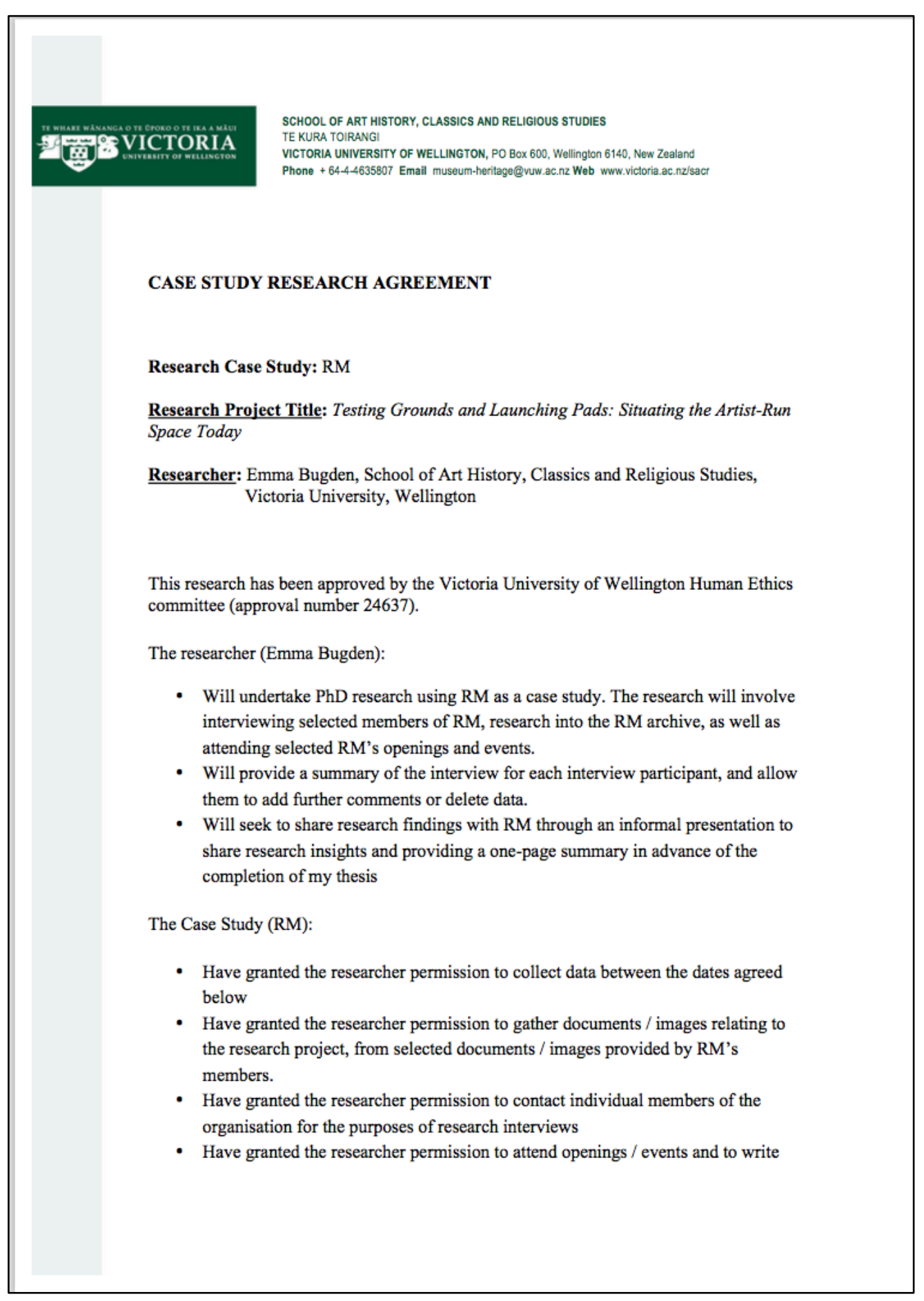


about these for the purposes of research. We understand that the aim of this research is to gain a sense of the workings of the RM community and the researcher will not be recording conversations. If aspects of conversations at the event (both overheard or engaged in personally) are relevant to her research, we understand she will use these confidentially, with speakers only identified by broad type (such as "senior public gallery curator" or "young art student".

- Understands that we can withdraw as a case study from this research at any stage until $1^{\text {st }}$ March 2018

Dates for research: $1^{\text {st }}$ September $2017-30^{\text {th }}$ June 2018.

Researcher's signature:

I consent to this research and confirm I have the authority to act on behalf of RM.

RM representative(s) signature:

Role(s): 


\section{Sample Participant Consent Form}

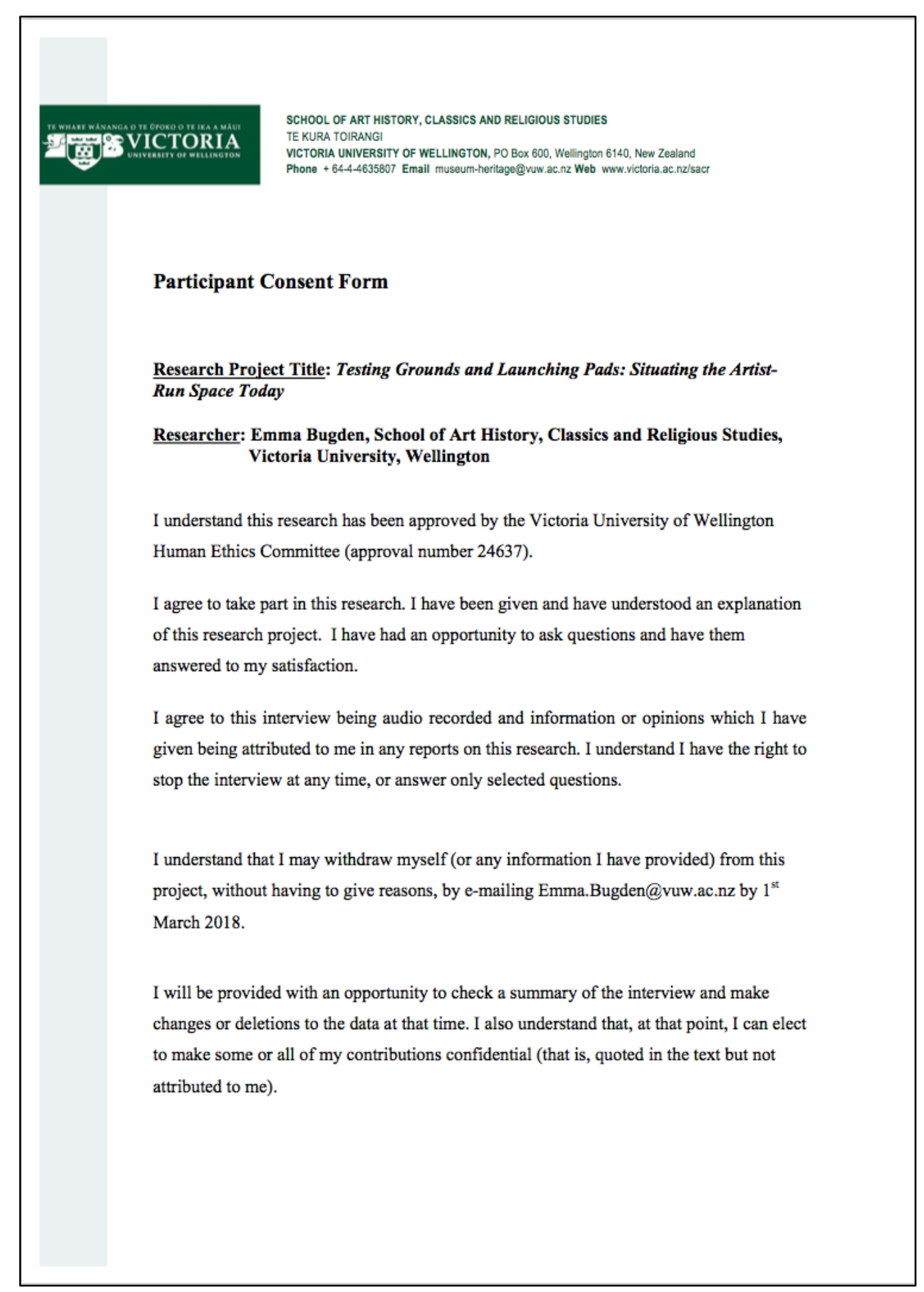


I understand that the recording and summary of the interviews will be erased within one year after the conclusion of the project. Furthermore, I understand that the data I provide will not be used for any other purpose or released to others, apart from researcher Emma Bugden and her research supervisors.

Signed:

Name of participant:

Date: 


\section{Sample Questions}

\section{Sample Questions for Case Study: Enjoy}

[Subject]

Tell me a little about yourself and your background?

How did you become involved in Enjoy?

What is your role at Enjoy?

Did you consider it a job? How do you see it fitting into your long-term career?

[Space]

How would you describe Enjoy? What does it do and why is it important? Is it an artist-run space?

Is there a particular kind of artist that Enjoy shows?

How are the artists and exhibitions selected?

Is cultural diversity something you think about when putting together a programme?

How about gender?

Is there a show that stands out for you as a defining one?

[Broader networks]

Where do you see Enjoy fitting into the bigger art world? Are there any particular networks or friendships with other galleries that are important?

Do you have much contact with CNZ in your role? If so, how does that relationship work?

[Board]

How does the relationship between Board and Staff work? [Chair main point of contact?]

Volunteers?

How often are meetings held?

How are decisions made? Consensus, voting, etc 
Are there any documents [mission, strategic plan, board JDs] you draw on to guide decision-making?

\section{[Future]}

Has Enjoy changed over the years? Where do you see Enjoy in ten years?

Will you be involved in other spaces? Other Boards?

Any other questions you wish I'd asked you? 


\section{Coding Categories}

\begin{tabular}{|c|c|}
\hline Categories prior to data collection & $\begin{array}{l}\text { Categories that emerged through the } \\
\text { data }\end{array}$ \\
\hline Cultural precarity & Savvy \\
\hline Tired & Gap in the system \\
\hline Experimentation & Need for standardisation \\
\hline $\begin{array}{l}\text { Tension between space and own } \\
\text { practice }\end{array}$ & Loss of institutional knowledge \\
\hline Workplace issues & Accessibility issues \\
\hline Risk taking & Reciprocal \\
\hline Inclusivity & \\
\hline Race issues & \\
\hline Class issues & \\
\hline Gender issues & \\
\hline Generational difference & \\
\hline Career development & \\
\hline Professional practice & \\
\hline
\end{tabular}




\begin{tabular}{|l|l|}
\hline Longevity & \\
\hline Professionalisation & \\
\hline Funding pressures & \\
\hline Short-lived & \\
\hline
\end{tabular}

\begin{tabular}{|l|l|}
\hline Headings Developed after Data & Sub-Headings Post-Data \\
\hline Terms & Testing grounds \\
& Community hubs \\
& Laboratories \\
& Development agencies \\
& Safe Spaces \\
& Workplaces \\
\hline Governmentality & Innovation Strong governance \\
& High quality, audience development \\
& Influencers \\
& Funding support \\
& Funding pressure \\
\hline Power & Gender issues \\
& Risk taking \\
& Safe spaces \\
& Non-binary \\
& Collaboration / collectivism \\
& Ownership \\
& Agency \\
& Control \\
\hline Time & Generational change \\
& Loss of institutional knowledge \\
& Longevity \\
& Foundational myths \\
\hline
\end{tabular}




\begin{tabular}{|l|l|}
\hline & Change \\
& Growth \\
& Legacy \\
\hline Assemblage & Community \\
& Hospitality \\
& Space \\
& Audiences \\
& Accessibility \\
& Inclusive / exclusive \\
Filling a gap \\
\hline Career & Professional practice \\
Career development \\
Professionalisation \\
Role of art school \\
More savvy \\
Reciprocal \\
Development \\
\hline Tension between space and own practice \\
Exhaustion \\
Need for standardisation between spaces / \\
galleries \\
Job environment changes \\
Housing crisis \\
\hline
\end{tabular}

